\title{
تصور مقترح لتحويل جامعة الأزهر إلى منظمة متعلمة
}

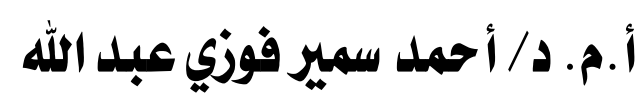

\section{أستاذ أصول التزبية المساعلد بكلية التربية جامعة الأزهر بـالقاهرة}

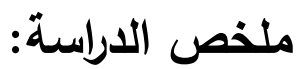

استهدفت الدراسة الوقوف على درجة توفر أبعاد المنظمة المتعلمة في جامعة الأزهر

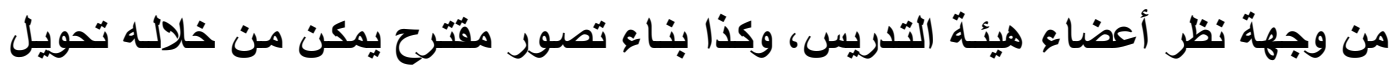

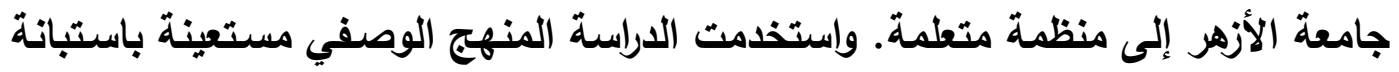

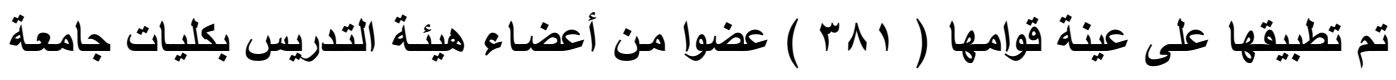

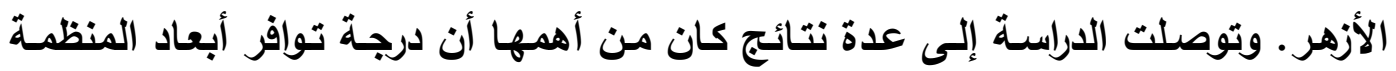

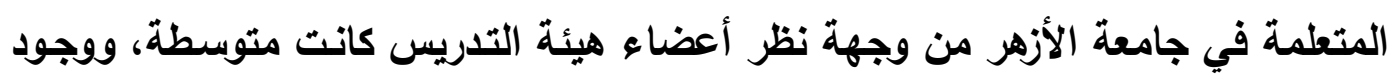

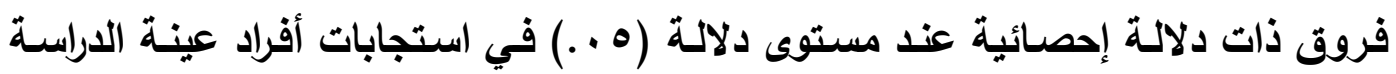

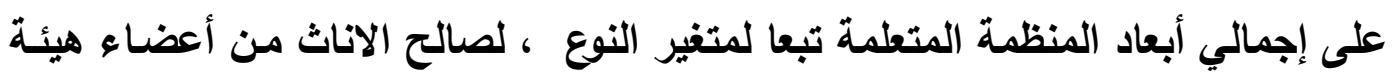

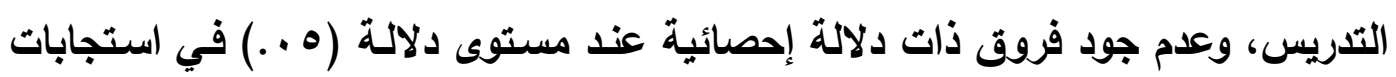

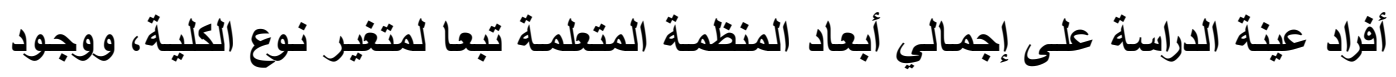

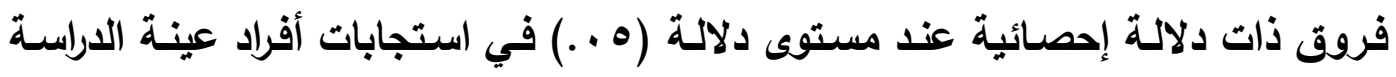

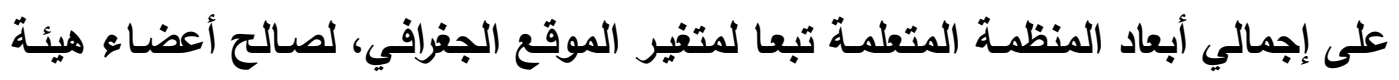

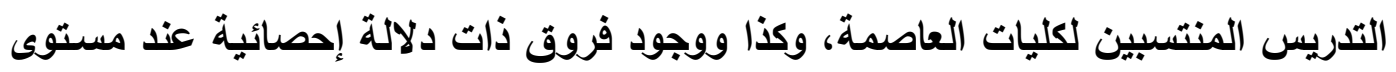

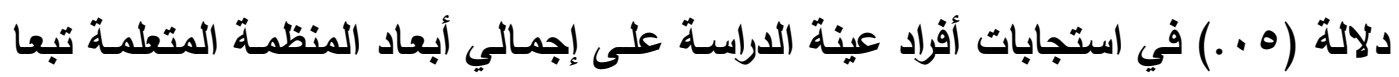

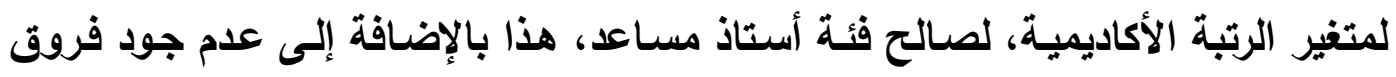

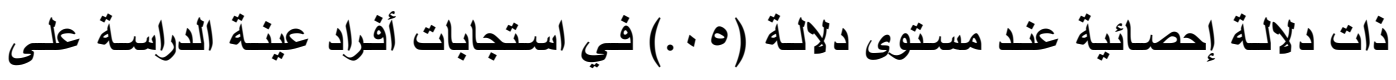

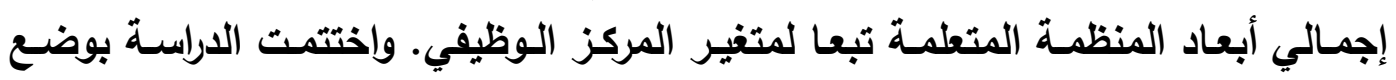

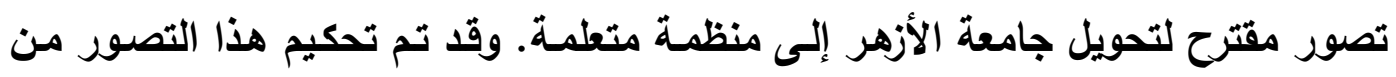

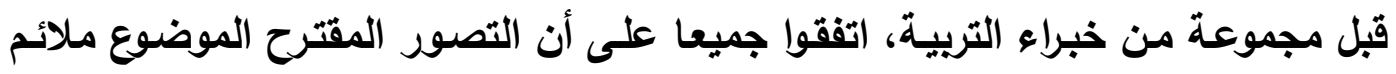

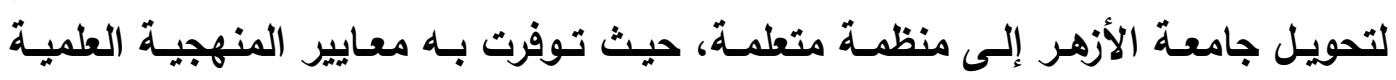
المطلوية، إلى جاتب اتفاقه مع التوجهات المعاصرة في إدارة مؤسسات التعليم العالي. الكلمات المفتاحية: تصور مقترح، وجامعة الأزهر، ومنظمة متعلمة. 


\title{
A Proposed Perspective to Transform Al-Azhar University into a
}

\section{Learning Organization}

\author{
By: \\ Dr. Ahmad Samir Fawzy Abdul-Allah
}

\begin{abstract}
The current study aimed at detecting the availability of the learning organization dimensions at Al-Azhar University from the viewpoints of the faculty members. More than that, the study developed a proposed perspective for transforming Al-Azhar University into a learning organization. The study adopted the descriptive method and made use of a questionnaire administered to the study participants, totaling 381 faculty members, at Al-Azhar University for collecting the target data. The results of the study revealed that the degree of the availability of the learning organization dimensions at Al-Azhar University from the viewpoints of faculty members was average. There were statistically significant differences at (0.05) level in the responses of the study participants to all the dimensions of the learning organization in the light of the gender variable in favor of the females. There were no statistically significant differences at (0.05) level in the responses of the study participants to all the dimensions of the learning organization in the light of the faculty type variable. There were statistically significant differences at (0.05) level in the responses of the study participants to all the dimensions of the learning organization in the light of the geographical location variable in favor of the faculty members at the faculties located in the capital of Egypt. There were statistically significant differences at (0.05) level in the responses of the study participants to all the dimensions of the learning organization in the light of the academic rank in favor of the assistant professors. There were no statistically significant differences at (0.05) level in the responses of the study participants to all the dimensions of the learning organization in the light of the career status variable. The study concluded with a proposed perspective for transforming Al-Azhar University into a learning organization. The proposed perspective was validated by a group of education experts who confirmed its suitability for transforming Al-Azhar University into a learning organization. Furthermore, the proposed perspective is
\end{abstract}


compatible with the scientific methodology and the contemporary trends in the management of higher educational institutions.

Keywords: perspective, Al-Azhar University, learning organization.

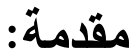

فرض عصر المطلوماتية الذي نعيش فيه على جميع المنظمات - وفي طليعتها الجامعات- تغيير ممارساتها ومسلماتها، واعادة التفكير بكل أنثطتها، والنظر من جليد في وظائفها، وكيفية توفير مخرجات ملائمة لسوق العمل، وتطوير الأداء الجامعي، ويالتالي تطوير المجتمع، كما فرض على تلك المنظمات الأخذ بمفاهيم قيادة إدارية جديدة؛ محورها التحول في اتجاه منظمات متعلمة. ( Wu, 2006,p.3 ) .

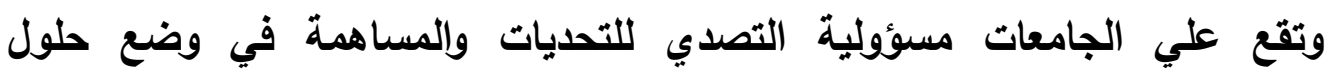
للمشكلات باعتبارها من أهم منظمات المجتمع - إن لم تكن أهمها بالكلية - التي تمتلك

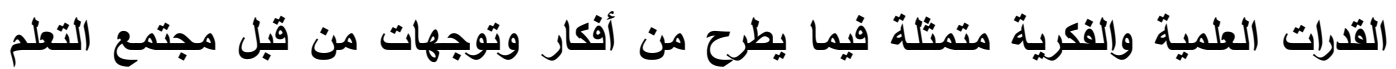
المهني بها وفي مقدمته أعضاء هيئة التريس، ويما تضمه من تخصصات علمية ونظرية، ويما يتوافر لايها من مراكز بحثية ومصادر ونظم معلوماتية. والواقع أن أعضاء هونهاء

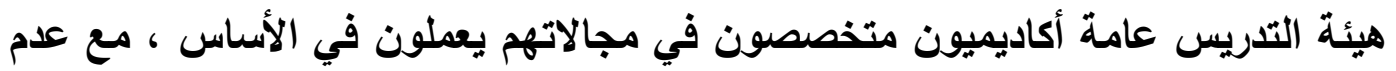
رفضهم الانخراط في عمل تعاوني. وتزداد استقلاليتهم في حال وجود مديرين أكاديميين متخصصين. وفي سبيل تحول الجامعة إلي منظمة متعلمة فإن علي أعضاء هيئة

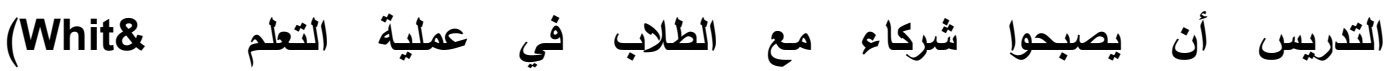
Rita,2005,p.295) والتحدي الذي يواجهه أعضاء هيئة التدريس هنا هو استيفاء

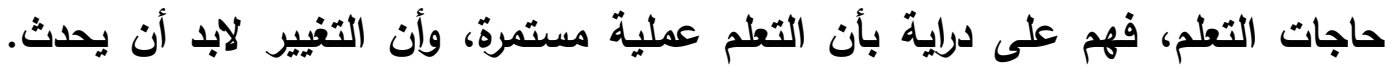
وليس هناك حلولا ثابتة وسريعة، لذا فهم يشجعون التجريب، والتأمل، للوقوف على

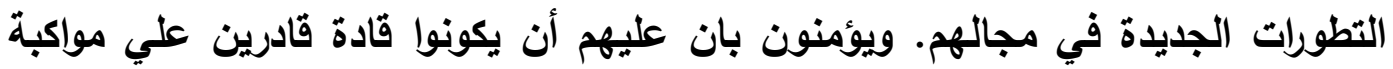

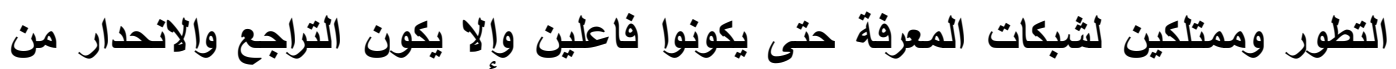

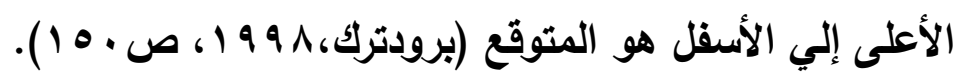

كما أن عضو هيئة التدريس الأي تحتاج إليه الجامعة كمنظمة متعلمة يجب أن يكون ذا إمكانات ومؤهلات، ومواصفات نوعية ومنطورة تتواءم والتطورات التي يثهاهها

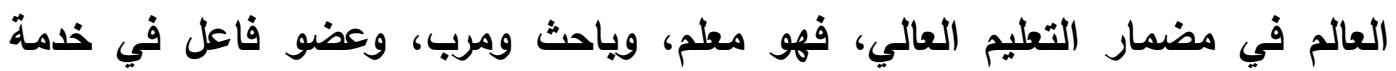

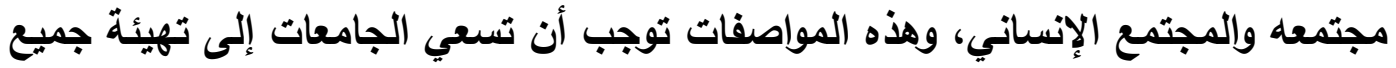
الظروف الملائمة لتحسين جودة أدائه، وتجديد معارفه وتطوير مهاراته، وزيادة خبراته وفاعليته، والارتقاء بدوره التعليمي والأكاديمي، والتريوي، والاجتماعي، وزيادة إنتاجه 


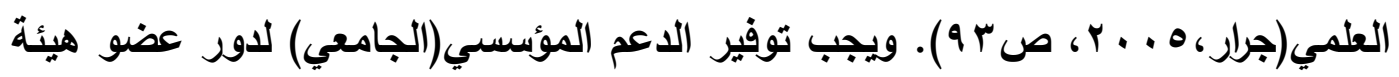

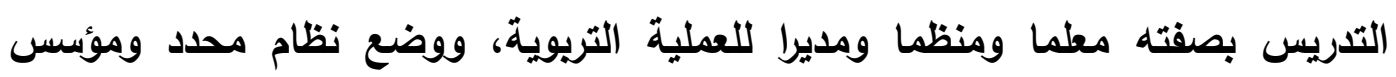

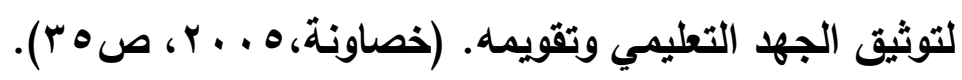

لذلك يجمع العديد من الباحثين علي أن مؤسسات التعليم العالي مطالبة باعتماد

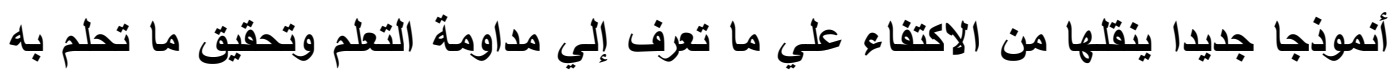
من جودة؛ لتصبح منظمات متعلمة، من خلال التركيز على أهمية واستمرارية التعليم والتعلم معا، وزيادة مقدرة أعضاء هيئة التدريس علي تحقيق النتائج التي يرغبون فئهيا .(Duke,2002,p.30; Smith,2004; Srikanthan\& Dalrymple,p.175) ومن الجدير بالذكر، ان الجامعات التي ترفض أن تتغير لن تستمر؛ الأمر الذي

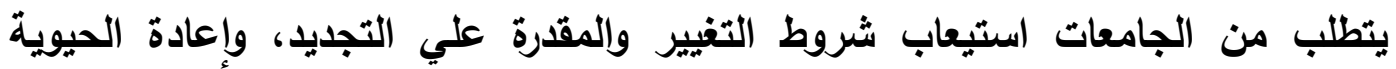

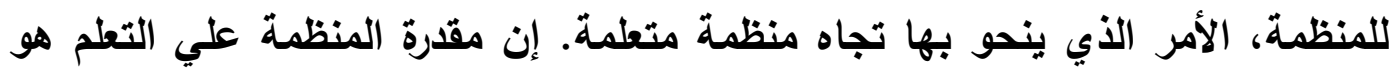
مفتاحها للبقاء والنمو، فالمنظمة المتعلمة ليست فقط القادرة علي التكيف، بل بالأحرى

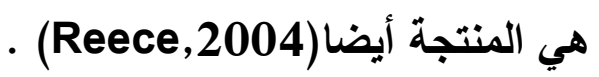
مشكلة الدراسة: تنطلق مشكلة الدراسة من أن جامعة الأزهر تعاني من جملة من المعوقات

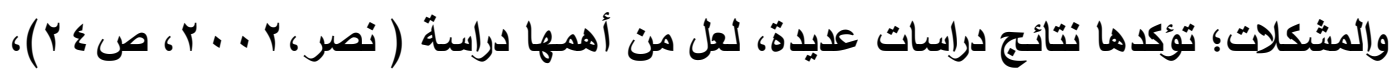

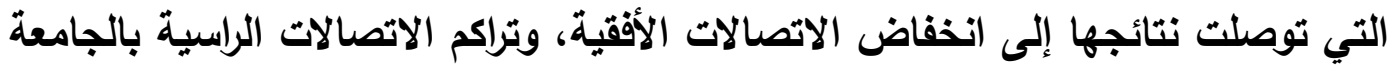

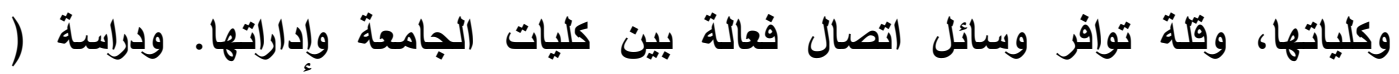

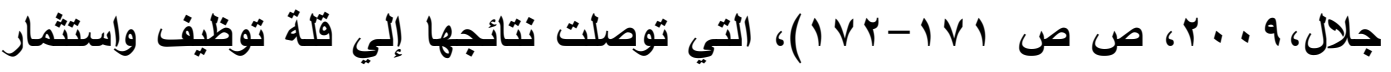

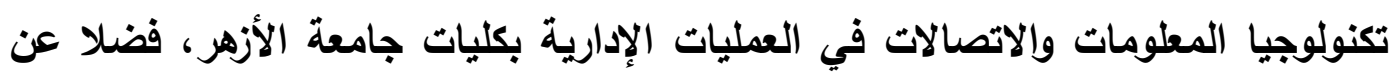

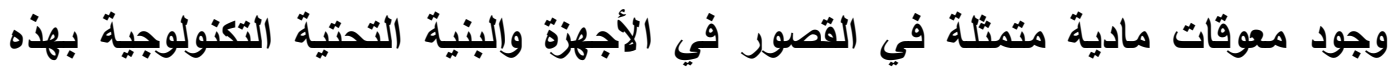
الكليات، ومعوقات بشرية متمثلة في قثلة إلمام كثير من الأفراد بهذه فئه الكليات باستخدام

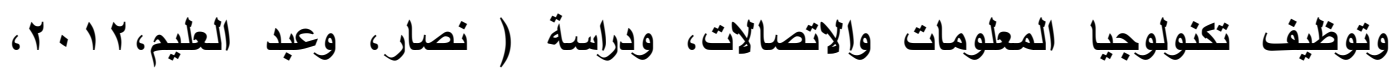

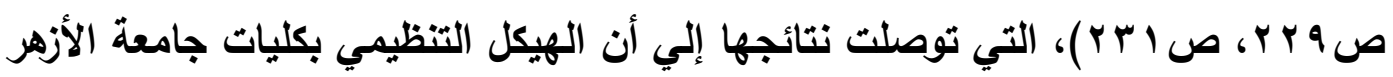

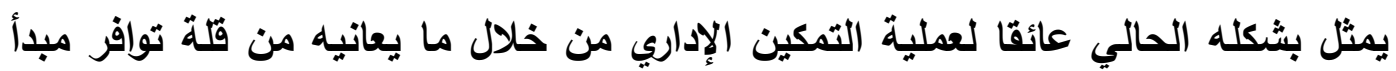

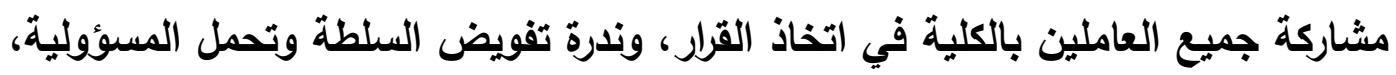

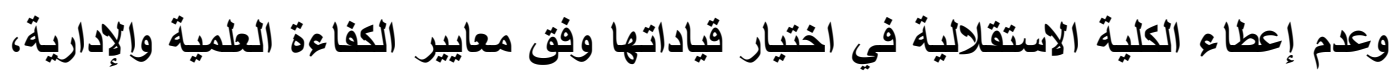
وضعف الانفتاح علي المجتمع من خلال قلة الروابط والصلات بين الكلية ومجتمعها 


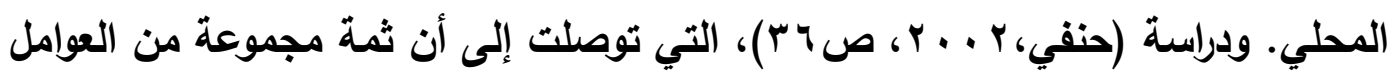

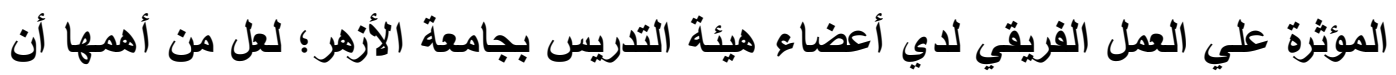

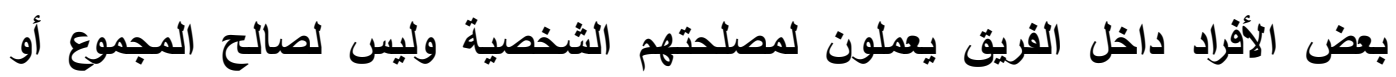

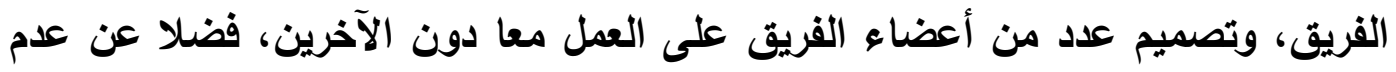

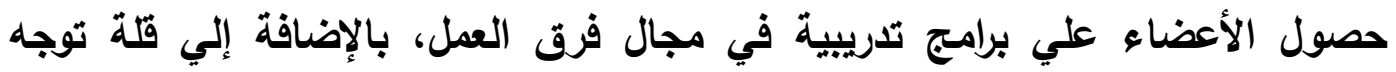

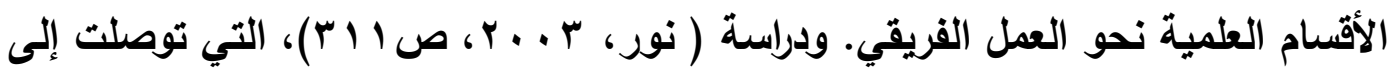

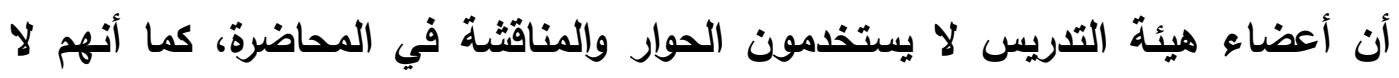
يتقبلون وجهات نظر الطلاب المختلفة، فضلا عن سيادة أسلوب المحاضرة الإلقائية في التدريس، وقلة تشجعيهم للطلاب علي التعلم الأتي، وندرة استخدامهم للأجهزة والوسائل

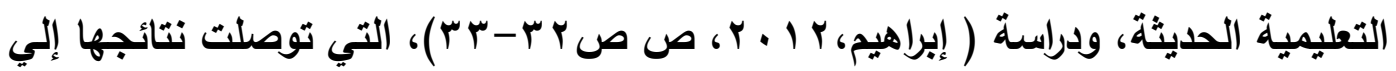

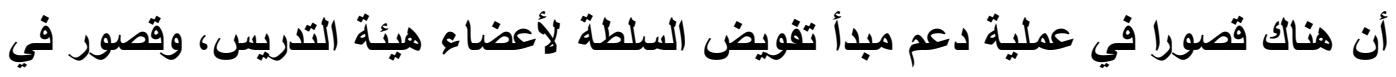

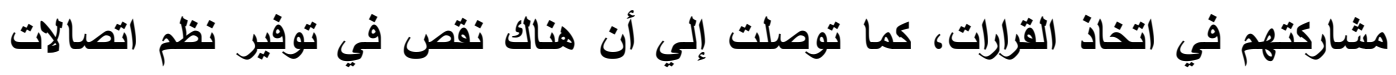

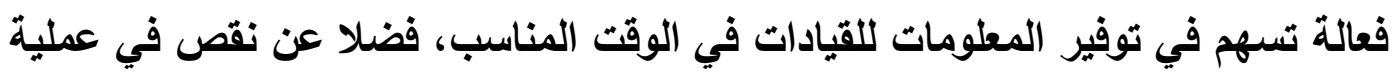

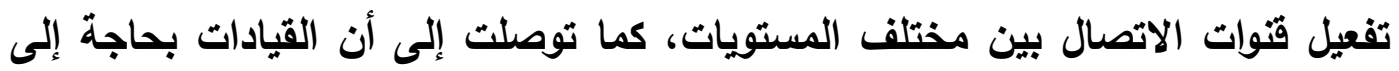
دورات تدريبية من أجل تنمية قدراتهم بما يحقق الأهداف المنشودة.

ولعل المشكلات السابقة التي تواجهها جامعة الأزهر تفرض عليها ضرورة تطوير

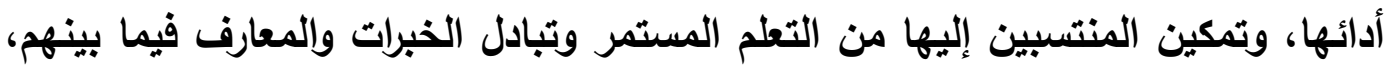
والتطوير في بنيتها من وقت لآخر، ولا يتحقق ذلك إلا من خلال تحول الجامعة من كونها

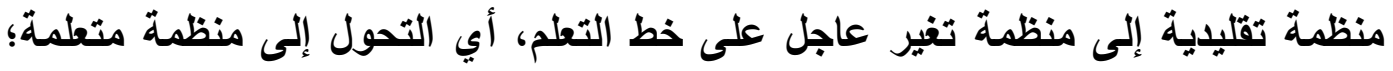
الأمر الذي شكل دافعا لاى الباحث لإجراء الدراسة. تساؤلات الدراسة: حاولت الدراسة الإجابة عن التساؤلات التالية: 1- ما الإطار الفكري والفلسفي للمنظمة المتعلمة؟ r- ما درجة توافر أبعاد المنظمة المتعلمة في جامعة الأزهر من وجهة نظر أعضاء هيئة التدريس؟

r- هل تختلف درجة توافر أبعاد المنظمة المتعلمة في جامعة الأزهر من وجهة نظر

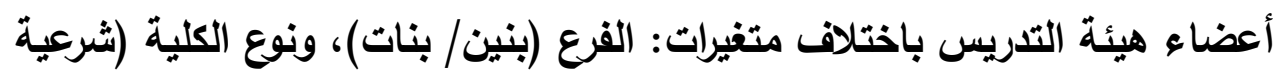
وعربية/ نظرية/ عملية)، والموقع الجغرافي للكلية (وجه قبلي/ عاصمة/ وجه الفئه بحري)، 
والرتبة الأكاديمية (مدرس/ أستاذ مساعد/أستاذ)، والمركز الوظيفي( شغل أو يشغل حاليا منصبا إداريا، لم يشغل منصبا إداريا).

ع- ما التصور المقترح لتحويل جامعة الأزهر إلي منظمة متعلمة؟

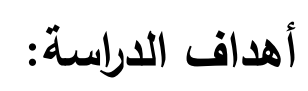

حاولت الدراسة تحقيق الأهداف التالية:

1- التعرف على الإطار الفكري والقلسفي للمنظمة المتعلمة.

r- الكشف عن درجة توافر أبعاد المنظمة المتعلمة في جامعة الأزهر من وجهة نظر

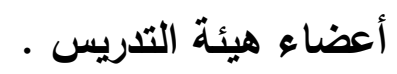
r- التعرف علي الفروق في استجابات أفراد عينة الدراسة علي درجة توافر أبعاد

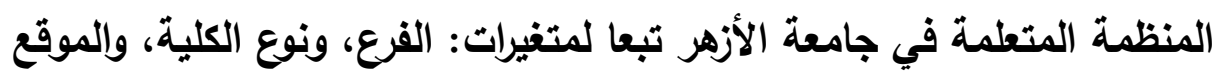
الجغرافي لها، والرتبة الأكاديمية، والمركز الوظيفي. ؛ - وضع تصور مقترح لتحويل جامعة الأزهر إلى منظمة متعلمة. أهمية الدراسة: - 20 - 20 تكمن أهمية الدراسة الحالية في كونها: 1 - تتناول نموذج المنظمة المتعلمة كمدخل للتطوير في جامعة الأزهر وهو من أحلث المداخل الإدارية.

r- تقدم صورة لمتذذي القرار عن مدى توافر أبعاد المنظمة المتعلمة في جامعة الأزهر وكيفية الاستفادة منها في إدارة التغيير.

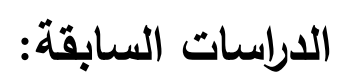

فيما يلي عرض لأهم الاراسات العربية والأجنبية ذات الارتباط بموضوع الدراسة،

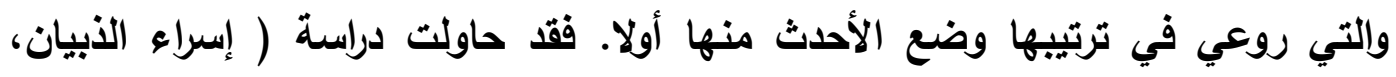

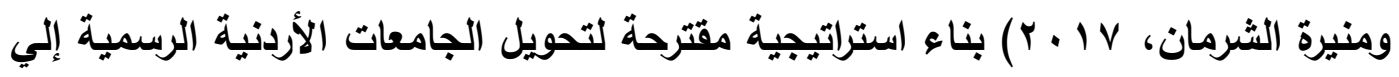
منظمات متعلمة من وجهة نظر القادة الأكاديميين وأعضاء هيئة التدريس فيهاء

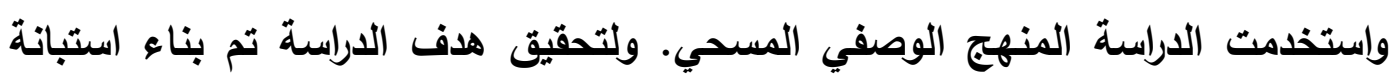

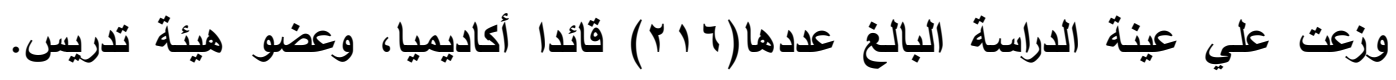
وتوصلت الدراسة إلي عدة نتائج كان من أهمها: أن درجة توافر متطلبات تحويل الجامعات 
الأردنية الرسمية إلي منظمات متعلمة كاتت بلرجة متوسطة، ووجود فروق ذات دلالة إحصائية حول إمكانية تحويل الجامعات الأردنية الرسمية إلى منظمات متعلمة تعزي لرئه لمتغير المسمى الوظيفي. وقد تكون الهيكل العام للاستراتيجية المقترحة من ست مراحل تمثلت في: التخطيط، وتحليل الأبعاد البيئية، ووضع استراتيجيات التخطيط وصياغتها إجرائيا، ووضع البرامج وتنفيذها، وتقييم الاستراتيجية وفاعليتها، وتصديق الاستراتيجية. كما استهافت دراسة( الصرايرة، والصنمور، V V P ) التعرف علي درجة توافر أبعاد منظمة التعلم في مديرية تربية وتعليم قصبة الكرك في الأردن من وجهة نظر مديري المدارس الثانوية. ولتحقيق هدفها استخدمت المنهج الوصفي مستعينة بالاستبانة التي وني فئه

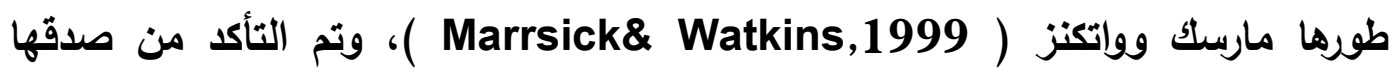

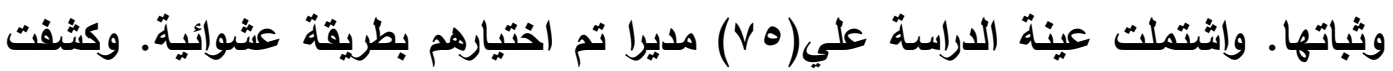

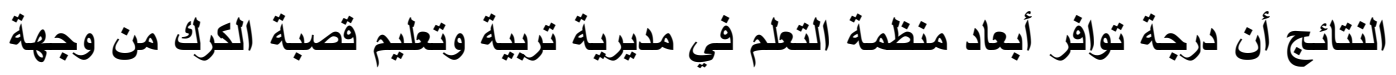
نظر مديري المدارس الثانوية كانت متوسطة بثكل عام، ولكل بعد من الأبعاد الثُلاثة،

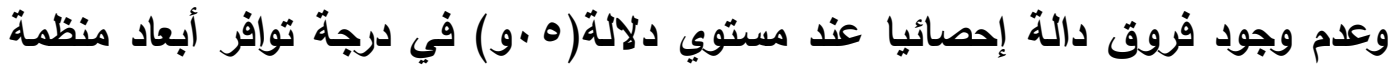
التعلم ترجع إلي متغيرات: النوع، والمؤهل العلمي، والخبرة.

واستهدفت دراسة ( العنزي، 17 ب ) الكثف عن مدى امتلاك جامعة تبوك لمعايير المنظمة المتعلمة من وجهة نظر أعضاء هيئة التدريس فيها. واستخدمت الدراسة

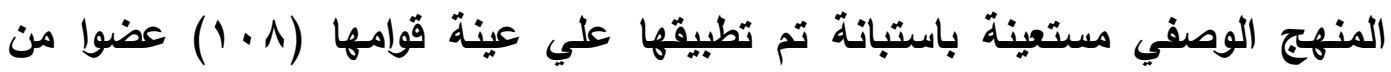

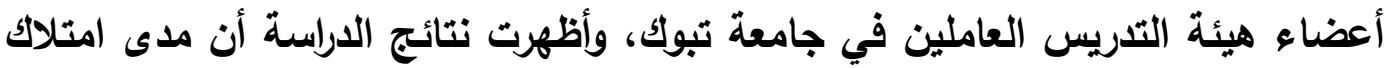

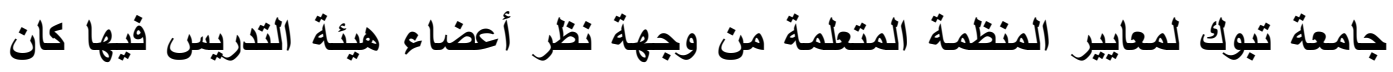

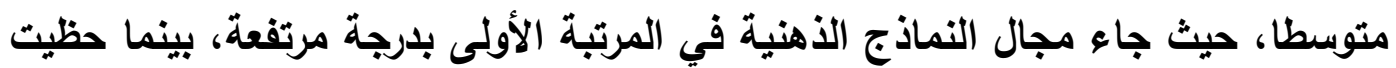

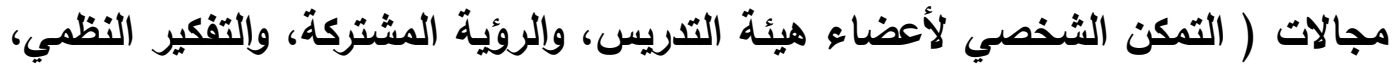

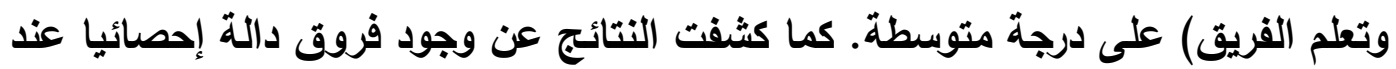
مستوي دلالة(ه .و) في استجابات أعضاء هيئة التدريس علي مجال(تعلم الفريق) ترجع

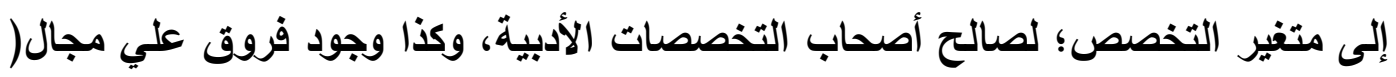

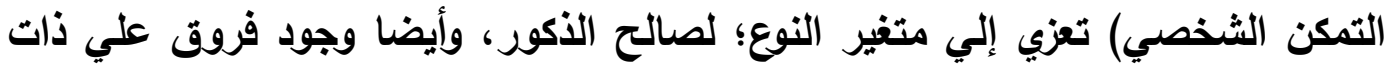
المجال تعزي إلي متغير طبيعة العمل؛ لصالح من يعملون في الإدارة والتدريس، مقارنة بزملائهم ممن يطلمون في التدريس فقط. أما دراسة ( الايحاني، 10 ـ ب) فقد استهدفت التعرف علي العلاقة بين أبعاد المنظمة المتعلمة والقيادة التحويلية لاى القيادات الجامعية من وجهة نظر أعضاء هيئة 
التدريس في جامعة الكويت. واستخدمت الدراسة المنهج الوصفي الارتباطي المقارن

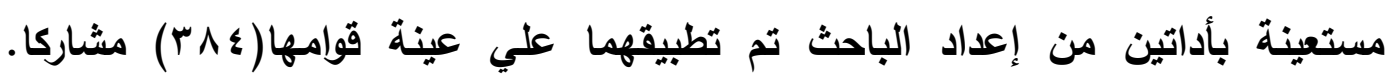

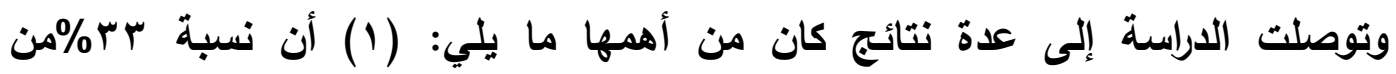

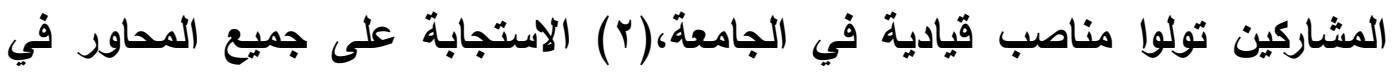
الأد|تين كانت في المدى المتوسط،(؟) العلاقة ايجابية طردية بين أبعاد المنظمة المتعلمة

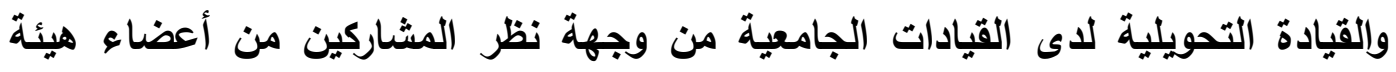
التدريس،(؟) وجود فروق ذات دلالة إحصائية في استجابات أفراد العينة حول توفر أبعاد

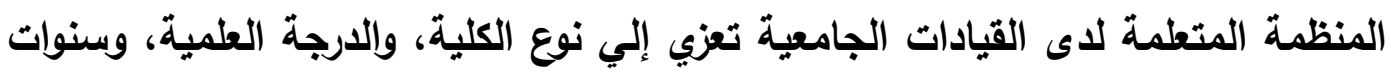

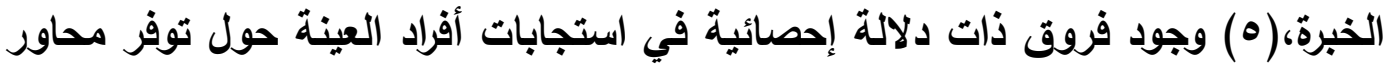

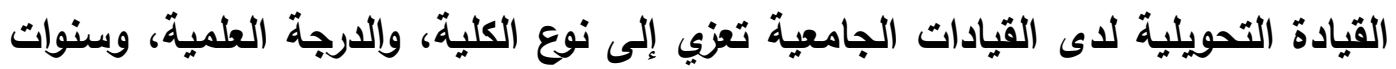
الخبرة،(7) وجود فروق ذات دلالة إحصائية لصالح القياديين حول أبعاد المنظمة المتعلمة

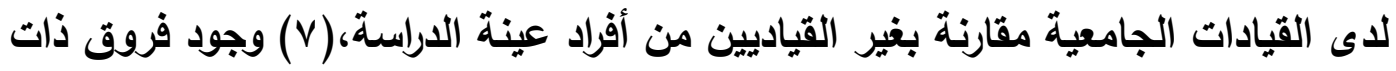

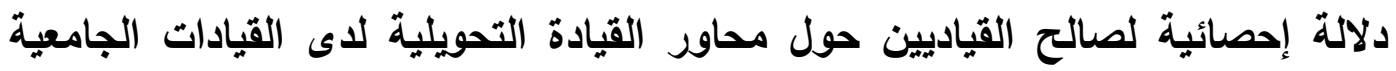
مقارنة بغير القياديين من أفراد عينة الدراسة.

بينما استهدفت دراسة كل من ( العياصرة، والحارثي، 10 ـ ب ) التعرف إلى درجة

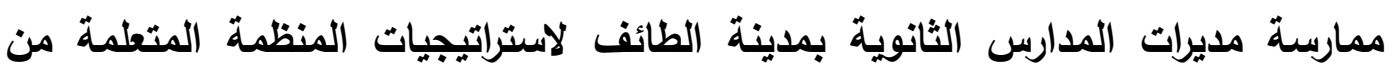
وجهة نظر المعلمات. واستخدمت الاراسة المنهج الوصفي مستعينة باستبانة تم تطبيقها علي عينة قوامها(IVI) معلمة من معلمات مدارس المرحلة الثانوية الحكومية للبنات

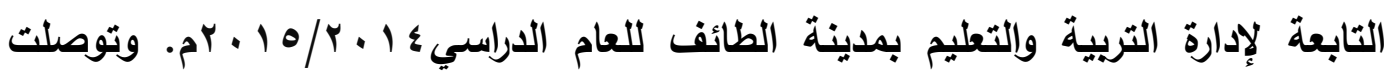
الاراسة إلى أن درجة ممارسة مديرات المدارس الثانوية بمدينة الطائف لاستراتيجيات

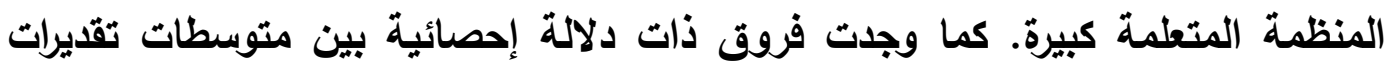
أفراد عينة الاراسة لارجة ممارسة مديرات المدارس الثانوية بمدينة الطائف لاستراتيجيات

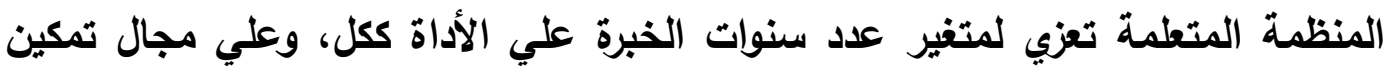

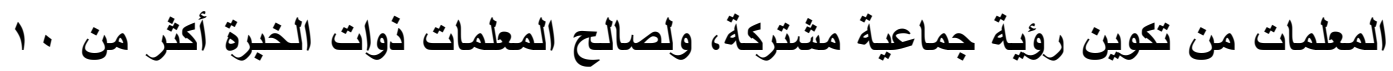

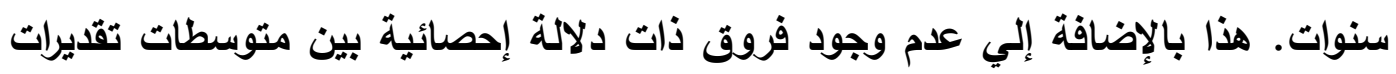
أفراد عينة الدراسة لارجة ممارسة المديرات لاستراتيجيات المنظمة المتعلمة تعزي لمتغيري

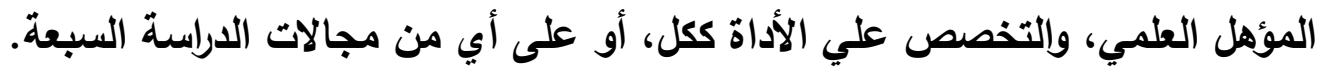
كما استهدفت دراسة ( العتيبي، وهيفاء إبراهيم، 10 ب ب) معرفة درجة توفر أبعاد المنظمة المتعلمة وعلاقتها بتمكين العاملين بجامعة الطائف، ومعرفة درجة اختلاف 
وجهات نظر العاملين باختلاف متغيرات: النوع، والتخصص، والمؤهل العلمي، وعدد سنوات الخبرة، وعدد الدورات التدريبية. ولتحقيق أهداف الدراسة استخدمت الدارية الدئة المنهج

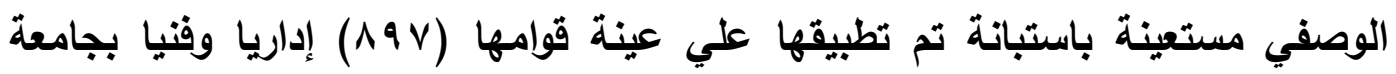

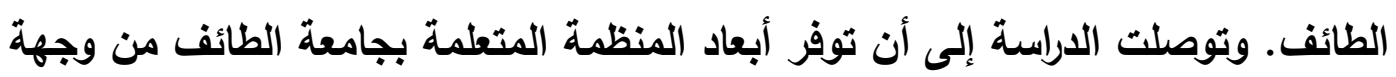

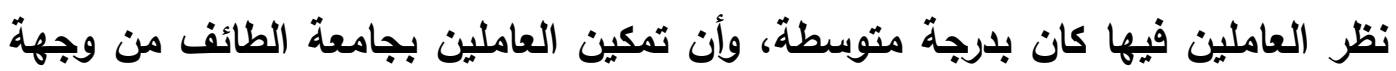
نظرهم أيضا كان بدرجة متوسطة، وكذا وجود علاقة ارتباطيه ذات دلالة إحصائية عند وند

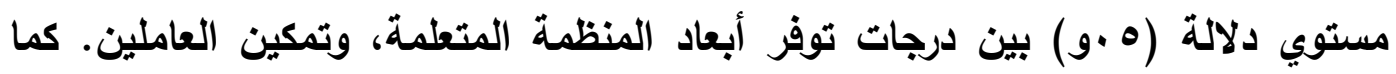

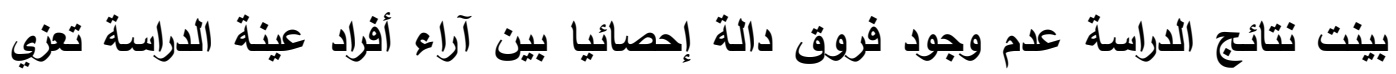

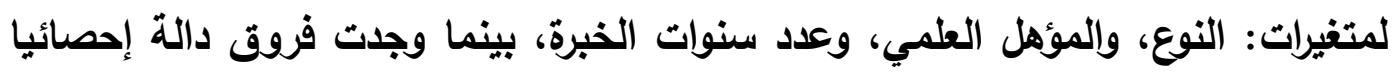

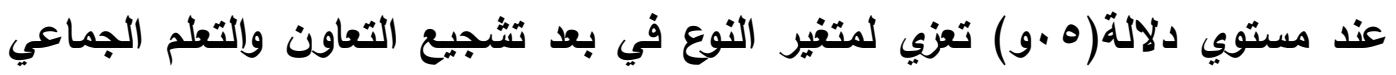

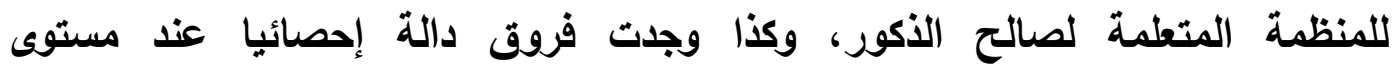

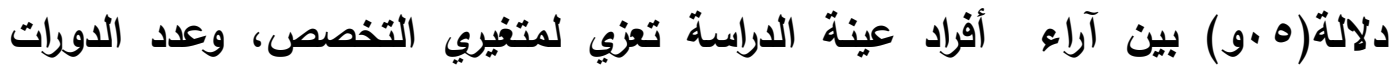

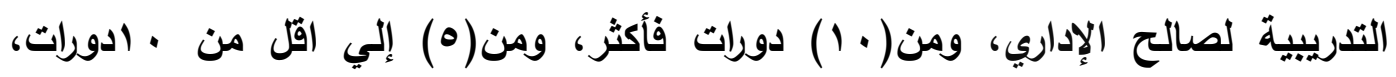

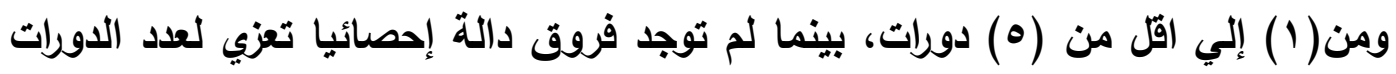
التدريبية في بعدي تمكين العاملين: معني العمل، والتأثير.

وإستهلت دراسة ( المزروع، 1 + ب) التعرف إلى درجة ممارسة أعضاء هيئة

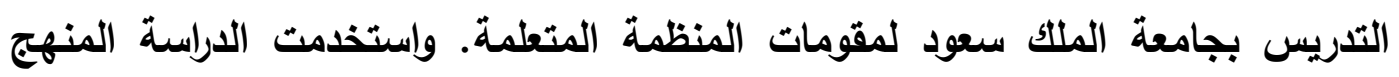

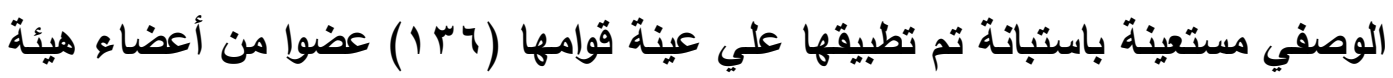

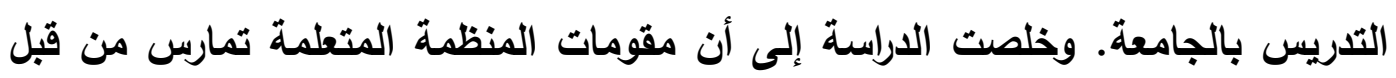

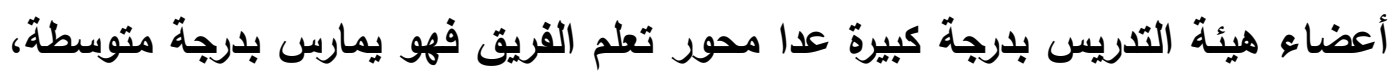

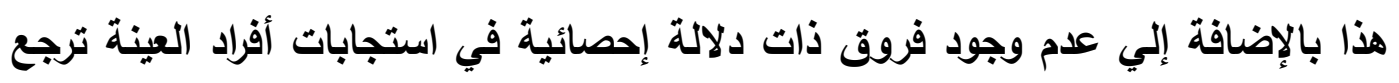
لمتغيرات: النوع، والرتبة الأكاديمية، والتخصص.

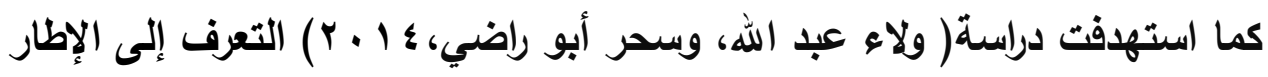
النظري والفكري للمنظمة المتعلمة وإمكانية الاستفادة منه في تطوير كليات التربية، وكذا عالها

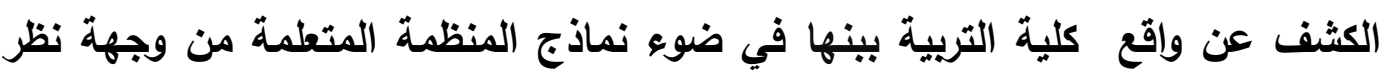

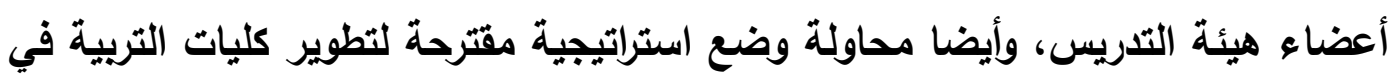

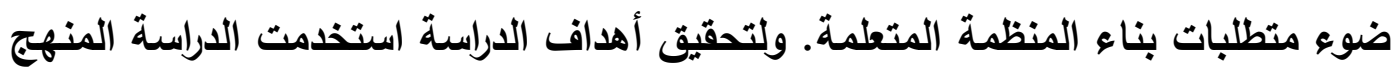

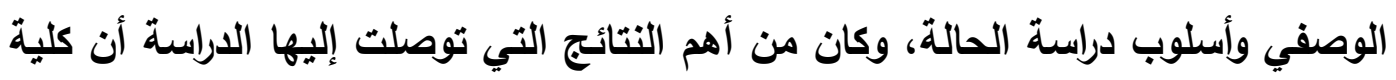
التربية لا تثجع العمل الفريقي باعتباره من مصادر التنمية المهنية لأعضاء هيئة 
التدريس، كما لا تبذل الكلية جهودا كبيرة في وضع أفكار داعمة لعمليات التظوير الخاصة

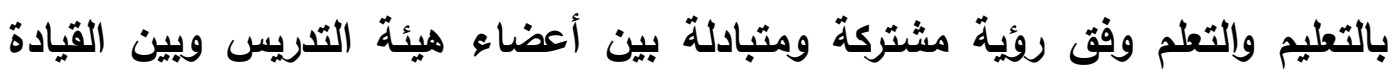

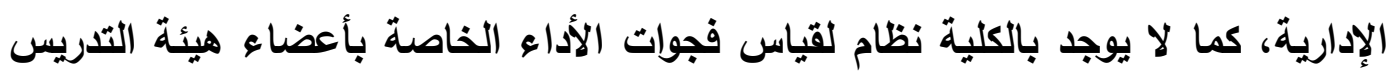

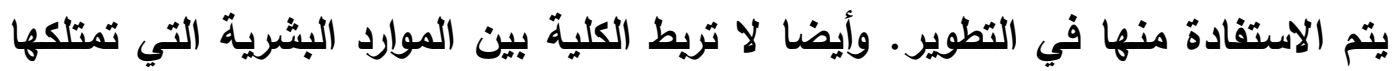

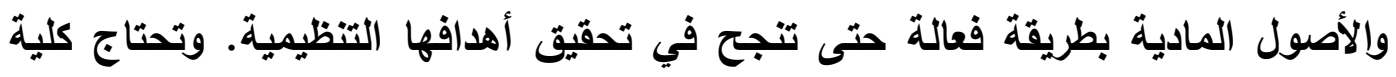

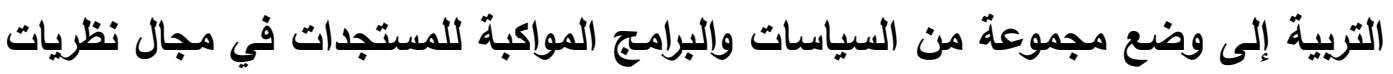

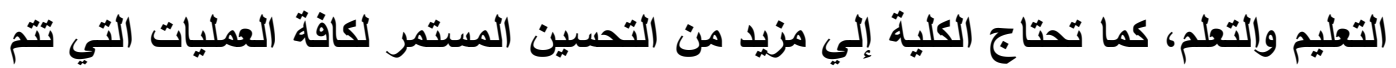
باخلها لضمان تحقيق أفضل للنتائج.

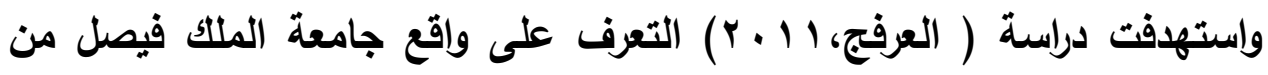

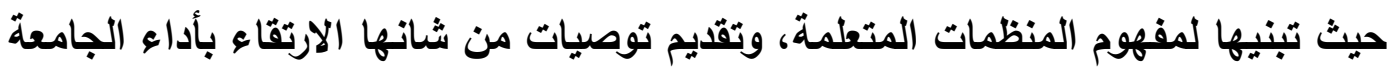
المتعلق بتنمية معارفها ورأسمالها الفكري. واستخدمت الدراسة المنهج الوصفي مستعينة ونئة

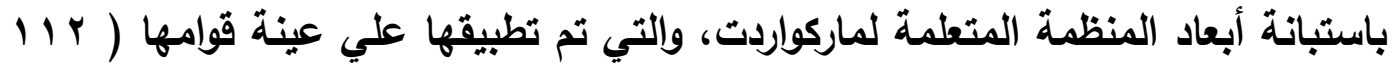

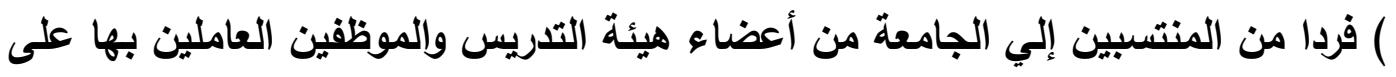

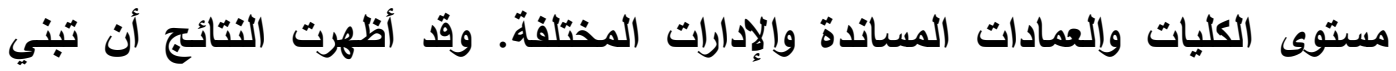
الجامعة لأبعاد المنظمات المتعلمة هو عند مستوى متوسط.

وقد هافت دراسة ضحى خضر، وخصاونة (11 + (1) إلى تطوير أنموذج لممارسة مجالات المنظمة المتعلمة كما يراها أعضاء هيئة التدريس في الجامعة العانهة الأردنية.

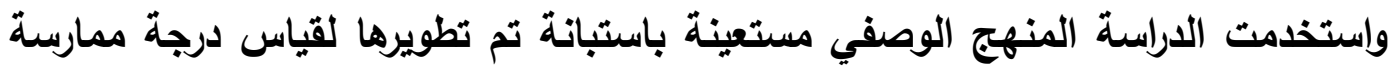

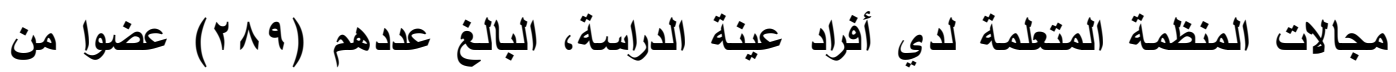

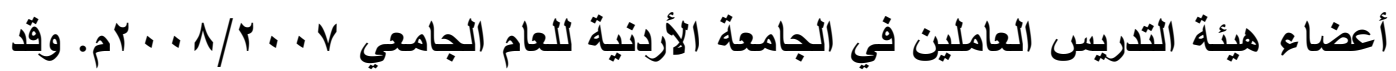

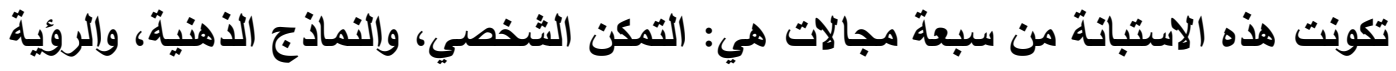

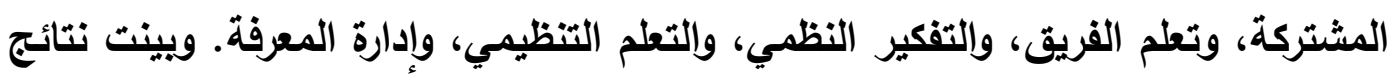
الاراسة أن درجة ممارسة أعضاء هيئة التدريس لمجالات المنظمة المتعلمة كبيرة في

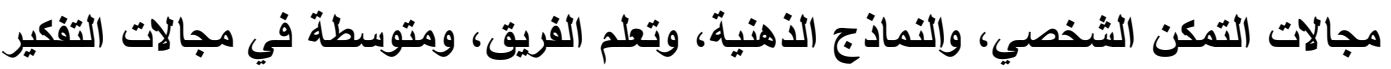

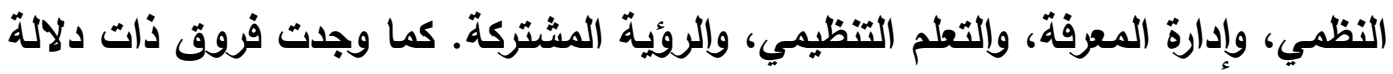

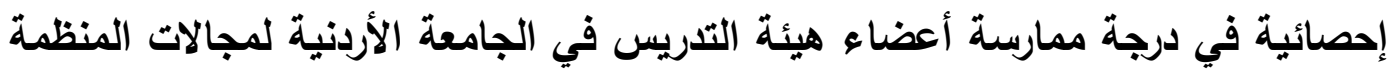

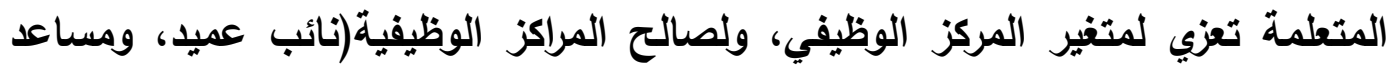
عميد، وعضو هيئة تدريس) في مجالات تعلم الفريق، والتعلم التنظيمي، وعلي الأداة

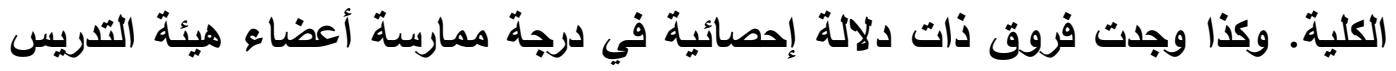


في الجامعة الأردنية لمجالات المنظمة المتعلمة تعزي لمتغير الرتبة الأكاديمية، ولصالح الرتب الأكاديمية (أستاذ، وأستاذ مشارك) في مجالات تعلم الفريق، والتفكير النظمي، والتعلم التنظيمي، وعلي الأداة الكلية، بينما كانت الفروق لصالح التالحيه الرتبة الأكاديمية (مدرس) في مجال إدارة المعرفة. هذا بالإضافة إلي عدم وجود فروق ذات الدات دلالة إحصائية في درجة ممارسة أعضاء هيئة التدريس لمجالات المنظمة المتعلمة تعزي لمتغير نوع

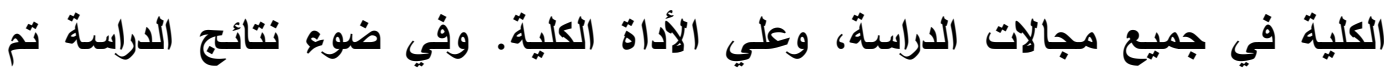

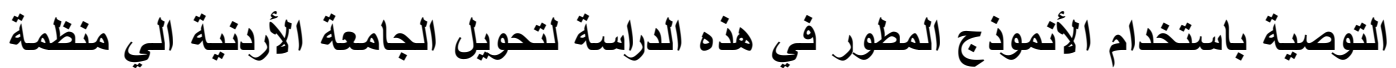

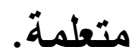

وحاولت دراسة ( أبو حشيش، ومرتجي، 11 +r) التعرف إلى مدي توافر أبعاد

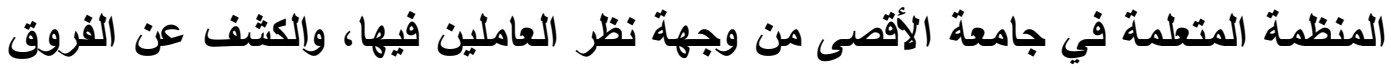
في استجابات أفراد العينة تبعا لمتغير( النوع، والتخصص، والتصنه وسنوات الخدمة، وطبيعة العمل)، ووضع بعض المقترحات لتطوير الجامعة في ضوء مفهوم المنظمة المتعلمة.

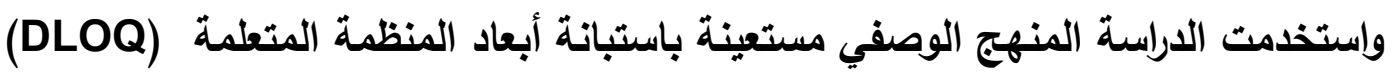

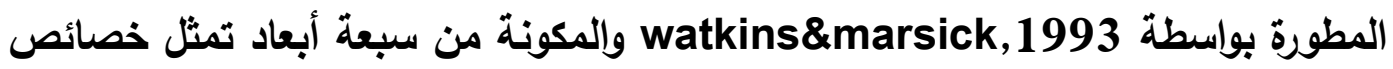

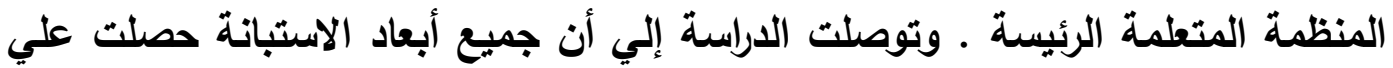
درجة متوسطة، ولم توجد فروق لصالح التخصص علي جميع أبعاد الاستبانة باستثناء

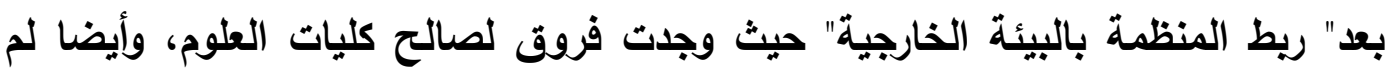

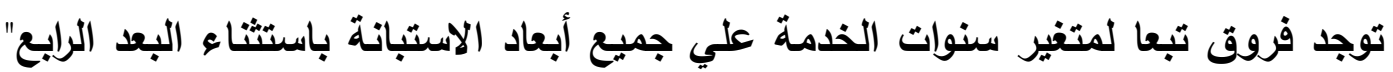
إنثاء أنظمة لمشاركة المعرفة والتعلم" حيث وجلت فروق لصالح سنوات الخدمة أكثر

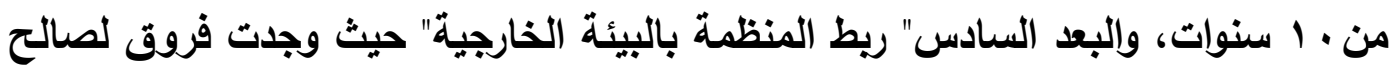
سنوات الخدمة أقل من • سنوات، وكذا لم توجد فروق حسب طبيعة العمل باستثناء بعد" إيجاد فرص التعلم المستمر" حيث وجدت فروق لصالح الإداريين، هذا بالإضافة إلي وجود

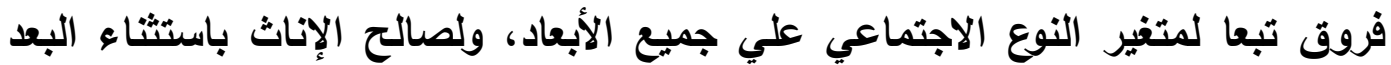

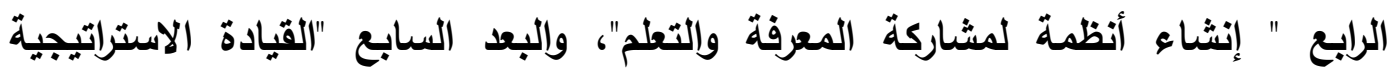
الاعمة للتعلم" حيث تبين عدم وجود فروق بينهما.

وأجرى كان(Can,2011) دراسة هدفت إلي الكثف عن الأنشطة التي تعمل علي

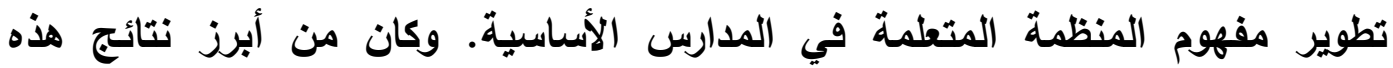
الاراسة، أن المنظمة المتعلمة تحتاج للتخطيط الفعال قبل أن تبدأ بممارسة أعمالها. ويجب أن تتضمن الثقافة التظظيمة للمنظمة المتعلمة أنثطة مثل: الاجتماعات الدورية، 
والنوادي التربوية، والبيئات المدرسية الآمنة، وأخيرا تضم المنظمة المتعلمة نظاما

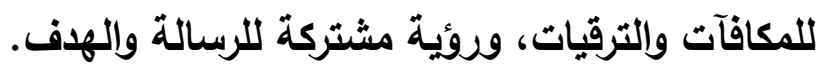

واستهدفت دراسة عبابنة ( • • ب ) التعرف إلى درجة ممارسة المعلمين والإداريين

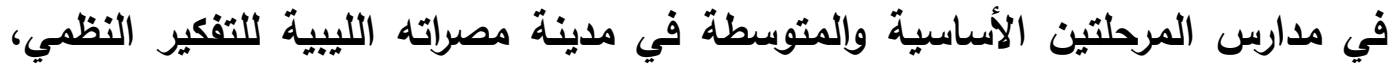
والكثف عن مقدار الاختلاف في تلك الارجة حسب متغيرات : الوظيفة، والنوع، ومستوي

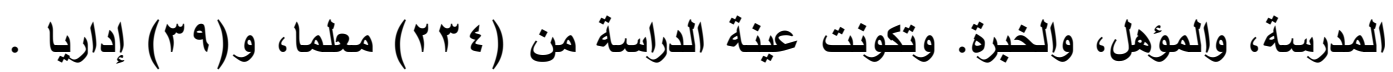

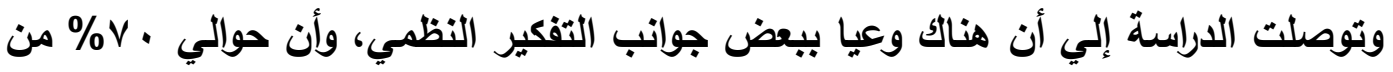

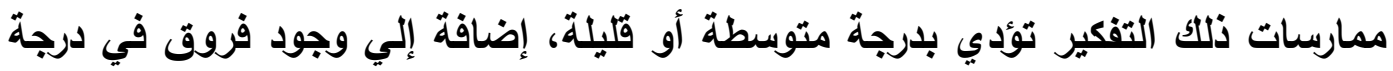
الممارسة لصالح الإناث، وأصحاب الخبرة الأطول.

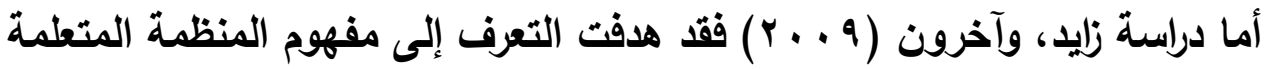
وخصائصها وتقييم الإمكانات ذات الصلة بهذا المفهوم في قطاعات الهيئة الملكية بالجيل.

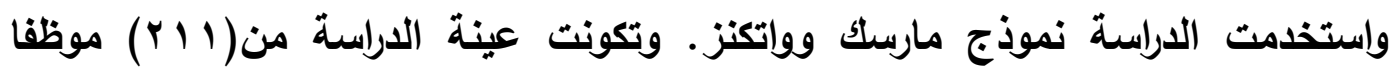

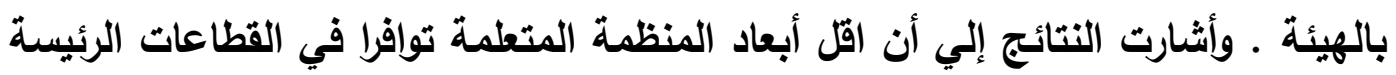

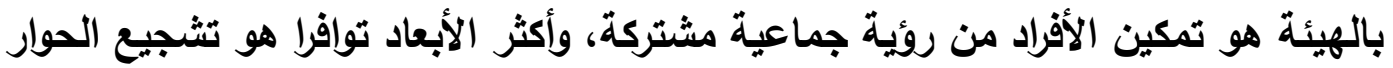

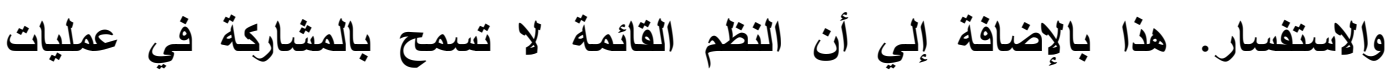

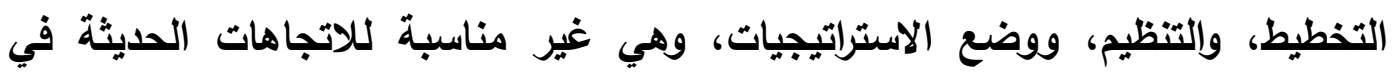
الإدارة مثل التعلم التظيمي، والمنظمات المتعلمة، وإنثاء نظم المعرفة والتعلم.

واستهدفت دراسة الحكيم، وآخرون(9 . . †) إلقاء الضوء على إمكانية استخدام

أدوات التعلم التظيمي في بيئة التعليم الجامعي ودورها في تحقيق الأداء المتميز، وهل التهل لاي الجامعة برامج للاستفادة من عمليات التعلم التنظيمي في تعزيز إمكانية نجاح الأداء

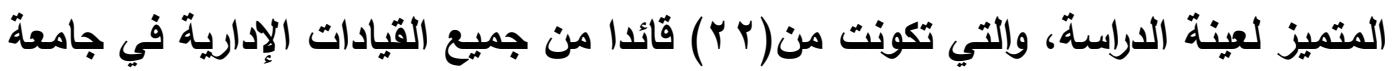

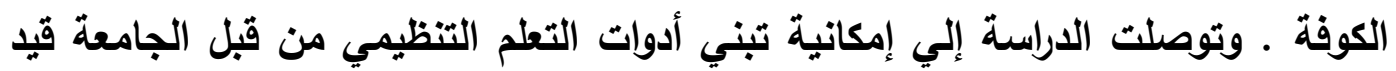
الاراسة لأنها في الأساس تعد منظمة معرفية، وأن استخدام أدوات التعلم التظظيمي يمكن

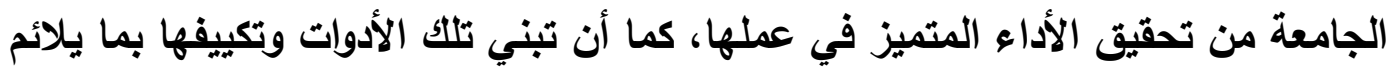

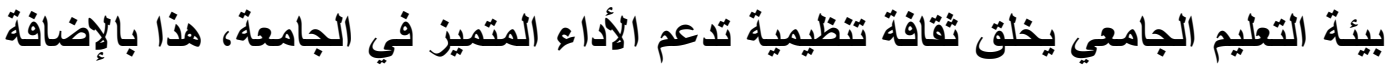

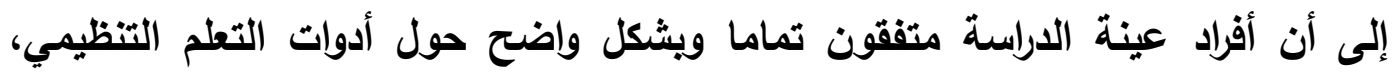
وحول خصائص منظمات الأعمال ذات الأداء المتميز، الأمر الأي يعني انه في في حال اله استخدام هذه الخصائص من قبل الجامعة فان ذلك يمكنها من تحقيق التميز في أعمالها. 


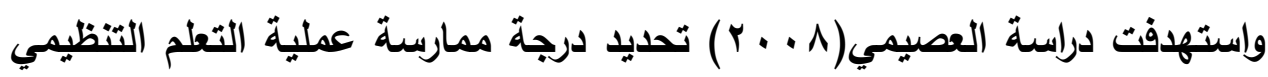

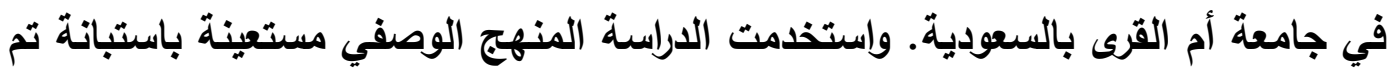

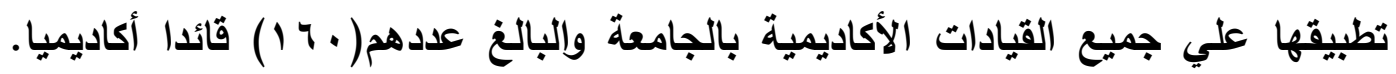
وبينت النتائج ان الممارسات المتعلقة بمجال التعلم التنظيمي بالجامعة في محاوره الثلاثة: استراتيجية التعلم التنظيمي، والبنية التنظيمية الداعمة للتعلم التنظيمي، والثقافة التنظيمية تتم بلرجة متوسطة.

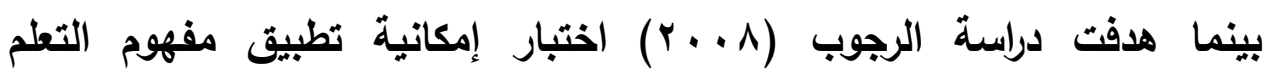

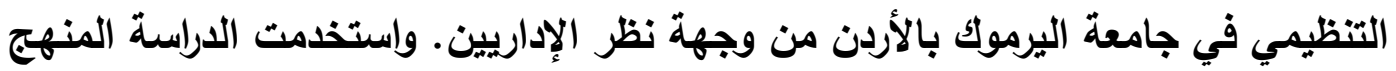

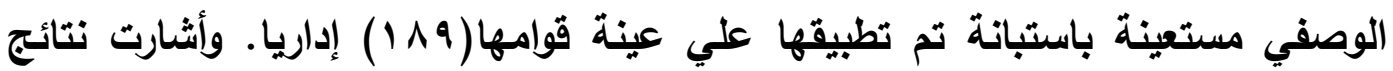
الاراسة إلى أن جامعة اليرموك تطبق التعلم التظيمي بأبعاده المختلفة، والتي جاء في في

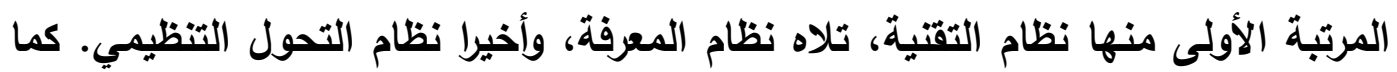
أوضحت النتائج عدم وجود فروق ذات دلالة إحصائية بين آراء الإداريين (أفراد عينة

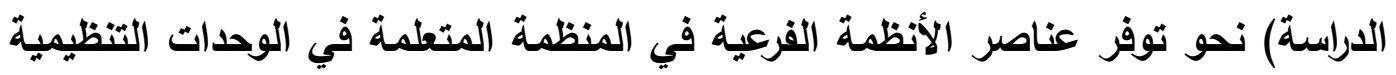
التي يعملون بها تعزي لمتغيرات: النوع الاجتماعي، والمسمى الوظيفي، وعدد الموظفين في الوحدة التنظيمية.

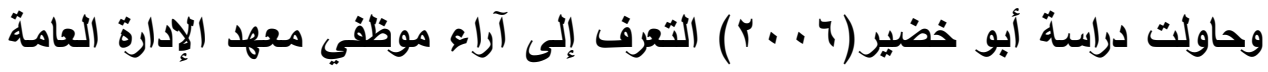
نحو توافر عناصر الأنظمة الفرعية الخمسة للمنظمة المتعلمة: نظام التعلم، ونظام التحول

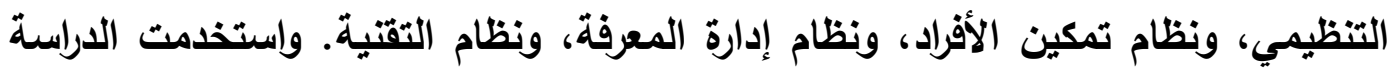

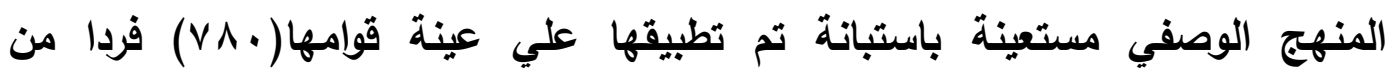
الموظفين والموظفات العاملين بمعهة الإدارة العامة في المملكة العربية السعودية. وقدانه

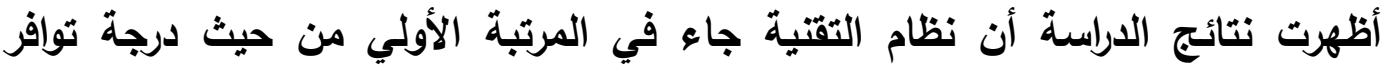

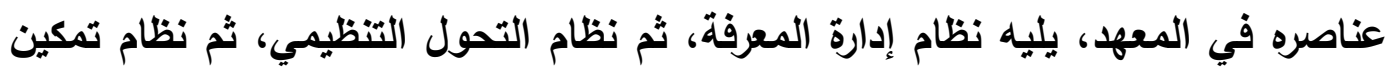

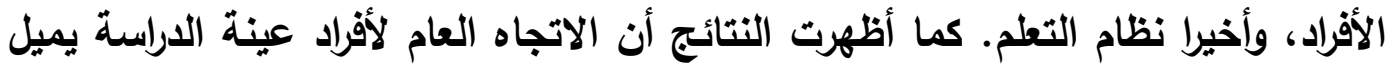

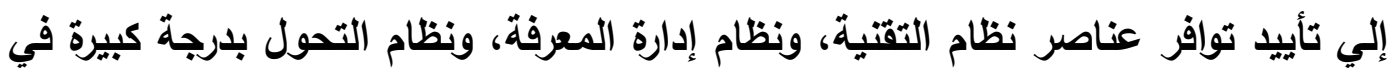

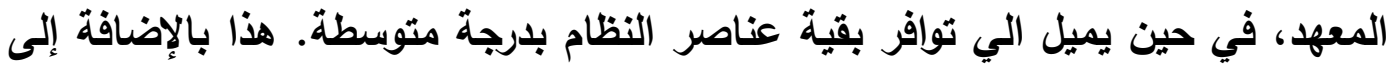

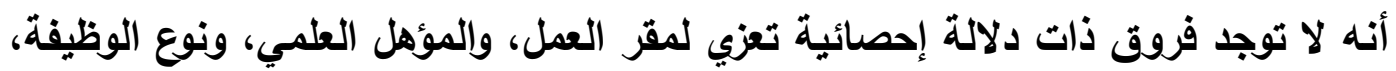
وسنوات الخبرة.

وأجرى بيرو(Berrio,2006) دراسة بهاف تقييم جامعة أوهايو كمنظمة متعلمة في الولايات المتحدة الأمريكية. واستخدمت الدراسة المنهج الوصفي مستعينة باستبانة 
نموذج ماركواردت (marquardt model,1996) التي شملت خمسة أبعاد للمنظمة المتعلمة وهي: التعلم، والفرد، والمنظمة، والتكنولوجيا، والمعرفة. والتي تم تطبيقها علي

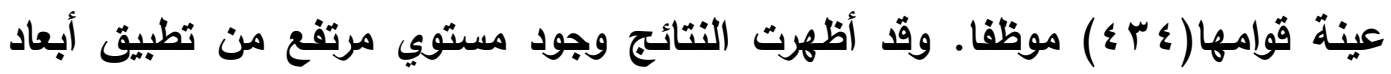

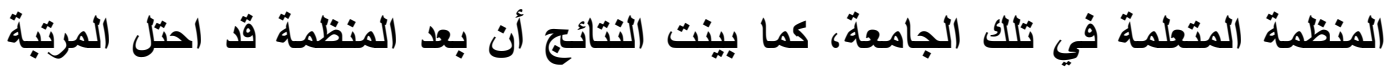
الأولي من بين أبعاد المنظمة المتعلمة، بينما احتل بعد التكنولوجيا المرتبة الاخيرة. واستهافت دراسة ويو(Wu 2006) الكثف عن درجة ممارسة الجامعات والكليات في تايوان لمجالات المنظمة المتطمة، وادارة الجودة الثاملة والعلاقة بينهما، ودور كل منهما في تطوير وتحسين الأداء. واستخذمت الدراسة المنهج الوصفي مستعينة

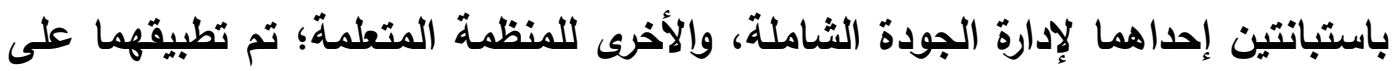

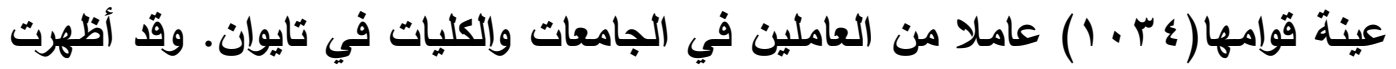

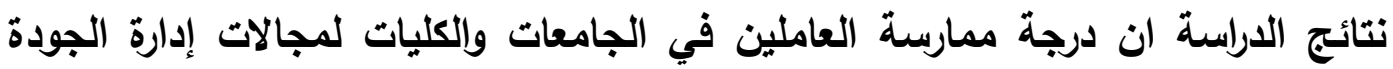

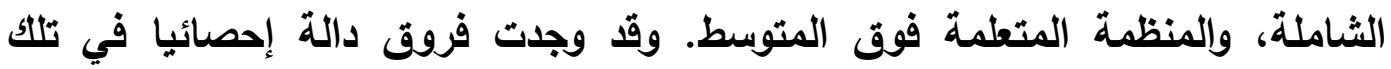

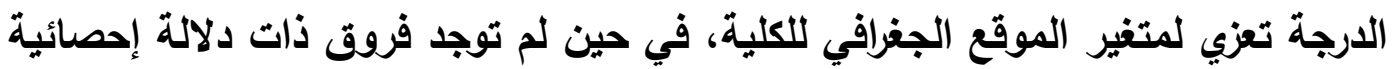
تعزي لمتغيرات النوع، والمؤهل، والدرجة العلمية.

وقد أجرت أماني أبو جزر(ه . . . دراسة هدفت إلى بناء مشروع مقترح لإدارة المعرفة في الجامعات الرسمية الأردنية بناء علي تعرف واقدع إدارة المعرفة فيها. واستخدمت الاراسة المنهج الوصفي مستعينة باستبانة تم تطبيقها علي عينة

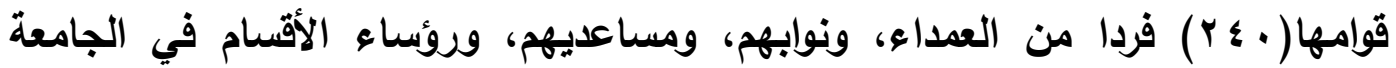
الأردنية، وجامعة اليرموك، وجامعة العلوم والتكنولوجيا، وجامعة البلقاء (المركز)، وجامعة وناء

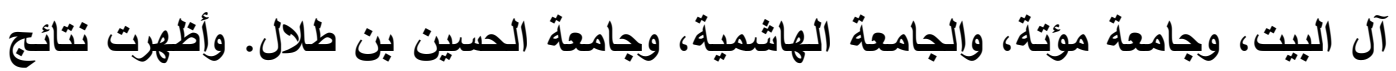
الدراسة واقع إدارة المعرفة في الجامعات الرسمية الأردنية، وعدم وجود فروق ذات دات دلالة

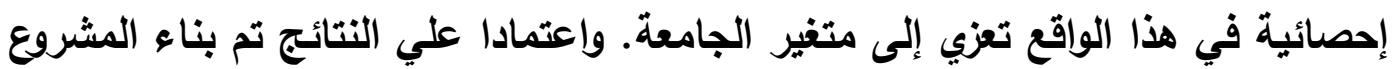
المقترح باعتماد المنهجية العلمية في صياغة أهداف المشروع، وتحديد محتواه، وتهيئة كل مستلزمات نجاحه من حيث المواصفات، والوقت، والميزانية، وإمكانية عمل المشروع

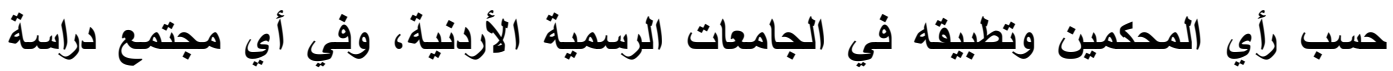
مشابه باعتبار إمكانية عمله.

وقد سعي آي هوا (Ai-huai,2005) في دراسته التي أجراها في جامعة خاصة بتايوان إلي الكشف عما إذا كان مفهوم المنظمة المتعلمة والمنتشر في الثقافة الغربية يمكن تطبيقه أكاديميا في تايوان. لذا حاولت هذه الدان الداسة اختبار درجة مقدرة جامعة 
أوشين الخاصة Ocean University علي التغيير في محتواها الفكري فيما يخص مجالين من مجالات المنظمة المتعلمة وهما: تعلم الفريق، وفريق العمل. ويالعودة إلى

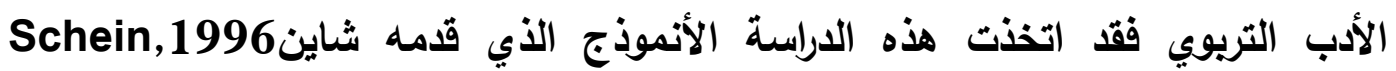

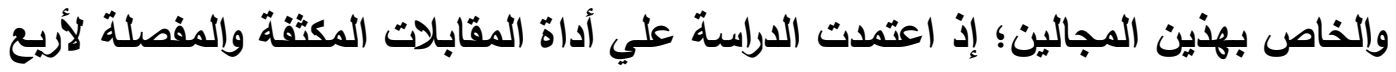
فرق في تلك الجامعة، من بينها فريق العمل في رئاسة الجامعة. ويتحليل البيانات التي

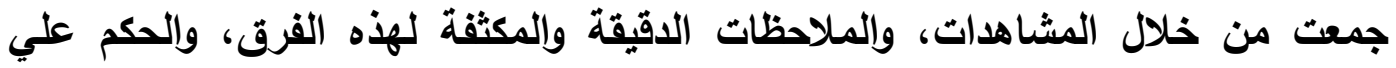

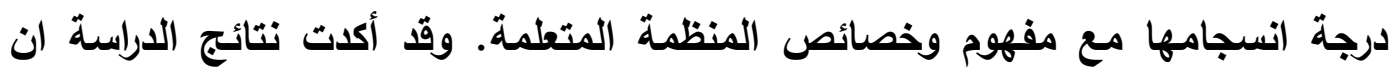
هناك علاقة ايجابية بين الثقافة والتعليم من جهة، والتغيير الذي أظهرته فرق العمل الأربعة من جهة أخري. ويبقي هناك بعض الفلق حول صعوية تغيير قناعات أعضاء هيئة التتريس في هذه الجامعة، فهم يمتلكون ثقافاتهم، ومعتقداتهم الراسخة، والهتماماتهم الثخصية، وجميعها أمور تعرقل عمليات التغيير والتحول الي منظمة متعلمة. أما دراسة برادفورد(Bradford,2004) فقد استهدفت معرفة درجة ممارسة أعضاء الهيئة التدريسية في كلية مجتمع ألينويس Illinois الأمريكية لمجالات الكلية المتعلمة. واستخدمت الدراسة المنهج الوصفي مستعينة باستبانة تم تطبيقها علي جميع

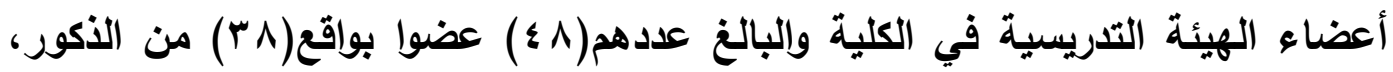

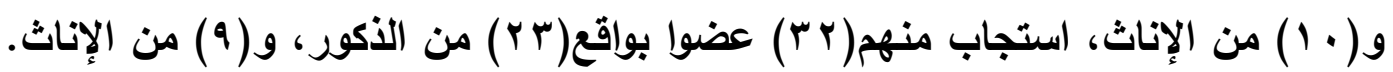

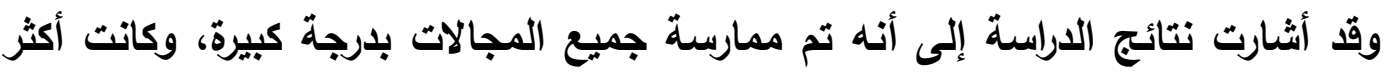

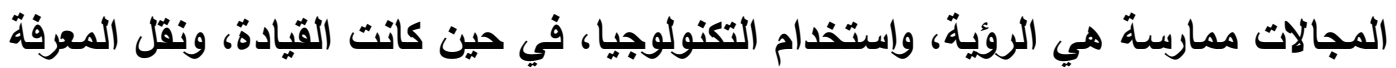
أقل المجالات استخدما. وكانت الفروق دالة إحصائيا حسب متغير المؤهل لصالح حملة الاكتوراه، وحسب متغير المركز الوظيفي لصالح عضو هيئة التدريس مقارنة بروئساء

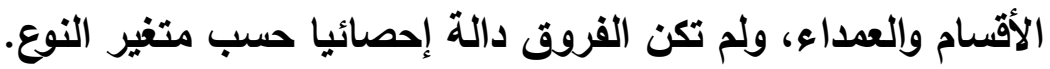
وفيما يخص الدراسة النوعية التي أجراها ريك(Recce,2004) في اثنتين من الجامعات الرسمية في غرب استراليا، وكانت إحداهما جامعة بحثية، والأخرى جامعة خاصة بالتدريس، فقد هدفت إلي معرفة المشكلات التي تعيق تحول الجامعات الاسترالية

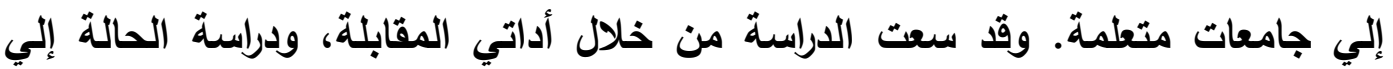

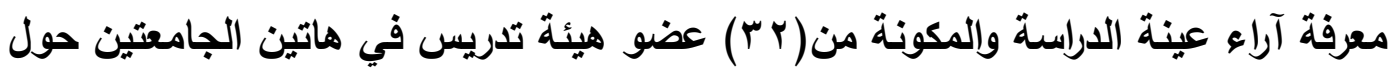

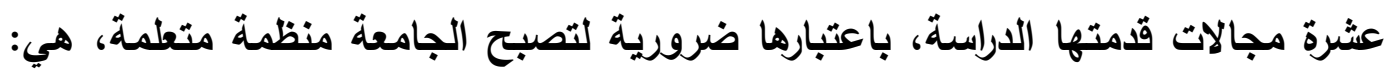

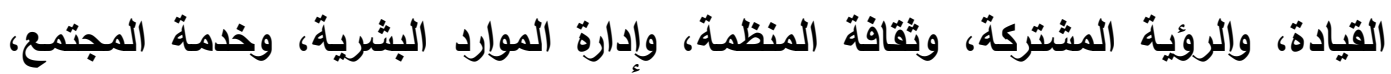
والتسهيلات والمرونة، والموارد، والابتكار، وتكنولوجيا المعلومات والاتصالات، وأخيرا 
الوصول إلي العالمية. وقد كثفت نتائج الدراسة أن جميع هذه المجالات مهمة لتصبح

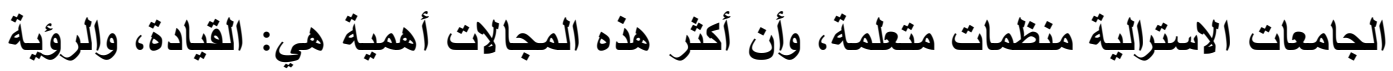

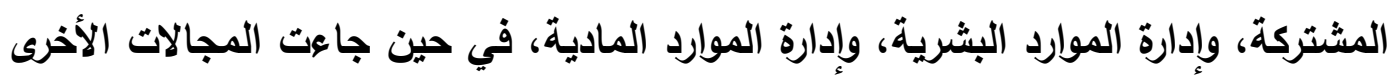

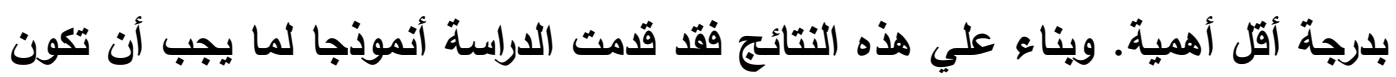
عليه الجامعات الاسترالية لتصبح جامعات متعلمة.

واستهدفت دراسة درادر(Drader,2004) الكثف عن التحديات التي تواجه جامعة مالاسبينا Malaspina University في إدارة التغيير المتزايد في مختلف دائف

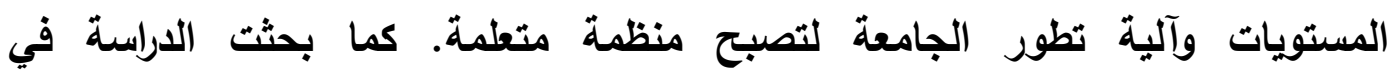
استراتيجيات إدارة التغيير التي يمكن تطبيقها في هذه الجامعة، باعتبار أن المنظمة الجئة

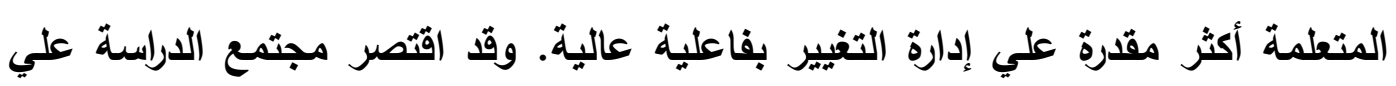

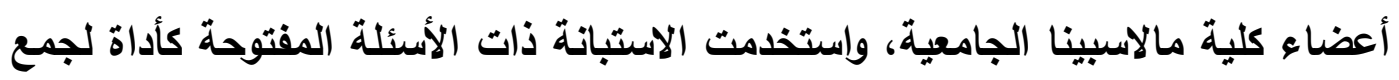

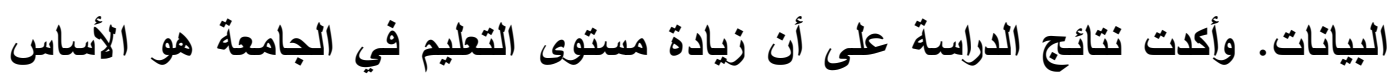

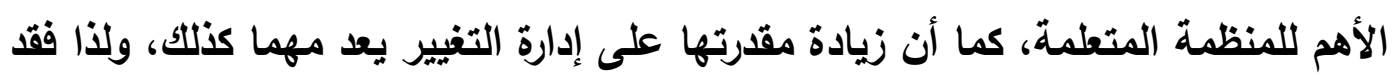
اقترحت الدراسة عددا من الاستراتيجيات التي يمكن تنفيذها في الجامعة لإدارة التغيير فيها

كمنظمة متعلمة.

وقد سعي لن (Lin,2004) من خلال دراسته التي أجراها في جامعة آيداهو Idaho University المستخدمة في المنظمات المتعلمة، وآليات تطبيقها في الجامعات، وعلاقتها بيرنامج تطوير مهني يتم تنفيذه في جامعة آيداهو . واستخدمت الاراسة المنهج الوصفي مستعينة

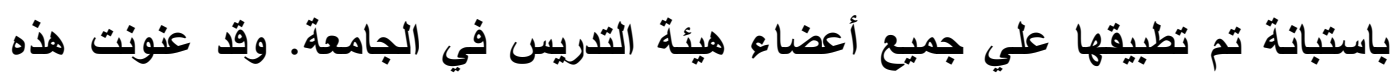

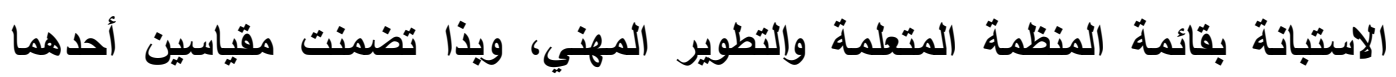

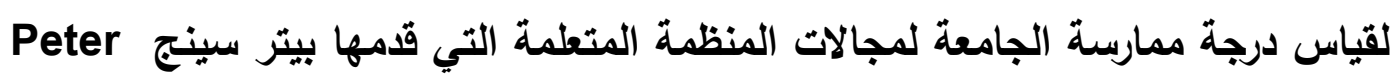
Senge، والآخر لقياس برنامج التطوير المهني ودرجة تحقق أهدافه. وقد أثنارت نتائج

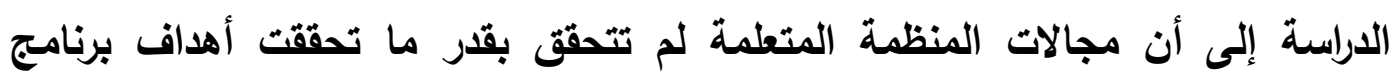
التطوير المهني في هذه الجامعة.

أما دراسة أبو تينة (Abu- Tineh,2003) فقد استهرفت اختبار العلاقة بين

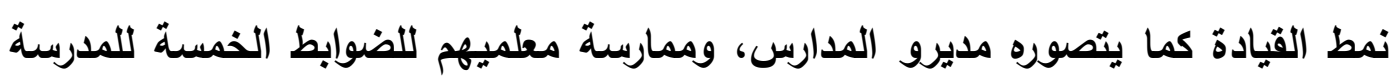
المتعلمة. واستخدمت الدراسة المنهج الوصفي مستعينة باستبانة تم تطبيقها علي عينة

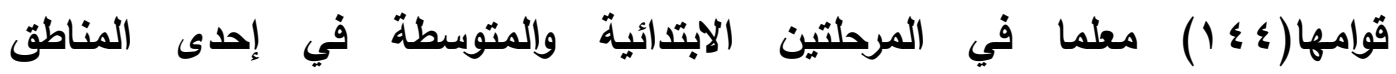




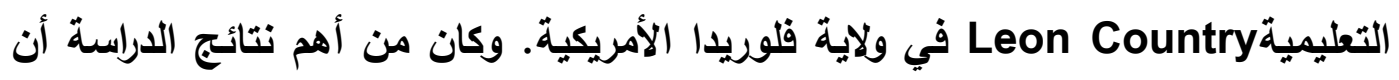

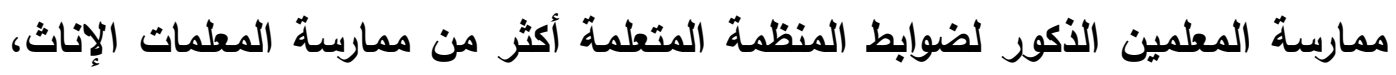
كما تقل ممارسة المعلمين لضوابط المنظمة المتعلمة بزيادة عدد سنوات الخدمة، هذا لفالئل

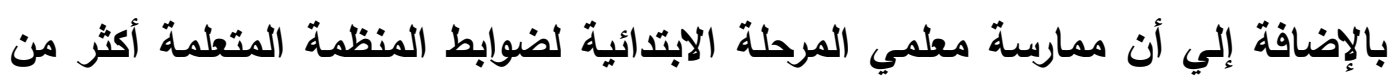
زملائهم معلمي المرحلة المتوسطة.

وحاولت دراسة ميوس(Muse,2000) الكثف عن درجة تفصيل أعضاء هيئة التتريس في جامعة أويرن الأمريكية لعدد من مجالات المنظمة المتعلمة، وما إذا كانت

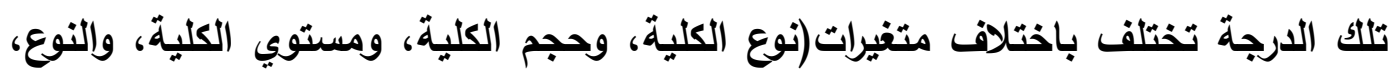
والرتبة الأكاديمية، والخبرة). واستخدمت الدراسة المنهج الوصفي مستعينة باستبانة تم

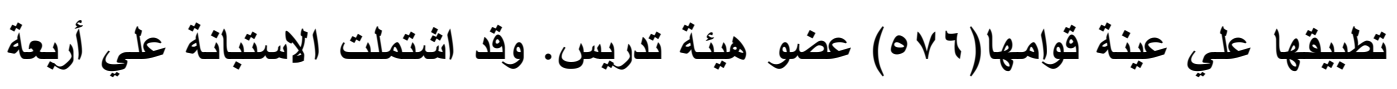

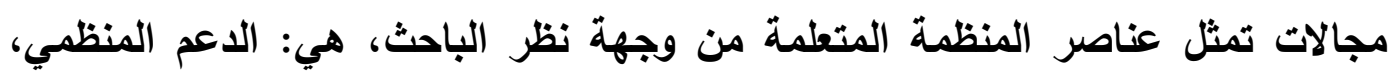

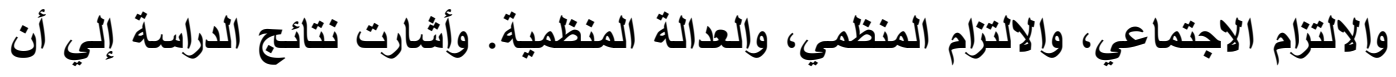

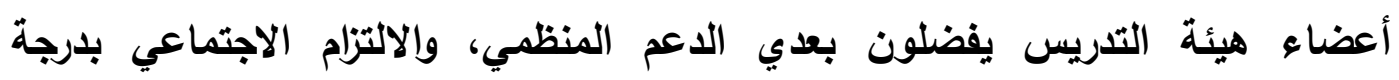

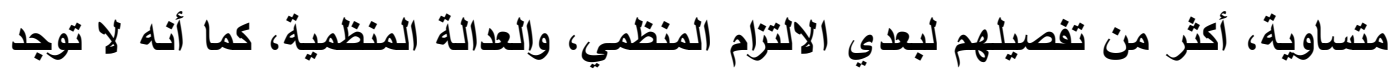

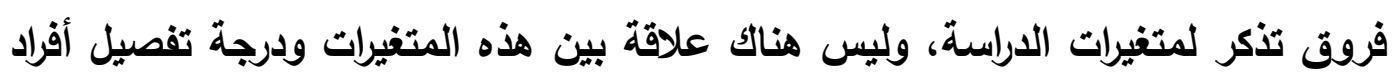
عينة الدراسة لأبعاد المنظمة المتعلمة الأربعة. التعليق علي الدراسات السابقة: من عرض الدراسات السابقة يمكن استخلاص ما يالي: 1 - الدراسات التي تناولت تحول الجامعات المصرية إلى منظمات متعلمة تتسم بالنقص الثديد.

ץ- إذا كانت الدراسات الخاصة بتحول الجامعات المصرية إلى منظمات متطمة تتسم

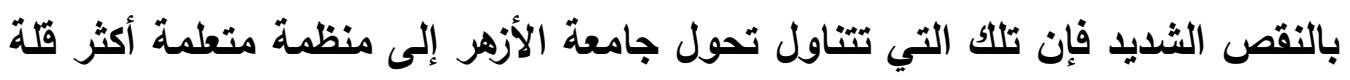

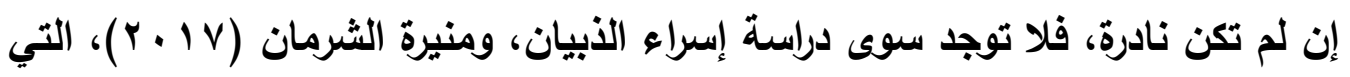

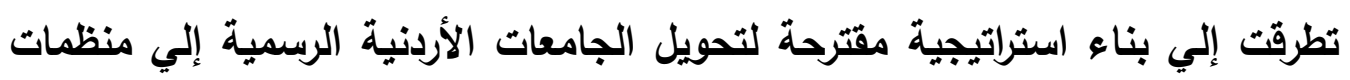

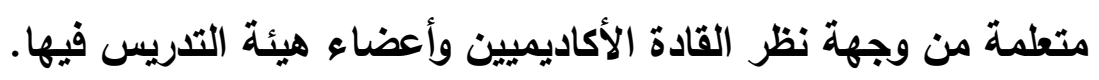
r- تمثلت الدراسات الأجنبية التي تناولت موضوع أبعاد منظمة التعلم في إحدى عثرة

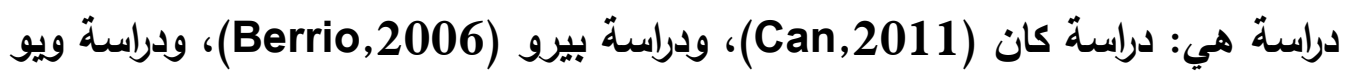

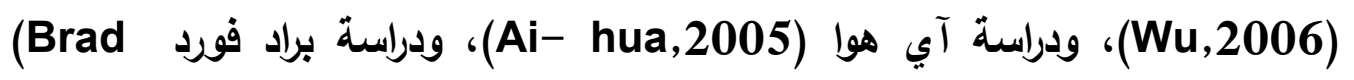




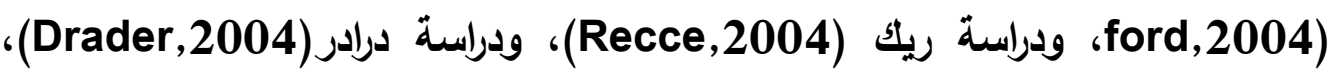

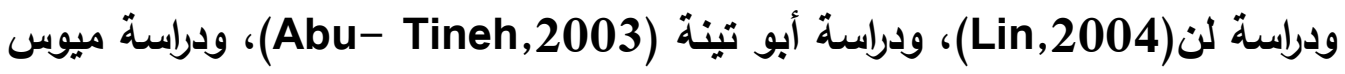
. (Muse, 2000)

ع- تمثلت الدراسات التي تم إجراءها في البيئة الأردنية في ست دراسات هي دراسة

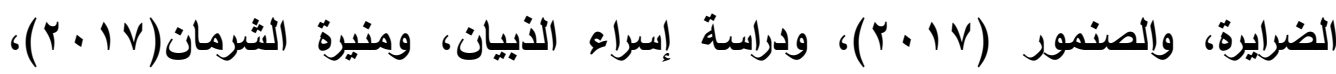

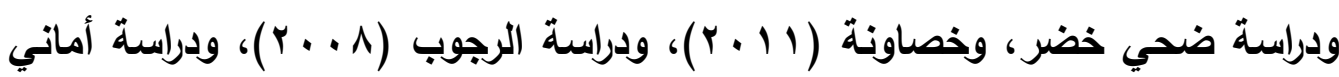

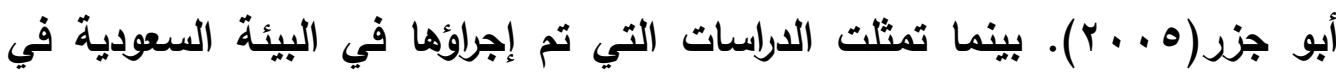

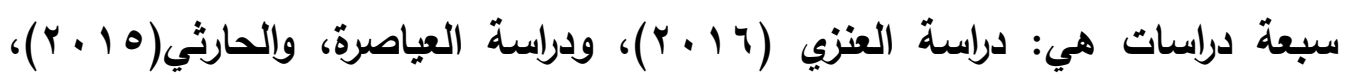

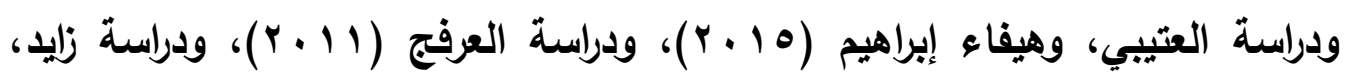

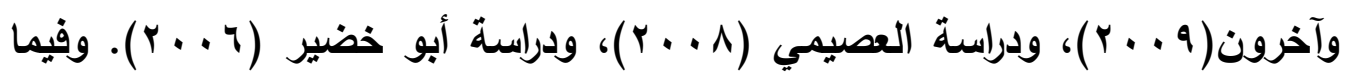

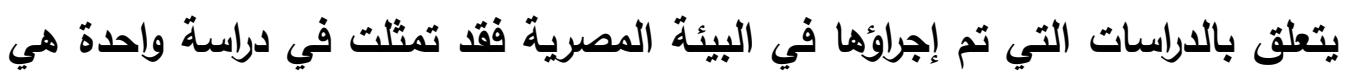

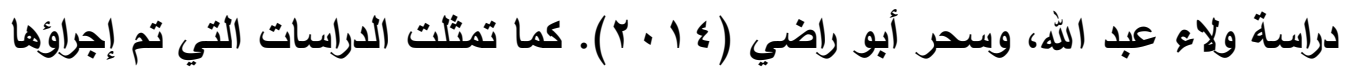

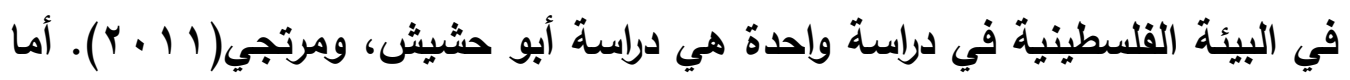

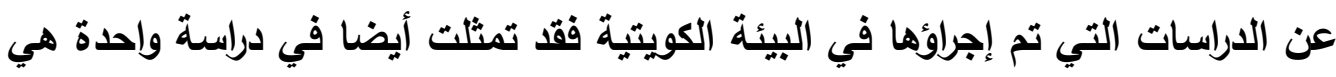

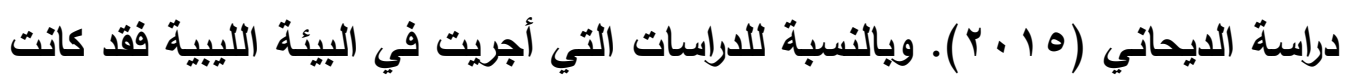

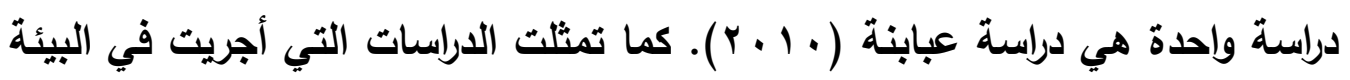

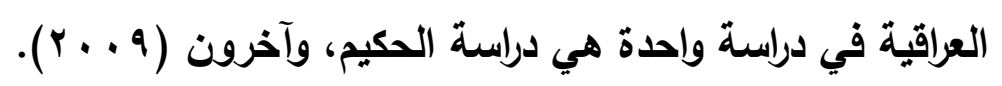

الإطار النظري للاراسة: - ماه

يتناول الإطار النظري للاراسة بعضا من الجوانب التي تتمثل في: مفهوم المنظمة

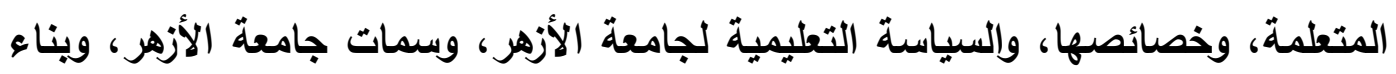

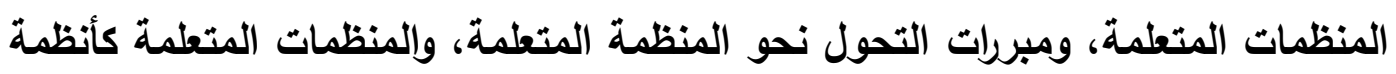

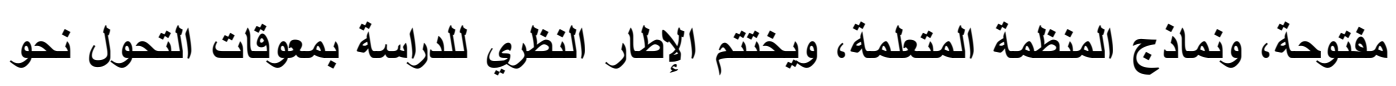
المنظمة المتعلمة.

مفهوم المنظمة المتعلمة:

يعد مفهوم المنظمة المتعلمة أحد المفاهيم المتنامية في العديد من المجالات التي

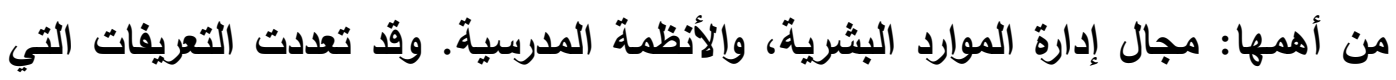

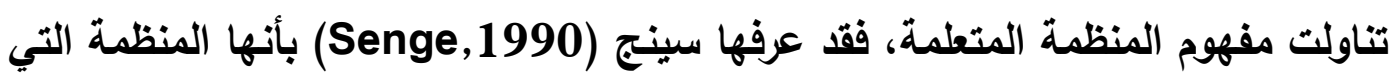
من خلالها يمكن للأفراد زيادة كفاءتهم الذاتية من اجل تحقيق نتائج أفضل، وتعزيز أنماط 
جديدة للتفكير ، وإطلاق العنان للطموح الجماعي، ومثابرة الأفراد من اجل التعلم مع بعضهم

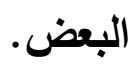

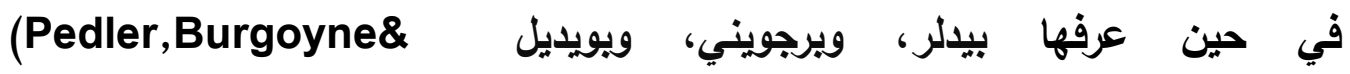
Boydell,1991,p.79) تقوم بتطوير نفسها طبقا للسياق. بينما عرفتها واتكنز، ومارسك (Watkins\& Marsick,1993) بأنها تلك المنظمة التي تتعلم بصورة مستمرة وتقوم بالتطوير في بنيتها من وقت لآخر . بينما عرفها جارفن (Garvin, 1993,p.82) بأنها تلك المنظمة الهادفة إلي بناء واكتساب ونقل المعرفة وتعديل سلوكيات الأفراد داخل المؤسسة من اجل تحقيق معارف ورؤى جديدة. كما عرفها شوجرمان (sugerman,1998,p.3) بأنها: المنظمة التي تحفز أفرادها على المشاركة فيها كمبدعين من خلال عمليات التعديل والتغيير لقواعد العمل، بالإضافة إلى أنها المنظمة التي تستفيد من الطاقات الناتجة عن عمليات التعلم الفردية والجماعية. بينما عرفها كل من ليثوود، ولويس(Leithwood\& Louis, 1998) بأنها: تلكك المنظمة التي تمتلك قائدا يدعم توجهات عمل الفريق، والتعلم المستمر، وممارسات العمل ولئل

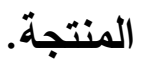

كما عرفها درافت (Draft,2000,p.40) بأنها المنظمة التي يحدد فيها كل واحد من العاملين المشكلات ويقوم بحلها بما يجعل المنظمة قادرة على أن تجرب وتغير بالهي وتحسن باستمرار من أجل زيادة قدرتها على النمو والتعلم وتحقيق أغراضها.

وتوصل ماركواردت (Marquardt,2002) إلي أن المنظمة المتعلمة هي المنظمة التي تتعلم بطريقة جماعية ويشكل فعال، وتعمل علي تحسين مقدرتها علي إدارة

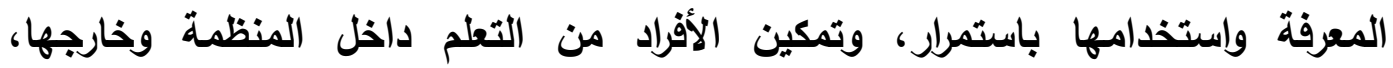
واستخدام التقتية لتنظيم التعلم والإنتاج.

في هين عرفها جريجو، وجيروى، وريت Griego, Geroy\& Wright,2000,p.9) الفعال المتحقق من خلال الوعي المتزايد. 
كما عرفها أولوك (Auluck,2002,p.112) بأنها: المنظمة القادرة علي خلق وتبادل ونقل المعرفة، وتعديل سلوك أفرادها بناء علي تلك المعرفة. بينما عرفها ( Dineen \& Noe,2003,p.5 ) بأنها المنظمة التي يواصل فيها الأفراد العاملون محاولة تعلم أشياء جديدة وتطبيق ما تعلموه في تحسين جودة المنتج أو

كما عرفها أرمسترنج، وفولي (Armstrong\& FoLey,2003,p.77) بأنها المنظمة التي تمتلك العديد من الرؤى، والقيم، والافتراضات، والسلوكيات والتي تدعم بيئة التعلم؛ والعمليات التي تعزز من تعلم الأفراد وتطورهم من خلال تصديد احتياجاتهم

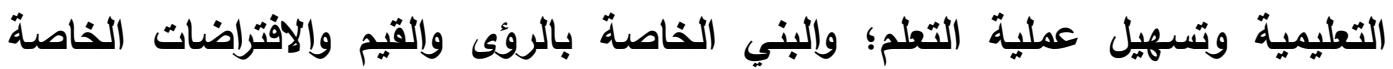
بالمؤسسة التي تدعم أنثطة التعلم ليتم تقويتها ودمجها داخل بنية التئه العمل.

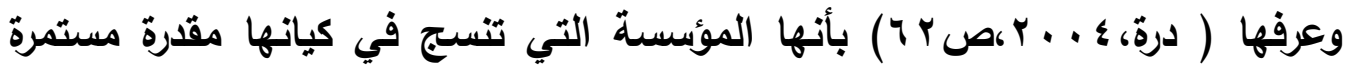

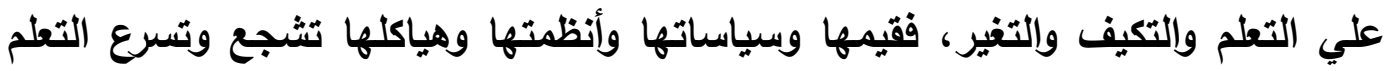
لجميع العاملين فيها.

وعرفها مايلونين (Moilanen,2005,p.73) بأنها: المنظمة التي يتم إدارتها بصورة واعية من خلال التعلم الذي يعد مكونا رئيسا في قيم المنظمة وروئيتها وأهدافها. في حين عرفها شونهراز (Chunharas,2006,p.4) بأنها المنظمة التي يتم تنظيم بيئتها بما ييسر عملية التعلم وتبادل المعارف بين أعضاء المنظمة أو العاملين فيها. كما عرفها كل من كاستانيدا، وروز(Castaneda\& Rios,2007,p.365) بأنها المنظمة التي تسعى إلي التعلم وتبني التعلم التنظيمي بهدف التطويل ورئ المستمر. وعرفها كل من برسنات، وسابارنس Bersenaite\& Saparnis,2007,p.24 ( بأنها منظمة تمتلك أهدافا تنظيمية محددة تتطلب مشاركة الموظفين في تبادل المعرفة

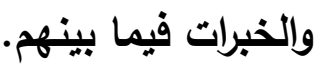

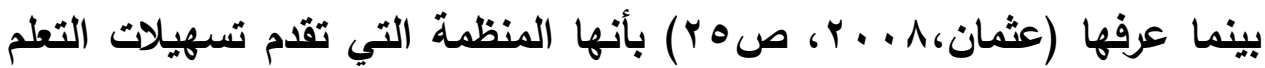
لجميع أعضائها لتكون قادرة علي تغيير وتحسين نفسها باستمرار، لتحقيق أها(فها وأهداف أعضائها وأهداف المجتمع الذي تعمل فيه.

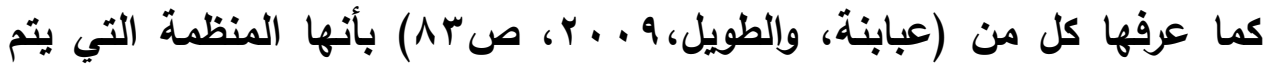
فيها ممارسة التعلم الفردي والمنظمي بثكل تلقائي مستمر لتحقيق التكيف مع المتغيرات 
الااخلية والخارجية، والاندماج مع البيئة، والانطلاق نحو التميز والإبداع، وتحقيق الأهداف بأقصى درجات الكفاءة وإلفعالية.

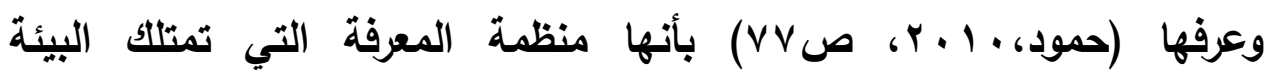
التكنولوجية القادرة علي تطبيق إدارة المعرفة في عملياتها الإدارية، وتمتلك الثقافة

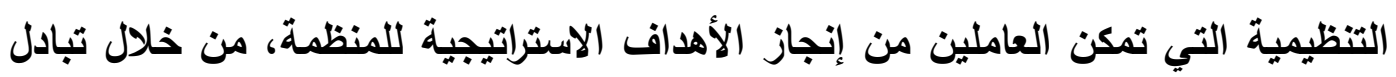
الأفكار والمعلومات المتاحة لايهم. وعرفها رويرت سون (Robertson,2015) بأنها المنظمة القائمة علي الإدارة

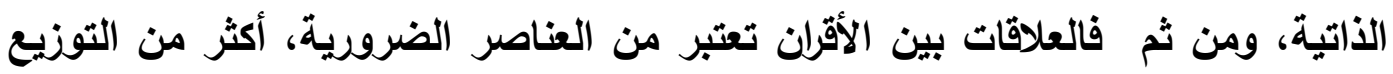

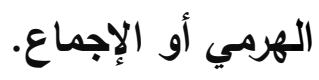

وفي ضوء ما سبق عرضه من تعريفات للمنظمة المتعلمة، يتبني الباحث تعريفا

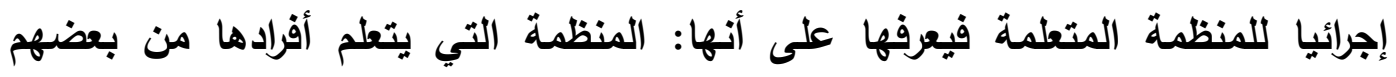

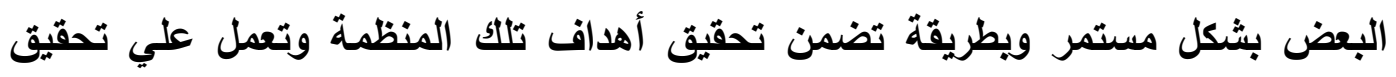
تميزها وتفردها عن غيرها من المنظمات التقليدية. الإطار الفكري والقلسفي لمفهوم المنظمة المتعلمة: يمكن إرجاع جذور المنظمة المتعلمة إلي عهد المدرسة العلمية التي ركز فيها

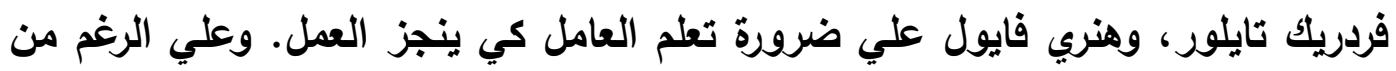

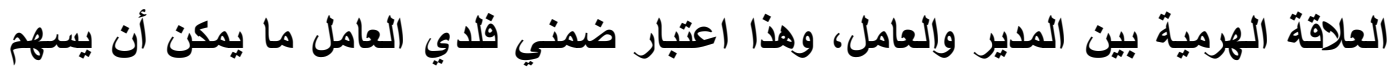
به في تظوير المنظمة. وتختلف فكرة منظمة التعلم عن مفهوم المصنع قديما، ومفاهيم

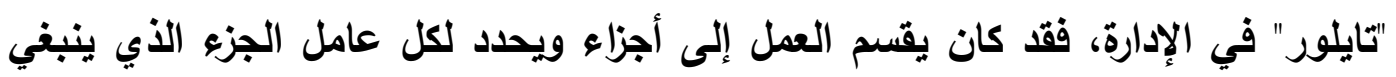

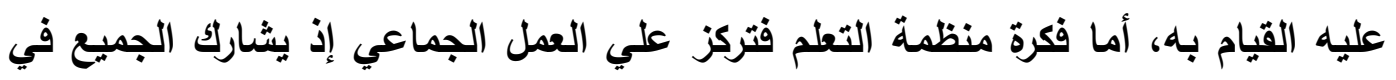

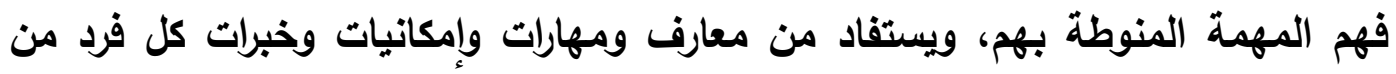

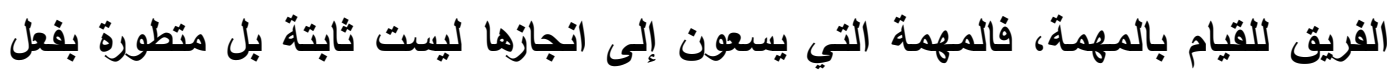

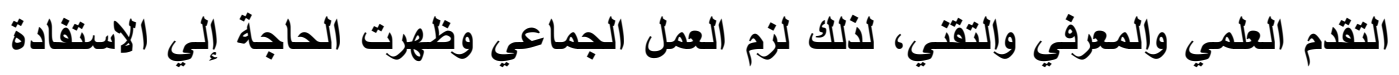

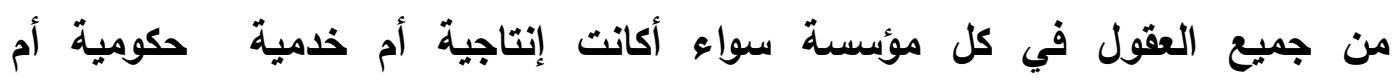

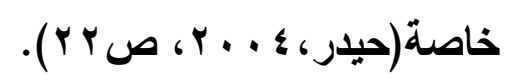

ولقد أفاض علماء النفس التريوي في وضع النظريات التي تفسر عملية التعلم

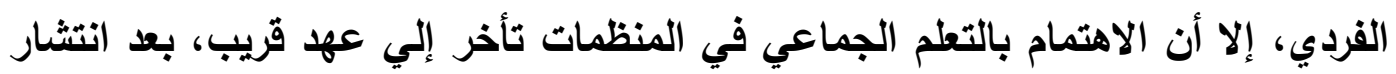

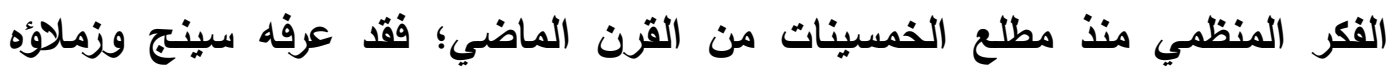


(Senge, et.al,2000) معارف يسهل الحصول عليها من قبل المنظمة ككل.

Organizational ومن أساسيات التعلم الجماعي مفهوما التعلم المنظمي (OL) Learning أن المفهوم الاول مقدمة الثاني، إلا أن كثيرا من الباحثين يعد المفهومين مختلفين، حيث الثئ

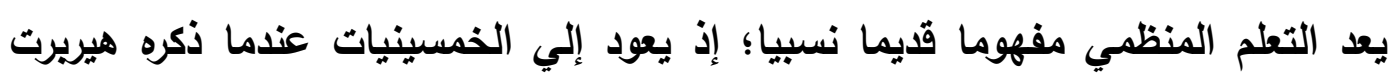

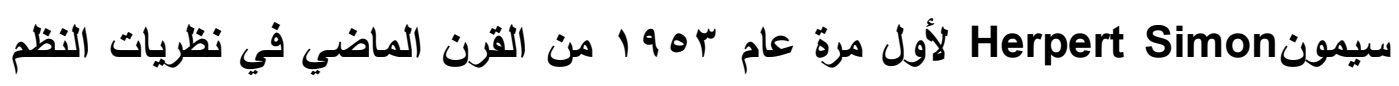

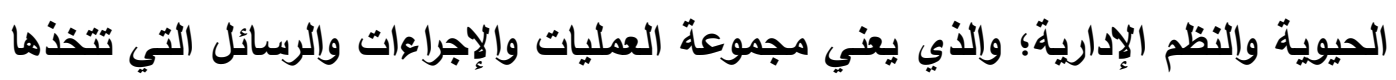

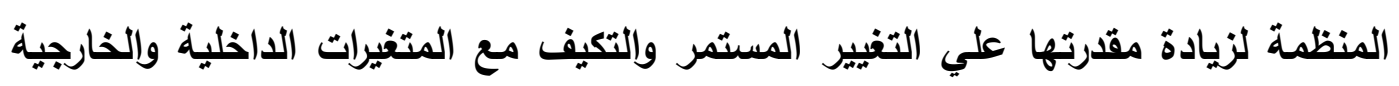

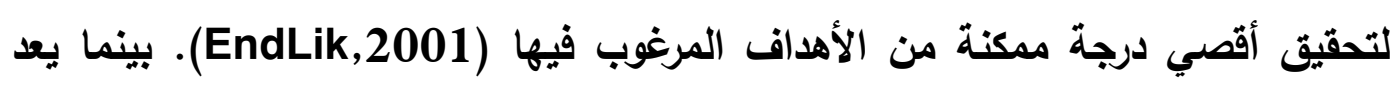

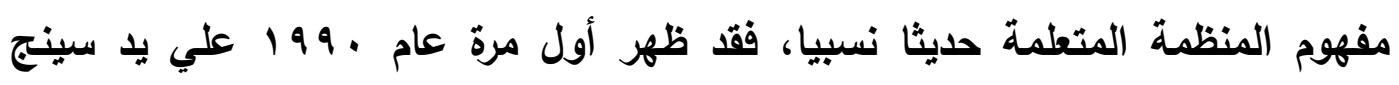
(Senge,1990) في كتابه الضابط الخامس: الفن والممارسة في المنظمة المتعلمة، المبا، حيث أطلق علي المنظمات التي تمارس التعلم المنظمي، ويصبح هذا التعلم سمة مهمة

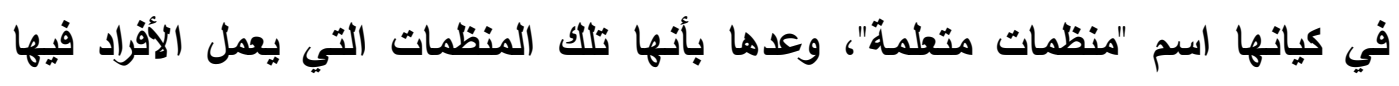
باستمرار علي زيادة مدركاتهم في تحقيق النتائج التي يرغبون فيها، باتخاذ أنماط من النيان

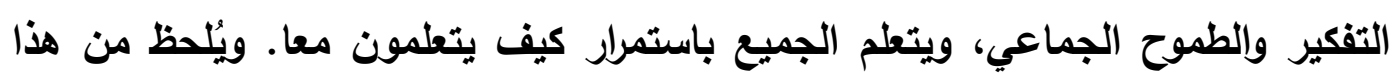

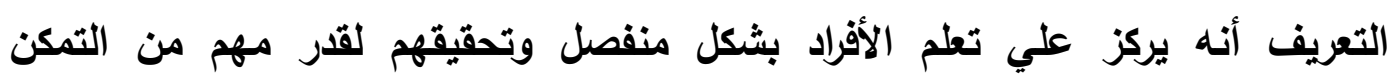

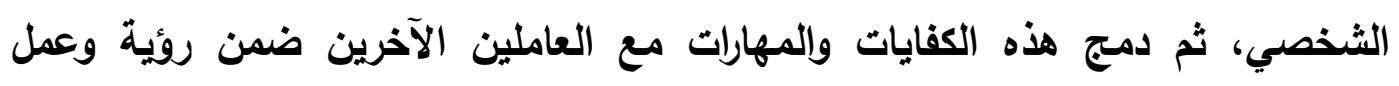
جماعي موحل ينتج عنه تحقيق التعلم المنظمي. لماه

Watkins\& وقت تم بلورة مصطلح المنظمة المتعلمة في أعمال

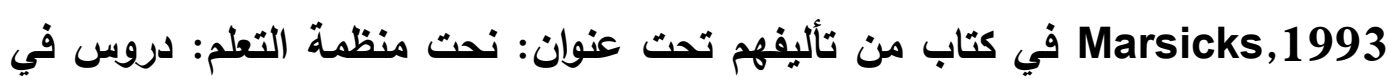
فن وعلم التغيير المنهجي. وفي هذا الكتاب، قاما بوصف التجارب الواعدة من اجل فئل بناء

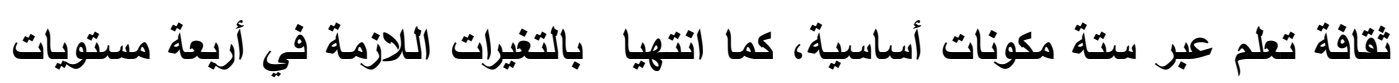

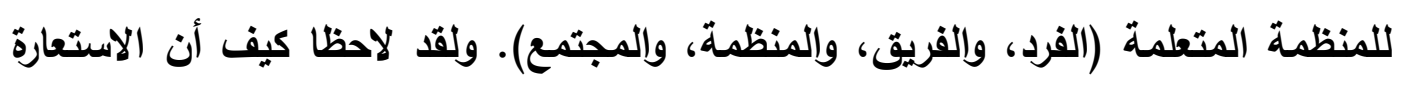

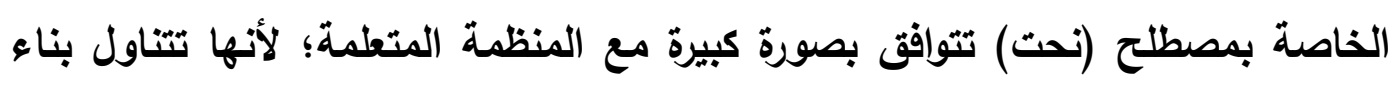

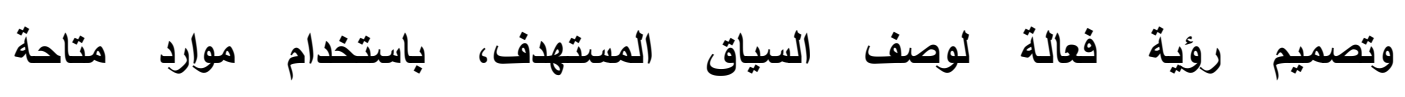

ومناسبة)(Watkins\& Marsick,1993,p.257).

ولقد أورد Watkins\& Marsicks,1993 أن الهلف الأساسي من كتابهما هو

مساعدة الفرد على أن يدرك أنه لا يوجد للآن تمثال منحوت واضح- المنظمة المتعلمة- 
ولإظهار أن بعض المنظمات قد بأت تغير نفسها لتصبح منظمات متعلمة. وإكتاب ليس كتاب استراتيجيات ولكنه عبارة عن تحليل للسمات، والخصائص، والجهود المبذولة

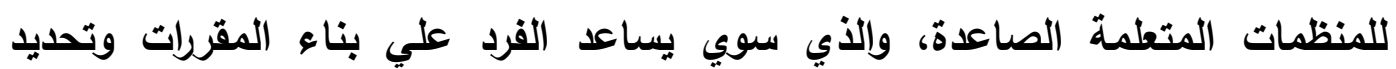

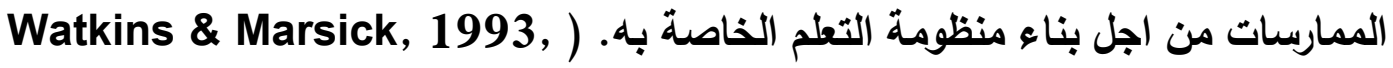

(P. 260

ولقد لاحظ Watkins\& Marsicks,1993 أنه للبدء في تصميم المنظمة المتعلمة، فيجب علي الفرد أن يبدأ أولا في الاراسة الدقيقة لطاقة المنظمة أو قدرتها على لهاء التعلم والتغيير في أريعة مستويات(Watkins\& Marsick,1993,p.262)، تتمثل في: التغير في سلوك الفرد ومعرفته ودوافعه وقرته على التطلم، والتغير في قدرة المجموعة علي التحديث والتطوير وتوليد المعرفة الجديدة، والتغير في طاقة المنظمة علي ولتهي التحديث

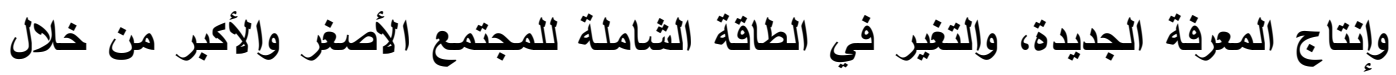
جودة حياة داخل سياق العمل والعديد من الأساليب الأخرى.

ولقد انتهي وإتكنز، ومارسك إلي تحديد سبعة سمات أساسية للمنظمة المتعلمة

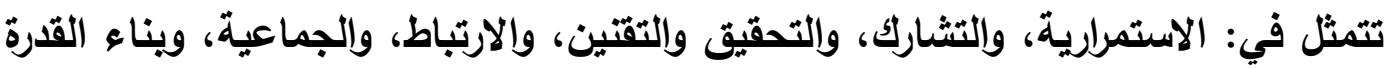
الاستيعابية. وهذه السمات من شأنها أن تضمن النمو الذاتي للمنظمة المتعلمة .(Watkins\& Marsick,1993,p.279)

كما أشار واتكنز، ومارسك (Watkins\& Marsicks,1996) إلى أن المنظمة المتعلمة ليست غاية وإنما هي وسيلة أو رحلة؛ فهي تتضمن العديد من المبادئ الأساسية والتي من الممكن استخذامها من اجل تصميم بنية مرنة للاحتياجات الخاصة بالفرد.

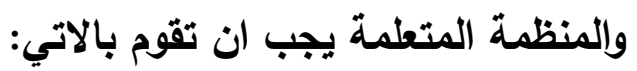
- - أن يتم تضمينها في البنية التحتية، وليس في قسم التدريب، باعتبارها أحد السبل السائدة من اجل بناء، وتحقيق، ونشر المعرفة. - بناء عادة تعلم لاى الأفراد في ثقافة المنظمة، ومن ثم تسيطر روح البحث والاستقصاء، والمبادرة، والتفكير التجريبي. - مراجعة رأس المال المعرفي في المنظمة بصوره منتظمة، ودراسة مستويات النمو من أجل إزالة عوائق التعلم (Wtkins\& Masicks,1996,pp.282-283). ولقد اكتملت النظرية تقريبا في عام9 99 19، حيث تثارك Watkins\& Marsick في كتاب آخر أسمياه؛ تسهيل المنظمة المتعلمة: جعل التعلم بنية عظيمة. ولقّد تناول 
الكتاب النموذج النهائي للمنظمة المتعمة، وقدم الأسس السبعة لهذه المنظمة تقديم الاستراتيجية القيادية للإدارة. ورغب المؤلفان في جعل تعريف المنظمة المتعلمة أكثر الكراب

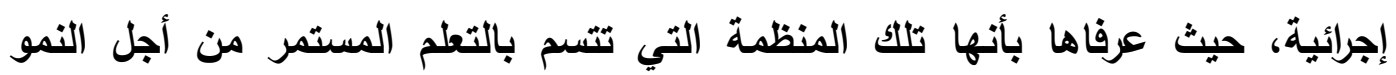
المستمر، كما تتسم بالقدرة علي تطوير وتغيير نفسها (Marsick\& Watinks,1999). ولقد ركز الكتاب سابق الاشارة إليه على الاستراتيجيات اللازمة لبناء المنظمة

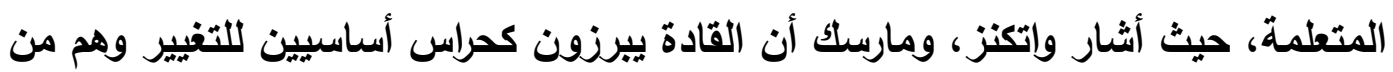
يجب عليهم تغيير أنفهه من اجل تحقيق نمذجة عملية التعلم، كما ذكرا أن الخطوة

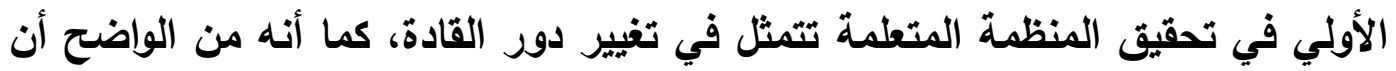

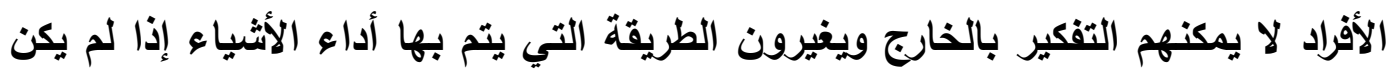

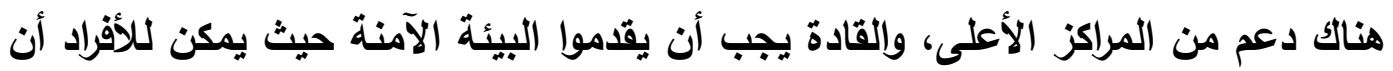

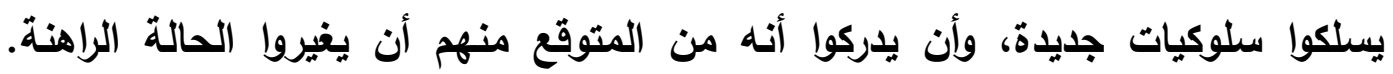

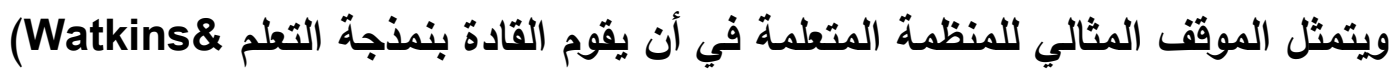

Marsicks,1999,p.159)

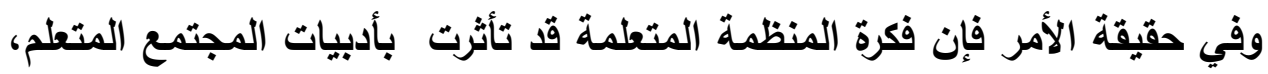

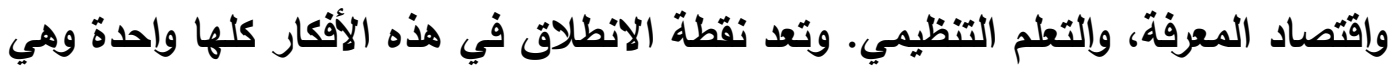
أن هناك تغيرا مستمرا يستلزم تعلما مستمرا. ويما أن العصر الحديث يتسم بسمة والطمة واحدة؛

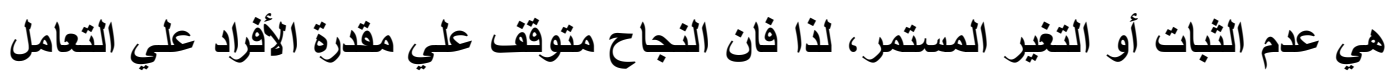

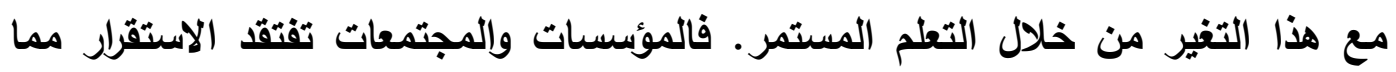

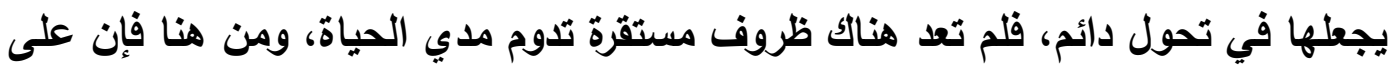

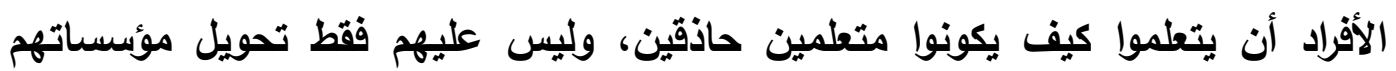

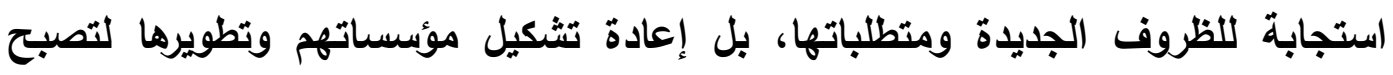
أنظمة متعلمة أي قادرة علي إحداث التحولات (Adrianna,2005,p,11).

خصائص المنظمة المتعلمة:

swieringa\& wierdsma, 1992, ) أثنار العديد من الباحثين

tosey, Visser\& Saunders, 2012, pp. 290-291) المنظمات المتعلمة تتسم بالعديد من الخصائص، لعل من أهمها ما يلي: - عدم وجود نماذج للقيادة، حيث لا يوجد قادة أو منسقون، فالجميع ببساطة أفراد داخل المنظمة. 
- تبعاً للثقة في الأفراد داخل المنظمة فلا حاجة لتوقيعات الحضور أو الانصراف. - الأفراد يعملون فيما يرغبون ومع الأفراد الذين يرغبون في العمل معهم. - الأفراد يمكنهم تجريب العناصر الجديدة بسهولة، حيث إنهم لا يخافون من ارتكاب الأخطاء.

- الثفافية هي إحىى السمات الضرورية في هذه المنظمة، فجميع المطلومات متاحة للجميع.

- الأفراد يصنفون من خلال الأدوار وليس من خلال الوظائف أو المسميات الوظيفية، وهذا من شأنه تحقيق المرونة.

- فرق العمل والعمل في مجموعات أحد أهم السمات الضرورية، وفي الحقيقة تميل هذه المنظمات نحو التركيز على أداء الفريق.

- أي فرد داخل المنظمة من المكن أن يتخذ العديد من القرارات بثأن أي قضية من القضايا، ولكن من الضروري أن يطلب النصيحة من الخبراء وإلمتخصصين. - توافر برامج للتدوير من أجل تقديم أفراد جدد داخل المنظمة. - تعد الصراعات من الأمور الطبيعية في هذه المنظمة، ولذا فـائما ما يتم الاعتماد على دلى إجراءات لإنهاء تلك الصراعات متعددة الخطوات. - بيئة المنظمة المتعلمة تساعد على التأمل والتفكر والجلوس بهاوء. - تدعم هذه المنظمة بصورة كبيرة البعد عن الرسمية من خلال التأكيا على أهمية

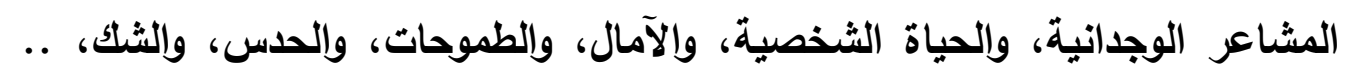

- - التكيف مع بيئة التعلم بصورة مستمرة.

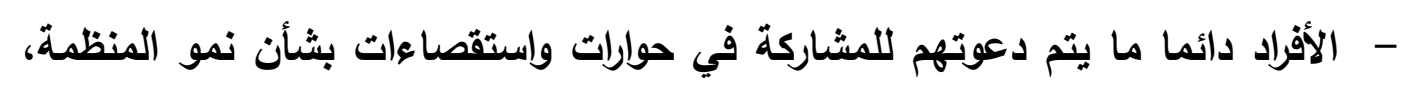
وأغراضها، وقيمها والافتراضات النظرية الخاصة بها، والتي ترتبط بصورة كبيرة بالتعلم ثلاثي الحلقة.

swieringa \& wierdsma, 1992; ) ويتحقق التعلم ثلاثي الحلقة جندما تكون المبادئ الأساسية للمنظمة محل tosey, 2012,et.al, p.300 ) جل ونقاش، بما يضمن تطوير مبادئ جديدة، يمكن من خلالها أن تنتقل المنظمة إلي الئل 
مرحلة لاحقة. وهذا المستوى من التعليم يعتبر من الأمثلة الرائدة والذي يتفوق على نظام

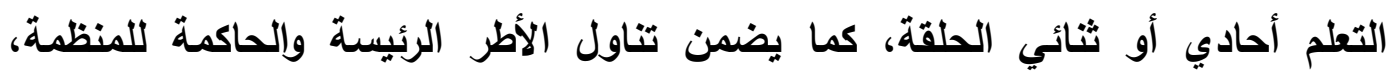

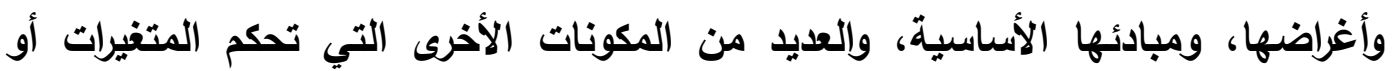

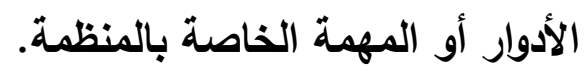

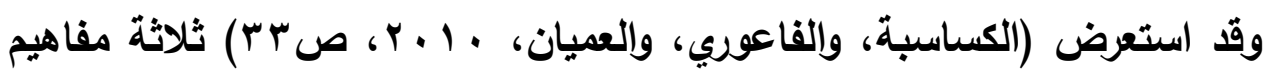
للمنظمة المتعلمة تعبر عن قوة التعلم في تحويل الروئة إلى واقع؛ الأول منها أن هذه وانه

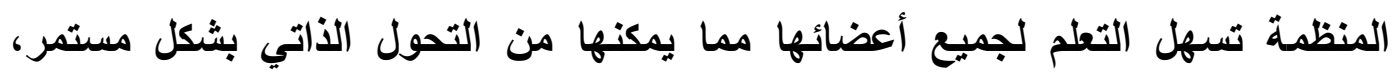

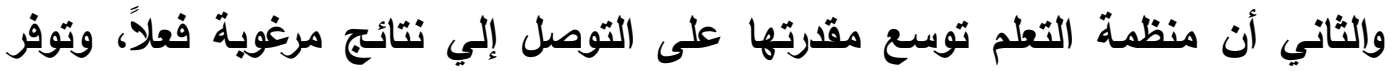
المجال للطموح الجماعي وتمكن العاملين من تعلم كيف يتعلمون من بعضهم البعض،

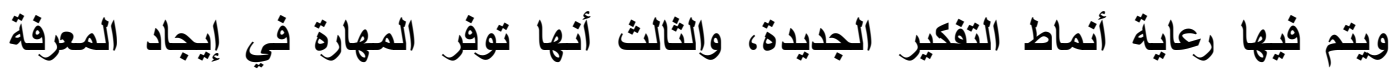
واكتسابها ونقلها، وتعمل على تعديل سلوكها بما ينعكس على إيجاد معارف جديدة.

skuncikiene, ) كما ذكر سكيونسايكين، بالفوكيوت، بالكيوناز Balvociute\& Balciunas, 2009, p. 60) المتعلمة منها: إتاحة الفرصة للجميع للتعلم بالتعاون والعمل المشترك في مناخ تنظيمي قابل للتطور باستمرار، والفاعلية والتفاوض في التعامل بين الأقسام في المنظمة الواحدة، وتصميم الوظائف والأدوار في الهيكل التظظيمي بأساليب تمكن المنظمة من التطور في

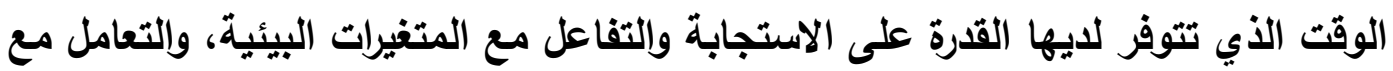
العاملين في الوظائف ذات الاتصال المباشر مع الجمهور عل أساس أنها أدوات للرصد التهابه البيئي قادرة على تنمية الوعي والتفاعل الايجابي إلى أقصى حد، وتنمية التباين الإيجابي بين الأفراد، فالاختلاف بين الأفراد لا يتم تثجيعه فقط، وإنما ينظر إليه كحالة صحية الئه

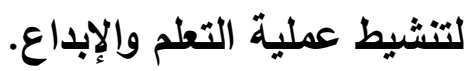

كما تتبنى المنظمة المتعلمة قيما وثقافة مختلفة يمكن إجمالها في: الكل أهم من الجزء والحدود بين الأجزاء قليلة ليسمح ذلك بحرية تدفق المعلومات والأفكار من خلال

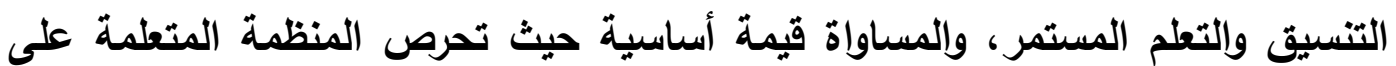
العدالة والمساواة كعنصر جوهري في ثقافتها وهو ما يؤكد على تعامل الجميع بعناية

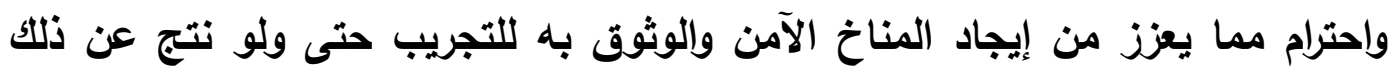

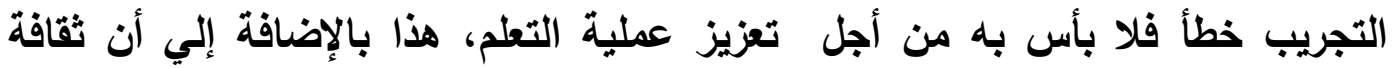

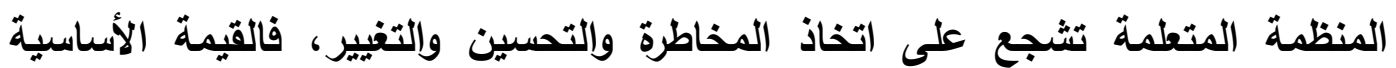


للمنظمة المتعلمة تكمن في فتح الأبواب للإبداع والتحسين والمكافأة عليهما حتى لريما

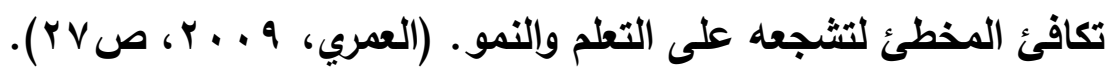

بينما أضاف باركيوس (Barcus, 2007, p.3, p.4) خصائص أخرى

تميز المنظمة المتعلمة وهي كالتالي:

- القيادة التعليمية؛ حيث تضطلع القيادة في منظمات التعلم بأدوار جديدة غير الأدوار التقليدية.

- المشاركة الفعالة؛ حيث يشترك الجميع في وضع الاستراتيجيات وتنفيذها بحيث لا تكون حكراً على فئة دون غيرها.

- التمكين؛ ويعني ترك حرية التصرف للعاملين من خلال الممارسة والتدريب وإعطائهر الصلاحيات وتوفير المعلومات لهم ومنحهم الثقة بالنفس.

- فرق العمل؛ وتتكون هذه الفرق من موظفين ذوي مهارات مختلفة، ولأعضاء الفريق الصلاحية في التغيير واتخاذ القزارات.

- حرية المطلومات؛ حيث يجب أن تكون المنظمات ذات شفافية في الأداء وأن توفير إمكانية الحصول على المعلومات يكون لكل أعضائها.

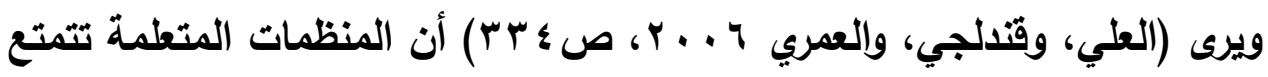
بمجموعة من الخصائص لعل من أهمها: شعور العاملين فيها بأنهم يقدمون عملا مهما

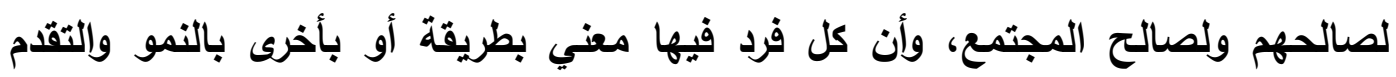

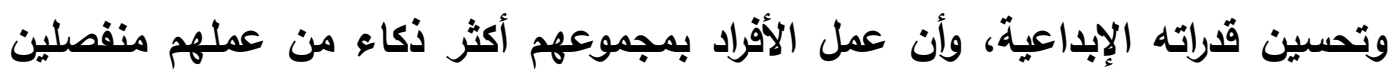
(التركيز على فرق العمل)، وتصبح المنظمة معتمدة على قاعدة معرفية من خلال تخزينها للمعارف وخاصة الضمنية منها، وأن الروئة المشتركة تستمد من المستويات الإدارية جميعها، ويكون العاملين مدعوين للتعلم عن ماذا يجري في جميع المستويات الإدارية

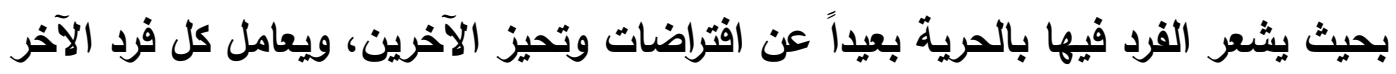

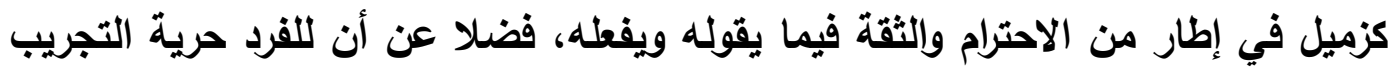

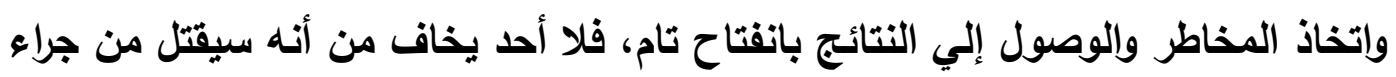
خطأ يرتكبه.

وقد أثشار أجاجلو (Agaaglu, 2006, p.23) إلى أن منظمات التعلم تتميز بالآتي: 
- لها القرة على إيجاد حلول بليلة لأزمات التمويل وكيفية حصولها على الموارد اللازمة لتشغيلها في ضوء الخبرات وإلتجارب. - تساعد على خلق ثقافة تنظيمية موحدة. - تيسر عملية انتقال المعلومات وإداراتها حتى يمكن الاستفادة منها بطريقة مثلى. - تدعم عملية التنمية المهنية المستمرة والذاتية للأفراد العاملين بالمنظمة على اختلاف مستوياتهم التعليمية والوظيفية. - - تحقق رسالة المؤسسة وأهدافها. - تلبي توقعات المسئولين عن المنظمة والعاملين فيها، والمتعاملين معها والمستفيدين منها. - إدارة التغيرات المؤثرة في المؤسسة والتعامل معها بكفاءة وفاعلية سواء كانت هذه

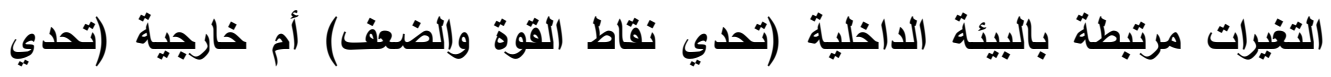
الفرص والتهديدات).

- وكافية ويدائل متعددة.

- تساعد على الاستغلال الأمثل للإمكانات المتاحة، وإتاحة خيارات واسعة أمام

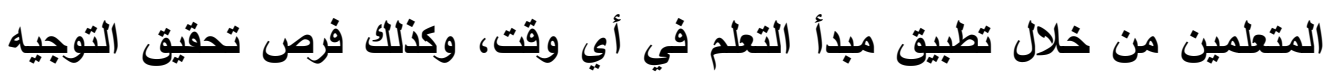
الذاتي للمتعلم وطرق التقويم الذاتي. - - تكثيف الميزات التنافسية للمنظمة (التركيز على أفضل ما يمكن أن تفعله). - - القدرة على تسويق مخرجاتها إلي سوق العمل في ظل ظروف السوق المتغيرة. - تتضمن فكرا مستقلا، وإعطاء الأفراد الأمل في تحسين الوضع القائم. - تنطابق مع الجزء الأساسي لإنسانيتنا وهو الحاجة للتعلم ولتحسين بيئتا وأن نكون فاعلين. - تتضمن فوائد مالية متأصلة عن طريق تحويل مكان العمل إلي مكان عمل يعمل بثكل جيا ويقر موظفيه بنفس الشكل.

وقث وصف اليكسيو (Alexiou, 2005, p.22) المنظمة المتعلمة بأنها تلك المنظمة التي تتجاوز الأهداف المتعلقة بتعظيم الريحية قصيرة الأجل، وتُشعر العاملين 
بأنهز يقدمون عملاً لصالحهم وصالح المجتمع، وكل فرد فيها معني بالنمو والتقدم

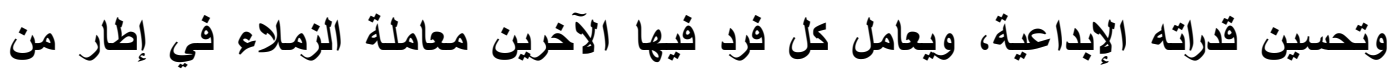
الاحترام والثقة، فضلا عن التركيز على العمل الفريقي.

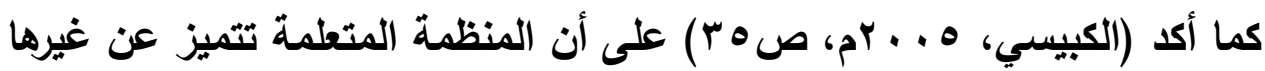

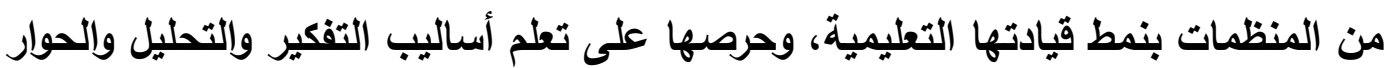

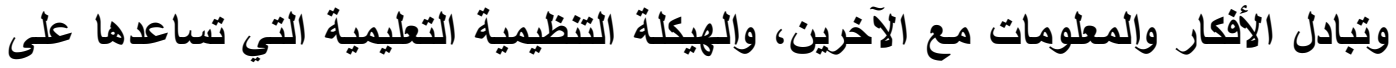

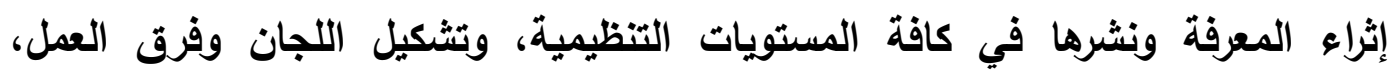

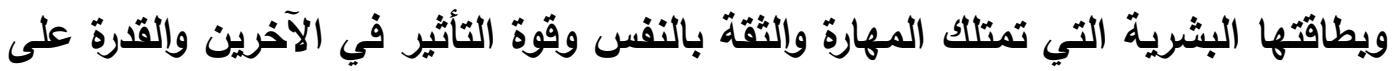
التصرف والتحرك بفاعلية.

ولعل أبرز ما يميز المنظمة المتعلمة، التوافق الحقيقي بين الصفات الثخصية

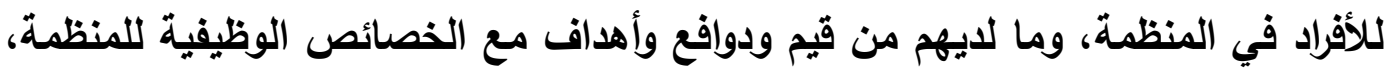

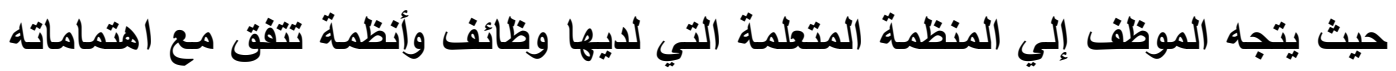
وقيمة ودوافعه، كما أن المنظمة المتعلمة تجذب إليها كل من يتفق معها في بيئتها المتعلمة. (Simonaitien Leonavien\& Zvirdauskas, 2004).

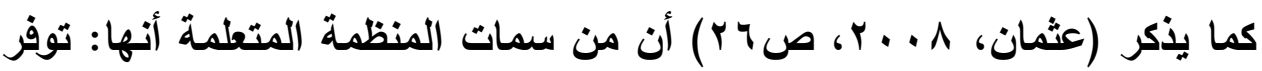

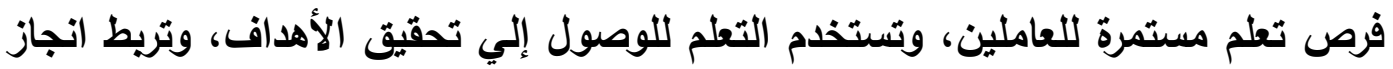

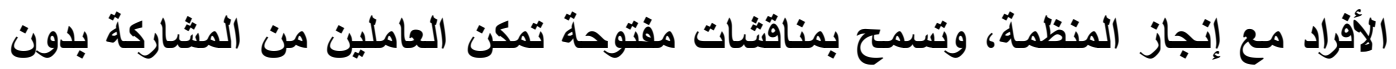
مجازفة أو خوف، وتتفاعل وتتكيف بشكل مستمر مع بيئتها الخارجية، وترفع من القيمة التهاز الاقتصادية للمعرفة، وتبين كيفية تطبيق تلك المعرفة وقياس نموها في المنظمة. بينما يرى ماركواردت (Marquardt, 2002) أن المنظمة المتعلمة تتميز بأنها: تثجع العاملين على المشاركة في اتخاذ القرارات، وتستخدم التفكير النظمي في

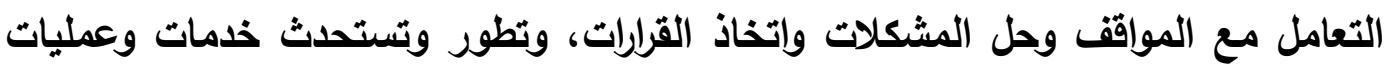

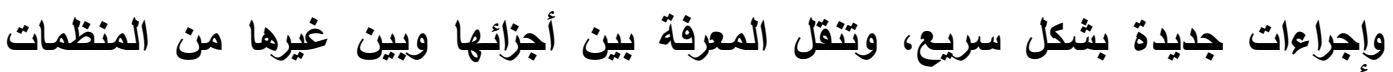

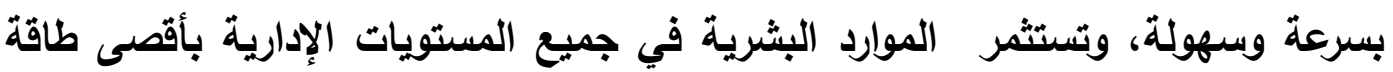
ممكنة، وتستثير عمليات التحسين، وتستقطب أفضل الطاقات البثرية المؤهلة.

ويتضح مما سبق أن المنظمات المتعلمة تعد نمطا جديدا من المنظمات يمكن موجبه للعاملين والإداريين أن يقودوا أنفسهم، ويقودوا من هم أعلى منهم في المستوى

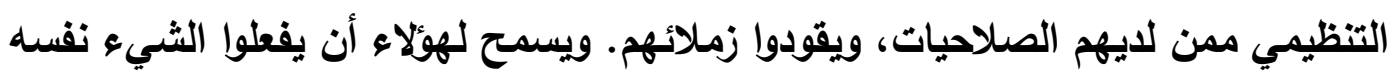


بحرية، فالكل يتعلم من تجاريه، وتجارب الآخرين، فلا يتكرر الخطأ ويعزز النجاح تمهيدا

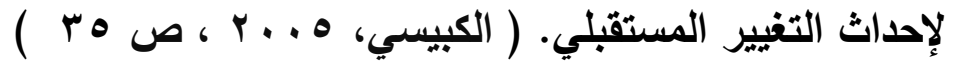

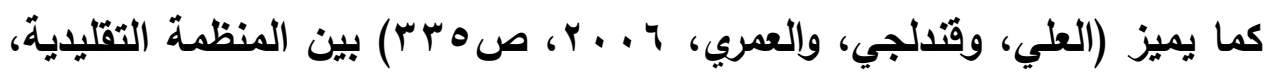
وإلمنظمة المتعلمة، وذلك من خلال الثكل التالي:

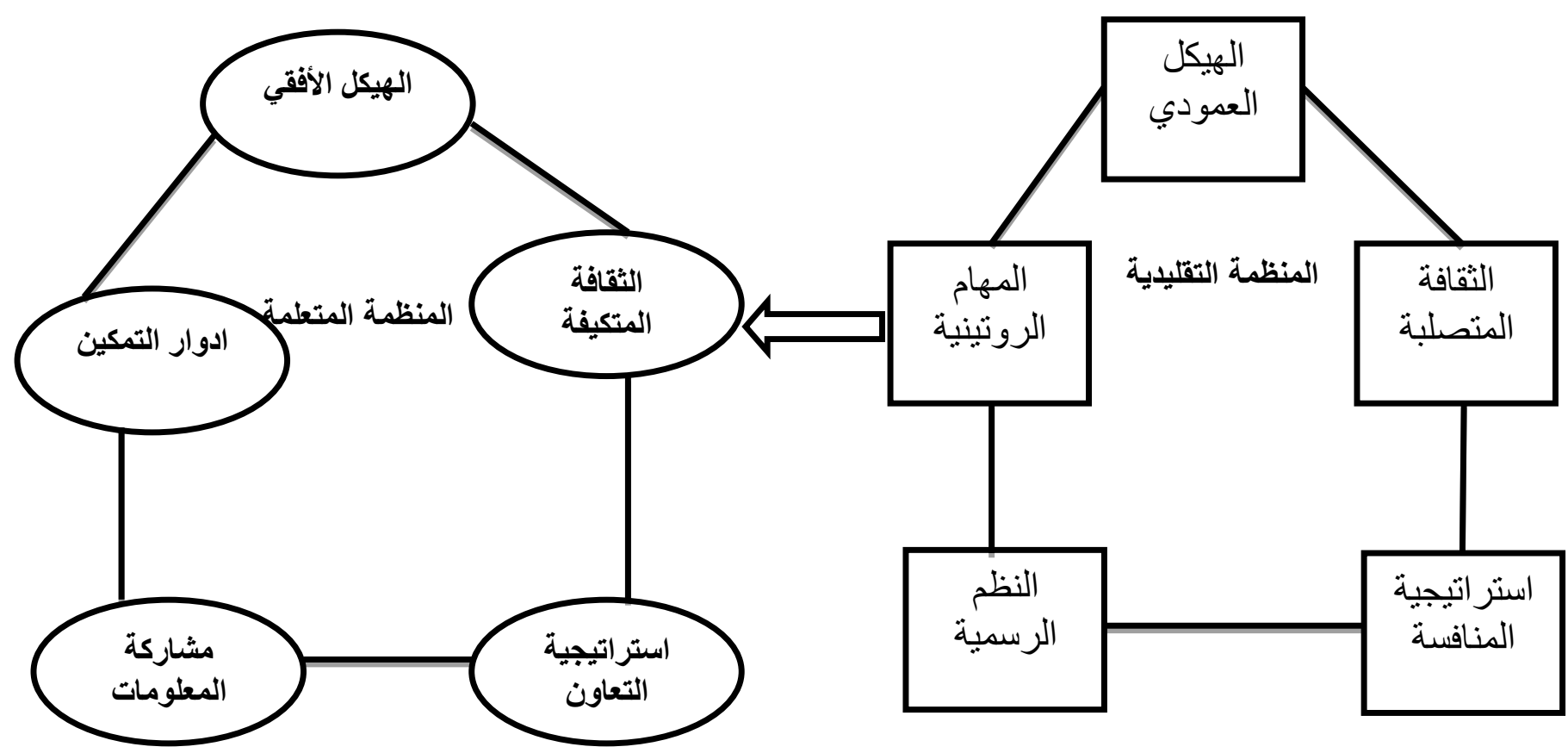

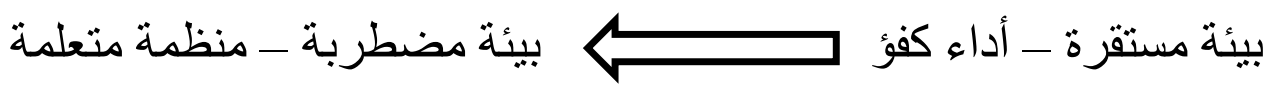

شكل رقم (1) يوضح الفرق بين المنظمة التقليدية والمنظمة المتعلمة

ويتضح من الثكل السابق أن التحول من المنظمة التقليدية إلي المنظمة

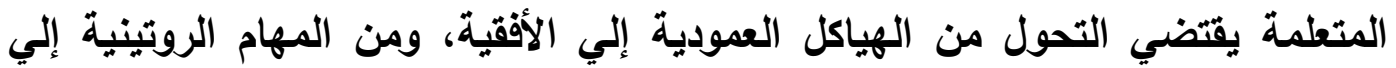

أدوار التمكين، ومن أنظمة الرقابة الرسمية إلي مشاركة المعلومات، ومن استراتيجية

المنافسة إلى استراتيجية التعاون، ومن الثقافة المتصلبة إلى الثقافة المتكيفة.

ومن جهة أخرى يتم الانتقال من نمط المنظمات التقليدية التي تعمل في بيئة ثابتة

نسبياً إلي منظمات متعلمة تعمل في بيئة مضطرة وسريعة التقلب، من خلان الأل إحداث

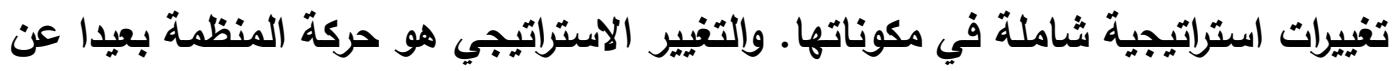

حالتها الحالية نحو حالة مستقبلية مرغوية لزيادة قدرتها التنافسية، وللوصول إلي تلكك

الحالة تتبع المنظمة أسلوب التغيير الجذري (الثوري)، أو التغيير التدريجي. وتعد إعادة 
الهندسة، وإعادة الهيكلة، والإبداع طرائق أساسية للقيام بالتغيير الاستراتيجي للمنظمة. .(Hill \& Jones, 2001, p.488)

كما تتسم المنظمة المتعلمة بعدد من السمات التي تميزها عن المنظمة التقليدية، والتي أوضحها براون (Brown, 2001 , p.270) في النقاط الخمس التالية: 1- شكل التظيم؛ فالهيكل العمودي (الرأسي) للمنظمة التقليدية لا يسمح بنشر وتوزيع

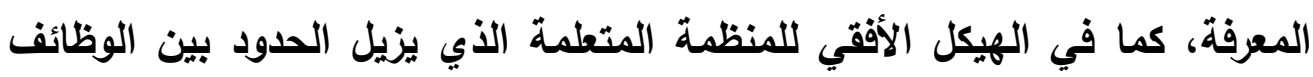
والدوائر بالمنظمة.

r- طبيعة المهام والوظائف؛ فالمنظمة المتعلمة تحول المهام الروتينية إلي أدوار التمكين، أي جعل العاملين قادرين على التصرف والتحرك بفاعلية ومرونة بإعطائهر الصلاحيات القانونية وتوفير مصادر القوة الأخرى.

r- أنظمة الرقابة؛ حيث تتسم المنظمة المتعلمة بالانتقال من الرسمية إلي المشاركة

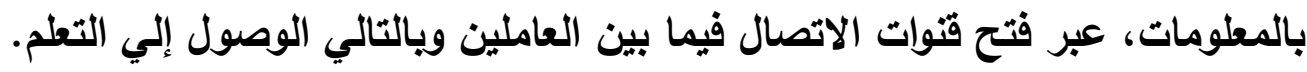
ع - استراتيجية المنظمة؛ حيث يتوافر بالمنظمة المتعلمة استراتيجية الاستخدام الأفضل والفعال للموارد المادية والبشرية، وتتيح للعاملين فرص تقديم المقترحات والحلول بالئهل الأفضل للمشكلات، وإتاحة كافة الفرص للتعلم. ه- الثقافة التظظيمية؛ حيث تمتلك المنظمات المتعلمة مجموعة من القيم، والمعتقات،

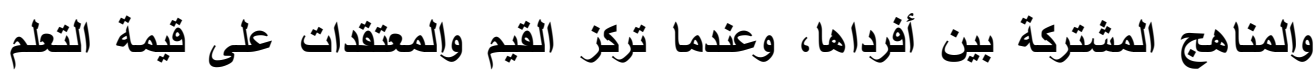

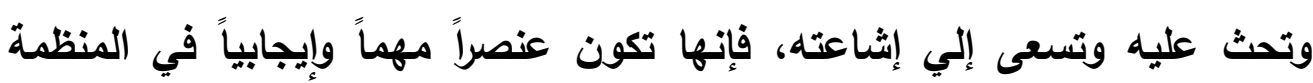
لتتكيف وتتطور.

وفي ذات السياق أوضح ماركواردت (Marquardt, 2002) الفرق بين المنظمة التقليدية، والمنظمة المتعلمة، في عدة أبعاد، تتضح من خلال الجدول التالي: جدول ( ) الفرق بين المنظمة التقليدية، والمنظمة المتعلمة.

\begin{tabular}{|c|c|c|}
\hline المنظمة المتعلمة & المنظمة التقليدية & البعد \\
\hline عقلية & مادية & الواجبات الأسساسية \\
\hline أفقية (زميل - زميل) & هرمية & العلاقات \\
\hline
\end{tabular}




\begin{tabular}{|c|c|c|}
\hline قليلة & متعددة & المستويات الإدارية \\
\hline فرق عمل متفاعلة & وظيفي & البناء التنظيمي \\
\hline متحركة & ثابتة & الحدود \\
\hline ديمقراطي (مشاركة) & أوتوقراطي & أسلوب الإدارة \\
\hline الالتزام بتحقيق النتائج & الطاعة وتنفيذ الأوامر & الثقافة السائدة \\
\hline مختلفون & متجانسون & الأفراد \\
\hline الابتكار & الفاعلية & التركيز الاستراتيجي \\
\hline
\end{tabular}

وتجدر الإثارة إلى أنه فيما سبق تمت الإثارة إلي خصائص المنظمة المتعلمة

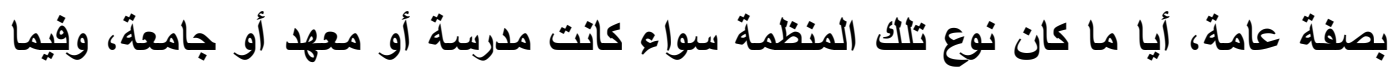
يلي تتم الإثارة بصفة خاصة إلي الخصائص التي تميز الجامعة المتعلمة على النحو التالي:

1- بيئة العمل؛ حيث تتصف تلك البيئة بالثقة والتعاون وتثثجع الاتصالات المفتوحة،

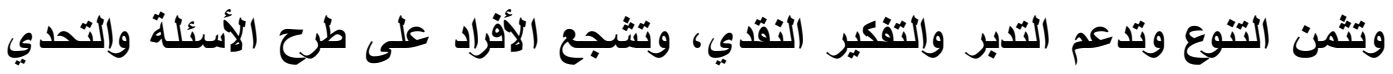

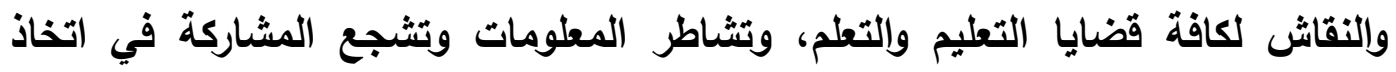

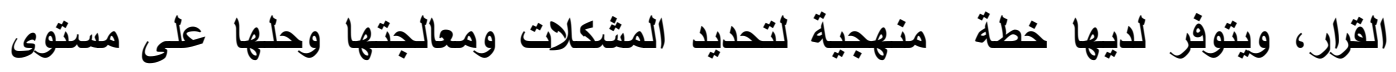
الجامعة، وهي جامعة منفتحة على تجريب أساليب جديدة وتتعلم من الخبرات الذاتية

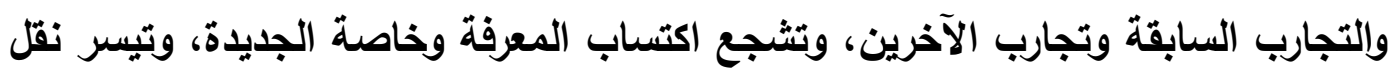

تلكك المعرفة بسرعة وفعالية في أرجائها ( Glenys, 1999, p.135 ). r- التحسين المستمر للأداء؛ وذلك من خلال التغذية الراجعة وإثراء القاعدة المعرفية وصقل المهارات وتخصيص كافة مستلزمات التطور المهني من أموال ووقت. r- متابعة ومراجعة رسالة الجامعة وأهدافها؛ وذلكك من خلال وضع القيم وإلممارسات

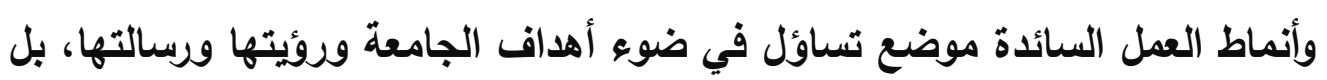
وإعادة النظر في جدوى تلك الأهداف.

ع- المبادرة والإقدام؛ حيث يُسمح بالتجريب وطرح البدائل بعد أن توضع الممارسات

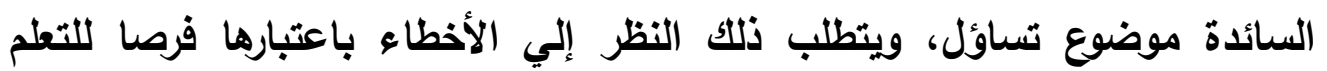

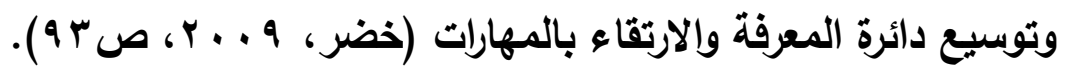


ه- القيادة التحويلية؛ حيث يتحول المديرون في الجامعة المتعلمة من قادة تعليميين إلي

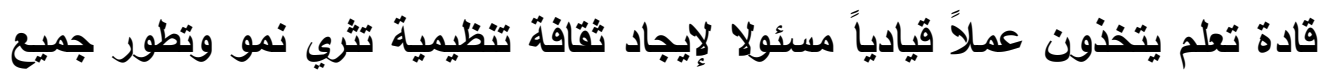

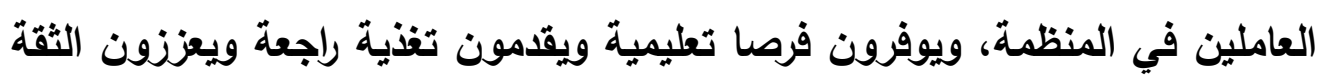
بالإنجاز ويبدون اهتماما بالنجاح المهني للعاملين، ويهذا يصبح التعلم ممكنا. فعلي ولئي

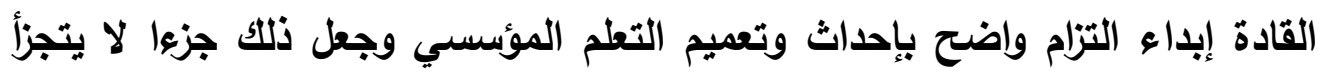

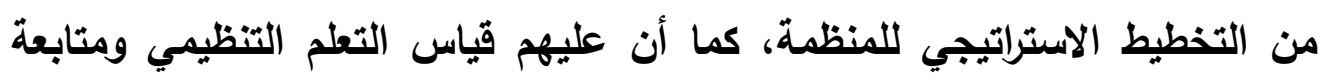

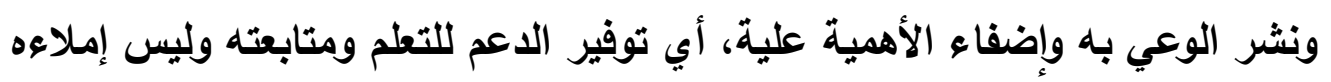

.(Friedman, Friedman\& Pollack , 2005, p.33)

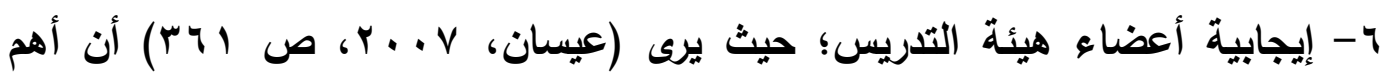
نقطة في المنظمة المتعلمة أن العاملين لايهم القدرة على تعديل الأنظمة والهياكل

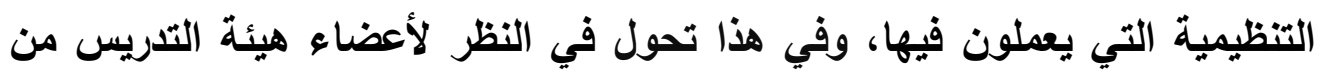

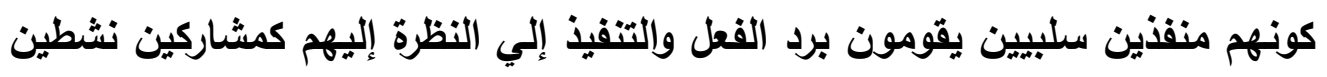

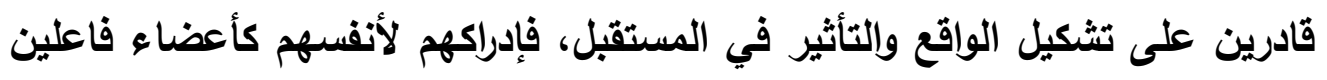

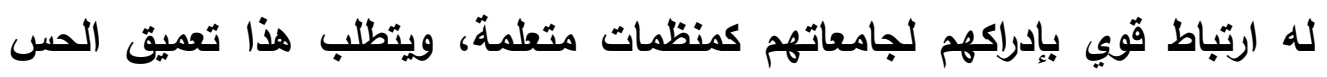

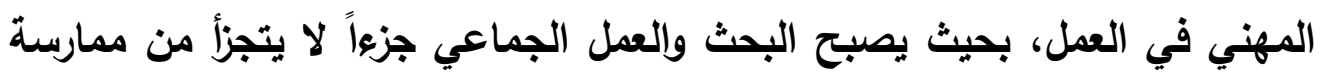
أعضاء هيئة التدريس، وحينئذ يصبح التعلم التنظيمي نتيجة حتمية. وإذا كان البحث قد تناول فيما سبق سمات وخصائص الجامعة المتعلمة، فإنه من

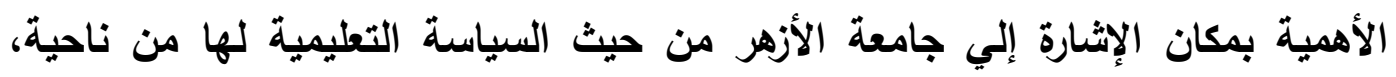

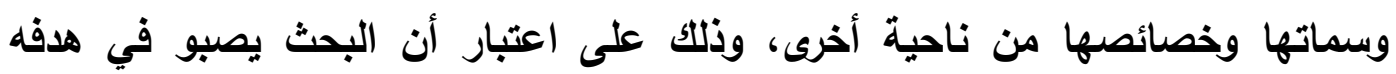
الرئيس إلي وضع تصور مقترح لتحويل جامعة الأزهر إلي منظمة متعلمة. السياسة التعليمية لجامعة الأزهر: جامعة الأزهر هي امتدادا طبيعي للأزهر الثريف، وتعد أقدم المعاهد العلمية

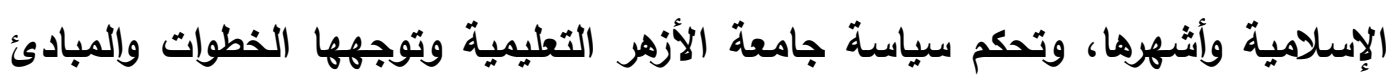

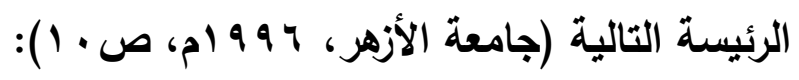
- أن تكون جامعة الأزهر مفتوحة الأبواب لكل مسلم يطلب العلم والمعرفة التخصصية وللراغبين في دراسة الاين الإسلامي دراسة متعقة الأهرة واعية.

- أن تسعى جامعة الأزهر من وراء ذلك إلي تحقيق نوع من الوحدة الفكرية بين أبناء العالم الإسلامي، وأن تعمل على تماسكهم وتنمية انتمائهم للإسلام. 
- أن تغني في مناهجها ويرامجها التعليمية بكل ما يقوي الروح الإسلامية وينمي الثعور الوطني، وأن تظل كما كانت منارة للإسلام، ومنهلا خصبا للعروية.

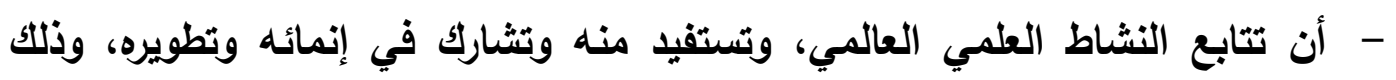

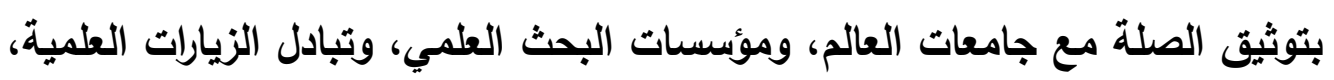
واستيفاء الكفايات النادرة.

- أن تعد لمصر وللعالم علماء وخبراء ذوي ثقافة متكاملة تجمع بين مطالب الانيا المادية ومطالب الدين، مؤهلين لخدمة مجتمعاتهم، والمشاركة في بنائها. - - أن توفر للأجيال القادمة ما تحتاج إليه من القيادات العلمية والدينية الرائدة.

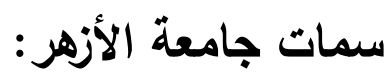

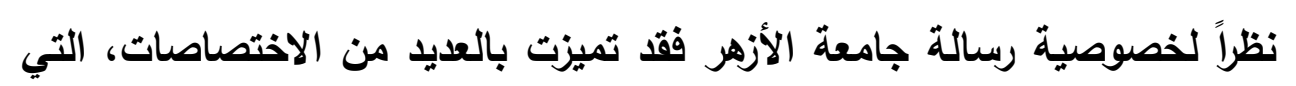

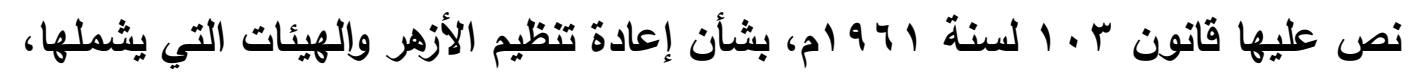

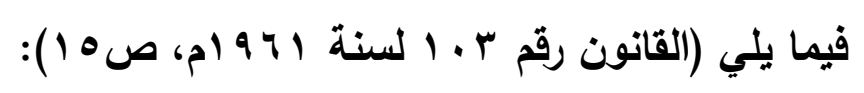

- تختص جامعة الأزهر بكل ما يتطق بالتعليم العالي الأزهري ويالبحوث التي تتصل بهذا

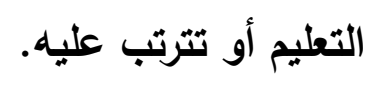

- تقوم الجامعة على حفظ التراث الإسلامي ودراسته وتجليته ونشره.

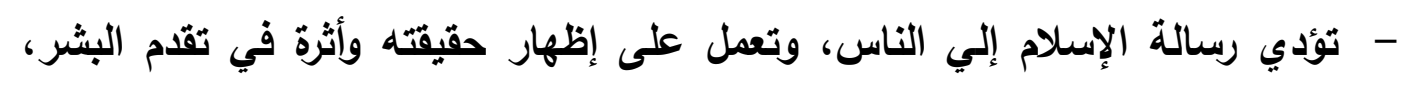
وكفالة السعادة لهم في الانيا والآخرة.

- تهتم ببعث الحضارة العربية والتراث العربي والفكري والزروحي للأمة العربية. - تعمل على تزويد العالم الإسلاهي والوطن العربي بالعلماء العاملين الذين يجمعون إلي

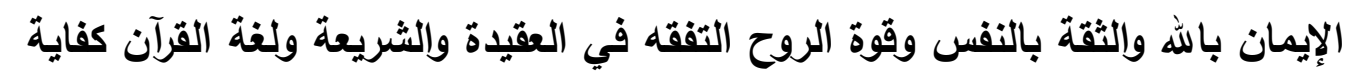
علمية وعملية ومهنية لتأكيد الصلة بين الدين والحياة.

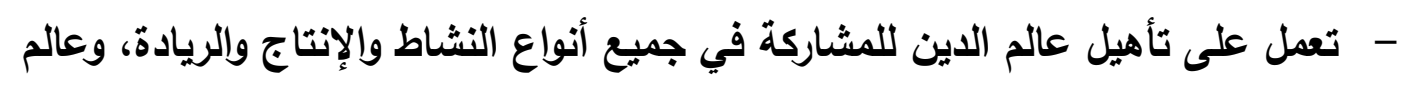
الانيا للمشاركة في الدعوة إلي الله بالحكمة والموعظة الحسنة. - تغني بتوثيق الروابط الثقافية والعلمية مع الجامعات والهيئات العمية والإسلامية والعربية والأجنبية.

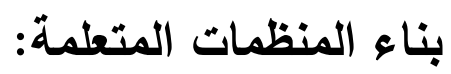


يبدأ بناء المنظمات المتعلمة عند التغيير والتحول من الثقافة التقليدية الهرمية إلي ثقافة التعلم، التي تتجسد في العمل بروح الفريق بهدف مساعدة جميع أفراد المنظمة

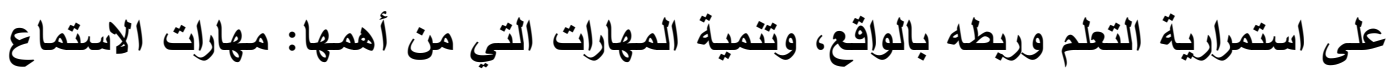
وإبداء الرأي، وإستخام أسلوب المناقثة المفتوحة، والبحث، والأسئلة الناقدة والأفكار البديلة، وهذا يُظهر بجلاء أهمية بناء ثُقافة تعلم تقوم على التخلص من العلاقات التات الهرمية

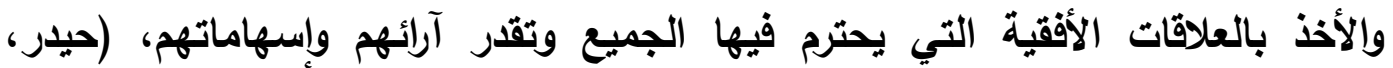

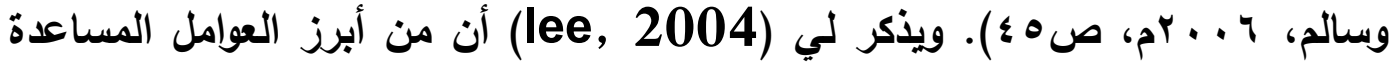

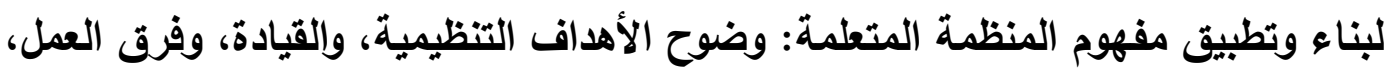
وحل المشكلات الجماعية، والاتصالات (lee, 2004).

كما يؤكد جوسيفيسين (Juceviciene, 2009, p.30) على أن المنظمة المتعلمة لابد أن توفر أمرين أساسيين أولهما: ضمان استمرارية عمليات التعلم وتطوير قرات العاملين بالمنظمة، والتطوير الذاتي المتواصل للمنظمة ككل، وثنانيهما: العمل على التى وضع قنوات تربط تعلم الأفراد بسياسات المنظمة وإستراتيجياتها.

Bowen, Ware, Rose\& Powe ) ويضيف بوين، ووار، وروز، ويو

(2007, p. 204) (أبان من المرتكزات التي يجب إتباعها للتحول من مؤسسات

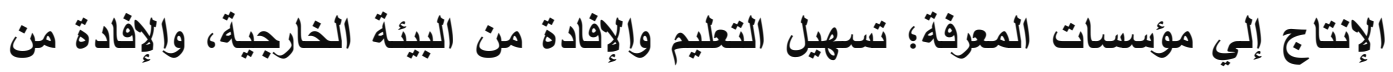
معارف الآخرين، والحفاظ على ذاكرة المنظمة، ومكافأة التعلم.

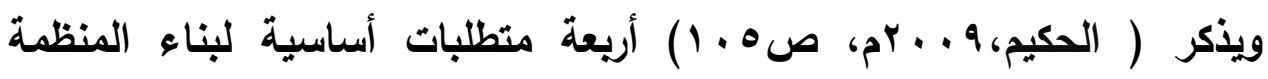
المتعلمة تتمثل في: تعزيز التعلم المستمر، وتثجيع التعلم الثانوي، وتحفيز القادة للتعلم الفردي والجماعي، وتطوير أنماط تفكيرية حديثة.

كما أثشار كل من ( Boyle, 2002, p.12; Carroll,1998,P.708, Collision \& Parcel, 2004, Hyatt,1998,Karash 2002; and Nutley \& Davies,2000, p. 320 ) المتعلمة لعل من أهمها: الانخراط والالتزام التام للوصول إلي منظمة متعلمة، ورعاية

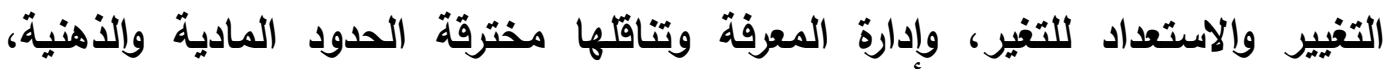
وتثجيع ورعاية التعلم الجماعي، والبحث عن الممارسات الناجحة بين المديريات والأقسام catch the employee doing ) وتقديم الدعم والتقدير والمكافأة 
عomething write)، وقبول المخاطرة والتسامح مع الأخطاء، والإيمان بقرة الفرد على الإبداع، ويناء العلاقات وتحفيز الاتصال مع الآخرين وفيما بينهم، والتعلم اللانهائي؛

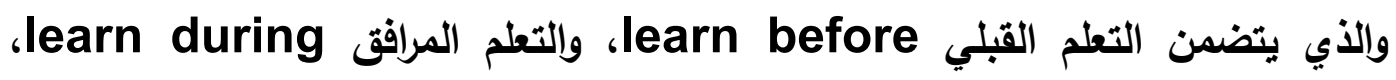
والتعلم البعدي learn after، وتثجيع مبادرات المراجعة والتساؤل، والمعرفة للجميع

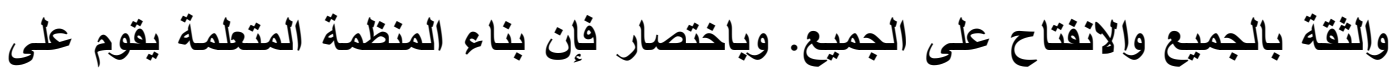

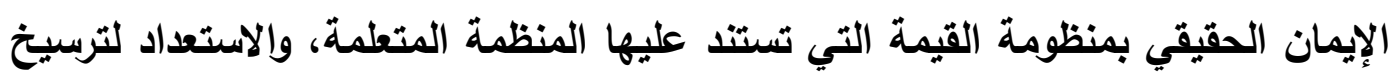
تلكك المنظومة ممارسة وسلوكاً.

وفي ذات السياق صنف (بكار، ؟ . . ب) الاستراتيجية الرئيسية لبناء المنظمة

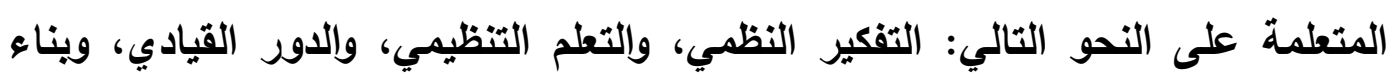
فرق التعلم، وثثقافة التعلم التنظيمية، وإدارة المعرفة.

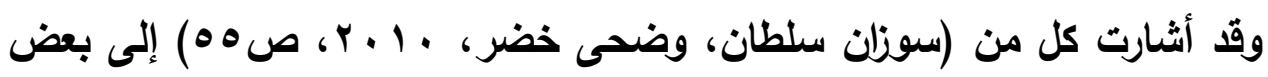

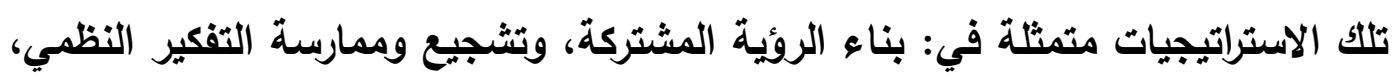

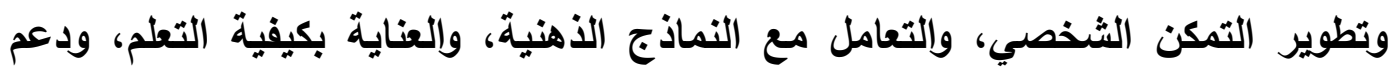
الفريق، وتطوير الحوار التنظيمي.

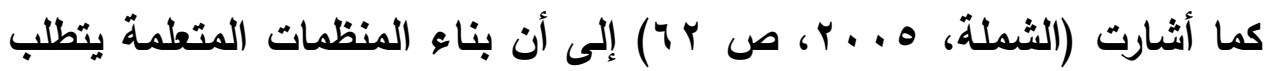

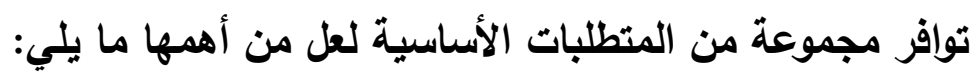
1- النقلة الفكرية؛ ويتعلق هذا الأمر بمتخذي القرار في المنظمة؛ إذ لابد من توافر أساليب فكرية وتحليلية جديدة من اجل التعامل مع الثكل الجديد للعالم بأجزائه الأله وعلاقاته المختلفة. r - منح العاملين التعلم المستمر طيلة الحياة الوظيفية؛ إذ لابد من العمل تجاه تحويل الأفراد العاملين إلي ما يسمى عمال المعرفة knowledge workers، وذلك من خلال توفير مستويات تعليمية وتدريبية أفضل تمكن أولئك الأفراد من التعلم من خلال الخبرات والممارسات اليومية وإلفرص المتاحة. r- التعلم المنظمي وتطوير المهارات القابلة للنقل. ع - التفوق والبراعة الثخصية، حيث تسعى المنظمات الراغبة بالنجاح والاستمرار إلي

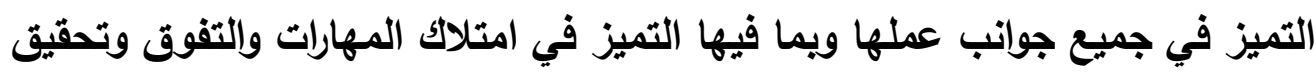

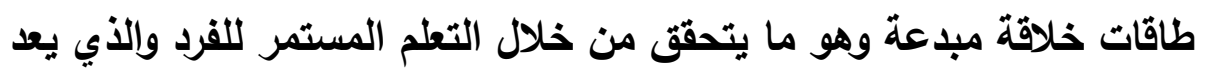


الأساس لتوسيع القدرات الثخصية للوصول إلى أقصى ما يمكن الوصول إليه من نتائج في جميع النواحي ويما يمكن من بناء المنظمات المتعلمة.

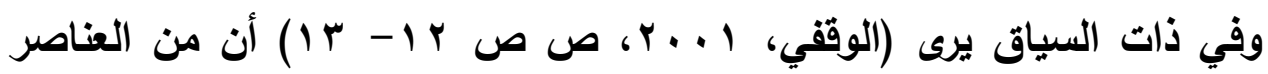
والاعائم التي ترتكز عليها المنظمة لكي تصبح منظمة متعلمة ما يلي: - اعتماد المنظمة على الأفكار والمهارات والخبرات، وتثجيع الأنثطة المرتكزة على لهـئ الإبداع. - اعتماد المنظمة على الايمقراطية بدل البيروقراطية، أي أن تفتح المنظمة مجالا للنقا وتوجيه الملاحظات من قبل العاملين، ومشاركتهم في اتخاذ القرارات. - ارتكاز عمل المنظمة على التعلم قبل البدء بالعمل وأثناءه ويعد انتهاءه، لأن التعلم

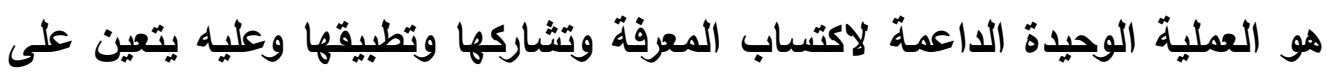

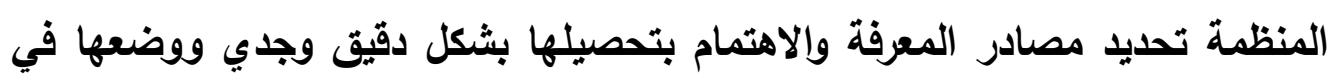
أوعية مناسبة لحفظها وتسهيل عملية نشرها فيما بعد. - توفير البنية التحتية الملائمة لتقنية المطومات، أي إنثاء بنية تحتية للمطومات والاتصالات تتميز بمرونة عالية. مبررات التحول نحو المنظمة المتعلمة: لقد بدأ الاهتمام بالمنظمات المتعلمة بعدما أصبحت مفاهيم الجودة الثاملة،

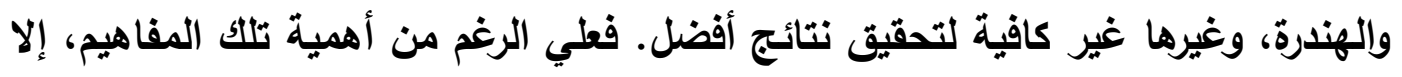

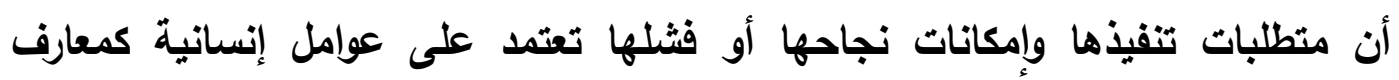

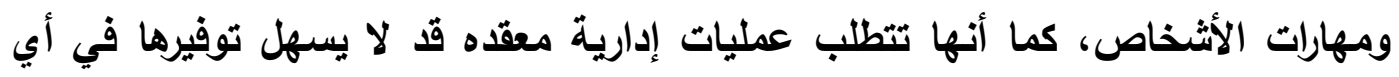

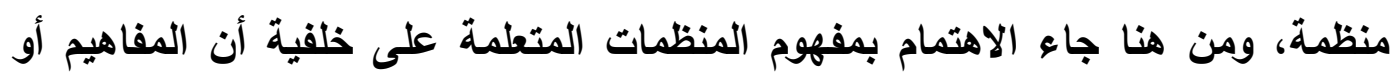

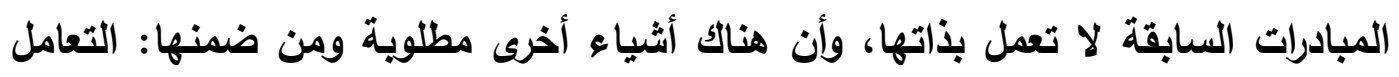

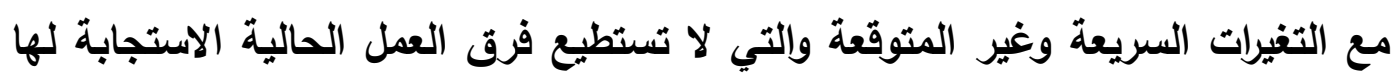

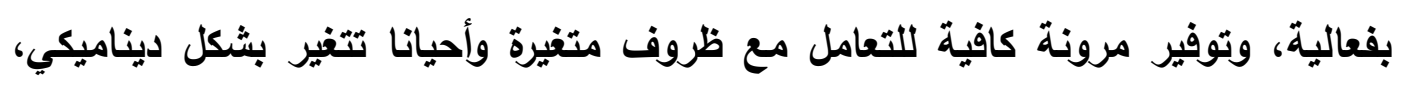

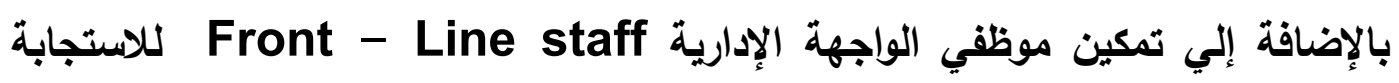
الفورية ويثكل مبادر لاحتياجات العملاء عوضا عن التقيد بعمليات إدارية محددة سلفاً

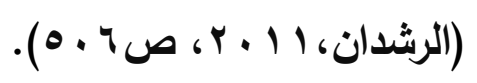


وتجدر الإشارة إلى أن مفهوم المنظمات المتعلمة لا يقتصر على المزيد من التدريب، حيث يساعد التدريب على تظوير المعارف والمهارات، ولكن المنظمة المتعلمة تتضمن تطوير مستوى أعلى من المعارف والمهارات والتي يمكن تحديدها بأريعة مستويات

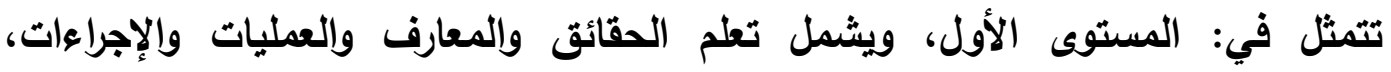

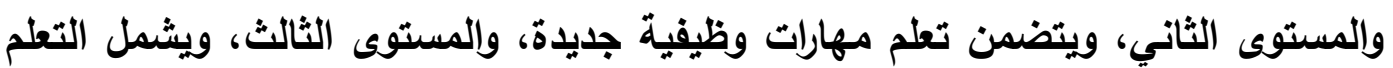
للتكيف، والمستوى الرابع، ويشمل التعلم للتعلم ويقصد به الخلق والإبداع وصياغة

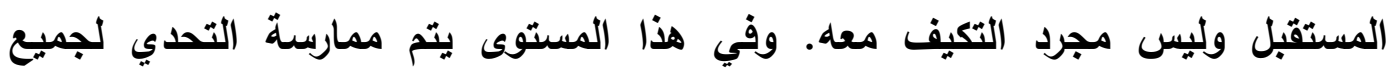

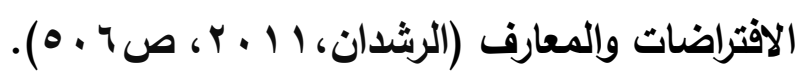

كما يرى كاراش (Karash, 1995 ) أن المنظمات المتعلمة تعد بيئة صحية أكثر من غيرها لأنها؛ تغذي التفكير الإبداعي المستقل، وتزيد من القدرة على إدارة التغيير، وتحسن نوعية المنتج، وتضمن بيئة عمل على درجة عالية من الالتزام، وتطمئن

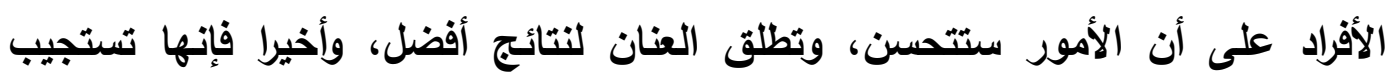
لحاجة إنسانية أساسية وهي الحاجة للتعلم والتظور. ولعل من الإضافات التي تحققها روئة المنظمات المتعلمة؛ أن تصبح المنظمات

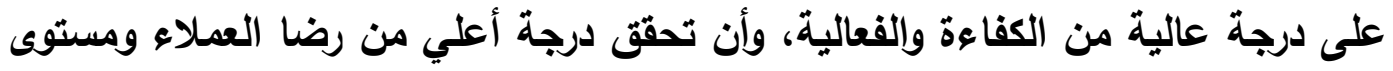

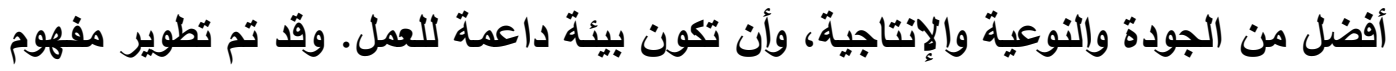

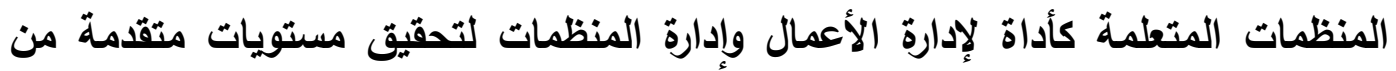

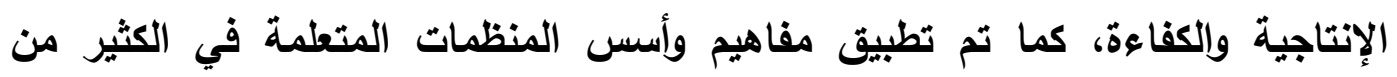

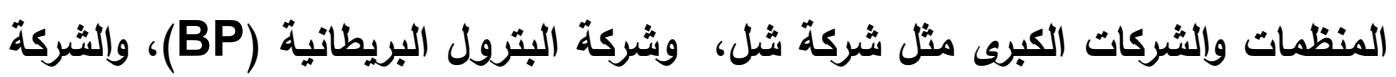
البريطانية للطاقة British Energy العاملة في مجال الطاقة النووية والتي طبقت أسس المنظمات المتعلمة لضمان درجة عالية من الأمان والسلامة المهنية في بيئة العمل مله

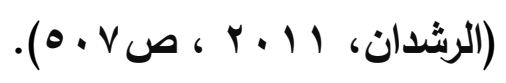

وقد ذكر سينج (senge, 1996, p.37) مجموعة من الأسباب الدافعة

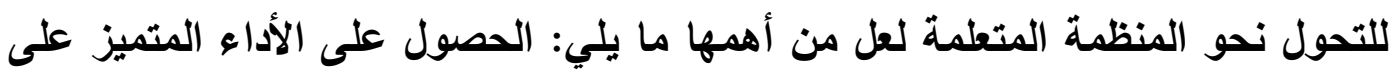

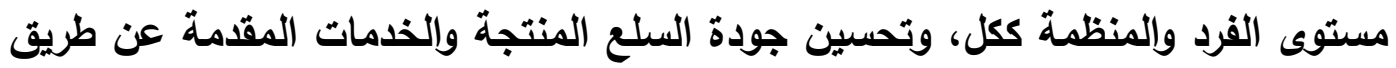

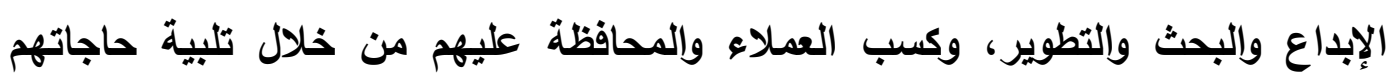

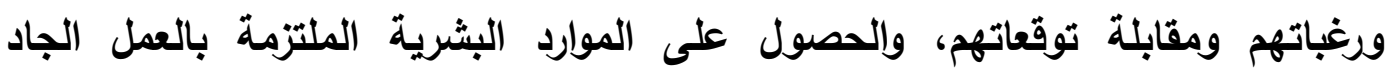
والمتماسكة فيما بينها، وأخيرا حاجة العصر الحديث للمنظمات المتعلمة. 
Thomas \& allen, 2006, pp. ) وفي ذات السياق أثنار ثوماس وألن 132-133) إلى عدد من العبررات التي تبين الحاجة إلى تبني مفهوم المنظمة

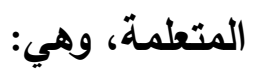
- العالمية؛ حيث تحقق العديد من المنظمات الاقتصادية أرياحا، وتقام خدمات خارج موطنها الأصلي، وهذا ما يعكس مقدرتها على التعلم من خبراتها وتجاربها السابقة.

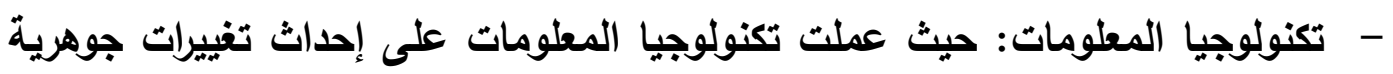

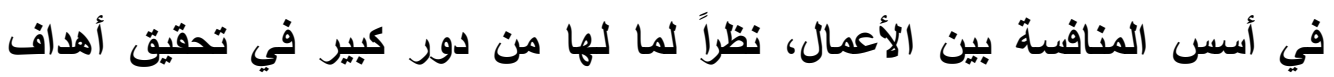

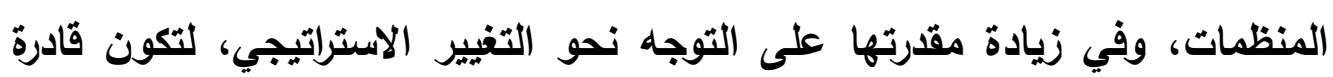
على التجليد والإبداع والمنافسة. - التغير في أساليب العمل؛ فق شهلت السنوات الأخيرة من القرن العثرين كثيرا من فئن

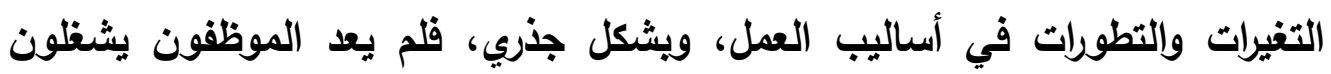

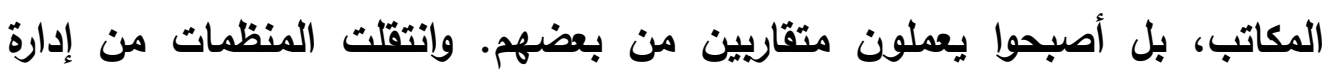

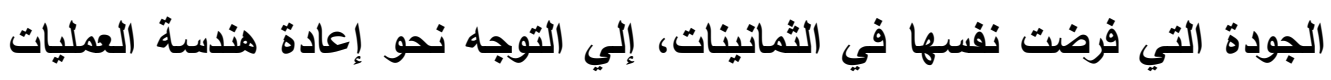

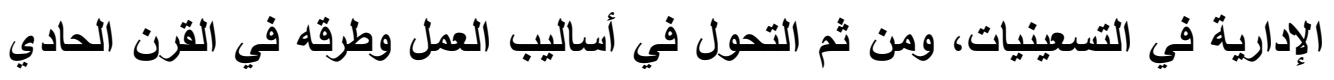

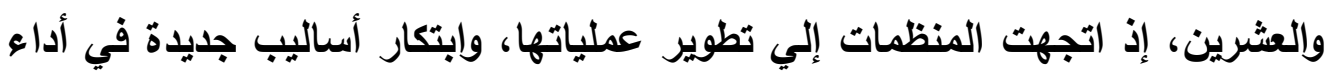
العمل لتكون قادرة على إدارة التفيير والتطوير المستمرين. - زيادة تأثير المستفيدين من المنظمة، حيث تسعى المنظمات بمختلف أنواعها إلى في

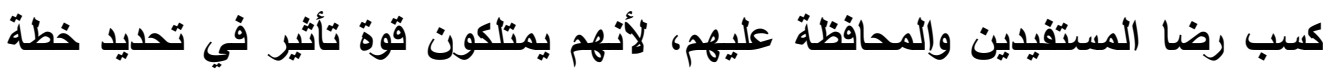

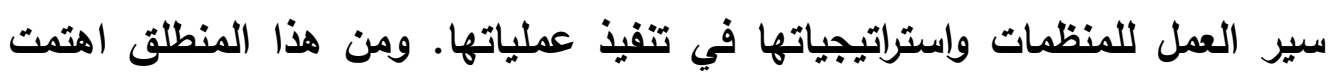

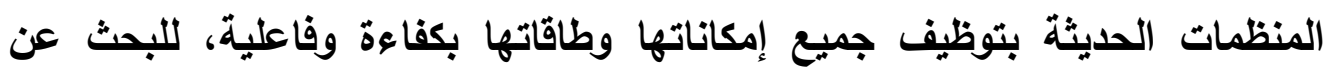
أحثث الأساليب التي تحقق الميزة التنافسية لها.

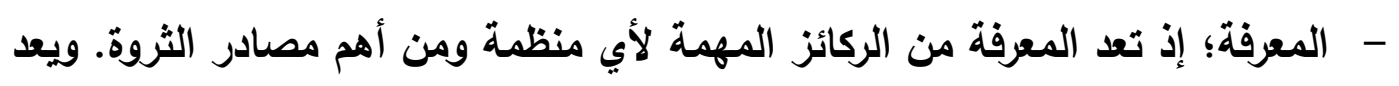

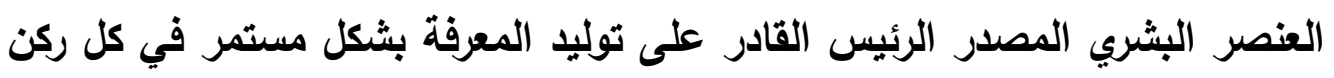

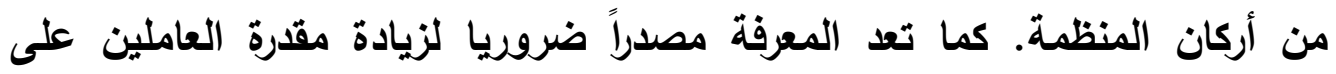
تحسين الأداء وتطويره على المستويات الفردية والجماعية والتتظيمية. - تطوير أدوار العاملين وتوقعاتهم؛ حيث تزداد أهمية الموارد البشرية مع تزايد خبراتها

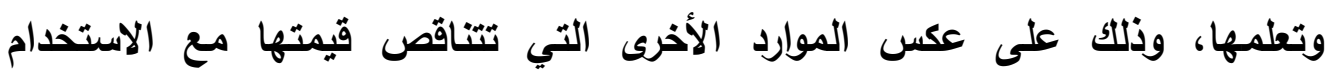
والتقادم. لذا تسعى المنظمات الحديثة إلي جذب صناع المعرفة واستقطابهم والاحتفاظ 
بهم وتحفيزهم، والعمل على توفير البيئة المناسبة المشجعة لهم على أداء مهامهر

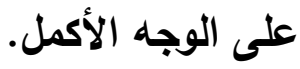

وقد اسنطاع كاراش (Karash, 1996) الوقوف على أسباب عديدة تدفع نحو

ضرورة تحول الجامعات إلى منظمات متعلمة، لعل من أهمها ما يلي:

- الحصول على أداء متميز والرغبة في تحقيق ميزة تنافسية. - تجنب الفشل وحالات التدهور.

- تحسين وتطوير نوعية المنتجات والخدمات التي يتم تقديمها للزيائن.

- تحسين القدرة في إدارة التغيير المخطط. - تفهم المشكلات والمخاطر بشكل أعمق. - - - التفاعل الأوسع مع المجتمع، - شحذ هم العاملين بالجامعة نحو التزام وتفاعل أكثر في العمل. - - تحقيق الاستقلالية والتحرر. - التعرف الأثثمل على حقيقة التفاعل فيما بين الأنثطة التنظيمية.

المنظمات المتعلمة كأنظمة مفتوحة:

تعد المنظمة المتعلمة أحد أفضل الأمثلة على الأنظمة المفتوحة، كما أثشار بذلك Ahrenfelt, 2001, Argyris\& Schon, 1996, ) العديد من الباحثين Granberg \& Ohlsson, 2000, Mulford, 2000, Morgan, 1986, Senge,1999, O' Connor \& McDermott, 1997) تعريف النظام على أنه مجموعة متصلة من العناصر فيما بينها، والأنظمة الفرعية التي يمكن رؤيتها على أنها بني مستقلة فيما بينها وأجزاء معتمد عليها في بنية متكاملة فئلة كوحدة واحدة في الوقت ذاته (O'Connor \& McDermott, 1996). ويمكن تعريف الجامعة على أنها منظومة أو نظام، حيث تعتبر الأقسام والتخصصات أمثلة على التى

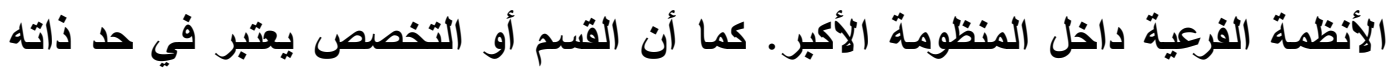
بنية منفصلة. ولكن في ذات الوقت تعتبر هذه الأجزاء مكونة للبنية الأكبر "الجامعة". 
والجامعة لا يمكن أن تكون جامعة بدون الأقسام والتخصصات، كما أن الأقسام والتخصصات لا يمكن أن تكون موجودة بدون وجود الجامعة جامعة باون الاعبام ولقد أوضح برن بوم Brinbaum, 1988 واوكونور، ومك ديرموت

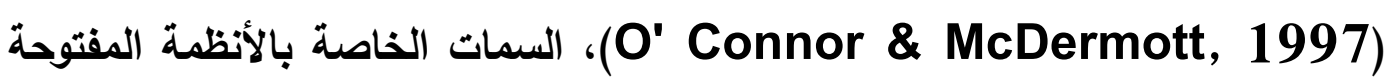
وعلاقاتها وتفاعلها مع البيئة، بالإضافة إلي قدرتها على مسح واكتثاف التغيرات في هذه

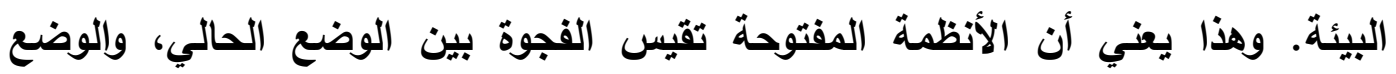
المستقبلي المأمول، والذي يمكن روئه على أنه سعى حثيث من أجل تحقيق علاقة ثابتة

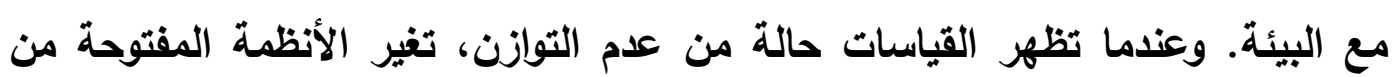

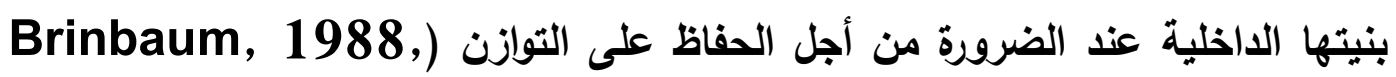
Morgan, 1986, O' Connor \& McDermott , Sporn,1999 1997 ) ). وتسمى هذه العملية "اتجاه النظام لحماية الاستقرار الاخلي" أو التظيم الأتي، حيث إن مورجان (Morgan, 2000) أكد وأثشار إلى أن المنظمات المتعلمة

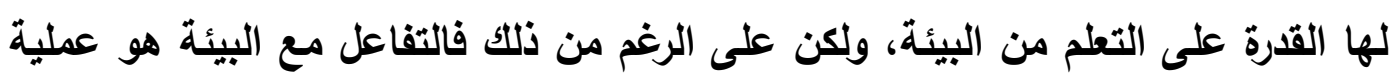

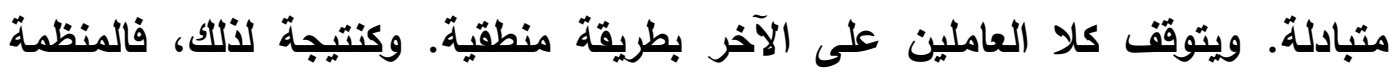
المتعلمة تؤئر أيضا في البيئة.

ولقد أثارت العديد من الأبحاث بثأن تكيف الجامعة، أنه من المكن اعتبار

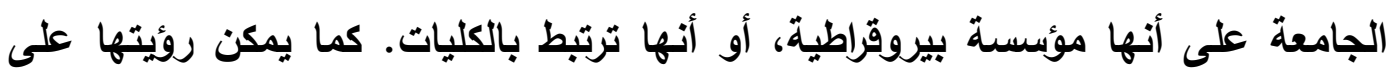

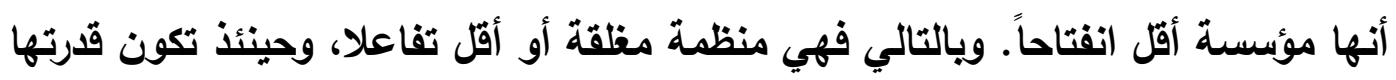
أقل على مسح واكتثاف التغيرات التي من الممكن أن تؤثثر فيها ( Argyris\& فأ 'O' connor \& McDermott, 1997, Schon, 1996, فالمنظمات المغلقة أو الأقل انفتاحا لايها قرة أقل على التعلم من البيئة. ولا تتعلق طاقة الأنظمة المفتوحة للتطلم فقط بالبيئة، ولكنها تعتمد ويصورة كبيرة

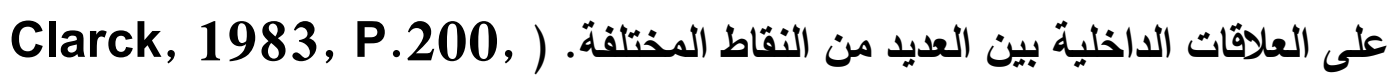
Morgan, 1986, O' Connor \& McDermott, 1997,and Weick, 2000, p.135) تتم العديد من التفاعلات الداخلية وقد تكون محدودة أو ممنوعة، اعتمادا على قوة

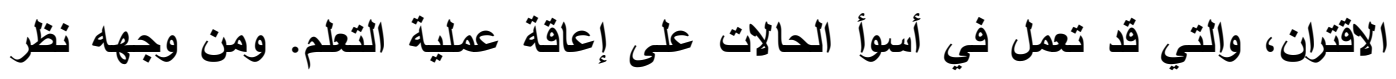


أخرى، فالمنظمات المتعلمة تتطلب وجود روابط قوية حيث تتفاعل الأجزاء بصورة مستمرة وتتعلم من بعضها البعض. ولقد ذكر كلارك (Clark, 1987, p.20) أن الأنماط الإدارية قد تتطور بصورة كبيرة لتصبح أكثر بيروقراطية، بما قد يزيد من العلاقات بين

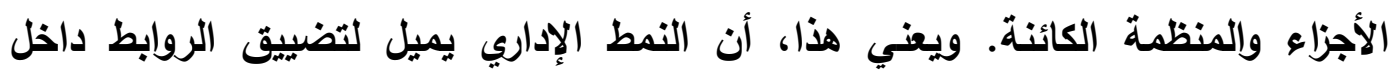
الجامعات، والتي يجب أن تعمل على زيادة طاقتها للتعلم. نماذج المنظمة المتعلمة: توجل نماذج عليدة للمنظمة المتعلمة، يمكن الإشارة إلى بعضها فيما يلى:

: marquardt model نموذج ماركواردت

توصل ماركواردت (Marquardt, 1996, p.41) بعد تجاريه الطويلة في مجالي التعلم التظيمي، وتطوير المنظمات إلي نموذج للمنظمة المتطمة يتكون من خمسة أنظمة فرعية ضرورية لتحقيق التعلم التظيمي والحفاظ على استمراريته، وهي: التعلم، والتتظيم، والأفراد، والمعرفة، والتقتية. ويواسطة هذه هذه الأنظمة الفرعية جميعاً تعزز

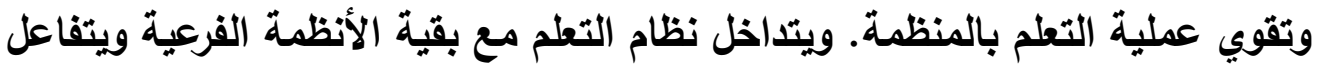

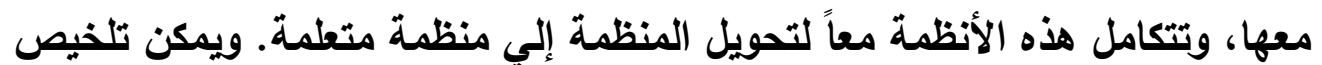
نموذج ماركواردت في الثكل التالي: معند

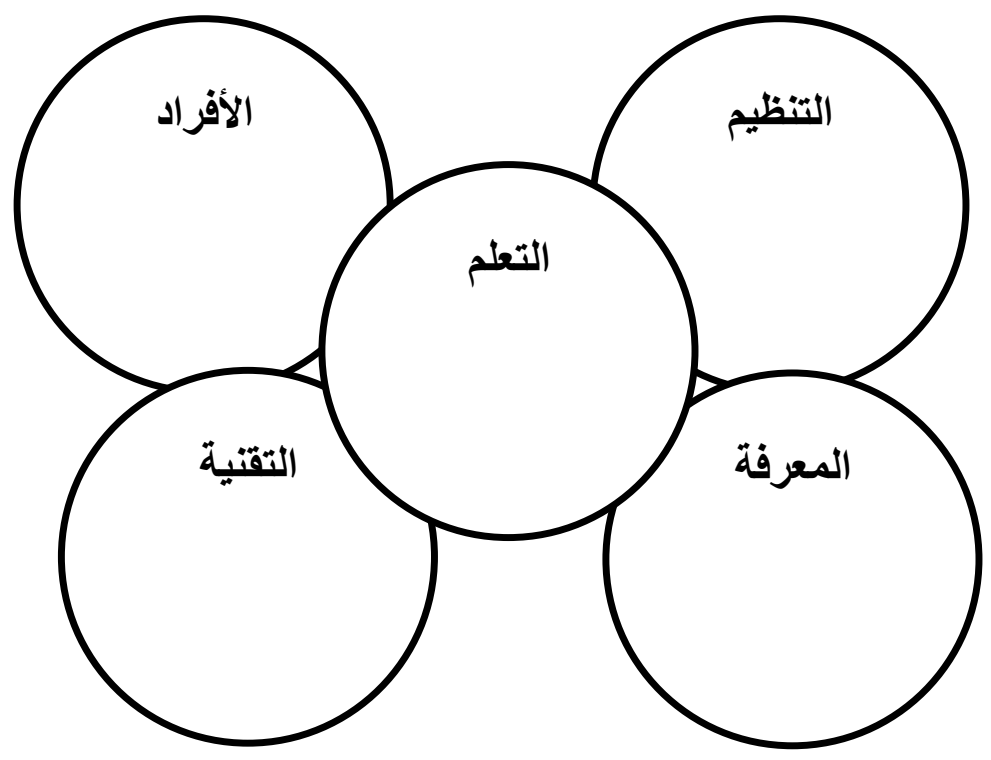

شكل رقم (Y) يوضح نموذج ماركواردت للمنظمة المتعمة

نموذج مارسك وواتكنز ( Marsick and Watkins model): 
قدمت كل من مارسك وواتكنز عام 999 ام نموذجا متكاملا للمنظمة المتعلمة

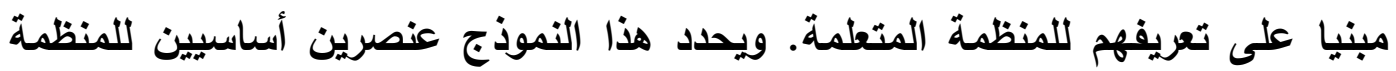

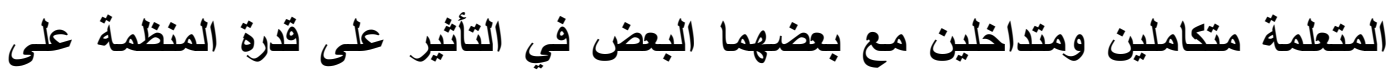

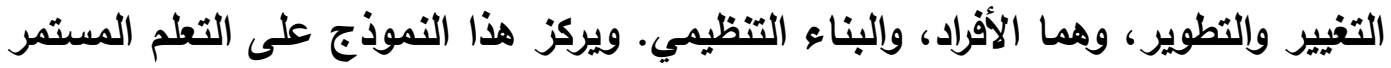

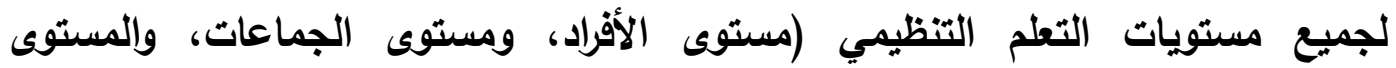
التنظيمي)، حيث يشتمل كل عنصر على مجموعة من العناصر الفرعية التي تتذاخل فيما بينها لتكون الأبعاد السبعة للمنظمة المتعلمة، وهي: خلق فرص للتعلم المستمر، وتثجيع الاستقصاء والحوار، وتثجيع التعاون والتعلم الجماعي، وتمكين العاملين من روئية

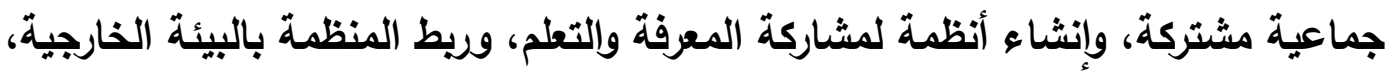
(Marsick \& Watkins, والقيادة الاستراتيجية. وفيما يلي توضيح موجز لهذه الأبعاد

1- خلق فرص للتعلم المستمر؛ ومعناه أن التعلم مصمم داخل بنية العمل، ومن ثم فالأفراد من المكن أن يحققوا التعلم من خلال الفرص الوظيفية. r- تثجيع الاستقصاء والحوار؛ بمعنى أن تدعم المنظمة ثقافة البحث والاستقصاء،

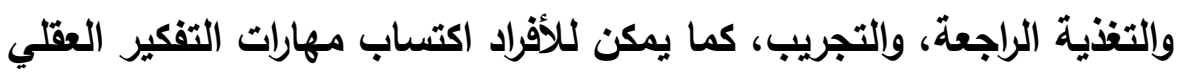

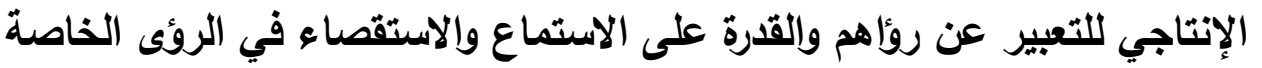
بالآخرين.

r- تثجيع التثارك والعمل بالفريق؛ ومعناه أن العمل مصمم طبقا لمجموعات من أجل تحقيق الاستفادة من الأنماط المختلفة للتفكير، كما أن المجموعات من المتوقع أن تتعلم من بعضها البعض وتعمل مع بعضها البعض، حيث إن التعاون يتم تقييمه من خلال ثقافة المنظمة، ويقدم له المكافآت.

ع - بناء الأنظمة من أجل تحقيق ومشاركة التعلم؛ بمعنى أن الأنظمة التكنولوجية المتقدمة وغير المتقدمة، البسيطة والمعقدة، يتم بناؤها والحفاظ عليها. والاعتماد

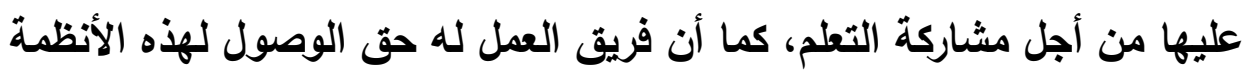
التكنولوجية البسيطة والمعقدة.

ه- دفع الأفراد نحو تحقيق روئة جماعية (التمكين)؛ ومعناه أن أفراد المنظمة يتم دمجهم

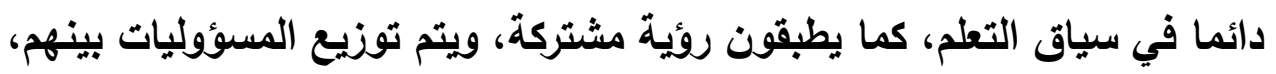
بحيث يكون لايهم الدافعية للتعلم بشأن ما هم مسؤولون عن القيام بهاف. 
צ- ربط المنظمة بالبيئة الخاصة بها؛ بمعني أن ترتبط المنظمة بالمجتمع الخارجي كما

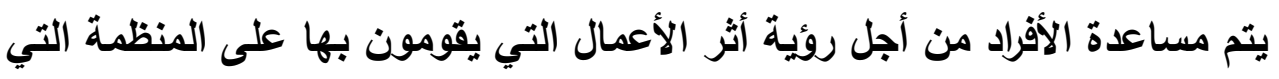

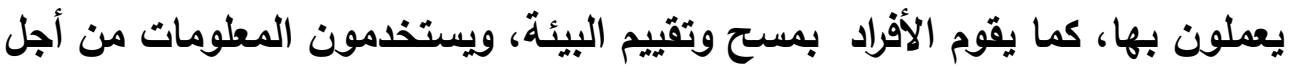

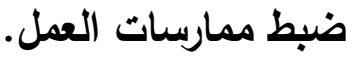

V - نموذج القادة ودعم التعلم: ومعناه أن يستخدم القادة التعلم بصورة استراتيجية من أجل تحقيق نتائج التعلم؛ نموذج القادة، والريادة، وتدعيم عملية التعلم.

$$
\text { نموذج العتيبي ( Al-Otaibi model ): }
$$

قام العتيبي Al- Otaibi ، بإعداد نموذج للمنظمة المتعلمة بعد أن قام بمراجعة مفاهيم المنظمة المتعلمة وممارساتها وأساليب تقويمها، ويتكون النموذج من ثلاثة أنظمة

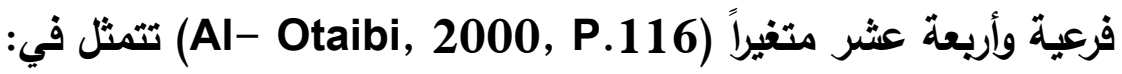

- نظام المنظمة، ويتضمن ثمانية متغيرات هي: هوية المنظمة، وروئيتها، واستراتيجيتها،

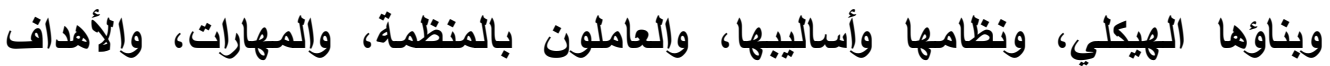
الرئيسة.

- نظام التعلم، ويتضمن أربعة متغيرات هي: التوجه نحو التعلم بالمنظمة، وإدارة المعرفة، وأنشطة التعلم ومستواها، وتسهيلات التعلم المتوفرة بالمنظمة. - نظام الثقافة الاجتماعية، ويتضمن متغيرين هما: أنماط السلوك المشتقة من القيم الاجتماعية، والاتجاهات الثقافية.

:Moilanen model نموذج مايلونين اقترح مايلونين Moilanen نموذجا للمنظمة المتعلمة مكونا من خمسة أبعاد رئيسية (Moilanen, 2001, p.14) تتلخص في: نمونائ - الدوافع المحركة driving forces: ويقصد بها مدى سعي قيادة المنظمة إلي وضع

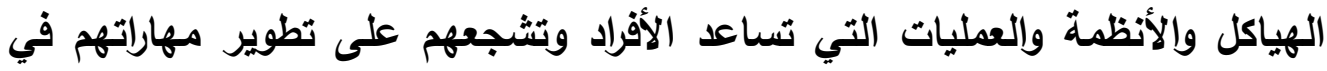

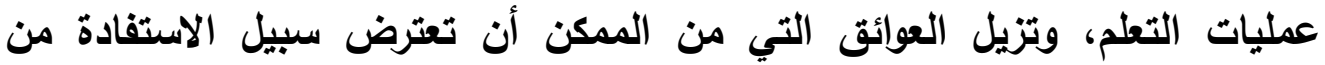

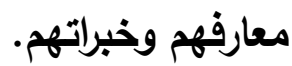
- تحديد الهذف finding the purpose: ويقصد به مدى وجود روية تنظيمية وأهداف مشتركة تكون مرتبطة باستراتيجية المنظمة واتجاهاتها، كما يثبر إلي ارتباط

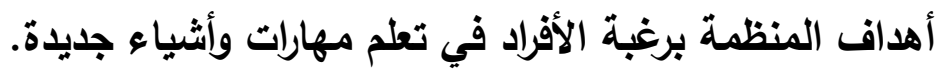


- الاستطلاع والاستفهام questioning: ويضم عناصر للتعرف على طبيعة البيئة التنظيمية الداخلية ومدى وجود العوامل التي تساعد الأفراد على تصحيح نماذجهم الأهنية وتحسين مستوى تطلمهم الفردي والجماعي.

- التمكين empowering: ويشير إلي مدى استخدام الأساليب المناسبة التي تمنح الأفراد فرصا للتعلم، وتعمل على تعزيز عملية التعلم ضمن فرق العمل وكيفية الاستفادة من معارف الأفراد وخبراتهم.

- التقييم evaluating: ويعني الاهتمام بنتائج التصرفات والأعمال التي تتلاعم مع خطط التطوير التظيمي، ومدى افساح المجال لفرق العمل بتقييم نتائج أعمالها ذاتيا.

:Senge model نموذج سينج

حدد سينج (Senge, 1990) خمسة ضوابط (disciplines) للمنظمة

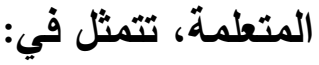
1- التمكن الشخصي personal mastery:

ويقصد به المستوى العالي من الإتقان العلمي والمهني لدى المتخصصين. ويمكن الوصول إلي هذه الارجة من الاحتراف المهني بتبني منهج التعلم المستمر، مما يجعل الفرد قادرا على تحقيق الأهداف المرغوب فيها. ولا تتعلم المنظمات إلا بتعلم أعضائها

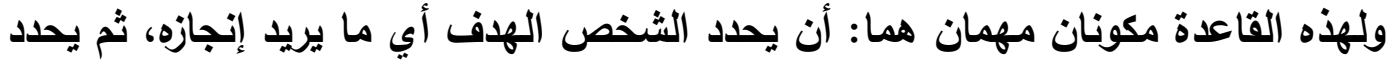
الإجراءات التي تضمن الوصول إلي الهدف. والهدف هنا يكون صالحا على المدى البعيد،

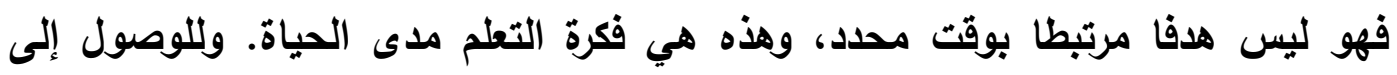

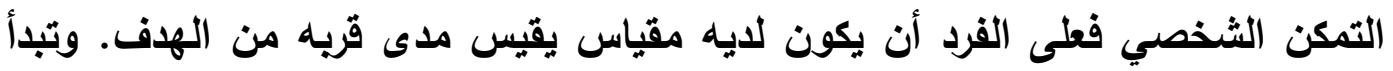
هذه المرحلة عندما لا يقتع المرء بالوضع الحالي، مما يدفعه نحو تغييره. ويتطلب التمكن

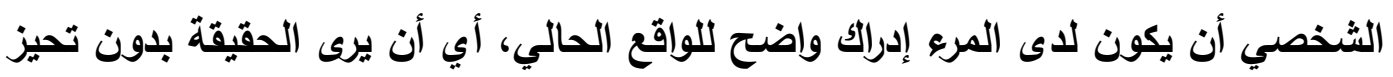

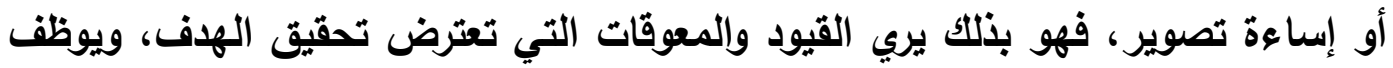

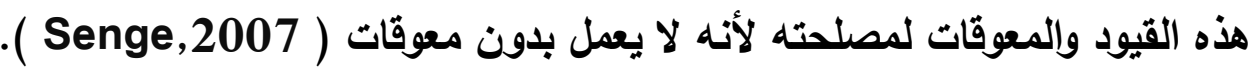
كما يتطلب التمكن الثخص تغييرا في نمط التفكير، واستخدام العقل والحدس

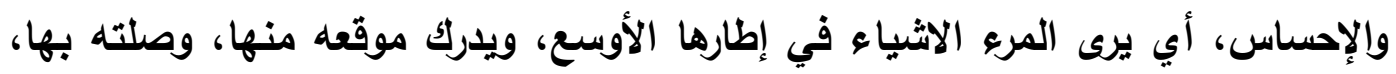

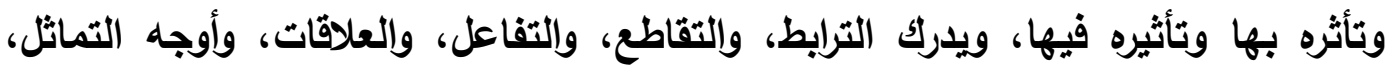


Smith, 1998, ) وإلفروق، وارتباط الجزء بالكل، والكل بالجزء، ومن خلط هذا بذاك

rental models النماذج الذهنية

هي مجموعة الافتراضات والتعميمات والصور التي يحملها أفراد المنظمة وتؤثر

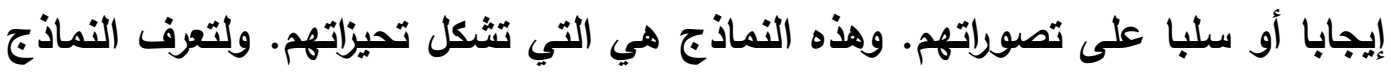
العقلية للعاملين لابد من اختبارها، وذلك بوضعهم في جو من الحوار المستمر لمختلف

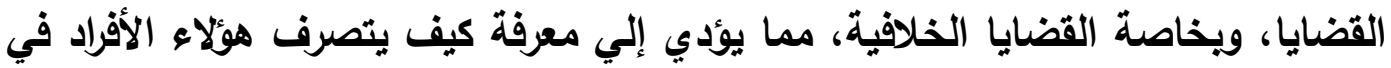
المواقف المختلفة، وأن الفثل في تعرف النماذج العقلية للعاملين يؤدي إلى الفشل في

إيجاد التفكير النظمي في المؤسسة (Senge, 1990; Senge,2000 \& et.al.)

كما أن النماذج الذهنية هي الصوت الاخلي القائل (إذا فعلت كذا بالطريقة كذا سيحث كذا). وتثكل تجارب الحياة عقول الأفراد ونماذجهم الذهنية. ويالمقابل تثكل

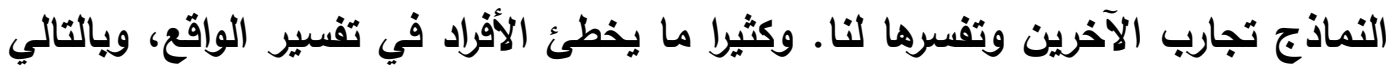
ينصب هجومهم على الأعراض الجانبية لمشكلاتهم بدلا من تعرف الأثياء الحقيقية

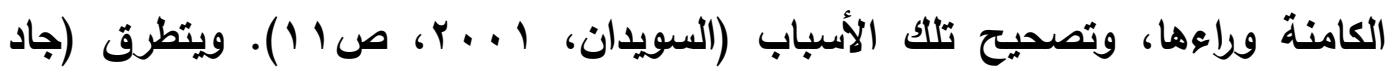

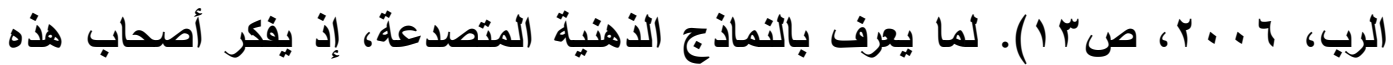

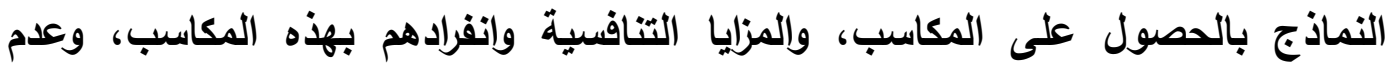
حصول منافسيهم على هذه المزايا والمكاسب، وهذا يعكس مفهوم الصراع السلبي. وهناك

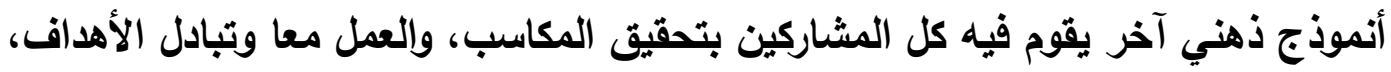

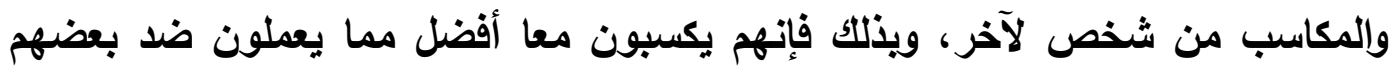
البعض.

ومن الأمثلة على النماذج العقلية السائدة في بعض المدارس روئة الإداريين أن

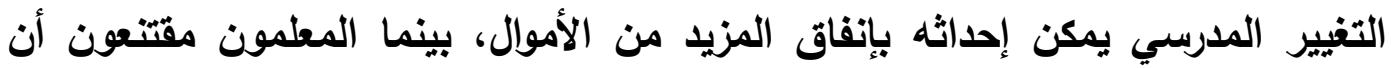

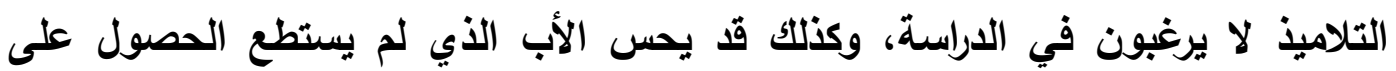

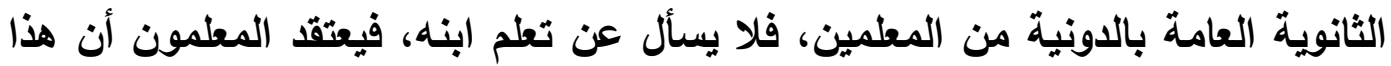

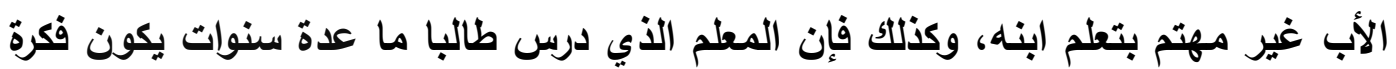

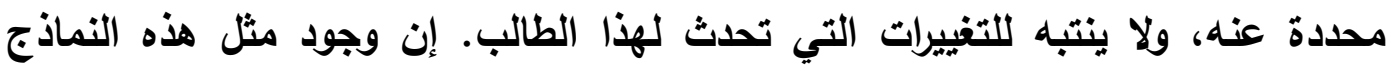

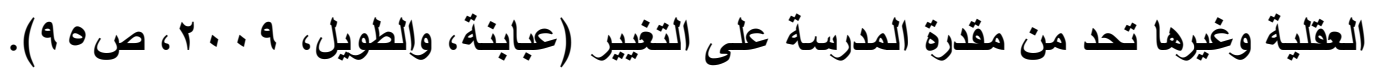


تبدأ الروئة المشتركة من الأفراد. وروئة الأفراد في المنظمة هي شيء ما يمكنه

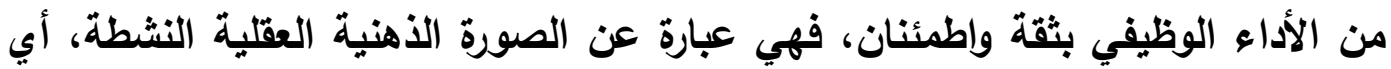
أنها صورة نابضة بالحياة، وغالبا ما تكون هدفا يرغب الأفراد في تحقيقه. وتبني الروائية المشتركة للمنظمة من خلال الروئية الفردية أو الثخصية للعاملين فيها، وللقادة في

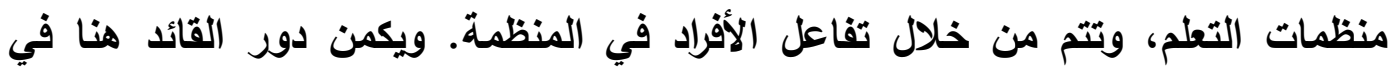

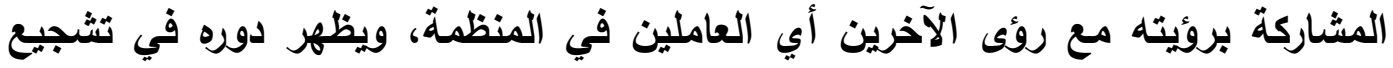

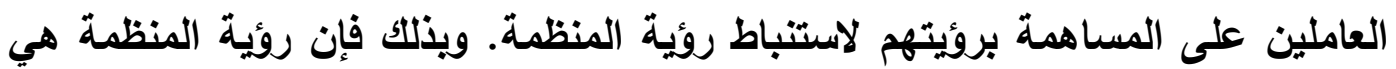
عبارة عن مجموعة الرؤى الثخصية وروئى القادة ورؤى الآخرين، وتذوب هذه الروئى

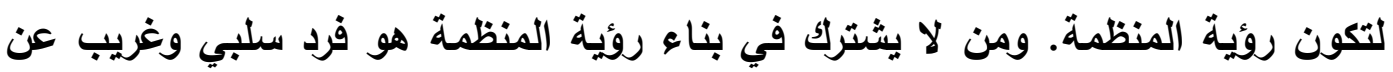

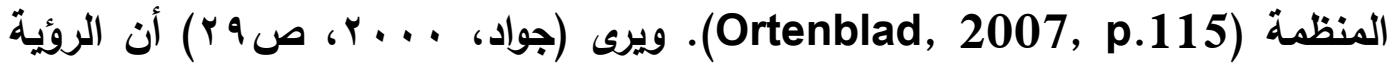
المشتركة، هي صورة جماعية مثلي قابلة للتحقيق في المستقبل، وتبدأ تلك الروئة بفرد

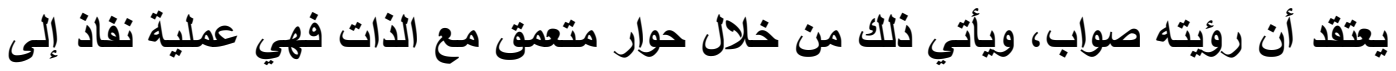
القلب " فالذين ينظرون إلي الخارج يحلمون، والذين ينظرون إلي الادخل يستيقظون". هذه

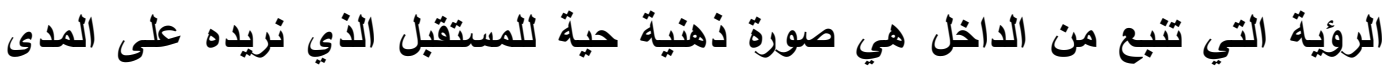

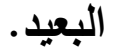

ويشير الواقع إلي أنه عندما تمتلك منظمة روئية مشتركة، ومستوى عاليا من

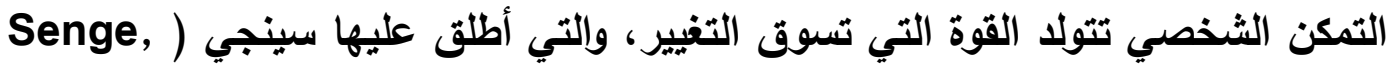

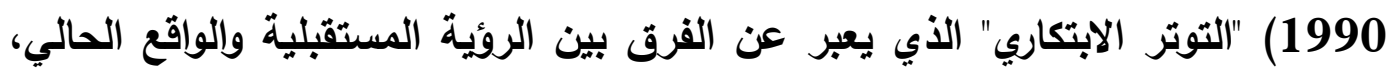
والذي يؤدي مع توفر التزام حقيقي عند الأفراد إلى تحقيق المنظمة المتميزة لأهدافها. وفي حقيقة الأمر، فإنه يمكن الوصول إلي الروئة المشتركة من خلال مناقشة

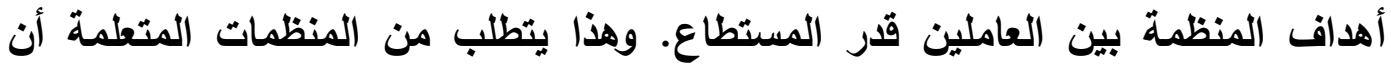

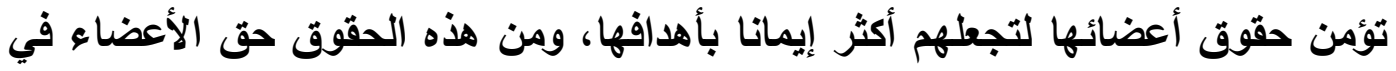
المعرفة والتعلم، والمشاركة في اتخاذ القرارات وخاصة المتعلقة بمصيرهم، وتأمين بيئة

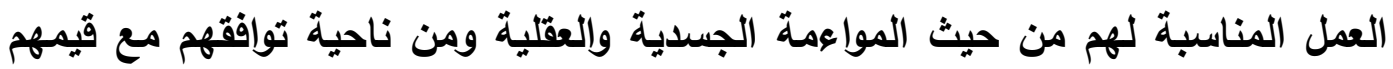
لتكون بيئة مساعدة على الإبداع والتطور، والثعور بالانتماء لمنظومة العمل والمنظمة

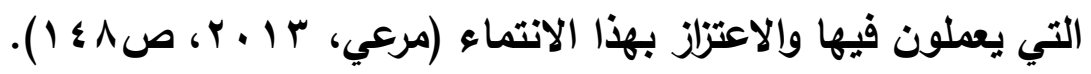




\section{تعلم الفريق team learning:}

يعد الفريق مجموعة من الأفراد يعملون معاً ومكان عملهم هو مكان لإنجازهم معاً،

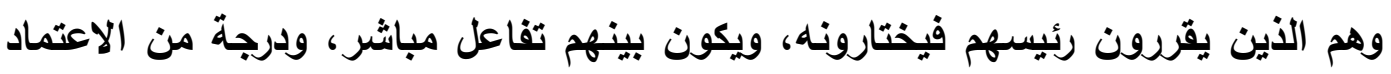

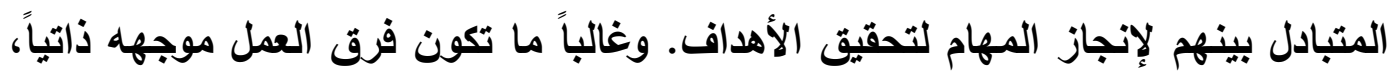

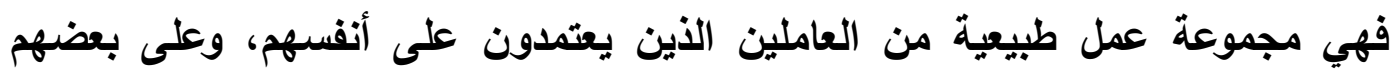
البعض، ويثتركون في معظم أو كل الأدوار المطلوية منهم، وتتوافر لقادتهم مهارات

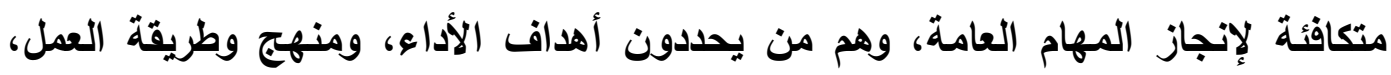
ومحاسبة أنفسهم داخل فرق العمل ( Freed, 2001 ).

ويمكن تحديد أريع مراحل متسلسلة متدرجة يتم المرور بها لتصبح مجموعة الأفراد فريقا يمكن ان يتطموا سويا وهي ما يسمي بشروط تثكيل الفريق، وهذه المراحل تتمثل في (Nonaka \& Takuchi, 1995): - التثكيل forming: أي توفر الحد الأدنى من الحس، والانتماء للفريق، وتبدأ بتحديد

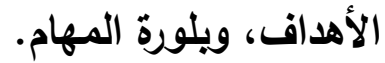
- العصف storming: فبعد التثكيل تبدأ مرحلة مشوية بالتوتر حول القواعد التي

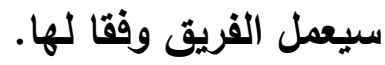

- - التطبيع norming: وتتمثل في تقبل الأدوار وتبلور شعور الفريق، ويتم تبادل

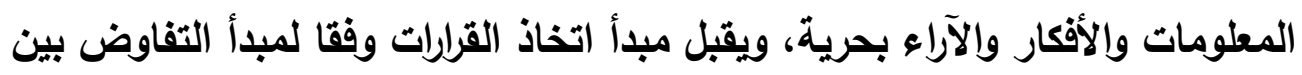

$$
\text { أعضاء الفريق. }
$$

- الأداء performing: وتبدأ هذه المرحلة عندما تتحقى مستويات مثلى في الإنتاج،

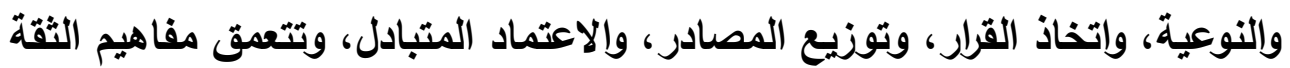

$$
\text { بين الأعضاء. }
$$

وتجدر الإثارة إلى أن التعلم الفريقي هو عملية تنظيم وتطوير قدرات مجموعة

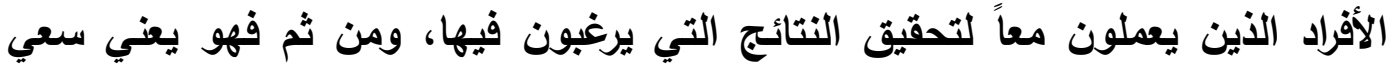

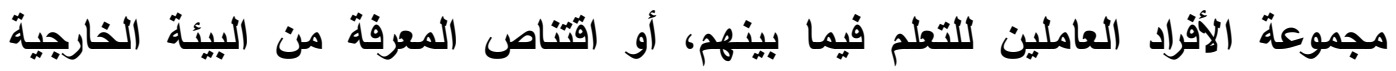

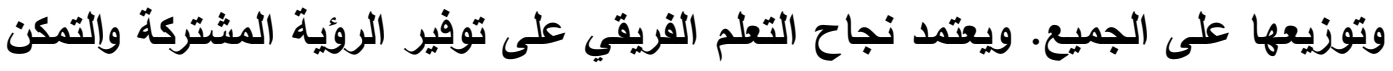

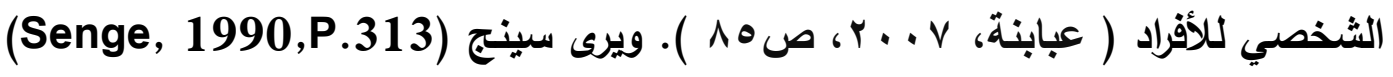


أن وحدة التعلم الأساسية في المنظمات المعاصرة هي الفريق وليس الأفراد. وإذا لم يستطع

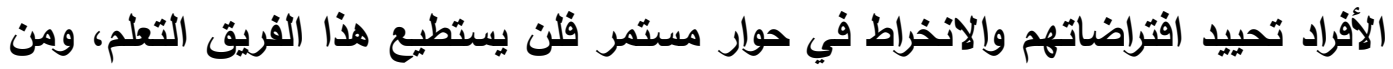

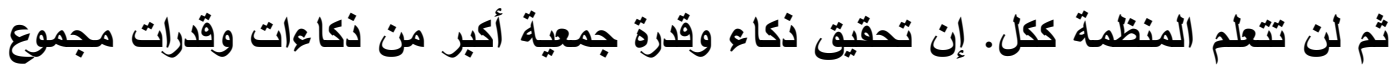
الأفراد، يمكن أن يعزز تعلم الفريق داخل غرفة الصف، حيث يحتاج كل فرد إلى الآخرين لتحقيق هدف متبادل، وهو تطوير مهاراتهم معاً من أجل إنجاح التغيير المدرسي.

كما أن التعلم الفريقي يعد مهارة جماعية يمكن تعلمها وترسيخها عبر توفير

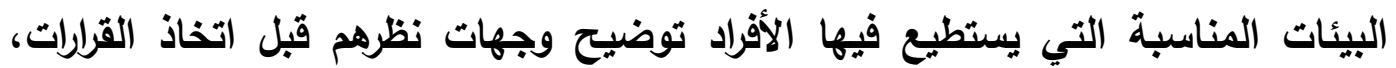
وتوفير وسائل الاتصال باتجاهين لتقييم وتأمل الممارسات التريوية ونقل الخبرات بين العاملين، مما يساعد على إيجاد الظروف المناسبة للعمل التعاوني مع الآخرين، والتعلم منهم، والتعلم معهم، وهذا من شأنه أن يعزز مفاهيم تعلم الفريق، و من ثم تحسين الأداء (الجامعي (Pang, 2003).

وتظهر أهمية فرق التعلم من خلال تأثيرها على المنظمة، إذ تعمل على تثكيل الهوية التظيمية من خلال التفاعل المشترك والعلاقات التي تريط بين الفرق في مختلف

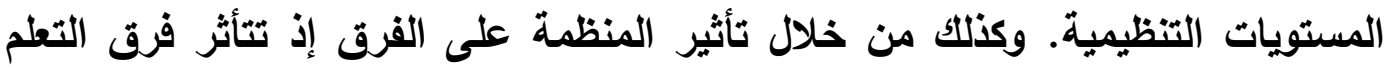
بالنظام الكلي الذي يضم ثقافة المنظمة واستراتيجياتها وسياساتها التنظيمية المختلفة، وتأثرها بأنماط القيادة وخصائصها والبنية التحتية التكنولوجية والمعلوماتية التي توفرها. .(Wu, Chwan\& Jeng, 2002,p.178)

ولكي تستفيد المنظمة من فرق التطلم عليها أن تسعي إلي تحقيق استقلالية الفرق في إدارة وتنظيم ذاتها، وتحديد أهدافها وثقافتها وطريقة عملها مع الابقاء على

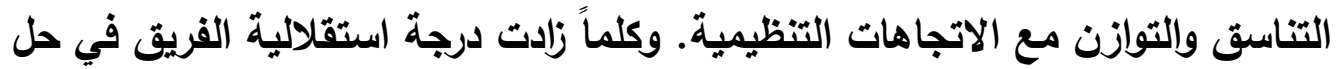
المشكلات، وصنع القرارات، وتحمل المسؤوليات كلما نجح في عملية التعلم بشكل أفضل. هذا ومن الخطأ تكوين فريق التعلم مع بقاء المنظمات على نفس المقدرات والسياسات التظيمية الموجودة، دون سعي إلي تطويرها وتغييرها لتتلاءم مع أوضاع الفرق الجديدة.

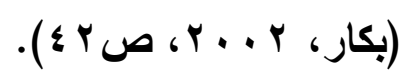

التفكير النظمي systems thinking:

تعود مبادئ هذا المفهوم إلي القرن الثالث الميلادي، وإلى دعوة بلوتينوس الإغريقي plotins إلي روئة الأوضاع، والنظم بشكل كلي، والتعلم من العلاقات التي تريط

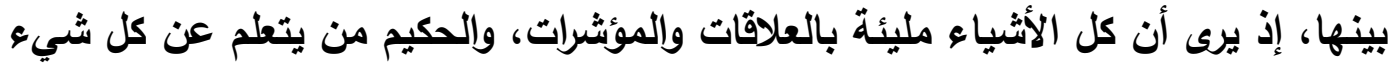


بدلالة الآخر. (Campbell \& Cairns, 1994). ويعتبر سينج Senge من أدخل هذا المفهوم إلي أدبيات المنظمة المتعلمة. ويركز التفكير النظمي على القوى والعلاقات المتبادلة بين أجزاء النظام والتي تؤئر أكثر من العوامل الخارجية على تثكيل سلوكئ سلوك

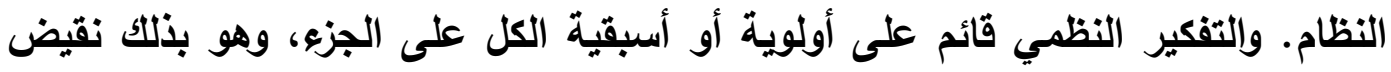

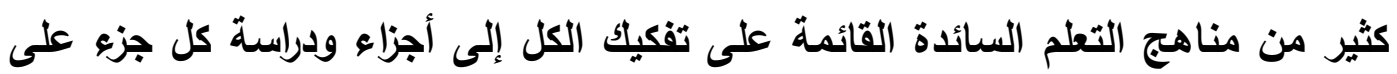
حدة، ثم التوصل إلي استتتاجات تنطبق على الكل. هذه الطريقة الخطية الآلية في التفكير

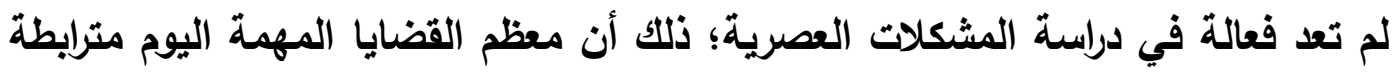
بشكل لا يلاعم. السببية الخطية، والبديل هنا هو السببية الدائرية إذ يكون كل متغير سببا هنا ونتيجة هناك كالعلاقة بين الاقتصاد والبطالة مثلاً. وما يميز النظام أنه لا يمكن فهمه لهابه بمعزل عن مكوناته، إذ لا يعتمد سلوك النظام على ما يقوم به كل جزء فيه، بل على

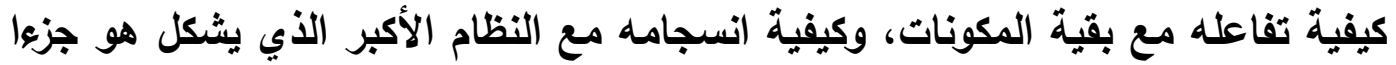
منه، ومعنى ذلك أنه قد تكون هناك عوامل خارج السياق المباشر للنظام وتؤئر فيه

.(Senge, 2007)

ومن الجدير بالذكر أن التفيرات السريعة والمستمرة في مكونات وعلاقات الأنظمة جعلت من الصعوية بمكان التتبؤ بهذه التغيرات وتوقع سلوكياتها، مما أضعف مقرة النماذج الذهنية للأفراد على فهم طبيعة المنظمات الكبيرة والمعقدة واستيعاب جذور مشكلاتها، ومن هنا أصبح من المهم اتخاذ أنماط تفكيرية حديثة للنظر إلي المنظمة ككل

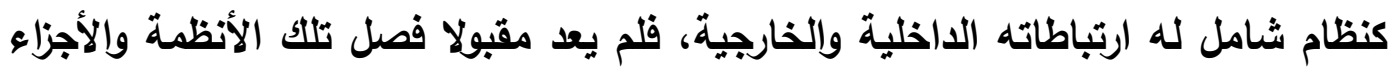
ودراستها منفصلة عن النظام الكلي (Mckenna, 1995). ومن هنا ظهرت الحاجة

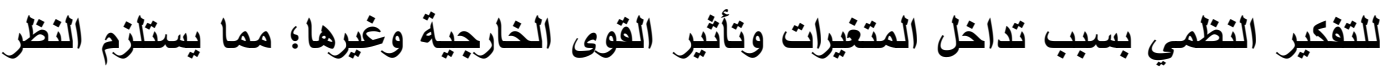
إلى الكل وليس الجزء. ويمجرد قبول التفكير النظمي يمكن تحسين تعلم الأفراد ليتوجهوا نحو فهم النظام ككل من خلال دعم الأفراد بالمهارات والأدوات التي تمكنهم من التعلم، ومن فهم وملاحظة أنماط السلوك السائدة في النظم التي يعملون فيها (جاد الرب،

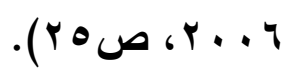

ويؤكد سينج (Senge, 1990) على أهمية التفكير النظمي، إذ إنه يساعد على تجنب وضع الحول المؤقتة المنفصلة للمشكلات في المنظمة، ويسمح بحدوث فهم أفضل المبه لثبكة العلاقات بين وحدات المنظمة وأفرادها، مما يؤدي إلي حلول ناجحة للمشكلات، ويضمن شمولية إحاث التغيير اللازم والانطلاق الأسلم نحو المستقبل. إن التفكير النظمي هو القادر على فهم التداخلات والتفاعلات في النظم التريوية الدينامية المعقدة. 
ويحتاج ذلك التفكير إلي قادة يستطيعون روئة كل جامعة بوصفها منظمة معقدة

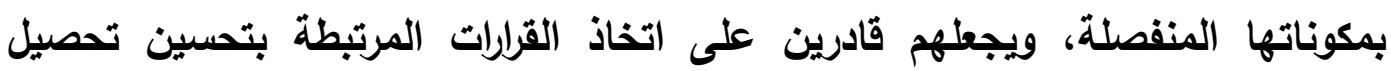
الطلاب، وهكذا يصبح التفكير النظمي مندمجا في العملية التريوية. ) Thornton \& (Perreautt, 2004, p. 225

وفي حقيقة الأمر فإن لمدخل التفكير النظمي تطبيقات عملية في الواقع الملموس،

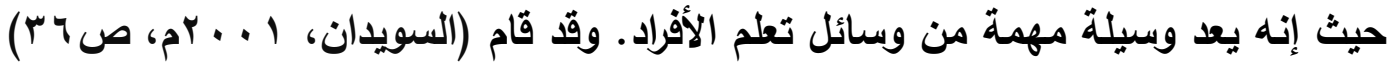

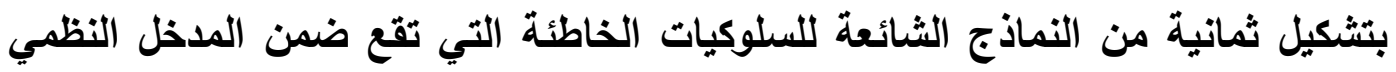
والتي اعتبرت كأدوات للتشخيص وإيجاد الحلول وهئ وهي: 1- الحلول الفاشلة (fixes that fail): ويقصد بها استخدام حلول قصيرة الأمد

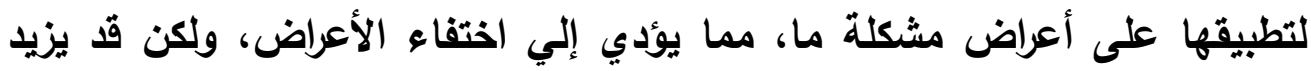
المشكلة الكامنة وراءها.

r- مأساة الاشتراك (tragedy of the commons): ويُعنى بها محاولة كل فرد مضاعفة منافعه بأقصى درجة ممكنة لصالحه هو، وعندها يعاني الجميع ويصبحون في مشكلة لأن كل فرد يسعى لتحقيق مصالحة هو وحده فقط. r- التصعيد (escalation): إذ تقوم منظمة ما بتصرف ما تفسرة منظمة أخرى على أنه تهديد لها، لذا فإنها ترد عليه بتصرف يمثل تهايدا أكبر، ويهذا تتوالى أفعال التصعيد وردود الأفعال حتى يفقد كل منهما السيطرة.

צ - تحويل الأعباء (shifting the burden): ويحدث عندما تتحقق نتائج إيجابية نتيجة إجراء قصير المدى، مما يشجع على إعادة استخدام هذا الإجراء لعدة مرات،

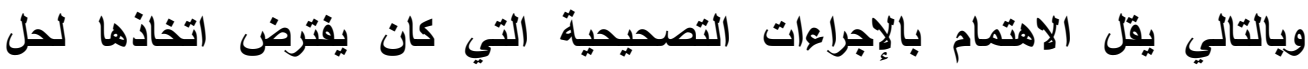
المثكلة، فتفق الإجراءات الأولى جدوالها مع الزمن.

ه- حدود النجاح (limits to growth): وهي عملية هدفها تسريع النمو أو التوسع لمرحلة ما ثم يبدأ هذا النمو بالتباطؤ إلي مرحلة التوقف أو الانهيار، فمرحلة النمو

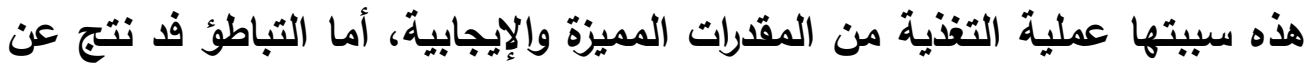

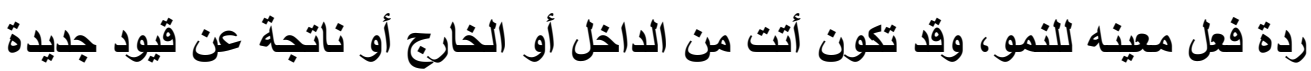

فرضت نفسها.

צ- النجاح للناجحين (success to the successful): فالنجاح يولد نجاحاً، فمن يحصل على دعم أكثر تزيد لايه احتمالات النجاح، مما يجعله يحصل على موارد 
أكبر في المستقبل، وفي نفس الوقت فإن من كانوا أقل حظاً ستكون احتمالات فشلهر في المستقبل أكثر.

V الأهداف الضائعة (eroding goals): في بعض الأحيان تغفل المنظمة عن أهدافها الأساسية التي أنثئت من أجلها في خضم ما تواجهه من تحديات وضغوطات كثيرة.

1- النمو وإنفاض الاستثمار (growth and under investment): إذ تصل المنظمة إلي قمة النمو، ثم تبدأ بتخفيض المستوى لاستيعاب المزيد من النمو بدلا

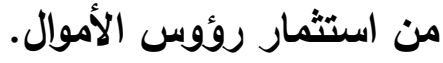
معوقات التحول نحو المنظمة المتعلمة:

يرى (السالم، 1 . . Y، ص T T)، وجود معوقات تحول دون تطبيق أبعاد المنظمة

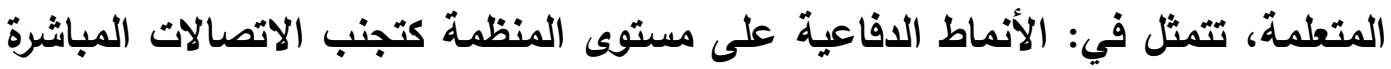
والمناقثات العلنية بخصوص الموضوعات الحساسة، والسيطرة على المناقشات العامة من أجل تجنب أو منع ظهور المشاعر السلبية، والاحتفاظ بوجهة النظر الخاصة وعدم التصريح بها أمام الآخرين، وعدم انتظام المعلومات ودقتها، وعدم توافر الوقت والمال

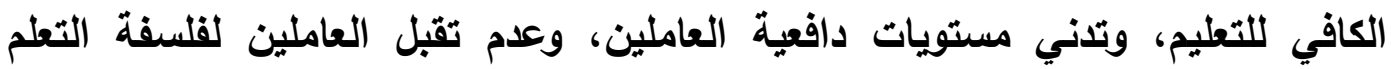

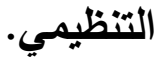

كما أن هناك معوقات أخرى تحول دون تحقيق التعلم التظيمي، يمكن تصنيفها

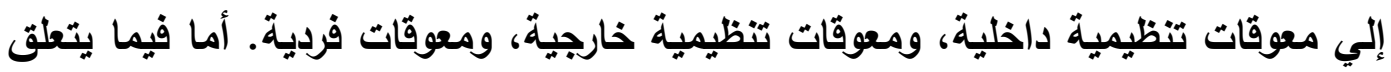

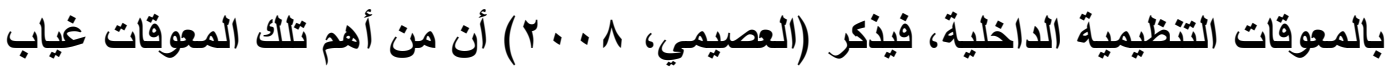

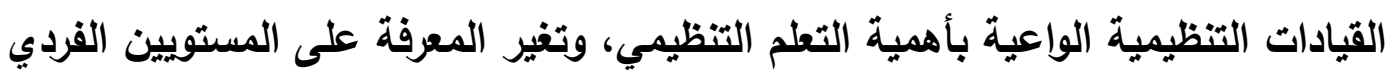

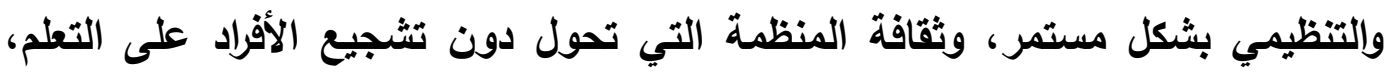

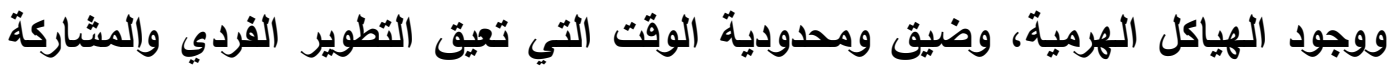
الجماعية. وأما ما يرتبط بالمعوقات التنظيمات الخارجية فيذكر (العصيمي، 1 . . rم) أيضا

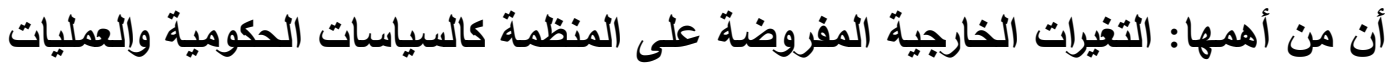

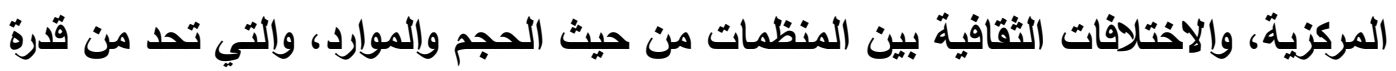
المنظمة المتعلمة على التعلم من تجارب المنظمات الأخرى. ويالنسبة للمعوقات الفردية فيذكر (Lee, 2004) أن من أبرزها: قلة بناء فرق العمل، وضعف نظام الاتصال بين الموظفين، وتجزئة القسم إلي عدة دوائر، والاعتقاد 
الخاطئ لاى المديرين بأن التعلم التظيمي يتطلب فقط عقد الدورات التي تثقل كاهل ميزانية المنظمة، وضعف المعرفة بالتفكير المنظمي، ومحدودية معرفة المديرين بالتعلم

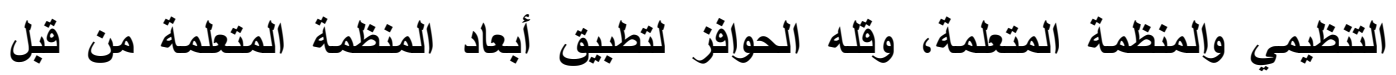
المديرين في القطاع العام.

ويالإضافة إلى ما سبق، فإن من أهم معوقات بناء المنظمة المتعلمة: الروتين

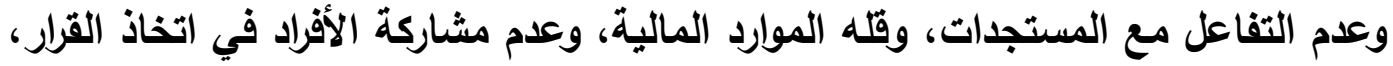

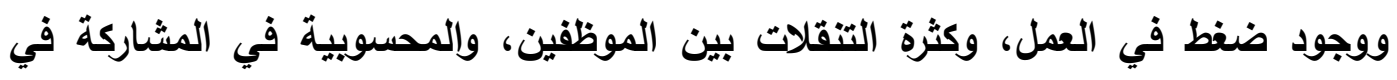
الادورات التدريبية، فضلا عن وجود أفراد يقاومون التغيير · O'connor \& Kotze, ) .(2008, p.176 


\section{الدراسة الميدانية}

\section{أولا: أهداف الدراسة الميدانية.}

تستهـف الاراسـة الميدانيـة التعرف على مدى توفر أبعاد المنظمـة المتعلمـة في جامعة الأزهر من وجهة نظر أعضاء هيئة التدريس.

\section{ثانيا: أداة الدراسة الميدانية.}

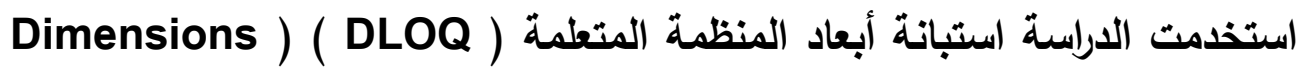
( of Learning Organization Questionnaire

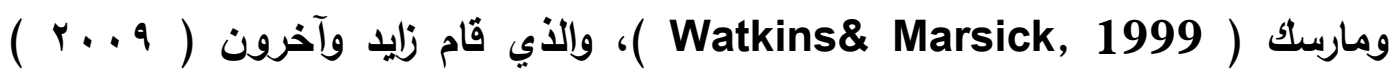

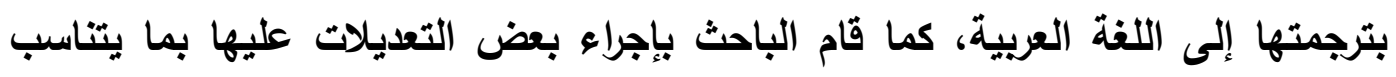

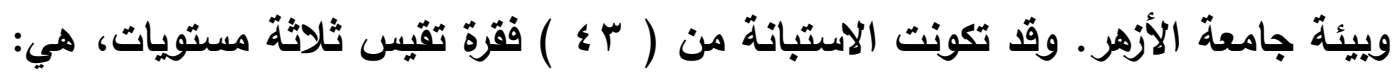

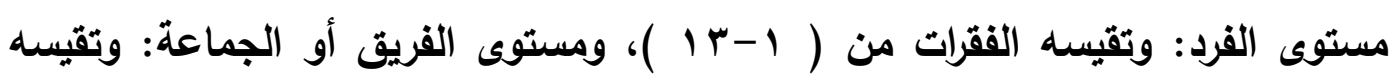

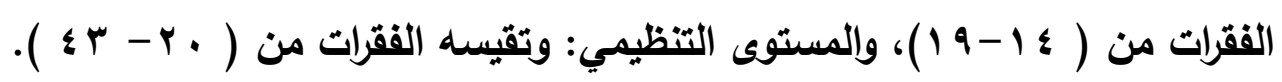
1- أوصف أداة الدراسة:

تكونت أداة الدراسة من ثلاثة محاور ، وقد كان المحور الأول بعنوان مستوي الفرد،

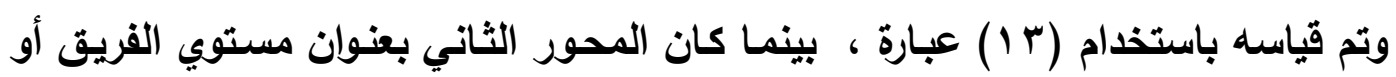

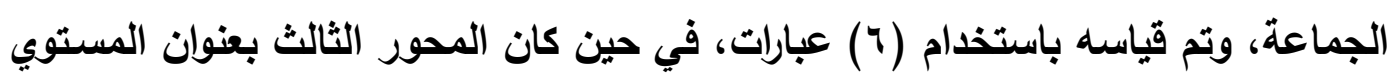

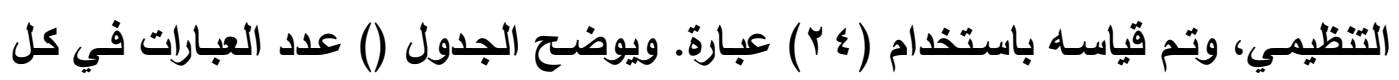

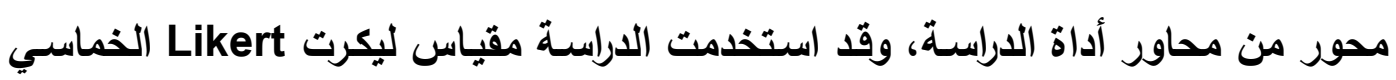
لتحديد درجة توفر أبعاد المنظمة المتعلمة في جامعة الأزهر من وجهة نظر أعضاء لوراء هيئة التدريس.

جدول (ץ) وصف أداة الدراسة

\begin{tabular}{|c|c|c|}
\hline عدد العبار ات & 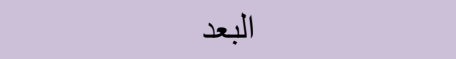 & 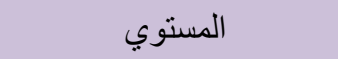 \\
\hline v & إيجاد فرص للتعلم المستمر & \multirow{3}{*}{ مستوي الفرد } \\
\hline 1 & تشجيع الحوار و الاستفسار & \\
\hline 14 & 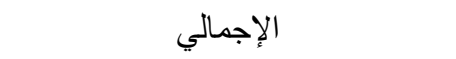 & \\
\hline 1 & تشجيع التعلم و التعاون الجماعي & مستوي الفريق أو الجماعة \\
\hline 1 & إنشاء أنظمة مشاركة المعرفة و التعلم & المستوي التنظيمي \\
\hline
\end{tabular}




\begin{tabular}{|c|c|}
\hline 7 & تمكين الأفراد من رؤية جماعية مشتركة \\
\hline 7 & ربط المنظمة بالبيئة الخارجية \\
\hline 7 & القيادة الاستر اتيجية الداعمة للتعلم \\
\hline$r \leqslant$ & 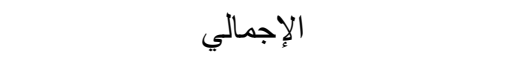 \\
\hline$\varepsilon r$ & أد أداة الدر اسة \\
\hline
\end{tabular}

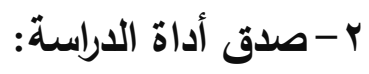

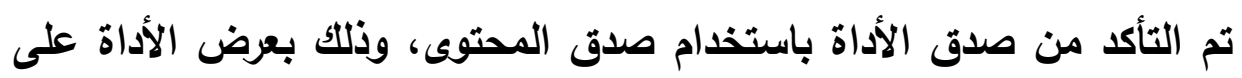

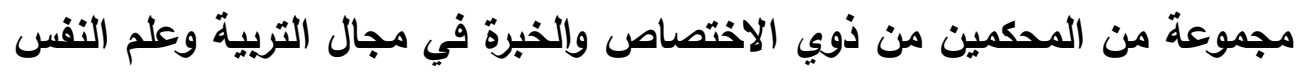

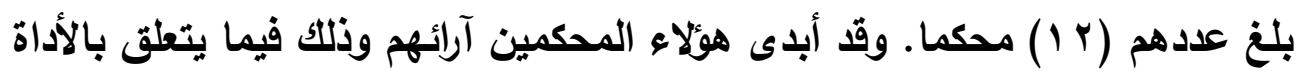

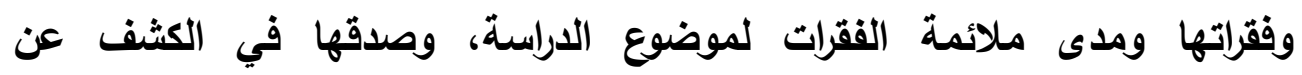
المطلومات المرغوية للاراسة، وكنلك من حيث ترابط كل فقرة بالمحور المندرجة تحته، ومدى وضوح الفقرة وسلامة صياغتها واقتراح طرق تحسينها بالإثارة

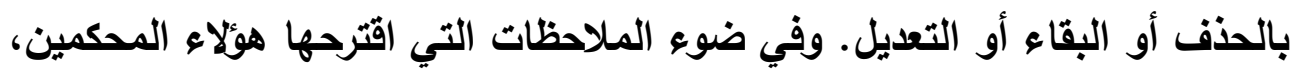
أجريت بعض التعديلات على الصياغة اللغوية لبعض الفقرات، واحتفظت الاستبانة بفقراتها كاملة من غير حذف أو إضافة.

ب- بات أداة الدراسة Reliability:

قام الباحث بحساب ثبات العوامل المستخرجة من الأداة باستخدام معادلة ألفا كرونباخ علي أفراد العينة كما هو موضح في الجدول التالي: جدول (r) معاملات ألفا كرونباخ لثبات أداة الدراسة

\begin{tabular}{|c|c|c|c|}
\hline الصدق الذاتي & معامل الفا كرونباخ & 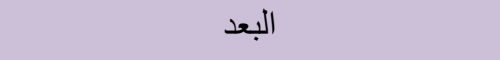 & 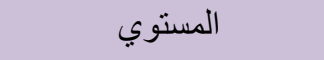 \\
\hline$\cdot 91$ & $\cdot \wedge \varepsilon$ & إيجاد فرص للتعلم المستمر & \multirow{3}{*}{ مستوي الفرد } \\
\hline$\because 9$ & $\cdot . \wedge$ & تشجيع الحوار و الاستفسار & \\
\hline .90 & $\because 9$. & 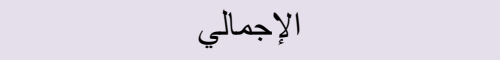 & \\
\hline .94 & $\cdot . \wedge 4$ & تشجيع التعلم و التعاون الجماعي & مستوي الفريق أو الجماعة \\
\hline .90 & $\because 9$. & إنشاء أنظمة مشاركة المعرفة و التعلم & \multirow{3}{*}{ المسنوي التنظيمي } \\
\hline .97 & .94 & تمكين الأفراد من رؤية جماعية مشتركة & \\
\hline .97 & $.9 r$ & ربط المنظمة بالبيئة الخارجية & \\
\hline
\end{tabular}




\begin{tabular}{|c|c|c|c|}
\hline .97 & $\cdot .94$ & القيادة الاستر اتيجية الداعمة للتعلم & \\
\hline .911 & $\because .9 v$ & 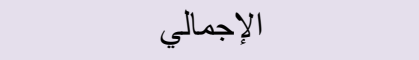 & \\
\hline .99 & $\cdot .9 \mathrm{~V}$ & \multicolumn{2}{|c|}{ إجمالي أداة الدراسة } \\
\hline
\end{tabular}

يتضح من الجدول السـابق أن قيمة معامل ألفا كرونباخ لثبات أداة الدراسـة قد بلغت

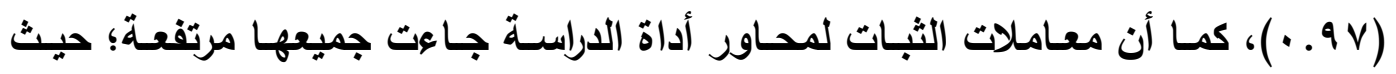

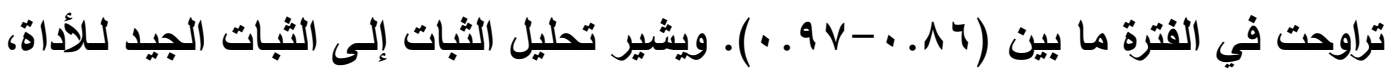
ويالتـالي الثقة في نتائج الاراسـة الميدانيـة وسـلامة البنـاء عليها. كمـا يتضـح من ذات الجدول أن الصدق الذاتي لأداة الدراسـة قد بلـغ (99. . .)، كما أن الصدق الذاتي لمحاور أداة الدراسة جميعها جاء مرتفعا؛ حيث تراوح في الفترة ما بين (ب و . . - 9 . .).

\section{ثالثً: هجتمع وعينة الدراسة الميدانية:}

قام الباحث بتطبيق أداة الدراسة علي عينة بلغ قوامها ( . . ع ) عضوا من أعضاء

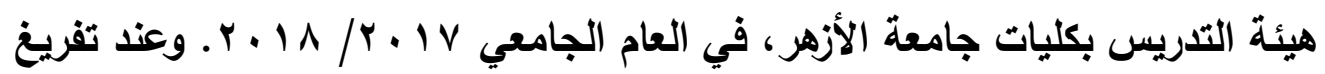
البيانات تم استبعاد استمارات المفحوصين الذين لم يكملوا البيانات الأولية، أو الذين لم يستجيبوا على بعض أجزاء الأداة، ومن ثم أصبحت العينة النهائية ( ( M ) عضو هيئة تلريس، وفيما يلي وصف العينة المستفتاة بحسب متغيرات الدراسة: • وصف عينة الاراسة بحسب كليات الجامعة: جدول (ع) وصف عينة الاراسة بحسب كليات الجامعة

\begin{tabular}{|c|c|c|}
\hline النسبة المئوية & 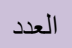 & 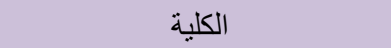 \\
\hline$\% \leqslant . V Y$ & 11 & لغة عربية الزقازيق \\
\hline$\%$ r. 10 & ir & أسنان بنين \\
\hline$\%$ \%.TV & $1 \varepsilon$ & علوم بنات \\
\hline$\%$ \%.Tr & 1. & الإعلام بنين القاهرة \\
\hline$\% \varepsilon . V Y$ & 11 & لغة عربية بنين جرجا \\
\hline$\% 0.01$ & r) & در اسات إسلامية بنات سو هاج \\
\hline$\%\urcorner . r$. & $r \varepsilon$ & بنات أسيوط \\
\hline$\%$ \%.tr & 1. & تجارة بنين القاهرة \\
\hline$\% 11 . \wedge 1$ & $\leq 0$ & كلية الدر اسات الإسلامية و العربية بنين \\
\hline$\% \circ . V V$ & rr & $\begin{array}{c}\text { الدر اسات الإسلامية و العربية بنات } \\
\text { الاسكندرية }\end{array}$ \\
\hline$\%$ \%.qะ & 10 & در اسات إسلامية بنات دمنهور \\
\hline
\end{tabular}




\begin{tabular}{|c|c|c|}
\hline$\% \leq . r$. & 17 & شريعة وقانون بنين دمنهور \\
\hline$\% \leqslant . Y Y$ & 11 & كلية تربية بنين القاهرة \\
\hline$\% r . q \leq$ & 10 & كلية العلوم بنين القاهرة \\
\hline$\%$ o.ro & $r \cdot$ & در اسات إسلامية بنات القاهرة \\
\hline$\left.\% r_{.}\right)$. & $\wedge$ & أسنان بنات القاهرة \\
\hline$\%$ \%.ru & 9 & كلية الدعوة القاهرة \\
\hline$\%$ \% ro & $r \cdot$ & كلية الدراسات الإنسانية بنات القاهرة \\
\hline$\%$ \%.TV & $1 \leq$ & لغة عربية إيناي البارود بنين \\
\hline$\%\urcorner . r$. & $r \varepsilon$ & تربية تفهنا الأشر اف \\
\hline$\%$ \%.Tr & 1. & شرعي وعربي بحري \\
\hline \%ฯ.Tท & $1 \leq$ & كلية الهندسة بنين قنا \\
\hline$\% \cdot . r q$ & 1 & شر عي و عربي قبلي \\
\hline$\% \cdot . \vee q$ & r & كلية الإعلام \\
\hline$\% 1 \ldots \ldots$ & rᄉl & ال الإجمالي \\
\hline
\end{tabular}

\section{• وصف عينة الدراسة بحسب متفيرات الدراسة:}

\section{جدول (0) وصف عينة الدراسة بحسب متغيرات الدراسة}

\begin{tabular}{|c|c|c|c|}
\hline النسبة المئوية & 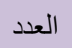 & \multicolumn{2}{|c|}{ المتغير } \\
\hline$\% 71.9 \leq$ & דוד & بنين & \multirow{2}{*}{ 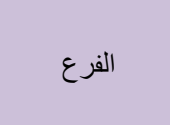 } \\
\hline$\%$ \%. . ч & $1 \leq 0$ & 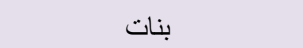 & \\
\hline$\% 01.11$ & $19 V$ & شر عية و عربية & \multirow{3}{*}{ نوع الكلية } \\
\hline$\%$ \%.V & $|r|$ & 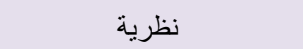 & \\
\hline$\% 17.0 \leq$ & 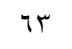 & عملية & \\
\hline$\%$ \%..^ & $1 \cdot v$ & 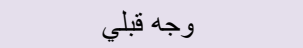 & \multirow{3}{*}{ الموقع الجغر افي } \\
\hline$\% \varepsilon \cdot .7 \wedge$ & 100 & عاصمة & \\
\hline \%Mr. & 119 & وجه بحري & \\
\hline$\% \leqslant r . \wedge r$ & 178 & مدرس & \multirow{3}{*}{ الرتبة الأكاديمية } \\
\hline$\%$ \%^.ro & $1 \cdot 1$ & أستاذ مساعد & \\
\hline$\%$ \% .Ar & 1.7 & 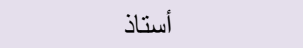 & \\
\hline \%rr.r人 & IrT & شغلت أو أشغل منصبا إداريا & \multirow{2}{*}{ المركز الوظيفي } \\
\hline \%rv.Vr & ron & لم أثثل منصبا إداريا & \\
\hline$\% 1 \ldots$. & rᄉl & \multicolumn{2}{|c|}{ 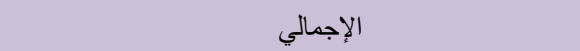 } \\
\hline
\end{tabular}


- وصف عينة الدراسة بحسب متغير الفرع ( بنين/ بنات ):

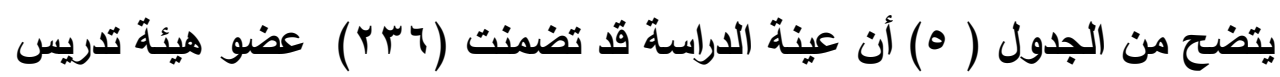

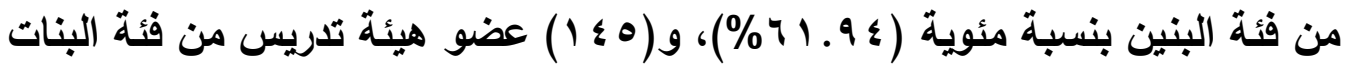

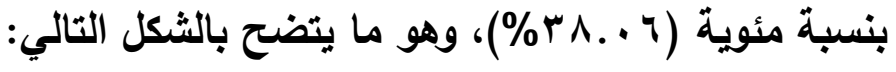

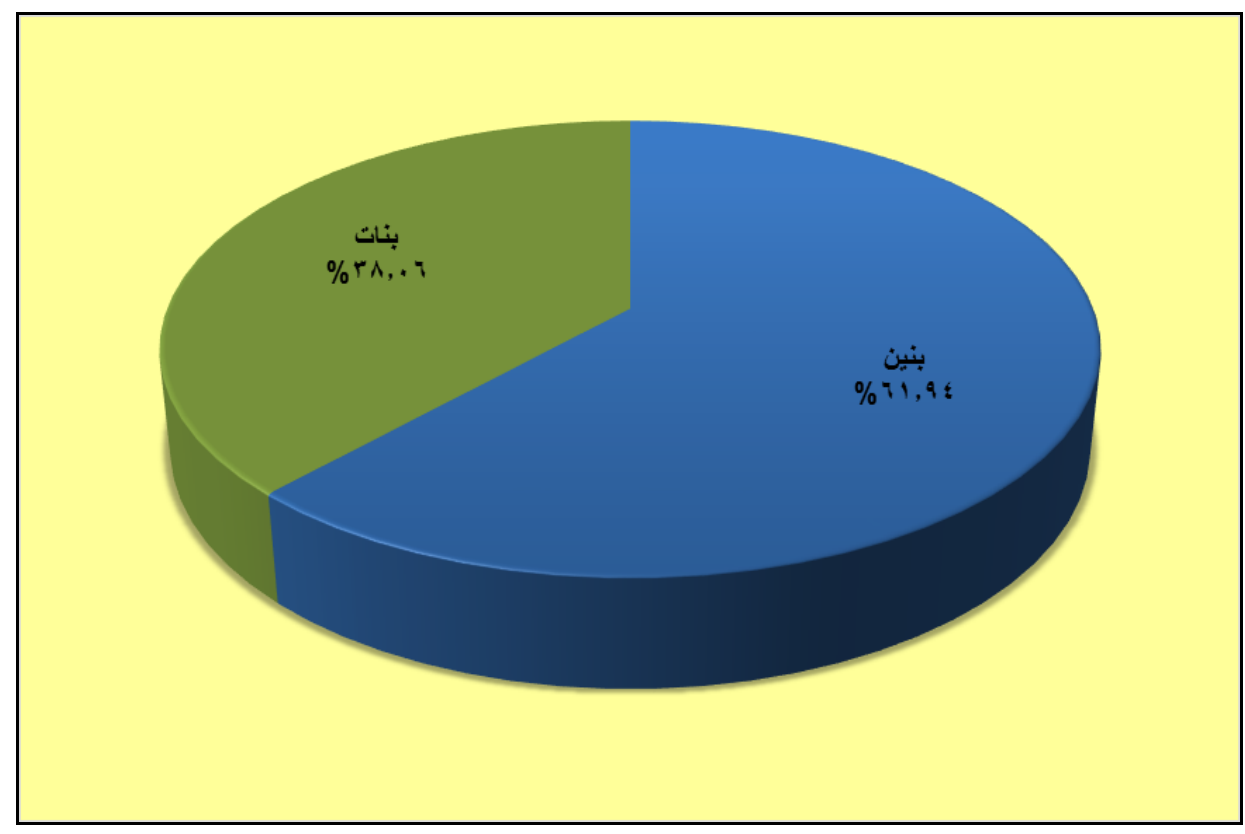

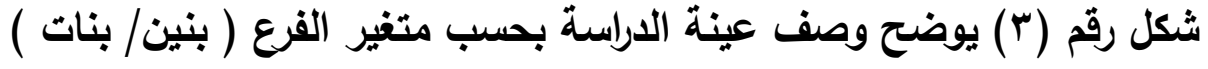
- وصف عينة الاراسة بحسب متغير نوع الكلية ( شرعية وعربية/ نظرية/ عملية يتضح من الجدول ( •) أن عينة الدراسة قد تضمنت (9v l ) عضو هيئة تدريس من

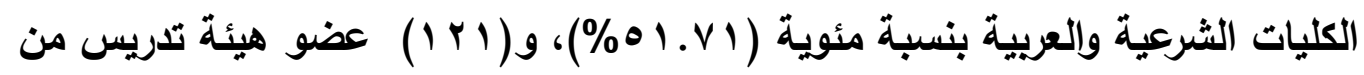

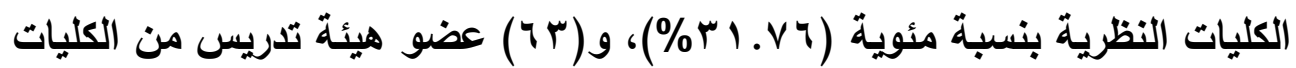
العملية بنسبة مئوية (؛ ه. 1 (\%\%)، وهو ما يتضح بالثكل التالي. 


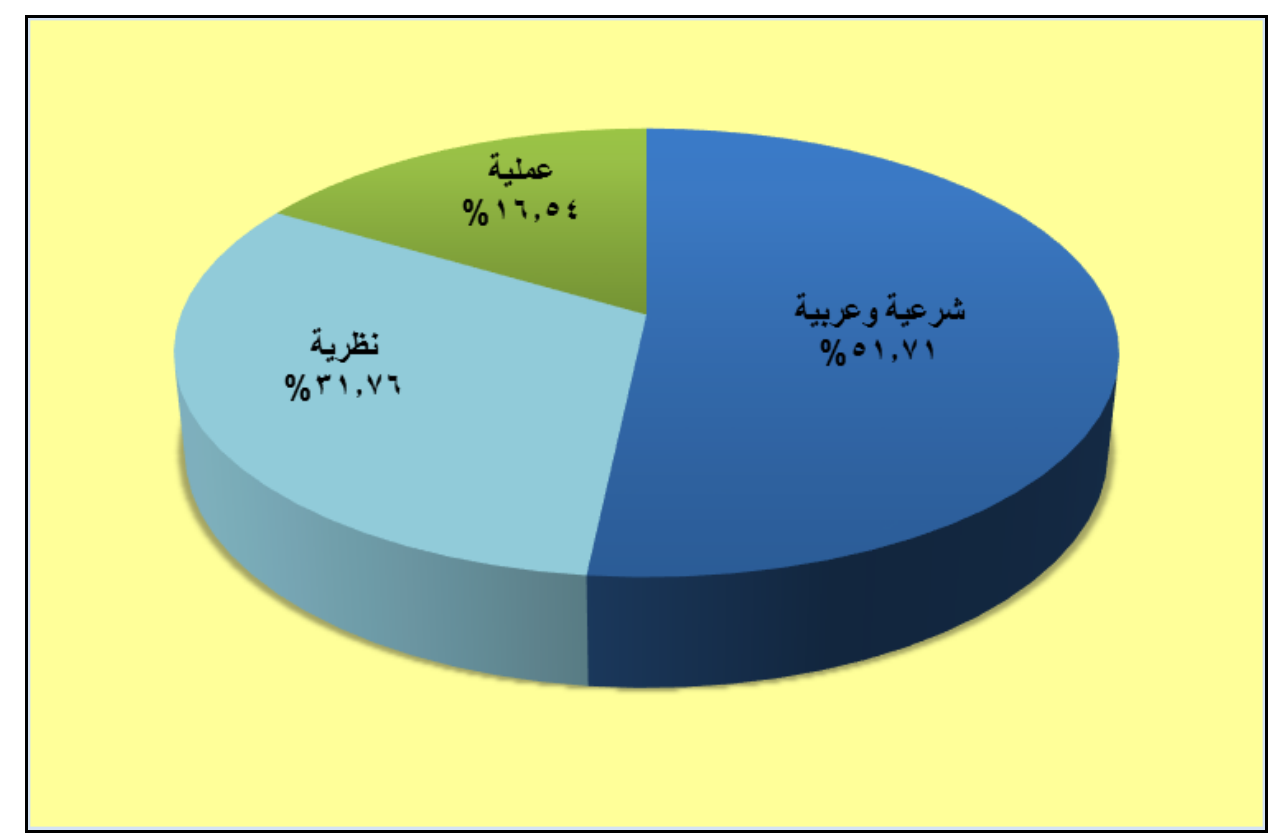

شكل رقم (؛ ) يوضح وصف عينة الاراسة بحسب متغير نوع الكلية( شرعية

وعربية/ نظرية/ عملية )

- وصف عينة الدراسة بحسب متغير الموقع الجغرافي ( قبلي/ عاصمة/ بحري ):

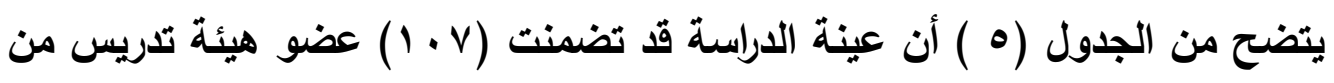

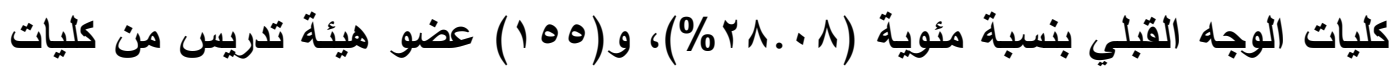

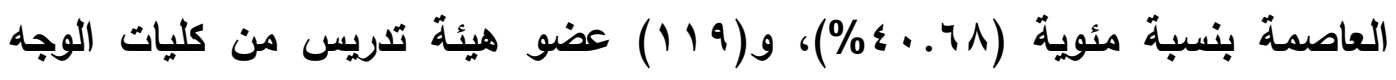

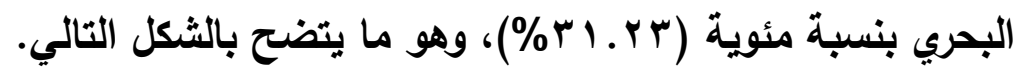

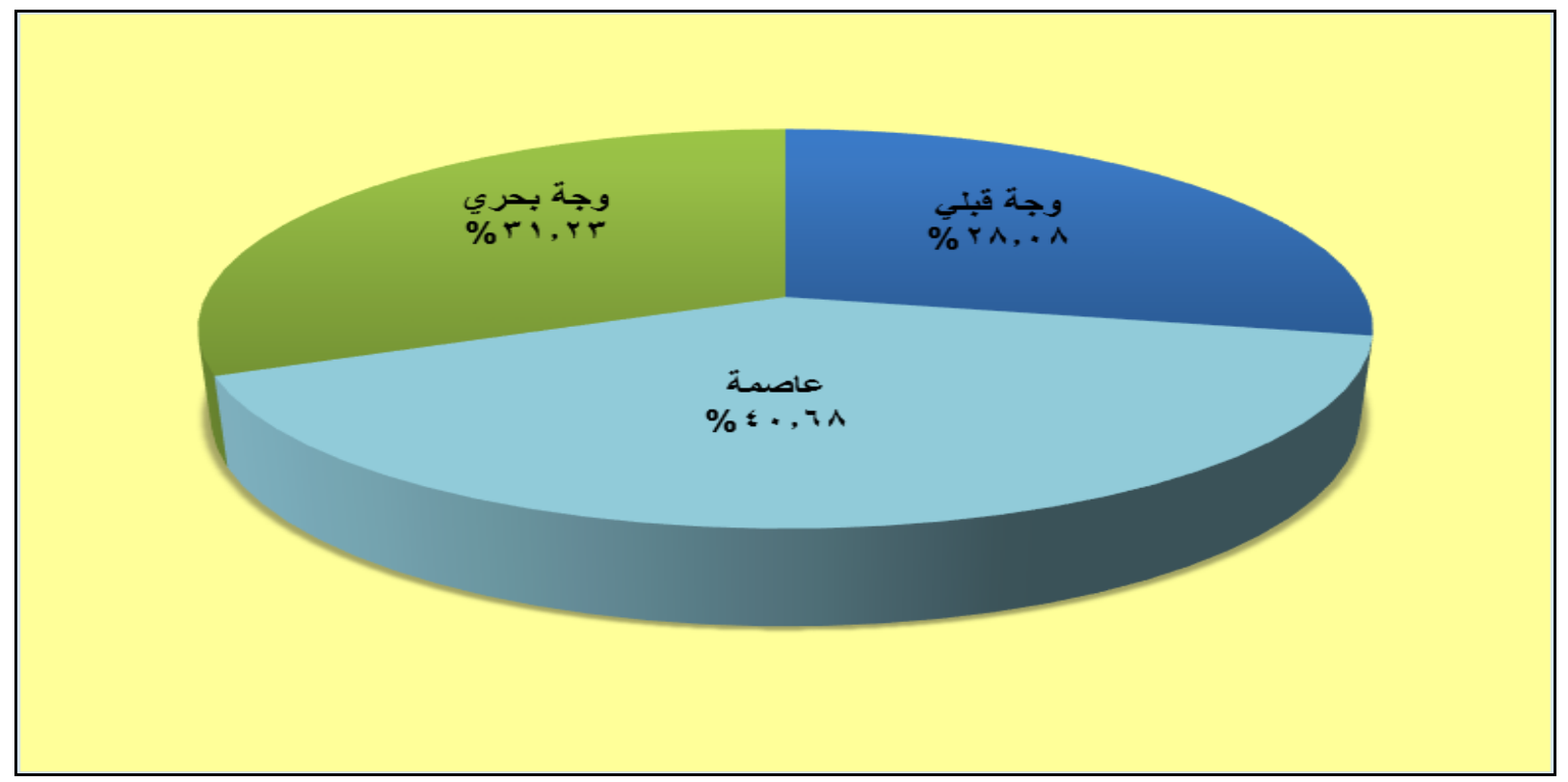


شكل رقم (0) يوضح وصف عينة الدراسة بحسب متغير الموقع الجغرافي( قبلي/ عاصمة/ بحري )

- وصف عينة الدراسة بحسب متغير الرتبة الأكاديمية ( مدرس/ أستاذ مساعد/

(أستاذ ):

يتضح من الجدول ( 0) أن عينة الدراسة قد تضمنت (IVV) مضو هيئة تدريس

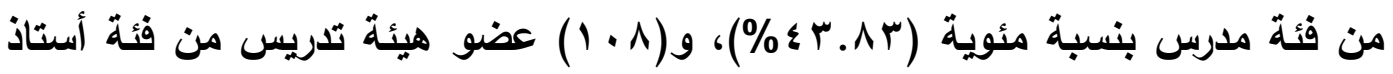

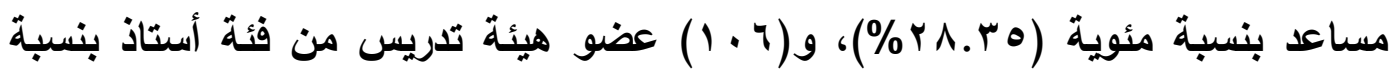

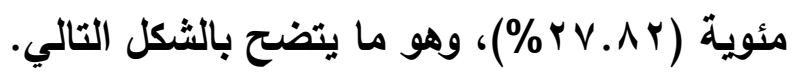

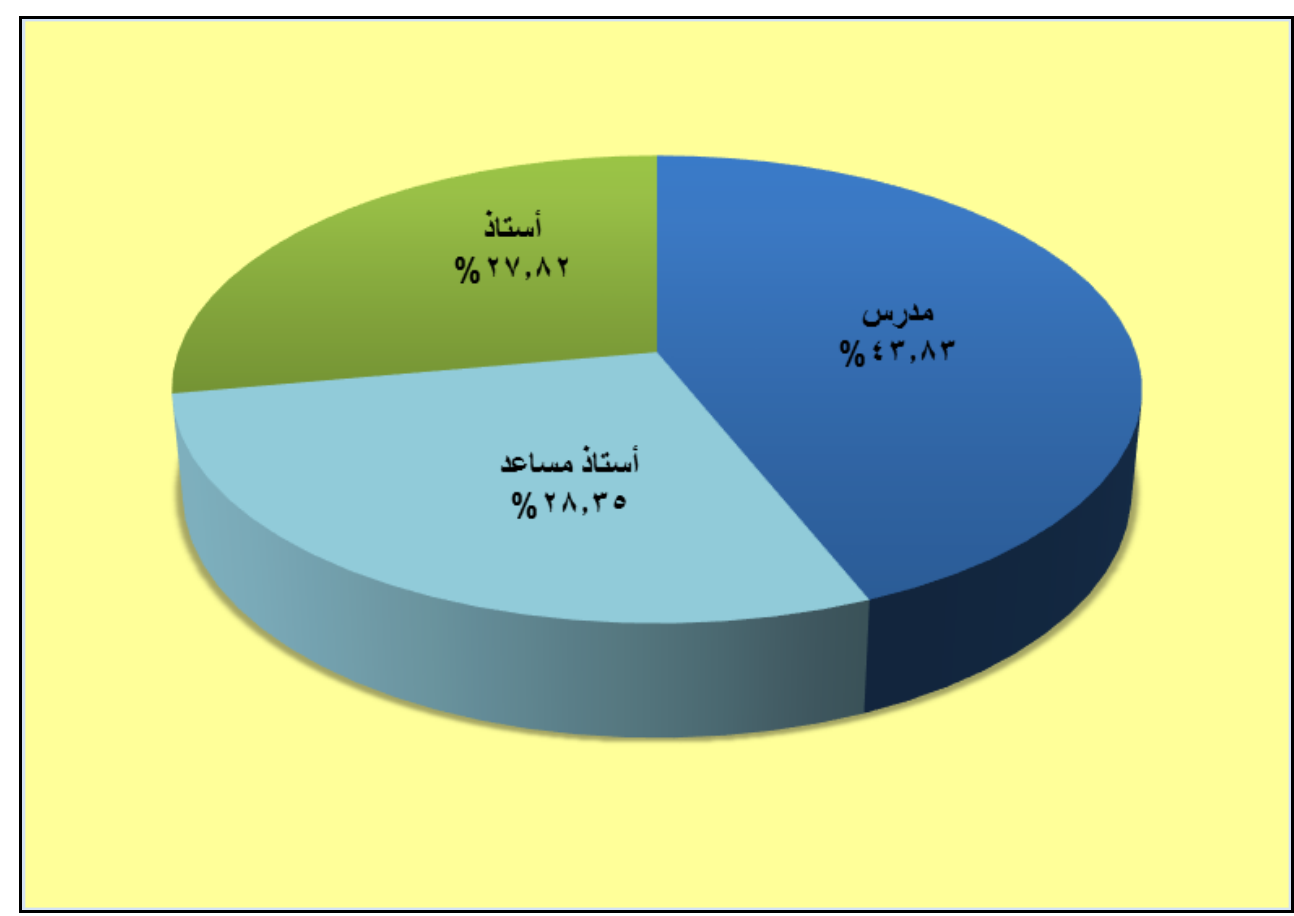

شكل رقم (آ) يوضح وصف عينة الدراسة بحسب متغير الرتبة الأكاديمية ( مدرس) (أستاذ مساعد/ أستاذ )

- وصف عينة الدراسة بحسب متغير المركز الوظيفي ( شغلت أو أشغل حاليا منصبا

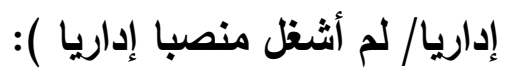

يتضح من الجدول (ه ) أن عينة الاراسة قد تضمنت (Y I I ) عضو هيئة تدريس من

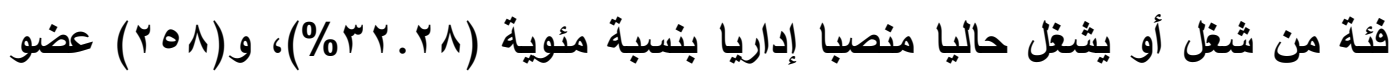


هيئة تدريس من فئة من لم يشغل منصبا إداريا بنسبة مئوية (Y.VY\%\%)، وهو ما يتضح بالثكل التالي.

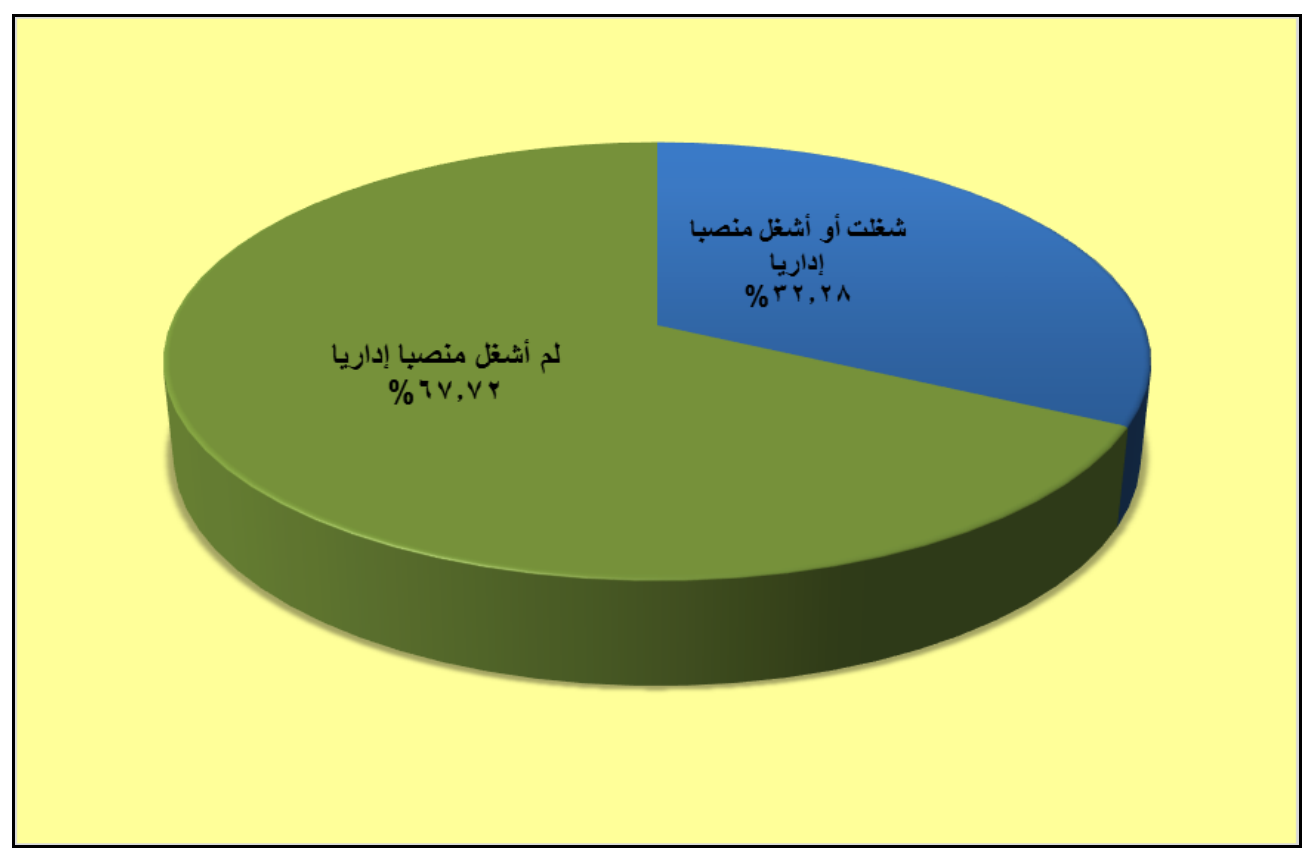

شكل رقم V) يوضح وصف عينة الاراسة بحسب متغير المركز الوظيفي( شغلت أو أشثل حاليا منصبا إداريا/لم أثغل منصبا إداريا )

\section{رابعا: عرض وتعليل نتائج الدراسة الميدانية.}

يتم عرض وتحليل نتائج الدراسة الميدانية من خلال عرض النتائج الإجمالية للمحاور، ثم دراسة الفروق في استجابات أفراد العينة بحسب متغيرات الدراسـة (الفرع - نوع الكلية - الموقـع الجغرافي - الرتبــة الأكاديميـة - المركـز الـوظيفي)، وأخيـرا دراســة النتـائج التفصيلية للعبارات الخاصة بكل محور.

$$
\text { أ- النتائج الإجمالية لمحاور الاراسة: }
$$

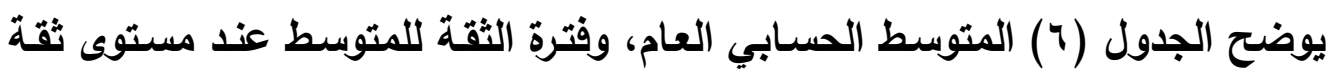
ه \%، والانحراف المعياري، ومعامل الاختلاف، والمتوسط الموزون، ودرجة التوفر لكل محور من محاور الدراسة. 
جدول (†) النتائج الإجمالية لمحاور الاراسة

\begin{tabular}{|c|c|c|c|c|c|c|c|c|}
\hline \multirow[t]{2}{*}{ الترتيب } & \multirow[t]{2}{*}{ التو افرة } & \multirow[t]{2}{*}{ الموزون } & \multirow[t]{2}{*}{ الاختلاف معامل } & \multirow[t]{2}{*}{ الالحياري } & \multicolumn{2}{|c|}{ فترة الثقة للمتوسط } & \multirow[t]{2}{*}{ الحستوسط } & \multirow[t]{2}{*}{ المستوي } \\
\hline & & & & & الأعلى الحد & الحد الأدنى & & \\
\hline 1 & متوسطة & r. ro & $\% r \cdot .0 r$ & $\Lambda . T V$ & $\varepsilon r . \wedge$ & $\varepsilon 1 . r \varepsilon$ & $\{r . Y)$ & مستوي الفرد \\
\hline r & متوسطة & $r .9 r$ & $\% r v .97$ & $\varepsilon .9$ & $11 . .1$ & $I V . r$ & $1 v .01$ & أو الجماعة الفريق \\
\hline r & متوسطة & $r . r$ & $\% r v . v$. & $r \cdot .1 \leq$ & $V \varepsilon . V Y$ & $V \cdot . T V$ & VY.V & التنظيمي \\
\hline- & متوسطة & $r . \wedge$ & $\% r r . \leq q$ & 111 & 110.00 & Irq.YA & IrT. $\leqslant r$ & المنظمة المنعلمة أبعاد \\
\hline
\end{tabular}

ويتضح من الجدول السابق أن درجة توفر إجمالي محاور الدراسة تقع في مستوى متوسطة، بمتوسط موزون (^ ..ب)، ويترتيب المحاور تنازليا بحسب المتوسط الموزون لارجة التوافر يلاحظ أن محور مستوي الفرد يأتي في المرتبة الأولى بمتوسط موزون

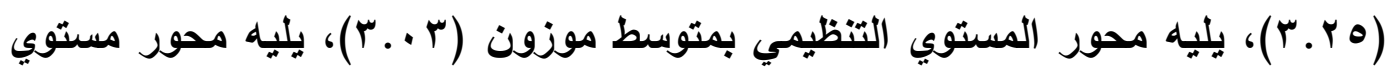

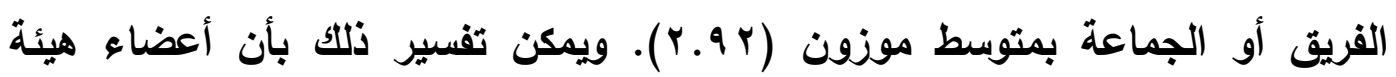
التدريس كل واحد منهم يكون حريصا على أن يعامل زميله باحترام، ولا يكون لايه أي باني

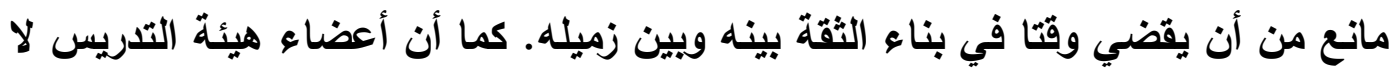
يخافون من الوقوع في الأخطاء، لأنهم يرون أن التعلم يحدث نتيجة الاستفادة من تلك فئك

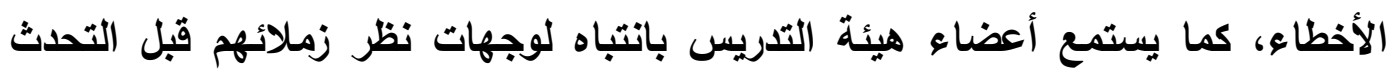

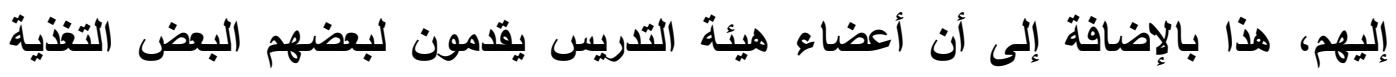
الراجعة الأمينة والمخلصة.

أما المستوى التظيمي فقد جاء في المرتبة الثانية ، حيث إن جامعة الأزهر تعمل

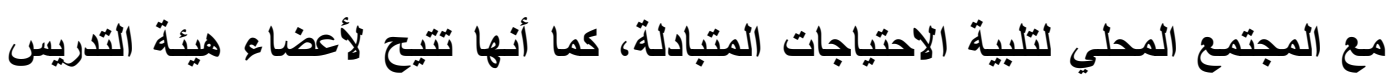
الحصول على المعلومات التي يحتاجونها في أي وقت بسرعة وسهولة عن طريق مكتبات

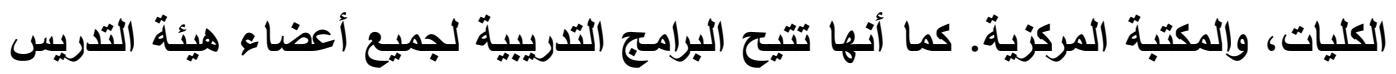

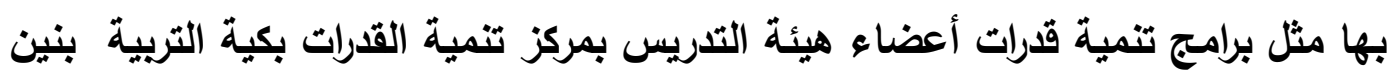
بالقاهرة، واثشراك الجامعة أعضاء هيئة التدريس في وضع رؤيتها ورسالتها، كما تهتم 
الجامعة بمعرفة أثر قراراتها في الروح المعنوية لأعضاء هيئة التدريس، هذا بالإضافة إلى احتفاظ الجامعة بقاعدة بيانات محثثة عن مهارات أعضاء هيئة التدريس.

ويالنسبة لمستوى الفريق فقد جاء في المرتبة الأخيرة، حيث إن أعضاء هيئة

التدريس يميلون إلى العمل الفريقي من خلال البحوث التثاركية، أيضا من خلال المقررات

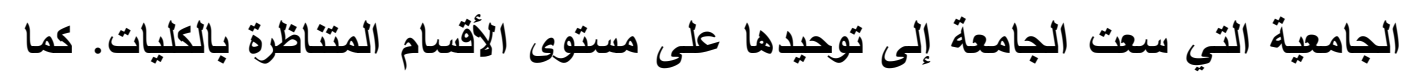

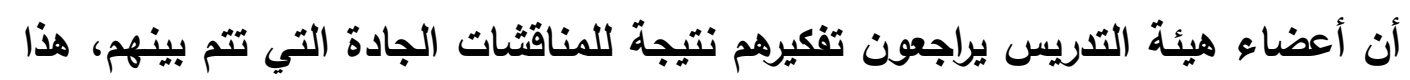
بالإضافة إلى أن أعضاء هيئة التدريس يكافئون على انجازاتهم كفريق عمل من قلهبل

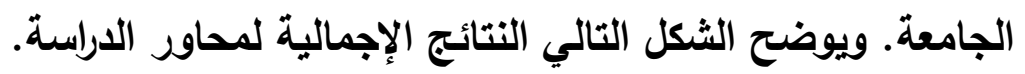

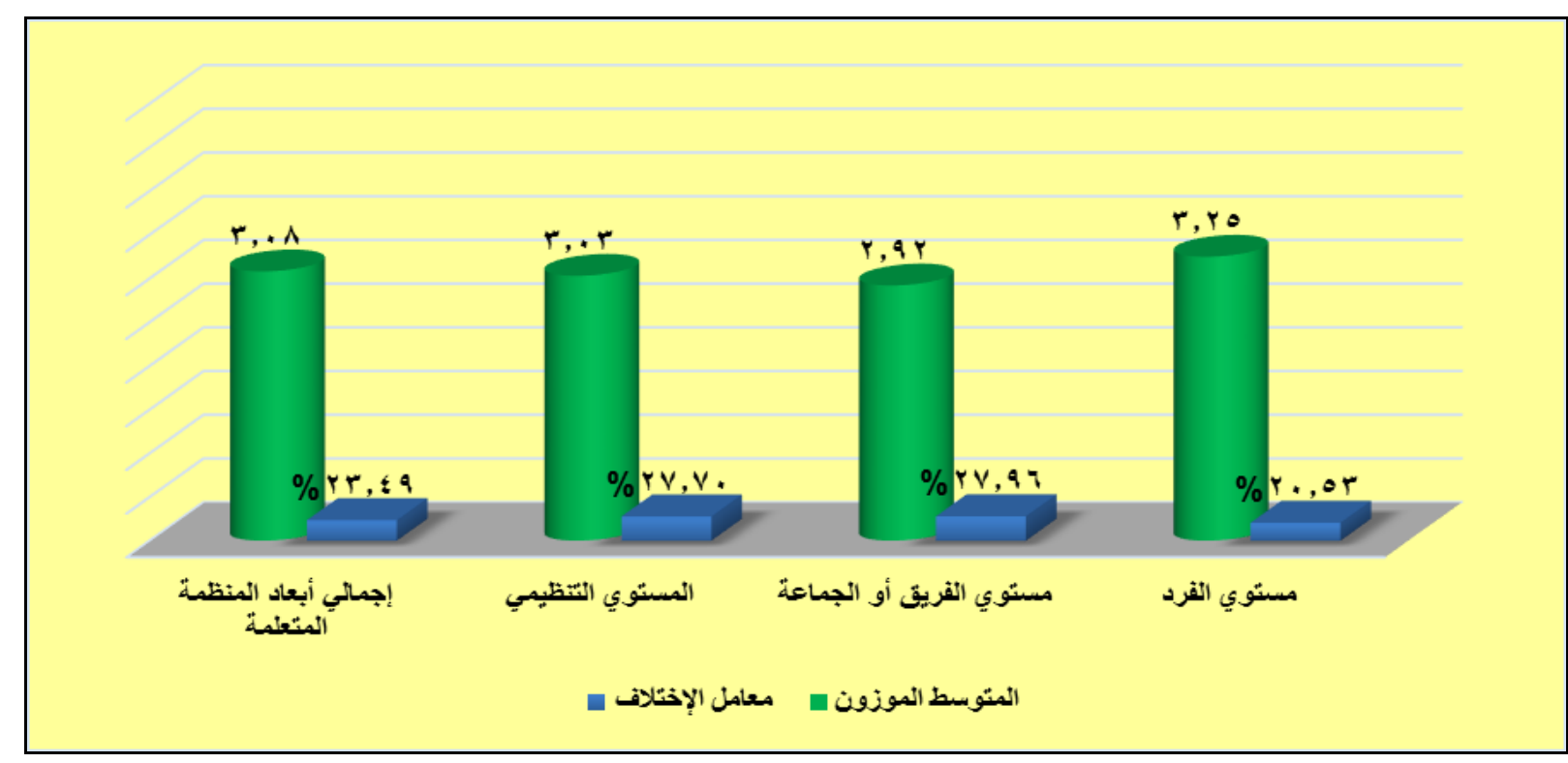

شكل رقم (^) يوضح النتائج الإجمالية لمحاور الدراسة

دراسة الارتباط بين أبعاد المنظمة المتعلمة: للتعرف على معاملات الارتباط بين المستويات تم حساب معامل ارتباط بيرسون وكانت النتائج كما هو مبين بالجدول التالي: جدول (V) مصفوفة الارتباط بين محاور الدراسة

\begin{tabular}{|c|c|c|c|c|}
\hline إجمالي أبعاد المنظمة المتعلمة & المستوي التنظيمي & مستوي الفريق أو الجماعة & \multicolumn{2}{|c|}{ المستوي - لمي } \\
\hline$\cdot \wedge \varepsilon$ & .79 & $\cdot$. vo & ارتباطل & مستوي \\
\hline$\because \cdot$ & $\because \cdot$ & $\because \cdot$ & الإلدصلة & الفرد \\
\hline$\cdot . \wedge 9$ & $\cdot . \Lambda 1$ & & ارتباطل & الفستويق \\
\hline$\because \cdot$ & $\because \cdot$ & & الإلدالة & الجماء \\
\hline
\end{tabular}




\begin{tabular}{|c|c|c|}
\hline$\because 9 V$ & رتباط & المستو \\
\hline$\because \cdots$ & لدصالة & التنظيه \\
\hline
\end{tabular}

ويتضح من الجدول السابق وجود ارتباط طردي دال إحصائيا عند مستوى دلالة

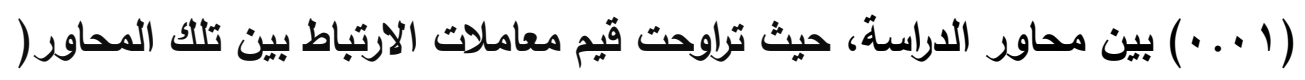

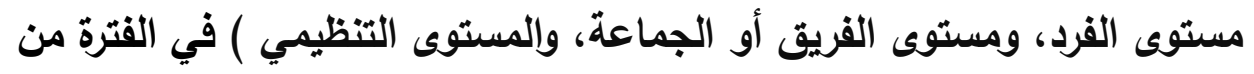

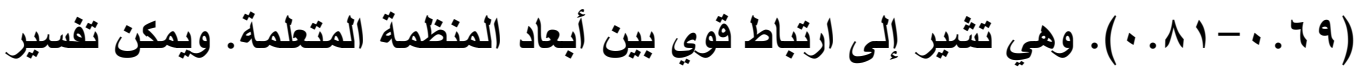

ذلك بأن كل بعد من أبعاد المنظمة المتعلمة يؤثر في البعد الآخر ويتأثر به.

ب- - دراسة الفروق في المحاور بحسب متغيرات الدراسة: 1- دراسة الفروق في المحاور بحسب متغير الفرع ( بنين/ بنات ):

لاراسة الفروق في المحاور بحسب متغير الفرع تم معالجة البيانات إحصائيا

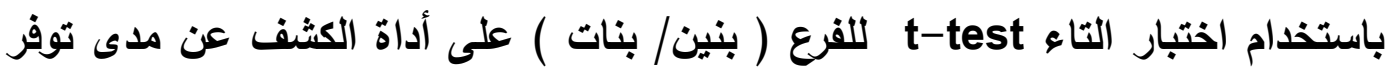

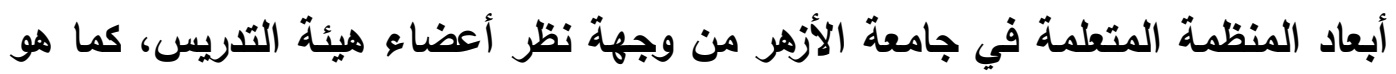

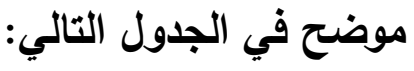

جدول (^) دراسة الفروق في المحاور بحسب متغير الفرع ( بنين/ بنات )

\begin{tabular}{|c|c|c|c|c|c|c|c|c|}
\hline الإحصلائية & قيمة التاء & التو افرة & المنوسط & الانحر اف & الحسابي & العدد & الفرع & المستوي \\
\hline \multirow{2}{*}{$\cdot \leqslant 9$} & \multirow{2}{*}{.79} & متوسطة & Tr. & ^. $\cdot \varepsilon$ & $\leqslant 1.9 V$ & דוT & بنين & \multirow{2}{*}{ مستوي الفرد } \\
\hline & & متوسطة & r.rk & 9.71 & $\varepsilon r .7$. & $1 \leqslant 0$ & بنات & \\
\hline \multirow{2}{*}{$\because \cdot 1$} & \multirow{2}{*}{ r. $\leqslant 9-$} & منوسطة & 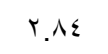 & $\varepsilon . V r$ & IV.r & דr Tr & بنين & \multirow{2}{*}{ مستوي الفريق } \\
\hline & & متوسطة & $r . .0$ & $0 . v$ & 1А.r. & $1 \leqslant 0$ & بنات & \\
\hline \multirow{2}{*}{$\because \cdots$} & \multirow{2}{*}{ r.^.- } & متوسطة & r.q. & $19.9 v$ & 79.71 & דוr & بنين & \multirow{2}{*}{ التنظيمي } \\
\hline & & متوسطة & r.ru & 19.01 & $V V .71$ & $1 \leqslant 0$ & بنات & \\
\hline \multirow{2}{*}{$\because \cdots$} & \multirow{2}{*}{ r. r. } & متوسطة & r. 99 & r..11 & IYA.TV & דיזr & بنين & \multirow{2}{*}{ المنظمة المنعلمة أبعاد } \\
\hline & & متوسطة & r.r. & M..$\wedge \varepsilon$ & $1 \% \Lambda .01$ & $1 \leqslant 0$ & بنات & \\
\hline
\end{tabular}

ويتضح من الجدول السابق ما يلي:

$$
\text { • المحور الأول (مستوي الفرد): }
$$

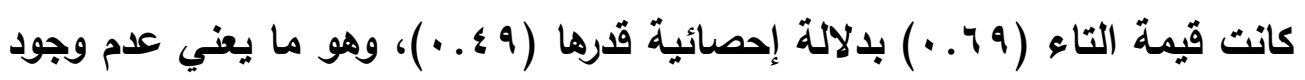
فروق ذات دلالة إحصائية عند مستوى دلالة (ه ...). وقد كانت أعلى المتوسطات لفئة 


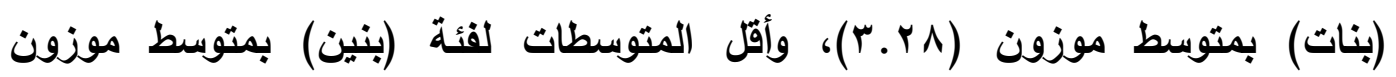

$$
\text { • المحور الثاني (مستوي الفريق): }
$$

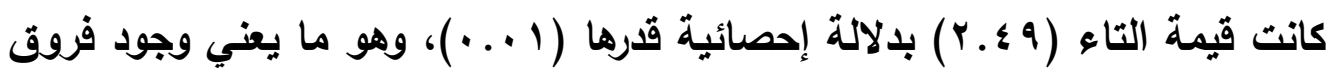
ذات دلالة إحصائية عند مستوى دلالة (ه ...). وقد كانت أعلى المتوسطات لفئة (بنات)

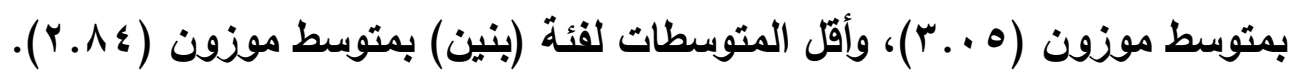

$$
\text { • المحور الثالث (المستوي التظيمي): }
$$

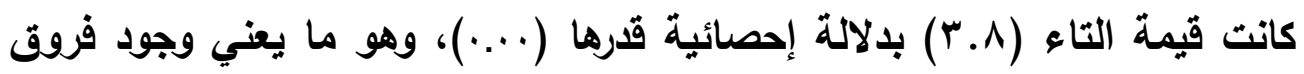

ذات دلالة إحصائية عند مستوى دلالة (ه ...)، وقد كانت أعلى المتوسطات لفئة (بنات)

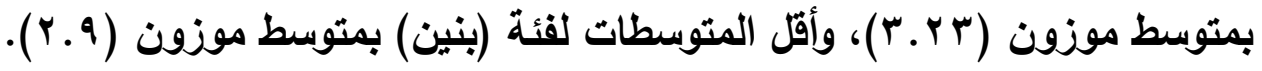

(إجمالي أبعاد المنظمة المتعلمة):

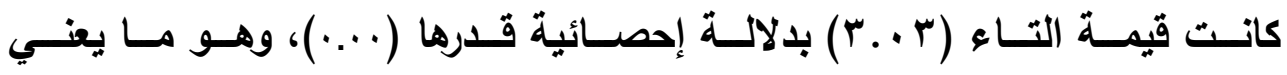

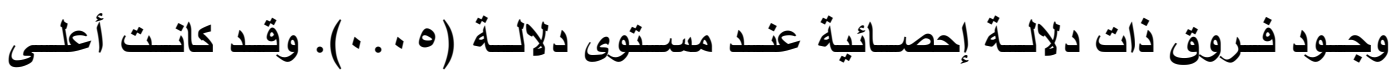

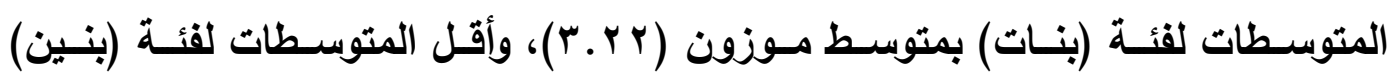

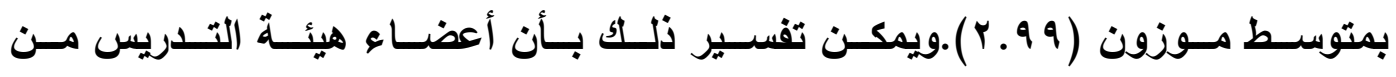

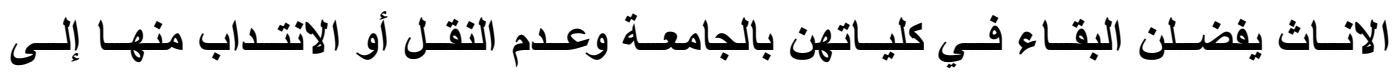
كليـات أخرى بـفس الجامعـة، الأمسر الذي يجعلهن أكثر احتكاكـا بالكليـات المنتسبين

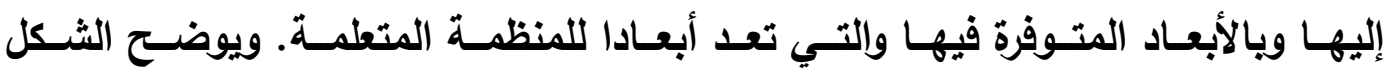


التـالي المتوســات الموزونــة لاسـتجابات أفـراد عينـة الاراســة بحسب متغيـر الفـرع.

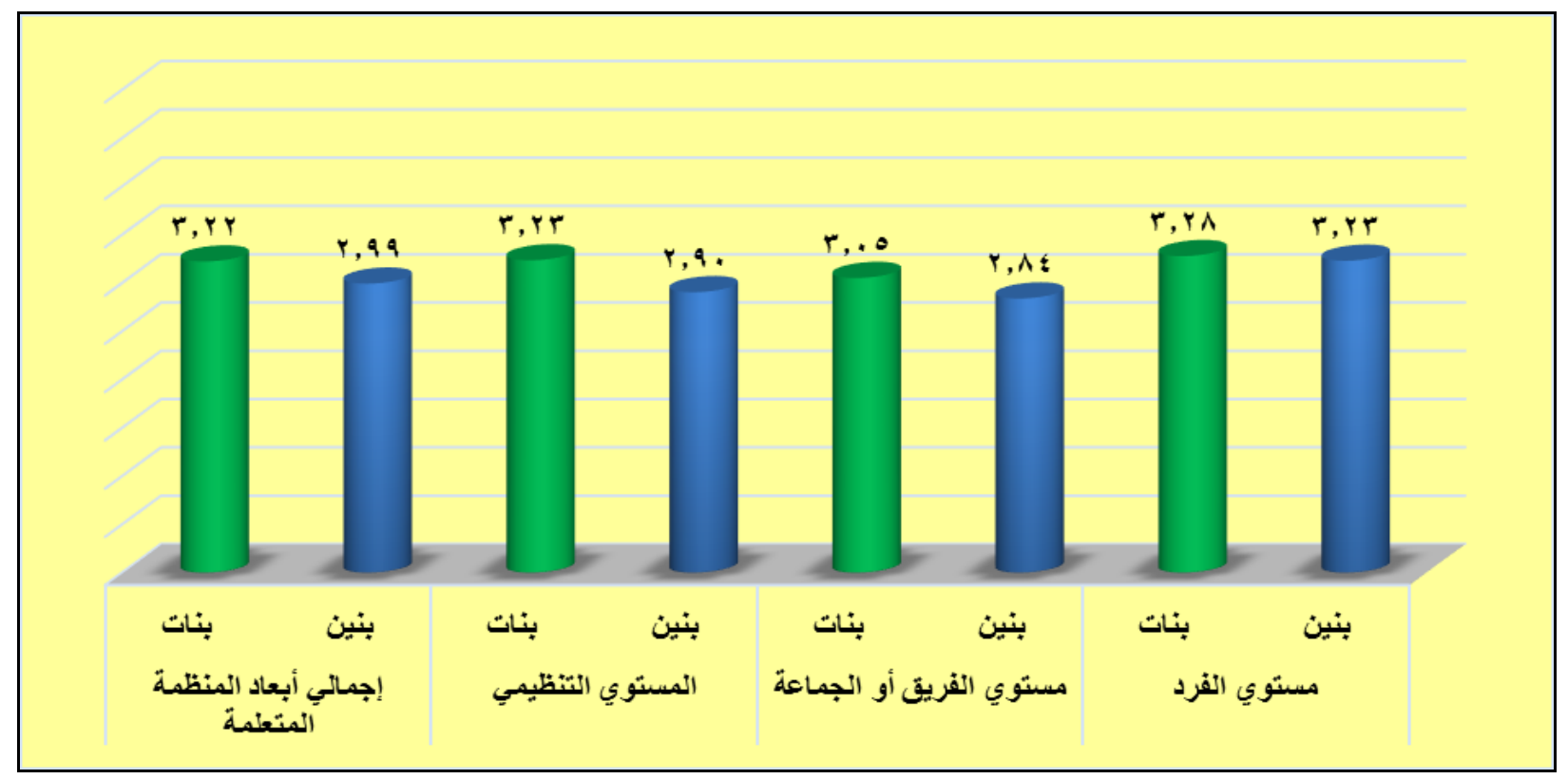

شكل رقم (9) يوضح المتوسطات الموزونة لاستجابات أفراد عينة الاراسة بحسب

متغير الفرع ( بنين/ بنات )

ץ- دراسة الفروق في المحاور بحسب متغير نوع الكلية (شرعية وعربية/ نظرية/

$$
\text { عملية ): }
$$

لاراسة الفروق في المحاور بحسب متفير نوع الكلية تم معالجة البيانات إحصائيا

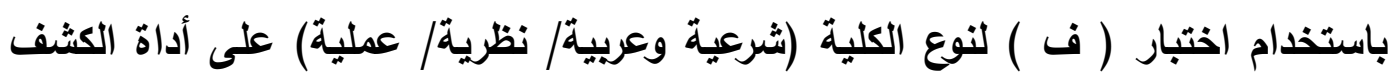
عن مدى توفر أبعاد المنظمة المتعلمة في جامعة الأزهر من وجهة نظر أنساع أعضاء هيئة

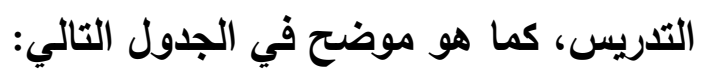

جدول (9) دراسة الفروق في المحاور بحسب متغير نوع الكلية(ثرعية وعربية/ نظرية/ عملية)

\begin{tabular}{|c|c|c|c|c|c|c|c|c|}
\hline الإحصائية & قيمة الفاء & التو افرة & الموزون & الانحر اف & الحسابي & العدد & نوع الكلية & المستوي \\
\hline \multirow{3}{*}{.77} & \multirow{3}{*}{$\cdot \varepsilon 1$} & متوسطة & $T . T V$ & $\wedge .9$. & $\varepsilon r .00$ & $19 V$ & وعربية & \multirow{3}{*}{ مستوي الفرد } \\
\hline & & متوسطة & r.r. & 1.09 & $\leqslant 1.7 \leqslant$ & $|r|$ & نظرية & \\
\hline & & متوسطة & T.Yo & $\Lambda .1 \mathrm{r}$ & $\varepsilon r . r_{0}$ & זי & عملية & \\
\hline \multirow{2}{*}{$\cdot .^{v}$} & \multirow{2}{*}{ דו } & متوسطة & r.90 & 0.11 & IV.V. & $19 V$ & وعربية & \multirow{2}{*}{ أو الجماعة الفريق } \\
\hline & & متوسطة & r.AV & 0.0 & IV.rY & $|r|$ & نظرية & \\
\hline
\end{tabular}




\begin{tabular}{|c|c|c|c|c|c|c|c|c|}
\hline & & منوسطة & $r .91$ & r.so & $\mid V . \leqslant 1$ & שז & عملية & \\
\hline \multirow{3}{*}{.1 . } & \multirow{3}{*}{ r. rq } & متوسطة & r.11 & 19.00 & $V \varepsilon .7 T$ & $19 V$ & وعربية & \multirow{3}{*}{ التنظيمي } \\
\hline & & متوسطة & r.91 & rr. & $v 1.01$ & $|r|$ & نظرية & \\
\hline & & منوسطة & $r . \wedge V$ & 10.11 & $71 . \vee q$ & שז & عملية & \\
\hline \multirow{3}{*}{ ד } & \multirow{3}{*}{1.47} & منوسطة & r. $1 \varepsilon$ & r.r. & $1 T \leqslant . \wedge \Lambda$ & $19 \mathrm{~V}$ & وعربية & \multirow{3}{*}{ الجمالي أبعاد } \\
\hline & & متوسطة & $r . r$ & $r \varepsilon . \wedge$ & $1 T \cdot . \varepsilon \varepsilon$ & $|r|$ & نظرية & \\
\hline & & متوسطة & $r .99$ & r.r. & IrA.Or & Tr & عملية & \\
\hline
\end{tabular}

ويتضح من الجدول السابق ما يلي:

• • المحور الأول (مستوي الفرد):

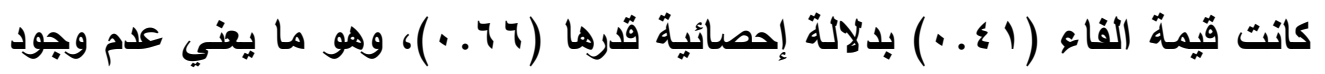
فروق ذات دلالة إحصائية عند مستوى دلالة (ه ...). وقد كانت أعلى المتوسطات لفئة

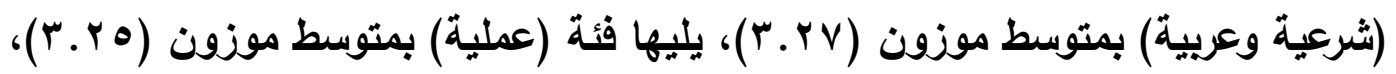

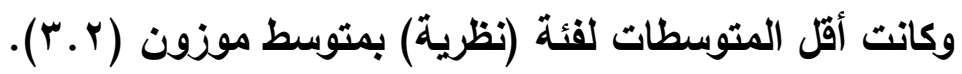

• • المحور الثاني (مستوي الفريق أو الجماعة):

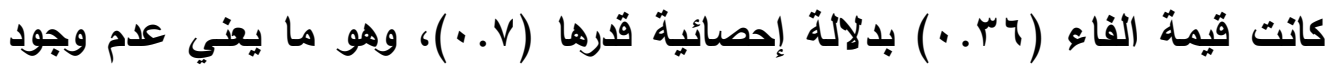
فروق ذات دلالة إحصائية عند مستوى دلالة (ه ...). وقد كانت أعلى المتوسطات لفئة

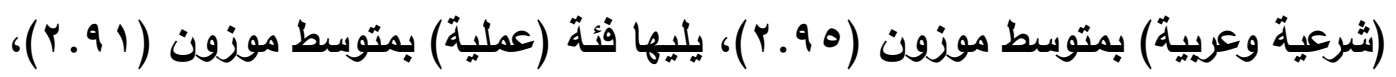
وكانت أقل المتوسطات لفئة (نظرية) بمتوسط موزون (r.Av).

• المحور الثالث (المستوي التنظيمي):

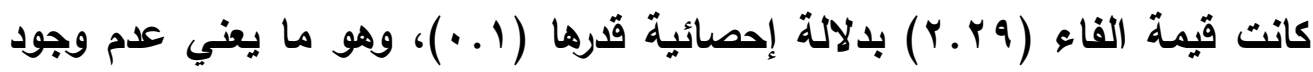
فروق ذات دلالة إحصائية عند مستوى دلالة (ه ...)، وقد كانت أعلى المتوسطات لفئة

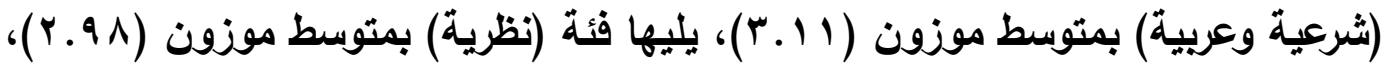

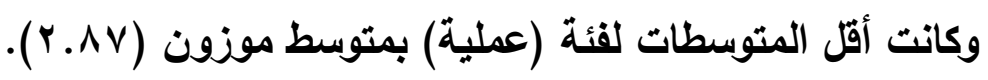

(إجمالي أبعاد المنظمة المتعلمة):

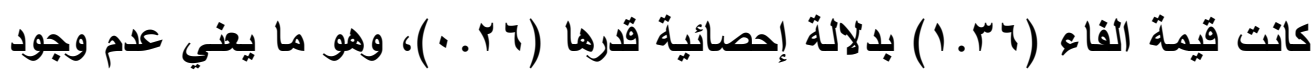
فروق ذات دلالة إحصائية عند مستوى دلالة (ه ...)، وقد كانت أعلى المتوسطات لفئة

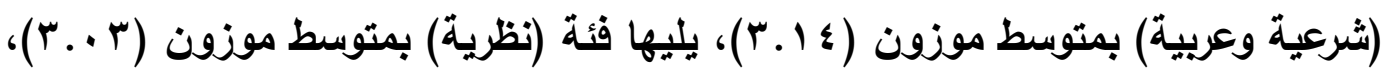


وكاتت أقل المتوسطات لفئة (عملية) بمتوسط موزون (9 9. ؟). ويمكن تفسير ذلك بأن جميع أعضاء هيئة التدريس من أصحاب التخصصات المختلفة ( الثرعية وإلعربية، والنظرية، والعملية ) يعملون في جامعة واحدة لها خطة استراتيجية واحدة، وروئية ورسالة

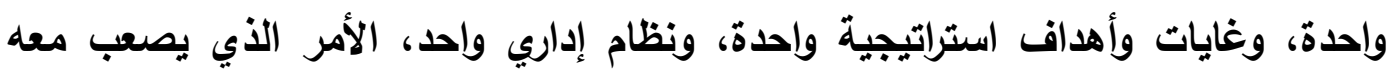

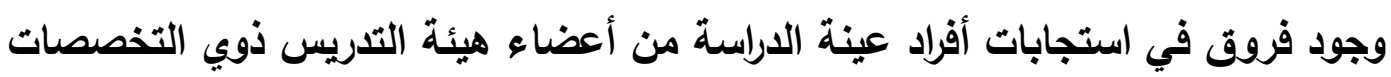

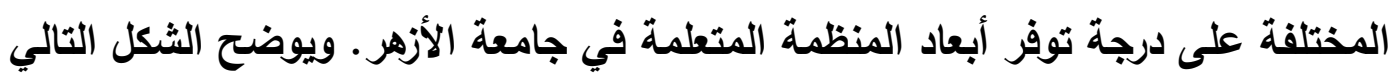
المتوسطات الموزونة لاستجابات عينة الدراسة بحسب متغير نوع الكلية.

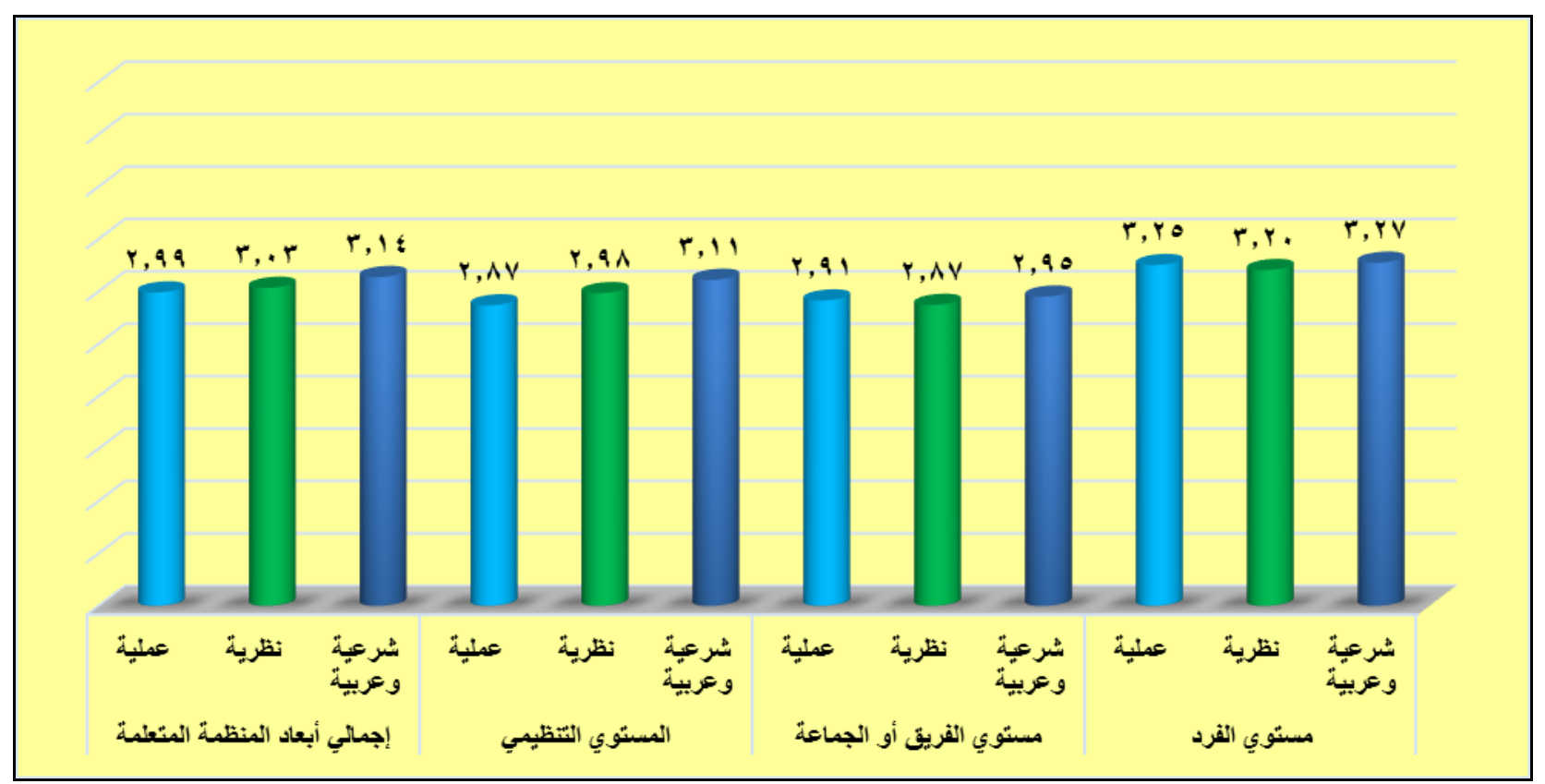

شكل رقم ( • 1) يوضح المتوسطات الموزونة لاستجابات عينة الدراسة بحسب متغير نوع الكلية (شرعية وعربية/ نظرية/ عملية).

r- دراسة الفروق في المحاور بحسب متغير الموقع الجغرافي ( وجه قبلي/ عاصمة/ وجه بحري ):

لاراسة الفروق في المحاور بحسب متغير الموقع الجغرافي تم معالجة البيانات

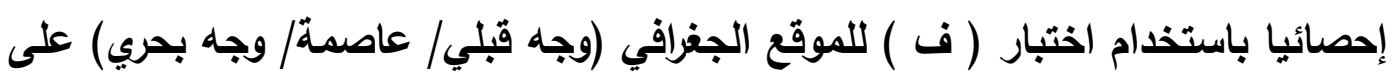

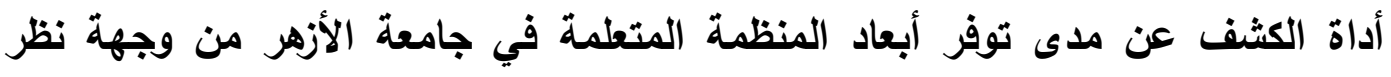
أعضاء هيئة التدريس، كما هو موضح في الجدول التالي: 
جدول (· (1) دراسة الفروق في المحاور بحسب متغير الموقع الجغرافي (وجه قبلي/

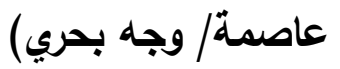

\begin{tabular}{|c|c|c|c|c|c|c|c|c|}
\hline الإحصائية الدلة & قيمة الفاء & التو افر & الموزوسط & الانحراف المعياري & الحستوسطي & العدد & الجغرقع افي & المستوي \\
\hline \multirow{3}{*}{$\because 0$} & \multirow{3}{*}{ r.11 } & متوسطة & r.IT & $\wedge . \leqslant 1$ & $\varepsilon .01$ & $1 . V$ & وجه قبلي & \multirow{3}{*}{ مستوي الفرد } \\
\hline & & متوسطة & r. r. & $9 . Y 7$ & ع.11 & 100 & عاصمة & \\
\hline & & كبيرة & r. & V. 9. & $\varepsilon r . \leqslant V$ & 119 & وجه بحري & \\
\hline \multirow{3}{*}{$\because \cdots$} & \multirow{3}{*}{$V .99$} & متوسطة & Y.VI & $\leqslant .00$ & 17. & $1 \cdot v$ & وجه قبلي & \multirow{3}{*}{ الفريت أُ } \\
\hline & & منوسطة & $r . \Lambda$ & 0.11 & 11.0. & 100 & عاصمة & \\
\hline & & متوسطة & r.A9 & $\varepsilon . \gamma$. & IV.rV & 119 & وجه بحري & \\
\hline \multirow{3}{*}{$\because \cdots$} & \multirow{3}{*}{9.7} & متوسطة & r.vo & IV.YO & 70.99 & $1 . v$ & وجه قبلي & \multirow{3}{*}{ التنظيمي } \\
\hline & & متوسطة & r.11 & r... 0 & VT.MT & 100 & عاصمة & \\
\hline & & متوسطة & $r . \wedge$ & 11.07 & $v \varepsilon .+1$ & 119 & وجه بحري & \\
\hline \multirow{3}{*}{$\because \cdots$} & \multirow{3}{*}{1.99} & متوسطة & r.Ao & Y. .91 & IYY.VE & $1 . v$ & وجه قبلي & \multirow{3}{*}{ أجمالي البعاد } \\
\hline & & متوسطة & I. & & I ז... & 100 & عاصمة & \\
\hline & & متوسطة & r.11 & $Y \wedge . \wedge \varepsilon$ & סג. זrו & 119 & وجه بحري & \\
\hline
\end{tabular}

ويتضح من الجدول السابق ما يلي:

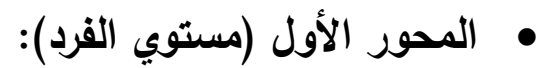

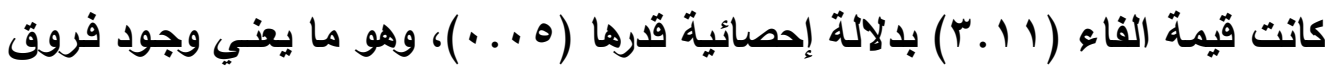

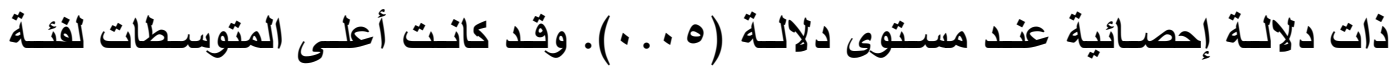

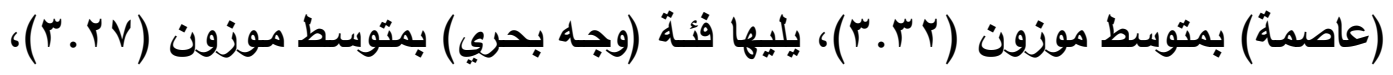

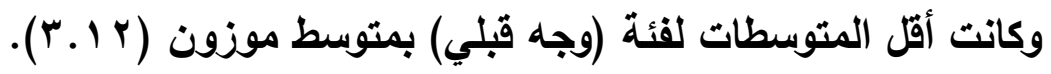
• • المحور الثاني (مستوي الفريق أو الجماعة):

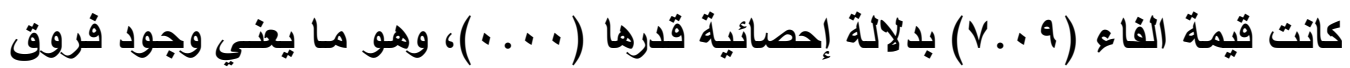

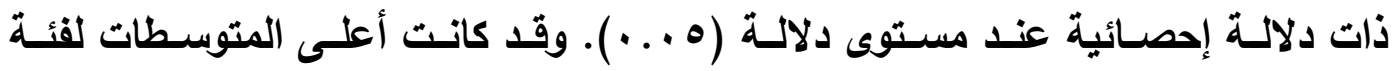

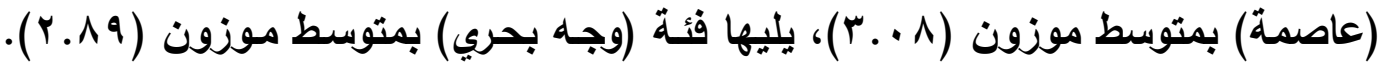
وكانت أقل المتوسطات لفئة (وجه قبلي) بمتوسط موزون (Y.V. (Y.Y). • • • المحور الثالث (المستوي التنظيمي): 


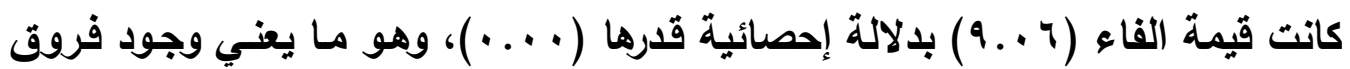

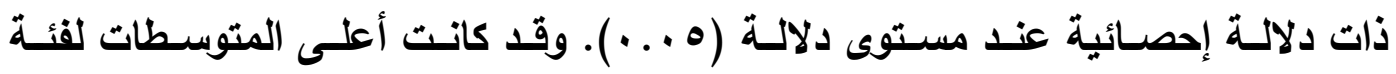

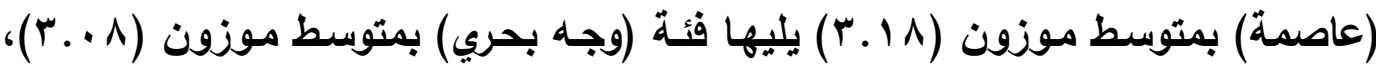
وكانت أقل المتوسطات لفئة (وجه قبلي) بمتوسط موزون (Y.V०). • (إجمالي أبعاد المنظمة المتعلمة):

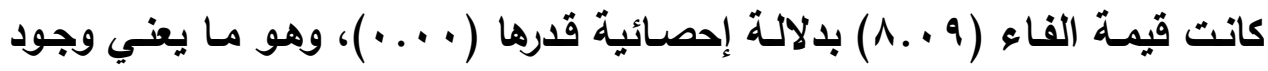
فروق ذات دلالة إحصائية عند مستوى دلالة (ه ...)، وقد كانت أعلى المتوسطات لفئة

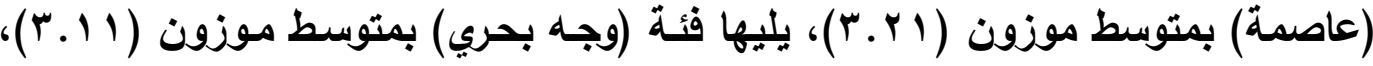
وكانت أقل المتوسطات لفئة (وجه قبلي) بمتوسط موزون (ه.^.ب). ويمكن تفسير ذلك بأن أعضاء هيئة التدريس المنتسبين لكليات العاصمة من حيث قربهم من قيادات الجامعة ومن موطن اتخاذ القرار وأحيانـا المشاركة فيه، ومن حيث وفرة الدورات التدريبية، وكذا لتانيات سهولة الاشتراك في المؤتمرات والتدوات التي تعقدها الجامعة بالقاهرة؛ ولجميع ما سبق هونق فإنهم يشعرون بالجامعة كمنظمـة متعلمـة أكثر من أقرانهم من أعضـاء هيئة التـريس المنتسبين لكليات الوجها البحري، والقبلي. ويوضـح الثكل التالي المتوسطات الموزونـة لاستجابات عينة الدراسة بحسب متغير الموقع الجغرافي.

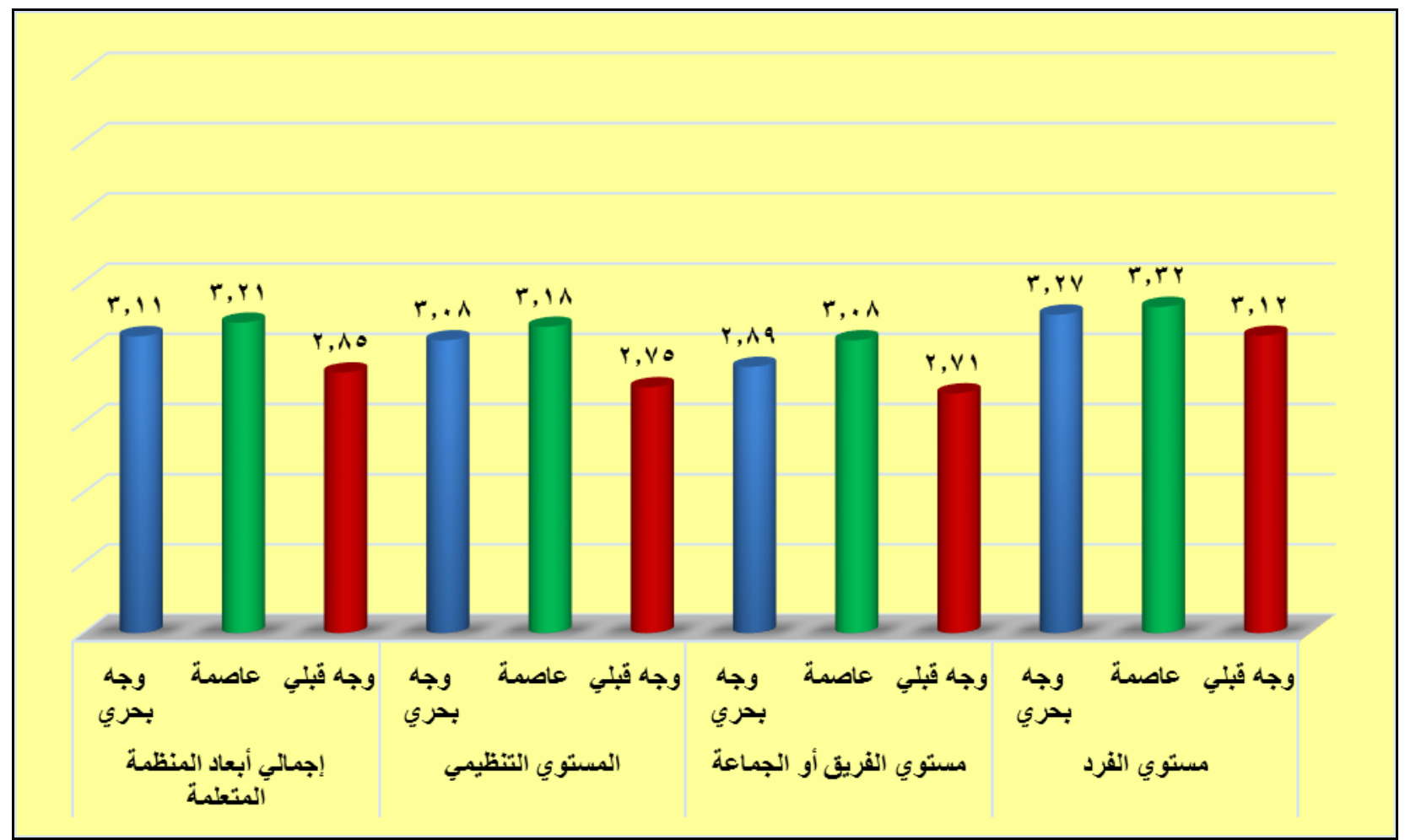


شكل رقم (11) يوضح المتوسطات الموزونة لاستجابات عينة الدراسة

بحسب متغير الموقع الجغرافي(وجه قبلي/ عاصمة/ وجه بحري)

المقارنات البعدية بطريقة شافية :

فيما يلي نتائج اختبار شافية للتعرف على اتجاهات الفروق في المحاور التي أظهرت

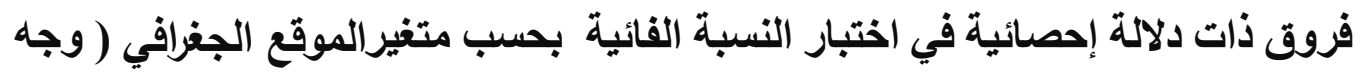

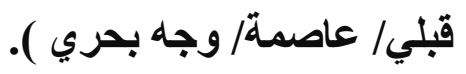

جدول (11) نتائج اختبار شافيه للفروق في المحاور بحسب متغير الموقع الجغرافي

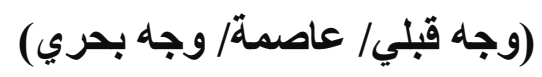

\begin{tabular}{|c|c|c|c|c|c|c|}
\hline \multicolumn{2}{|c|}{ الدلالة الإحصائية } & الخطأ المعياري & الفرق بين & الجغر افيع & الموقع & المستو \\
\hline 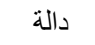 &.$\cdot 1$ & $1 . \cdot 1$ & r.TV- & عاصمة & \multirow{2}{*}{ وجه قبلي } & \multirow{3}{*}{ الفرد } \\
\hline غير دالة & $\because 9$ & 1.10 & 1.97 & وجه بحري & & \\
\hline غير دالة & $\because 0$. & $1 . .0$ & $\because v 1$ & وجه بحري & عاصمة & \\
\hline دالة ل & $\because \cdots$ & .71 & T. Y V & عاصمة & \multirow{2}{*}{ وجه قبلي } & \multirow{3}{*}{ الفرتوي } \\
\hline غير دالة & $\because \cdot \Lambda$ & $\cdot .7 \varepsilon$ & $1.1 \leqslant-$ & وجه بحري & & \\
\hline 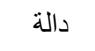 & $\because .0$ &. .09 & 1.14 & وجه بحري & عاصمة & \\
\hline 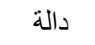 & $\because \cdots$ & T. ¿A & $1 \cdot r_{-}$ & عاصمة & \multirow{2}{*}{ وجه قبلي } & \multirow{3}{*}{ التئيم } \\
\hline دالة ل & $\because \cdots$ & זד. & $\Lambda_{.} \cdot r_{-}$ & وجه بحري & & \\
\hline غير دالة & $\cdot r \varepsilon$ & r. $\varepsilon$. & r.r. & وجه بحري & عاصمة & \\
\hline دالة & $\because \cdots$ & $\Gamma . \wedge \varepsilon$ & $10 . T_{-}$ & عاصمة & \multirow{2}{*}{ وجه قبلي } & \multirow{3}{*}{ ألمألمادي } \\
\hline دالة &.$\cdot 1$ & $\varepsilon . \cdot V$ & $11.11-$ & وجه بحري & & \\
\hline غير دالة & $\cdot r V$ & T.VT & $\leqslant .10$ & وجه بحري & عاصمة & \\
\hline
\end{tabular}

\section{ويتضح من الجدول السابق ما يلي:}

مستوي الفرد: توجد فروق ذات دلالة إحصائية بين فئة (وجه قبلي)،

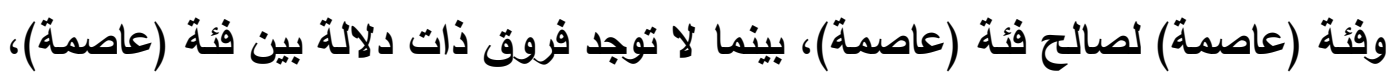

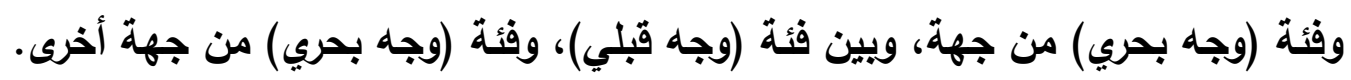

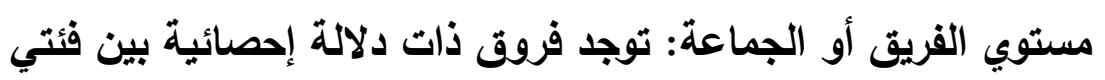

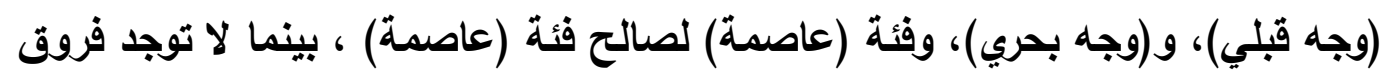

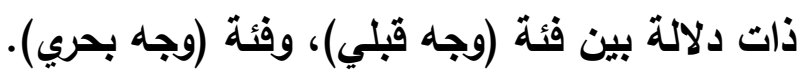


المستوي التنظيمي: توجد فروق ذات دلالة إحصائية بين فئة (وجه قبلي)

وفئتي (عاصمة) و (وجه بحري) لصالح فئتي (عاصمة) و (وجه بحري)، بينما لا توجد

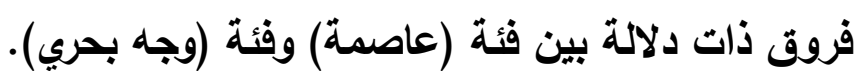
إجمالي أبعاد المنظمة المتطلمة: توجد فروق ذات دلالة إحصائية بين فئة

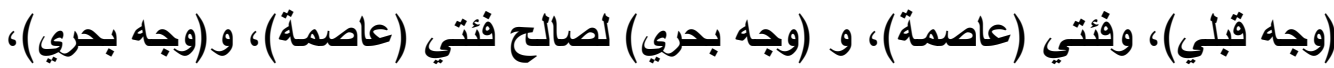

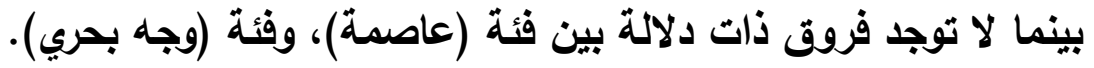

ع - دراسة الفروق في المحاور بحسب متغير الرتبة الأكاديمية( مدرس/ أستاذ

مساعد/ أستاذ):

لاراسة الفروق في المحاور بحسب متغير الرتبة الأكاديمية تم معالجة البيانات

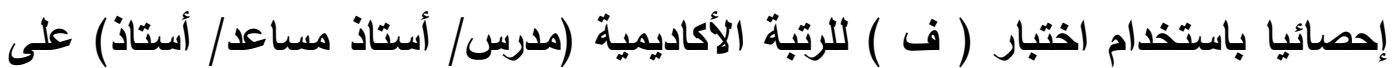
أداة الكثف عن مدى توفر أبعاد المنظمة المتعلمة في جامعة الأزهر من وجهة نظر لتراديه أعضاء هيئة التدريس، كما هو موضح في الجدول التالي:

جدول (Y Y) دراسة الفروق في المحاور بحسب متغير الرتبة الأكاديمية ( مدرس /

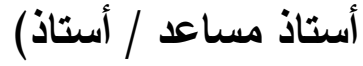

\begin{tabular}{|c|c|c|c|c|c|c|c|c|}
\hline الإحصائية & قيمة الفاء & التو افرجة & الموزوسط & الانحرياري & الحسابي & العدد & الأكاديمبة الرتبة & المستوي \\
\hline \multirow{3}{*}{$\because \cdots$} & \multirow{3}{*}{7.19} & متوسطة & $r .10$ & 9.14 & $\varepsilon \cdot .9 V$ & 178 & مدرس & \multirow{3}{*}{ مستوي الفرد } \\
\hline & & كبيرة & T. $\varepsilon \varepsilon$ & V.V. & $\varepsilon \varepsilon . \vee \varepsilon$ & 1.1 & أستاذ مساعد & \\
\hline & & متوسطة & r.r. & $\Lambda . r q$ & $\leqslant 1.01$ & 1.7 & أستاذ & \\
\hline \multirow{3}{*}{$\because \cdot r$} & \multirow{3}{*}{ r.یr } & متوسطة & r.A. & $\varepsilon . \wedge T$ & 17.11 & 178 & مدرس & \multirow{3}{*}{ أو الجماعة الفريق } \\
\hline & & متوسطة & $r . \wedge$ & $\varepsilon .91$ & $11 . \leq 0$ & $1 \cdot 1$ & أستاذ مساعد & \\
\hline & & منوسطة & $r .9 \leq$ & $\varepsilon . V \varepsilon$ & 1V.T4 & 1.7 & أستاذ & \\
\hline \multirow{3}{*}{$\because \cdot r$} & \multirow{3}{*}{$\varepsilon .1 T$} & متوسطة & r.qY & $r \cdot r_{0}$ & $v \cdot .17$ & 178 & مدرس & \multirow{3}{*}{ التنظيمي } \\
\hline & & منوسطة & r.rr & 19.17 & VV.19 & $1 \cdot 1$ & أستاذ مساعد & \\
\hline & & متوسطة & $r .$. & 19.87 & VY.U & 1.7 & أستاذ & \\
\hline \multirow{3}{*}{$\because \cdots$} & \multirow{3}{*}{$0 . \leqslant V$} & متوسطة & $r .91$ & T.V $v \varepsilon$ & IrV.qT & 178 & مدرس & \multirow{3}{*}{ إجمالي أبعاد } \\
\hline & & منوسطة & ד.r. & $r 9.70$ & $1 \varepsilon \cdot . r q$ & 1.1 & أستاذ مساعد & \\
\hline & & منوسطة & $r . .0$ & $r$. ro & דr.וTו & 1.7 & أستاذ & \\
\hline
\end{tabular}




\section{ويتضح من الجدول السابق ما يلي: \\ • • المحور الأول (مستوي الفرد):}

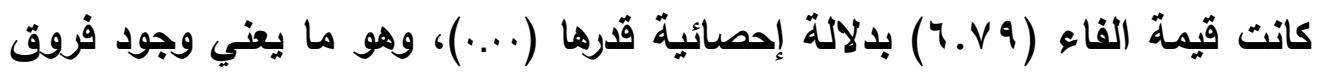
ذات دلالة إحصائية عند مستوى دلالة (ه ...). وقد كاتت أعلى المتوسطات لفئة (أستاذ

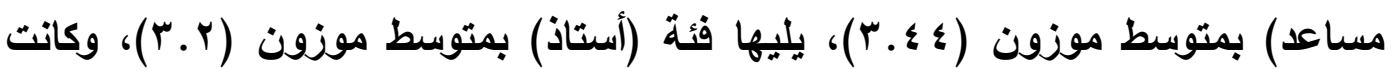

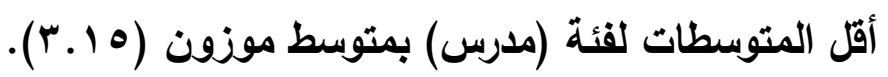

$$
\text { • • المحور الثاني (مستوي الفريق أو الجماعة): }
$$

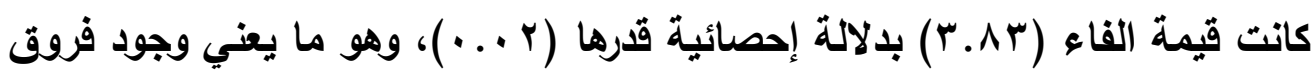
ذات دلالة إحصائية عند مستوى دلالة (ه ...). وقد كانت أعلى المتوسطات لفئة (أستاذ

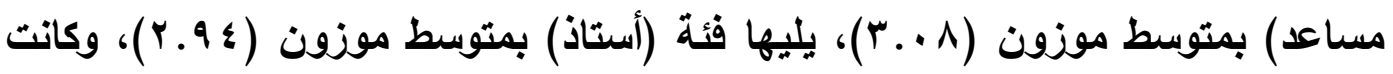
أقل المتوسطات لفئة (مدرس) بمتوسط موزون (r.^).

$$
\text { • المحور الثالث (المستوي التظيمي): }
$$

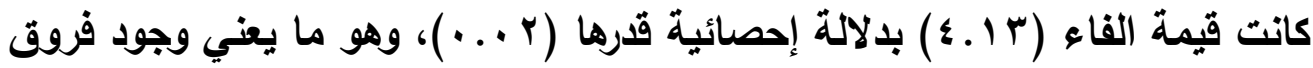
ذات دلالة إحصائية عند مستوى دلالة (ه ...). وقا كانت أعلى المتوسطات لفئة (أستاذ

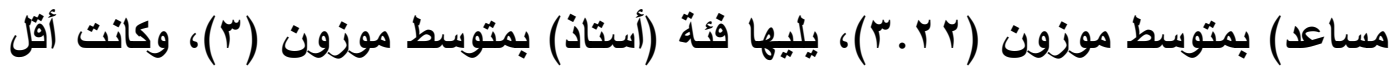

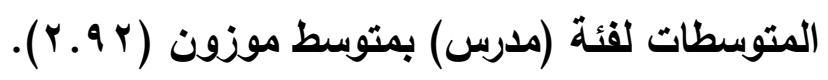
• (إجمالي أبعاد المنظمة المتعلمة):

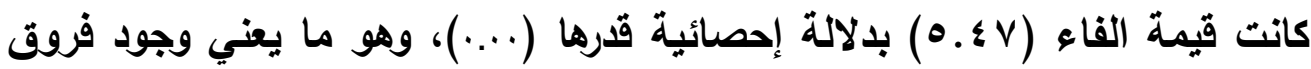
ذات دلالة إحصائية عند مستوى دلالة (ه ...). وقد كانت أعلى المتوسطات لفئة (أستاذ

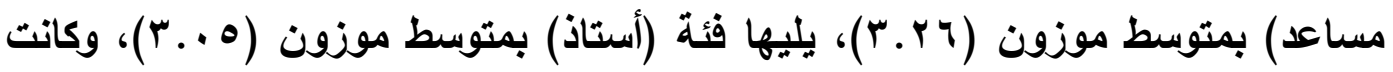

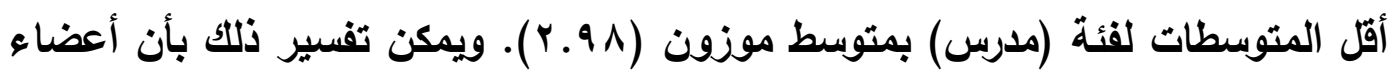
هيئة التدريس من الأساتذة المساعدين يكون الهتمامهم بالجامعة ويأبعاد المنظمة

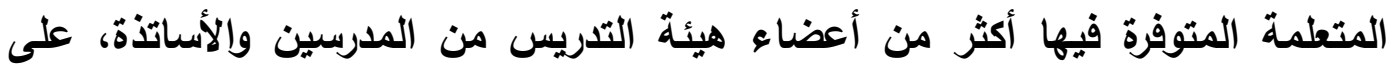

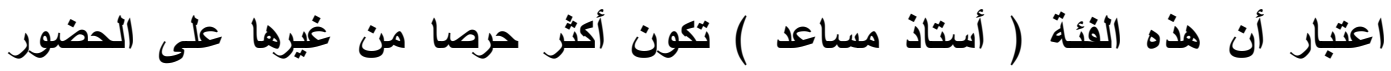

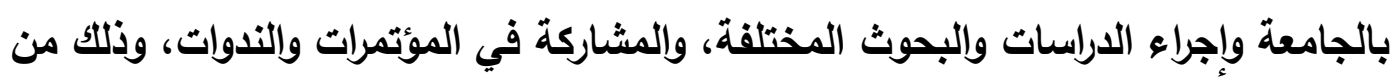




\section{أجل الترقي والحصول على درجة أستاذ. ويوضح الثكل التالي المتوسطات الموزونة}

لاستجابات عينة الداسة بحسب متنير الرتبة الأكاديمية.

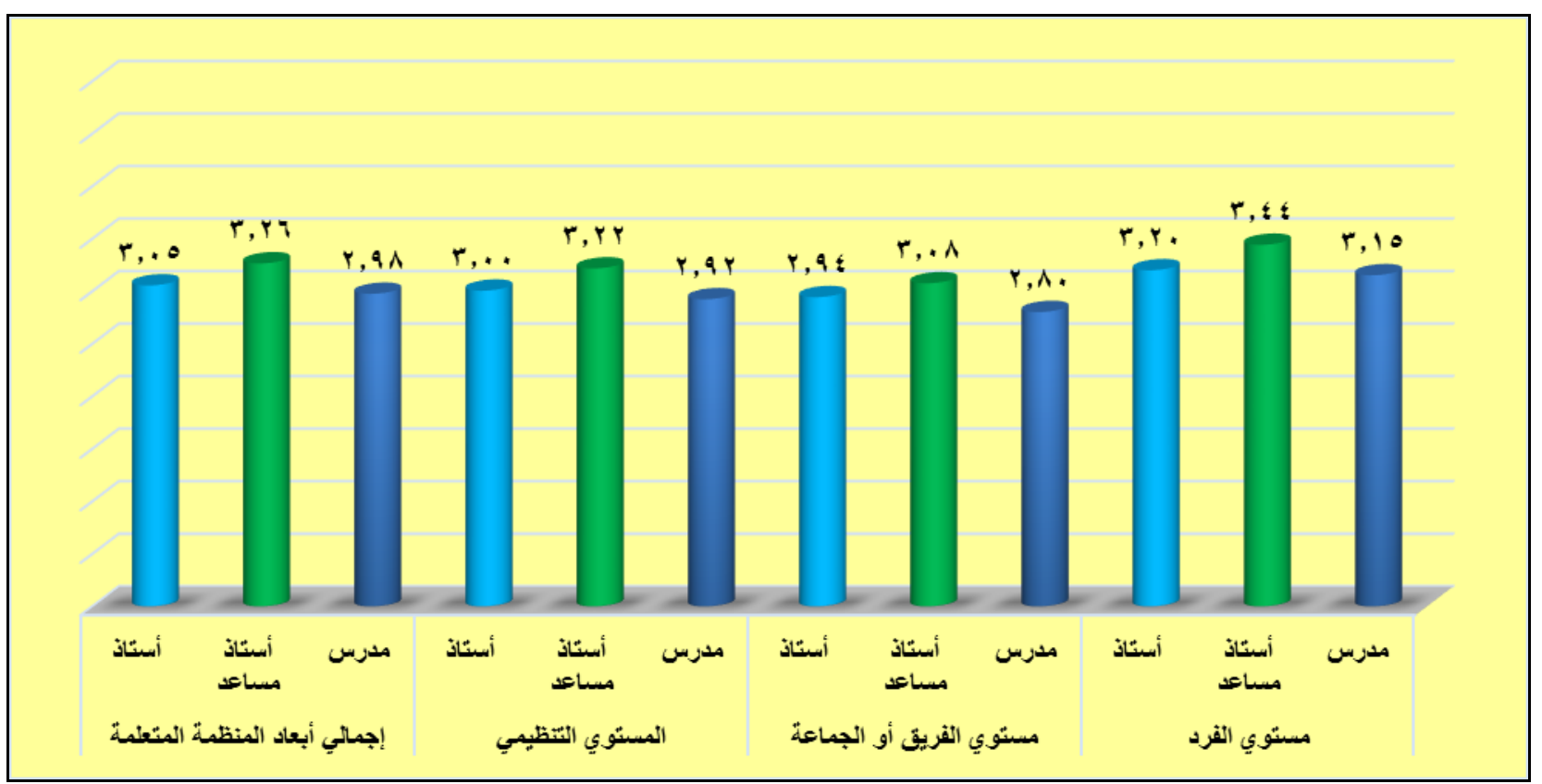

شكل رقم (r I ) يوضح المتوسطات الموزونة لاستجابات عينة الدارسة بحسب

متغير الرتبة الأكاديمية(مدرس / أستاذ مساعد / أستاذ)

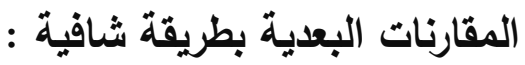

فيما يلي نتائج اختبار شافية للتعرف على اتجاهات الفروق في المحاور التي أظهرت

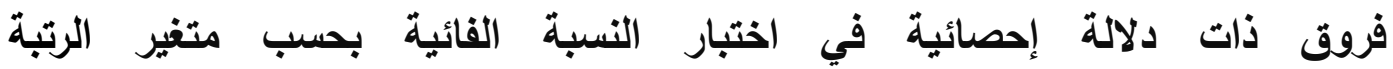
الأكاديمية(مدرس / أستاذ مساعد / أستاذ)

جدول (ז') نتائج اختبار شافيه للفقوق في المحاور بحسب متغير الرتبة الأكاديمية(مدرس / أستاذ مساعد / أستاذ)

\begin{tabular}{|c|c|c|c|c|c|c|}
\hline \multicolumn{2}{|c|}{ الدلالة الإحصائية } & الخطأ المعياري & المتوسطين (أ- الفرق بين & (ب) الركبة & (أ) الرتبة & المستوي \\
\hline دالة & $\because$ & 1.0 & $r . v v_{-}$ & أستاذ مساعد & \multirow{2}{*}{ مدرس } & \multirow{3}{*}{ مستوي الفرد } \\
\hline غير دالة & .07 & 1.7 & $\cdot 71-$ & أستاذ أ & & \\
\hline دالة & .1 & $1.1 \mathrm{~V}$ & r.17 & أستاذ أ & أستاذ مساعد & \\
\hline دالة & .1 & .7 & 1.70 & أستاذ مساعد & \multirow{2}{*}{ مدرس } & \multirow{3}{*}{ أو الجماعة الفريق } \\
\hline غير دالة & .17 & .7 & $\because \wedge 0_{-}$ & أستاذ & & \\
\hline غير دالة & תז. & .77 &..$\vee 9$ & أستاذ & أستاذ مساعد & \\
\hline
\end{tabular}




\begin{tabular}{|c|c|c|c|c|c|c|}
\hline دالة & $\because \cdots$ & $r_{\text {. }} \varepsilon V$ & $V_{.} \cdot \varepsilon_{-}$ & أستاذ مساعد & \multirow{2}{*}{ مدرس } & \multirow{3}{*}{ التنظيمي } \\
\hline غير دالة & $\cdot \varepsilon r$ & r. $\varepsilon \wedge$ & 1.97 & أستاذ & & \\
\hline غير دالة & $\because \cdot 7$ & Y.VT & 0.11 & أستاذ & أستاذ مساعد & \\
\hline
\end{tabular}

يتضح من الجدول السابق ما يلي:

مستوي الفرد: توجد فروق ذات دلالة إحصائية بين فئة (مدرس)، وفئة

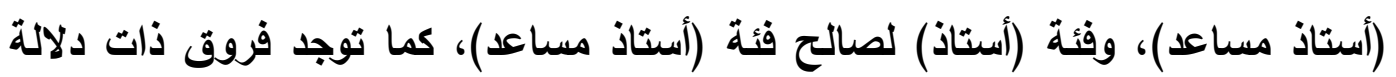

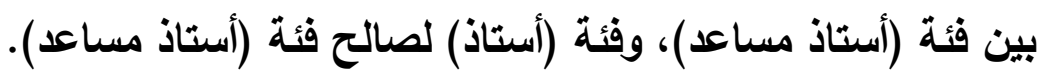

مستوي الفريق أو الجماعة: توجد فروق ذات دلالة إحصائية بين فئة

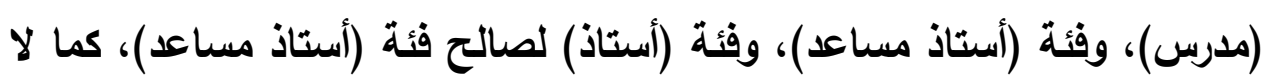
توجد فروق ذات دلالة بين فئة (أستاذ مساعد) وفئة (أستاذ).

المستوي التنظيمي: توجد فروق ذات دلالة إحصائية بين فئة (مدرس)،

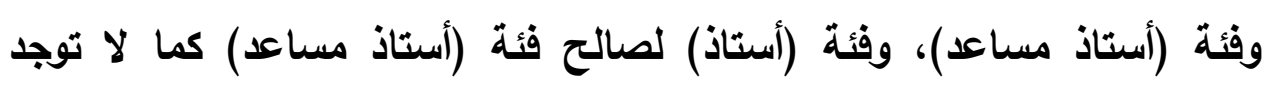
فروق ذات دلالة بين فئة (أستاذ مساعد) وفئة (أستاذ)

ه- دراسة الفروق في المحاور بحسب متغير المركز الوظيفي ( من شغل أو يشغل

حاليا منصبا إداريا/ من لم يشغل منصبا إداريا ):

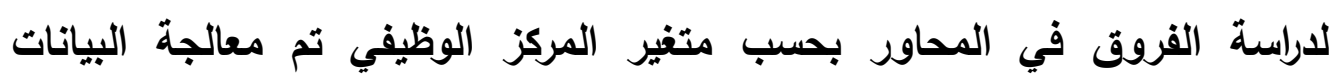

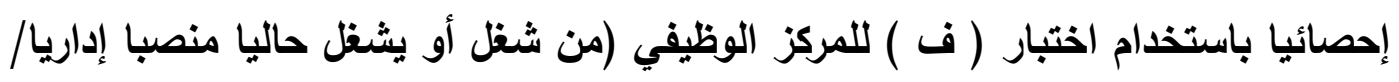

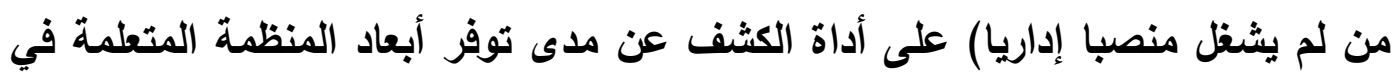

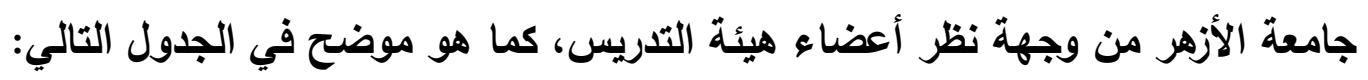
جدول ( ا 1) دراسة الفروق في المحاور بحسب متغير المركز الوظيفي(من شغل

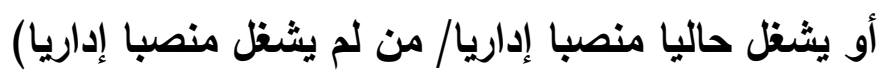

\begin{tabular}{|c|c|c|c|c|c|c|c|c|}
\hline الإحصائية & قيمة التاء & التو افرة & الموزون & الالنحر اف & الحسابي & العدد & الوظيفي & المستوي \\
\hline \multirow[b]{2}{*}{.9.} & \multirow{2}{*}{. } & منوسطة & r.ro & V. $. q \leq$ & $\varepsilon r ., q$ & IrT & ششغلت أو & \multirow[b]{2}{*}{ مستوي الفرد } \\
\hline & & متوسطة & $r . r \leq$ & 9.1 & $\varepsilon r . I V$ & roN & 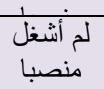 & \\
\hline$\cdot V \varepsilon$ & . r & متوسطة & ५. . ६ & $\varepsilon .94$ & T.TY & TrT & شُشتَت أو & مستوي الفريق \\
\hline
\end{tabular}




\begin{tabular}{|c|c|c|c|c|c|c|c|c|}
\hline & & متوسطة & r.91 & $\varepsilon . \wedge 9$ & IV. $\varepsilon 0$ & ron & لم لم أشغل & \\
\hline \multirow{2}{*}{$\cdot{ }^{V}{ }^{\prime}$} & \multirow{2}{*}{.$r \varepsilon$} & متوسطة & $r .0$ & $19 . Y Y$ & VT.Y. & Kr & شغظلت أو & \multirow{2}{*}{ التظظيمي } \\
\hline & & متوسطة & $r . r$ & $r \cdot r v$ & $v r . \leqslant 0$ & rod & لم أَثنا' & \\
\hline \multirow{2}{*}{$\cdot V 4$} & \multirow{2}{*}{$\cdot r$} & متوسطة & r... & rq. 9 r & ITr.IT & Kr & شُشغلت أو & \multirow{2}{*}{ المنظمة المنعلمة ألعاد } \\
\hline & & متوسطة & $r . \cdot v$ & 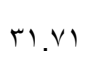 & $1 \pi r . \wedge$ & roN & لمنصبا & \\
\hline
\end{tabular}

يتضح من الجدول السابق ما يلي:

$$
\text { • • المحور الأول (مستوي الفرد): }
$$

كاتت قيمة التاء (ب ا. ·) بدلالة إحصائية قدرها (9 . +)، وهو ما يعني عدم وجود فروق ذات دلالة إحصائية عند مستوى دلالة (ه ...)، وقد كانت أعلى المتوسطات لفئة

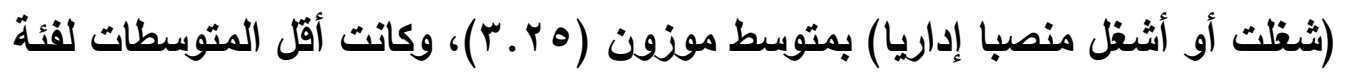
(لم أثخل منصبا إداريا) بمتوسط موزون ( ؟ ب.r). • • المحور الثاني (مستوي الفريق أو الجماعة): كانت قيمة التاء ( ع r. •) بدلالة إحصائية قدرها ( ع V. •)، وهو ما يعني عدم وجود فروق ذات دلالة إحصائية عند مستوى دلالة (ه ...)، وقد كانت أعلى المتوسطات لفئة

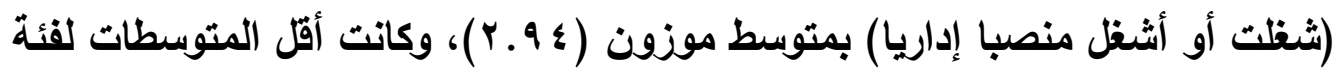

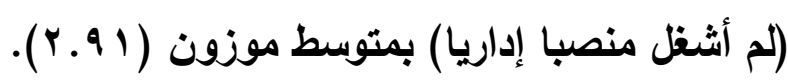
• • المحور الثالث (المستوي التنظيمي):

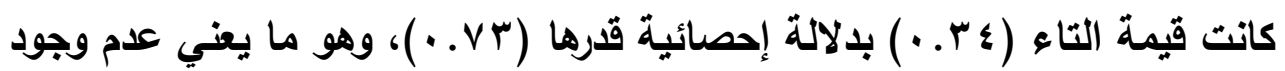
فروق ذات دلالة إحصائية عند مستوى دلالة (ه ...)، وقد كانت أعلى المتوسطات لفئة (شغلت أو أثنظل منصبا إداريا) بمتوسط موزون (ه . ب)، وكانت أقل المتوسطات لفئة

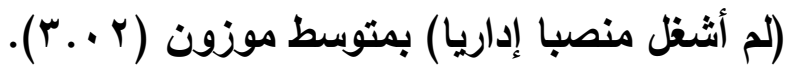
• • (إبمالي أبعاد المنظمة المتعلمة):

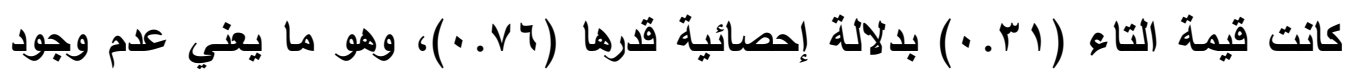
فروق ذات دلالة إحصائية عند مستوى دلالة (ه ...)، وقد كانت أعلى المتوسطات لفئة

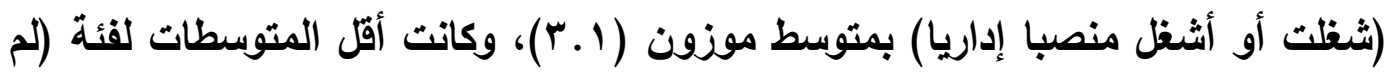

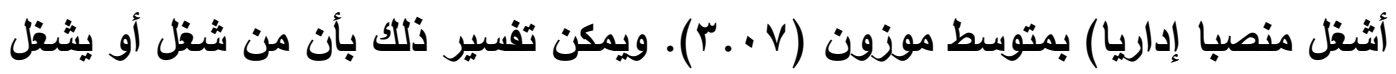


منصبا إداريا بقسمه أو بكليته أو بجامعته هو زميل لعضو هيئة تدريس لم يشغل منصبا

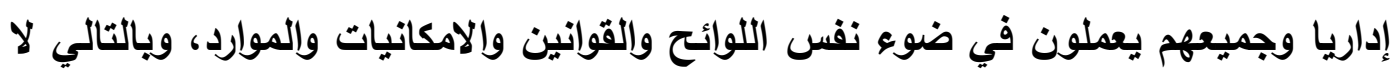
توجد بينهم فروق في درجة استجاباتهم على توفر أبعاد المنظمة المتعلمة بالجامعة.

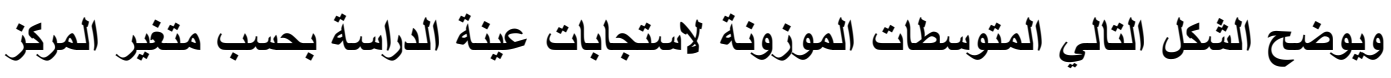

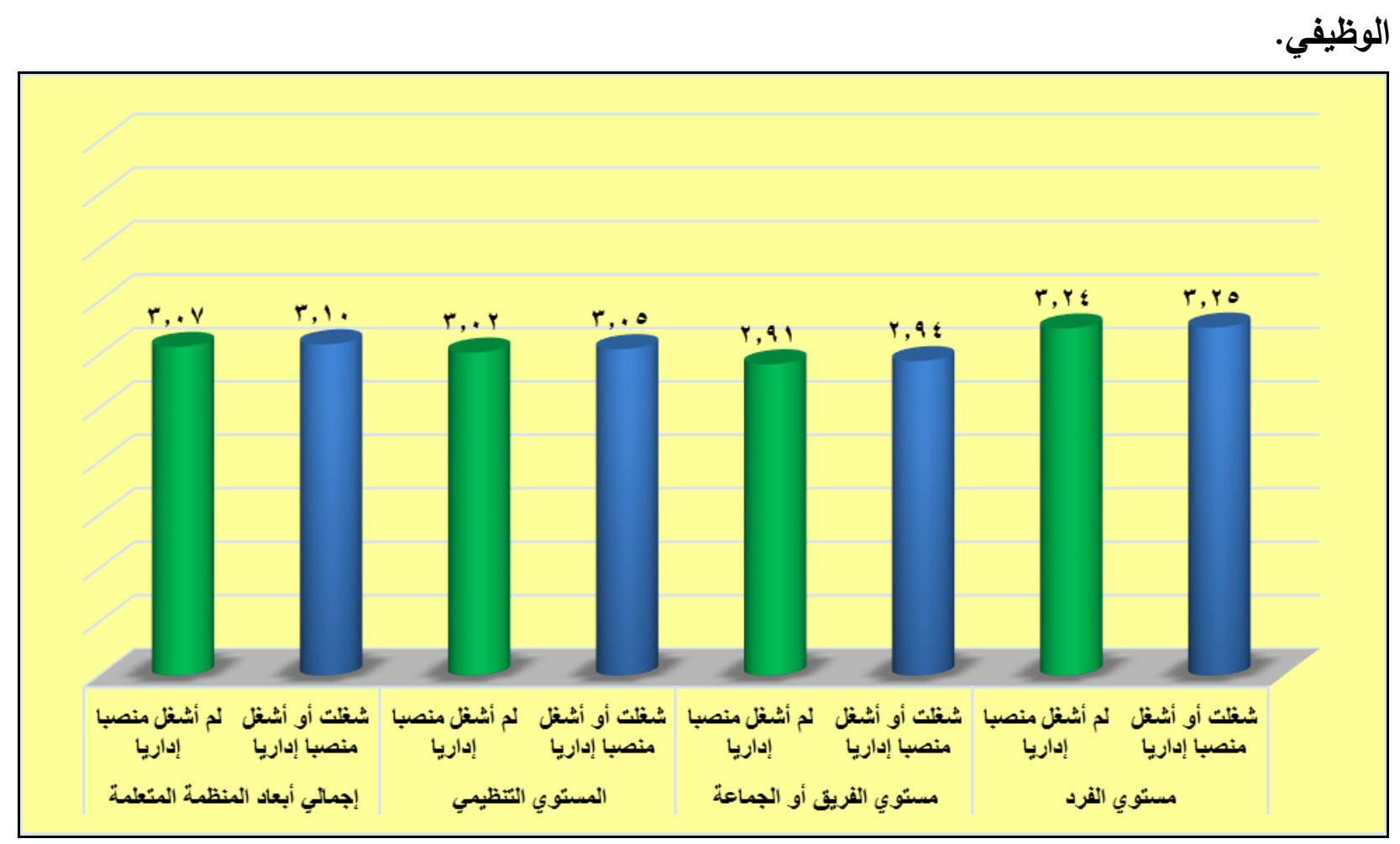

شكل رقم (T 1 ا ) يوضح المتوسطات الموزونة لاستجابات عينة الدراسة بحسب

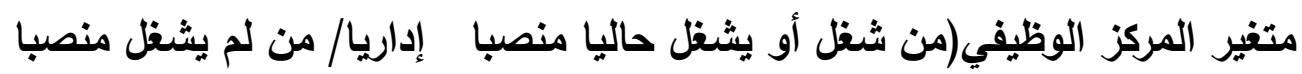
إداريا).

ج- النتائج التفصيلية للعبارات:

• • •

جدول (0 1 ) نتائج العبارات الخاصة بمستوي الفرد.

\begin{tabular}{|c|c|c|c|c|c|c|c|c|c|c|}
\hline \multirow{2}{*}{ كربع } & \multirow{2}{*}{ الترتيب } & \multirow{2}{*}{ الموزون المتوسط } & \multirow{2}{*}{ الالحياري } & \multicolumn{5}{|c|}{ الاستجابات } & \multirow{2}{*}{\multicolumn{2}{|c|}{ العبارة }} \\
\hline & & & & قليلة جدا & قليلة & متوسطة & كبيرة & كبيرة جدا & & \\
\hline \multirow{2}{*}{ r.T.1T } & \multirow{2}{*}{$\varepsilon$} & \multirow{2}{*}{ T. $\leqslant 0$} & \multirow{2}{*}{$\cdot .97$} & 17 & 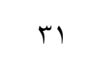 & $1 \leqslant 7$ & $1 \leq$. & $\varepsilon \wedge$ & 5 & الجامعة \\
\hline & & & & $\% \varepsilon . r$. & $\% \wedge .1 \leq$ & \%rی.r & \% r. vo & \%।r.T. & $\%$ & لأعضاء وقلاء \\
\hline $1 \leqslant 7.10$ & 9 & $r .1 T$ & $1 . r$ & rA & $7 \varepsilon$ & $1 \leqslant 1$ & $11 \%$ & rq & ك & أعضاء هيئة \\
\hline
\end{tabular}




\begin{tabular}{|c|c|c|c|c|c|c|c|c|c|c|}
\hline & & & & \%V.To & $\% \backslash 7 . \wedge$. & $\%$ \%.ی० & $\%$ \% & $\% \vee .71$ & $\%$ & لوجهة التدريس \\
\hline \multirow{2}{*}{ ד. } & \multirow{2}{*}{7} & \multirow{2}{*}{ r. } & \multirow{2}{*}{1.0} & rY & 0. & $|r|$ & 1149 & $\leqslant 9$ & ك & يحدد \\
\hline & & & & $\% \circ . V V$ & $\%$ & $\%$ & $\%$ \%. ₹ᄉ & $\%$ & $\%$ & التدريس ما بحته \\
\hline \multirow{2}{*}{$r \leqslant V .70$} & \multirow{2}{*}{1} & \multirow{2}{*}{$\varepsilon . \cdot V$} & \multirow{2}{*}{$\cdot \wedge \Lambda$} & $r$ & 10 & VY & $10 \leqslant$ & $1 T V$ & ك & أعضاه هلئة \\
\hline & & & & $\% \cdot . \vee q$ & $\% r .9 \leq$ & $\% 1 \wedge .9$. & $\% \varepsilon \cdot . \varepsilon r$ & $\%$ & $\%$ & بعضهم التدريس \\
\hline \multirow{2}{*}{ IAV. YA } & \multirow{2}{*}{$r$} & \multirow{2}{*}{ r.o. } & \multirow{2}{*}{.99} & IV & TE & Ir & 100 & or & ك & أعضاء هضيئة \\
\hline & & & & $\% \varepsilon . \leq 7$ & $\% \wedge .9 r$ & \%rr.r人 & $\% \varepsilon \cdot .71$ & $\% 1 T .70$ & $\%$ & وقتا في بناء \\
\hline \multirow{2}{*}{$I V Y . \leqslant 0$} & \multirow{2}{*}{ V } & \multirow{2}{*}{ דr.r } & \multirow{2}{*}{$1 \ldots$} & $r$. & $\varepsilon r$ & $1 \leq \varepsilon$ & Tr & $\varepsilon r$ & ك & أعضاء هيناقة \\
\hline & & & & $\% 0$. ro & $\% 11 . \cdot r$ & $\%$ \%.^. & $\% r \leq .70$ & $\% 11.49$ & $\%$ & بصر احة ما التدريس \\
\hline \multirow{2}{*}{ س } & \multirow{2}{*}{$\wedge$} & \multirow{2}{*}{ r.Tr } & \multirow{2}{*}{1.4} & ro & 07 & $1 \leq 7$ & 117 & 巾人 & ك & أعضاء هيئة \\
\hline & & & & $\% 7.07$ & $\% \backslash \leq . \vee$. & $\%$ \%.r & $\% \Gamma \cdot . \leqslant 0$ & $\% 9.9 V$ & $\%$ & بعضهم التريس \\
\hline \multirow{2}{*}{$r .0 . \cdot r$} & \multirow{2}{*}{0} & \multirow{2}{*}{$r . \varepsilon \varepsilon$} & \multirow{2}{*}{.90} & 10 & rv & דאו & 101 & $\varepsilon r$ & ك & أعضاء هيئة \\
\hline & & & & $\%$ \%.q & $\% 9.71$ & \%ro.v. & \% \% & $\% 11 .+r$ & $\%$ & التشريسلات مع \\
\hline \multirow{2}{*}{ rrI.19 } & \multirow{2}{*}{ r } & \multirow{2}{*}{$r .00$} & \multirow{2}{*}{$\because 9$} & 7 & $\varepsilon 1$ & $|r|$ & 170 & $\varepsilon \wedge$ & ك & أعضاء هينئة \\
\hline & & & & $\% 1.0 \mathrm{~V}$ & $\% 1 \cdot V T$ & $\%$ \% & $\% \leq r . r \mid$ & $\%$ \%. & $\%$ & لوجهات الندريس \\
\hline \multirow{2}{*}{ loV.YO } & \multirow{2}{*}{ r } & \multirow{2}{*}{$r .00$} & \multirow{2}{*}{.91} & 9 & rq & דשו & Tr & VI & 5 & أعضاء هيئة \\
\hline & & & & \% & $\% 1 \cdot r \leq$ & $\%$ ro.v. & \%rr.v & $\% \backslash \wedge .7 \leq$ & $\%$ & بعضهم التذريس \\
\hline $1>0$ & & & & $11 \leq$ & $1 \cdot r$ & $11 \varepsilon$ & rv & IT & 5 & أعضاء هيئة \\
\hline & & & & $\%$ \% $9.9 r$ & $\% r v .+r$ & $\% r q .9 r$ & $\% 9 . \vee 1$ & $\%$ \%. & $\%$ & تدبير الدريس \\
\hline Ir re & $1)$ & חז ז & & $1 \cdot r$ & $11 r$ & 111 & rv & IT & ك5 & الجامعة \\
\hline 111.78 & 11 & 1.11 & .8 & \% r . V & $\%$ \% & $\% r \cdot .9 v$ & $\% 9 . \vee 1$ & $\%$ \%. 10 & $\%$ & أعضاء هيئة \\
\hline & & & & ז & $\wedge 1$ & 174 & $V T$ & ro & ك & أعضاء هيئة \\
\hline & & & & $\% 9 . \leq 0$ & \% & $\% \leq r . \vee \wedge$ & $\% 19.90$ & $\% 7.07$ & $\%$ & بعضهم اللذريس \\
\hline
\end{tabular}

يتضح من الجدول السابق أن عبارات محور مستوى الفرد قد جاءت بدرجات توفر قليلة ومتوسطة وكبيرة، حيث تراوحت المتوسطات الموزونـة للعبارات في الفترة ( • ب. - V . . ؛). ويترتيب العبارات تنازليا بحسب المتوسط الموزون يلاحظ أنها جاءت بالترتيب

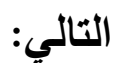

• يعامل أعضاء هيئة التّريس بعضهم البعض باحترام، بمتوسط موزون V..؛،

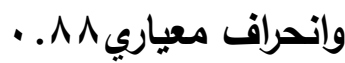


يساعد أعضاء هيئة التدريس بعضهم بعضا بهاف التعلم والاستفادة من التجارب، بمتوسط موزونه ه.r، وانحراف معياري 91 . . • يُصغي أعضاء هيئة التريس لوجهات نظر الآخرين قبل التحدث معهم، بمتوسط

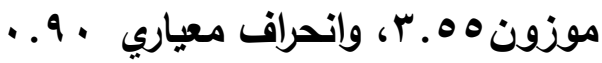
• يقضي أعضاء هيئة التدريس وقتا في بناء الثقة فيما بينهم، بمتوسط موزون

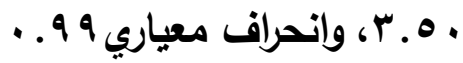

• توفر الجامعة وقتا لأعضاء هيئة التدريس لاعم عملية التعلم، بمتوسط

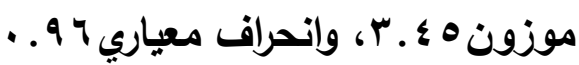
• يتعامل أعضاء هيئة التدريس مع المشكلات التي تواجههم باعتبارها فرصا للتعلم، هورئ

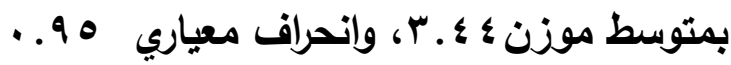

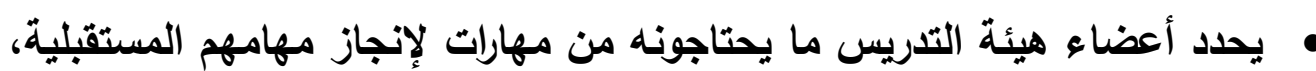
بمتوسط موزون ^ץ.ץ، وانحراف معياريه ه. ـ1. يناقش أعضاء هيئة التدريس بصراحة ما يقعون فيه من أخطاء بهاف التعلم والاستفادة، بمتوسط موزون צr. با، وإنحراف معياري . ..1. يزود أعضاء هيئة التدريس بعضهم بعضا بتغذية راجعة منفتحة وأمينة، بمتوسط مونط

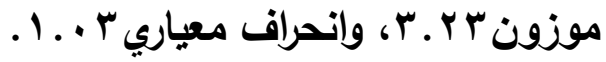
• عرض أعضاء هيئة التتريس لوجهة نظرهم لا يعفيهم من سماع وجهة نظر مورئ الزملاء، بمتوسط موزون ب ا.ب ، وانحراف معياري ץ ..1. • يشجع أعضاء هيئة التدريس بعضهم بعضا على أن يسألوا الآخرين " لماذا "

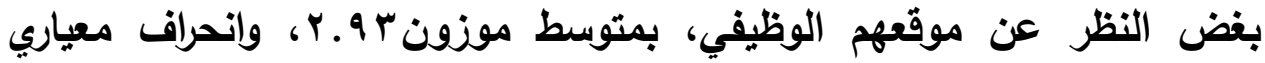
$.1 .+r$

• تكافأ الجامعة أعضاء هيئة التدريس على تعلمه مهارات جليدة، بمتوسط

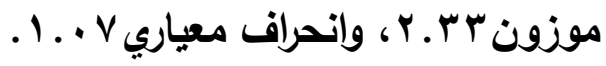
• يستطيع أعضاء هيئة التدريس تدبير الامكانات اللازمة لدعم تعلمهم وتطوير

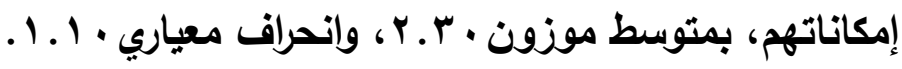
• • نتائج عبارات المحور الثاني: مستوي الفريق أو الجماعة: 
جدول (7 1 ) نتائج العبارات الخاصة بمستوى الفريق أو الجماعة

\begin{tabular}{|c|c|c|c|c|c|c|c|c|c|c|}
\hline \multirow{2}{*}{ كربع } & \multirow{2}{*}{ الترتيب } & \multirow{2}{*}{ الموزون } & \multirow{2}{*}{ الانحرياري } & \multicolumn{5}{|c|}{ الاستجابات } & \multirow{2}{*}{\multicolumn{2}{|c|}{ العبارة }} \\
\hline & & & & قليلة جدا & قليلة & متوسطة & كبيرة & كبيرة & & \\
\hline \multirow{2}{*}{$9 \leq . Y 7$} & \multirow{2}{*}{7} & \multirow{2}{*}{$r . \leqslant 1$} & \multirow{2}{*}{1.15} & 1.0 & $9 \pi$ & 117 & $0 \varepsilon$ & $1 \pi$ & s & \multirow{2}{*}{ أنكافأ الجامعة هيئة } \\
\hline & & & & $\%$ YV.0T & $\% r \leq . \leq 1$ & $\% ץ \cdot . \leq 0$ & $\%) \leq .1 V$ & $\% r . \varepsilon 1$ & $\%$ & \\
\hline \multirow{2}{*}{$1 \leq \cdot .71$} & \multirow{2}{*}{ r } & \multirow{2}{*}{$r .9$} & \multirow{2}{*}{$1 . r$} & צ & vo & $1 \leqslant 9$ & $1 \cdot r$ & rq & ك & \multirow{2}{*}{ تلفكير هاجئ التيسية } \\
\hline & & & & $\%$ \%.Ar & $\% 19.79$ & $\%$ \%.11 & \%rч.VY & $\% \vee .71$ & $\%$ & \\
\hline \multirow[b]{2}{*}{$1 . r . r \mid$} & \multirow[b]{2}{*}{$\varepsilon$} & \multirow[b]{2}{*}{ r.qT } & \multirow[b]{2}{*}{1.1} & 0. & VY & ITs & $1 \cdot \varepsilon$ & r) & 5 & \multirow{2}{*}{ ألتامل التداء هيئة } \\
\hline & & & & $\%$ \%.T & $\% \backslash 1.9$. & $\%$ ro. IV & \%rv.r. & $\% 0.01$ & $\%$ & \\
\hline \multirow{2}{*}{100.70} & \multirow{2}{*}{$r$} & \multirow{2}{*}{$r .0$} & \multirow{2}{*}{.99} & $r \varepsilon$ & $\wedge$. & 100 & 97 & rT & 5 & \multirow{2}{*}{ أتحرية التدريسية التهيئة } \\
\hline & & & & $\%$ \%.r. & $\% r ! .$. & $\% \leq \cdot .71$ & $\% r_{0}, r$. & $\%\ulcorner. \wedge r$ & $\%$ & \\
\hline \multirow{2}{*}{101.11} & \multirow{2}{*}{1} & \multirow{2}{*}{ r.וT } & \multirow{2}{*}{$1 . r$} & TV & $7 \varepsilon$ & 109 & 97 & ro & s & \multirow{2}{*}{ تركز التدريسية } \\
\hline & & & & $\% v . \cdot 9$ & $\% 17 . \wedge$ & $\% \leqslant 1 . V T$ & $\%$ \%,$r$. & $\% 9.19$ & $\%$ & \\
\hline \multirow{2}{*}{$97.9 \leq$} & \multirow{2}{*}{0} & \multirow{2}{*}{ r.q. } & \multirow{2}{*}{1.11} & $\leqslant \wedge$ & 1) & $1 \leqslant 1$ & ה & rA & ك & \multirow{2}{*}{ 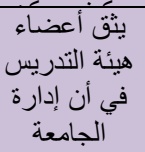 } \\
\hline & & & & $\%$ \%.т. & $\%$ Yl.ru & $\% r v .+1$ & $\%$ \% .VA & $\%$ \%.ro & $\%$ & \\
\hline
\end{tabular}

يتضح من الجدول السابق أن عبارات محور مستوى الفريق أو الجماعة قد جاءت بلدرجات توفر قليلة ومتوسطة حيث تراوحت المتوسطات الموزونـة للعبارات في القترة

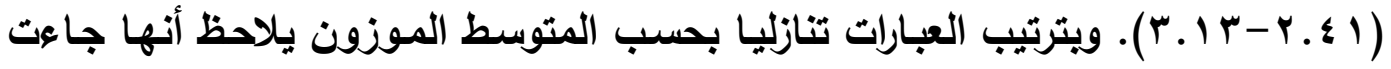
بالترتيب التالي:

• تركز الهيئة التدريسية على مهمتها كفريق، وكيف يمكن أن يعمل بشكل جيد،

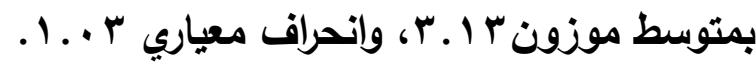
تراجع الهيئة التدريسية تفكيرها نتيجة للمناقشات الجادة التي تتم بين أعضائها، بمتوسط موزون 9 . .ب، وانحراف معياري r ... •تتمتع الهيئة التدريسية بحرية لتكيف أهدافها حسب حاجة الجامعة، بمتوسط موزون ه ...r، وانحراف معياري 99. 
• تعامل الجامعة أعضاء هيئة التدريس على قدم المساواة بغض النظر عما بينهم

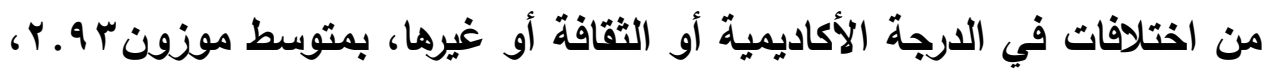

$$
\text { وانحراف معياري • 1. 1. }
$$

يثق أعضاء هيئة التدريس في أن إدارة الجامعة ستعمل في ضوء توصياتهم.

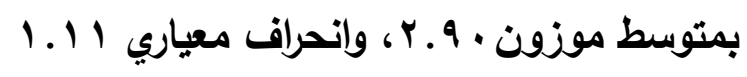

• تكافأ الجامعة أعضاء هيئة التريس على إنجازاتهم كفريق عمل، بمتوسط

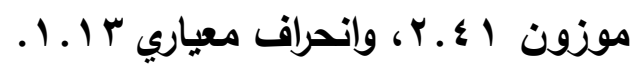

\begin{tabular}{|c|c|c|c|c|c|c|c|c|c|c|}
\hline \multirow{2}{*}{ كربع } & \multirow{2}{*}{ الترتيب } & \multirow{2}{*}{ الموزون } & \multirow{2}{*}{ الالانحراف } & \multicolumn{5}{|c|}{ الاستجابات } & \multirow{2}{*}{\multicolumn{2}{|c|}{ العبارة }} \\
\hline & & & & قليلة جدا & قليلة & متوسطة & كبيرة & كبيرة جدا & & \\
\hline \multirow{2}{*}{$110.9 \leqslant$} & \multirow{2}{*}{ r } & \multirow{2}{*}{$r . \wedge$} & \multirow{2}{*}{1.11} & $r \Lambda$ & זיד & $10 \xi$ & הT & $\varepsilon r$ & ك & \multirow{2}{*}{ الجاتصعة } \\
\hline & & & & $\% 9.9 \vee$ & $\% 17.0 \leq$ & $\% \varepsilon \cdot . \leqslant r$ & $\%$ \%.VA & $\% 11.49$ & $\%$ & \\
\hline \multirow{2}{*}{$149 . \leqslant 1$} & \multirow{2}{*}{10} & \multirow{2}{*}{ r.Ar } & \multirow{2}{*}{$1 . r$} & $\varepsilon r$ & $9 \pi$ & $10 \leqslant$ & VI & r. & 5 & \multirow{2}{*}{ النظم لقبامعة النجوة بين } \\
\hline & & & & $\% 11.49$ & $\% r \leq \leq \leq 1$ & $\% \leqslant \cdot . \leqslant r$ & $\% \backslash 1.7 \varepsilon$ & $\%$ o.ro & $\%$ & \\
\hline \multirow{2}{*}{149.11} & \multirow{2}{*}{$\wedge$} & \multirow{2}{*}{ r.9r } & \multirow{2}{*}{$1 . \cdot \varepsilon$} & $\varepsilon 1$ & VI & $10 \mathrm{~V}$ & $\wedge \varepsilon$ & rT & 5 & \multirow{2}{*}{ الجامعة مع المجمل } \\
\hline & & & & $\% 1 \cdot . \vee 4$ & $\% 19.90$ & $\% \leq l . r \mid$ & $\%$ rr.. & $\%\urcorner . \cdot \leq$ & $\%$ & \\
\hline \multirow{2}{*}{$1 \leqslant r . \wedge r$} & \multirow{2}{*}{0} & \multirow{2}{*}{$r . r$} & \multirow{2}{*}{$1 . \cdot \varepsilon$} & rr & vr & 109 & $\wedge T$ & r & ك & \multirow{2}{*}{ أعضاء هيئة التحنح } \\
\hline & & & & $\% \wedge . \varepsilon$. & $\% 19.17$ & $\% \leqslant 1 . V r$ & \%rr.ov & $\% \wedge .1 \leq$ & $\%$ & \\
\hline \multirow{2}{*}{$109 . \mathrm{K}$} & \multirow{2}{*}{$\wedge$} & \multirow{2}{*}{ r.qT } & \multirow{2}{*}{1.1} & $r \varepsilon$ & Ar & 174 & $\wedge$ & rr & 5 & \multirow{2}{*}{ تُقلقيم الجامعلة } \\
\hline & & & & $\% \wedge .9 r$ & $\%$ Y . Or & $\% \leqslant r .0 r$ & $\% r l, r u$ & $\% ० . V V$ & $\%$ & \\
\hline \multirow{2}{*}{ l.v.ro } & \multirow{2}{*}{$1 \leqslant$} & \multirow{2}{*}{$r . \wedge r$} & & $0 \leqslant$ & $\wedge \varepsilon$ & 101 & 07 & 4 & ك & التُفوضة \\
\hline & & & 1.11 & $\%$ \%. $\mid V$ & $\% r r . .0$ & $\%$ \% & $\% 1 \leq . \vee$. & $\% 9 . \leq 0$ & $\%$ & التضاء هيئة \\
\hline & & & & 0 . & A. & $1 \leqslant 9$ & 10 & IV & ك5 & الجامعنة \\
\hline Tro.V7 & IT & 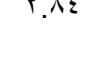 & 1.9 & $\%$ \% & $\% r 1 .$. & $\%$ \%.11 & \%rr.r. & $\% \leq . \leq 7$ & $\%$ & ألتدريس مناء هيئة \\
\hline & & & & vi & $1 . r$ & IT & or & rI & ك5 & تمعر فة أثرعة \\
\hline . & r & . & 1.11 & $\% \backslash \wedge .7 \varepsilon$ & $\%$ \% .VV & $\% r 0.1 \mathrm{~V}$ & $\% 1 r .91$ & $\% 0.01$ & $\%$ & قرار اتها في \\
\hline & & & & $\leq 7$ & $\wedge 7$ & 179 & Ar & $r \wedge$ & s & الجامعة \\
\hline . & 10 & .10 & .1. & $\%$ 'r. .V & \%rr.ov & $\%$ \%. $\leqslant \wedge$ & $\%$ \% .Or & $\%$ \%.ro & $\%$ & بيانات \\
\hline
\end{tabular}

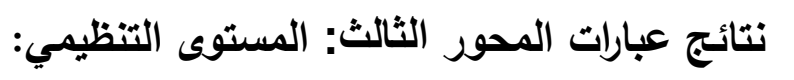

جدول ( V V ن ائج العبارات الخاصة بالمستوى التنظيمي 


\begin{tabular}{|c|c|c|c|c|c|c|c|c|c|c|}
\hline \multirow{2}{*}{$99.1 \mathrm{~V}$} & \multirow{2}{*}{7} & \multirow{2}{*}{$r . .1$} & \multirow{2}{*}{1.1} & $\varepsilon r$ & VY & ع & $1 \cdot \varepsilon$ & rA & ك5 & \multirow{2}{*}{ أعضاء هيئة التشعة } \\
\hline & & & & $\% 11.49$ & $\% 1 \wedge .9$. & $\%$ ro. IV & $\% Y Y . r$. & $\% \vee . r o$ & $\%$ & \\
\hline \multirow{2}{*}{$9 \vee .1}$. & \multirow{2}{*}{1} & \multirow{2}{*}{$r . \cdot 1$} & \multirow{2}{*}{1.1} & $\leqslant 1$ & vo & 1ro & $1 \ldots$ & $r$. & ك & \multirow{2}{*}{ التبرامتحة التبح } \\
\hline & & & & $\% 1 \cdot . \vee 7$ & $\% 19.79$ & $\%$ \% & \%rт.ro & $\% \vee . \wedge \vee$ & $\%$ & \\
\hline \multirow{2}{*}{$97 . \wedge 7$} & \multirow{2}{*}{ ir } & \multirow{2}{*}{ r.AT } & \multirow{2}{*}{1.99} & $\varepsilon \wedge$ & 9. & & NV & rr & ك5 & \multirow{2}{*}{ ألخاء هلدعة } \\
\hline & & & & $\%$ \%. & \%rt.tr & $\%$ ro. IV & \%rr.Ar & $\% \circ . V V$ & $\%$ & \\
\hline \multirow{2}{*}{$1 \leqslant r . \wedge v$} & \multirow{2}{*}{ v } & \multirow{2}{*}{ r. $9 \varepsilon$} & \multirow{2}{*}{$1 . \cdot r$} & rr & 19 & 100 & $\wedge$. & ro & ك & \multirow{2}{*}{ بي الإداريون القادة } \\
\hline & & & & $\% \wedge . \varepsilon$. & \% \% & $\%\{\cdot .71$ & $\% ఛ ! .$. & $\% 7.07$ & $\%$ & \\
\hline \multirow{2}{*}{ irr.q. } & \multirow{2}{*}{ IV } & \multirow{2}{*}{5.79} & \multirow{2}{*}{$1 . \cdot v$} & 07 & 1.7 & $1 \leqslant 0$ & o. & $r \varepsilon$ & 5 & \multirow{2}{*}{ ألجضاء هيئة } \\
\hline & & & & $\%) \leq . \vee$. & $\% r v . \wedge r$ & $\%$ \%.. & $\%$ & $\% ч . r$. & $\%$ & \\
\hline \multirow{2}{*}{170.10} & \multirow{2}{*}{10} & \multirow{2}{*}{ r.Ar } & \multirow{2}{*}{$1 . \cdots$} & $\leq 0$ & Ar & $17 \varepsilon$ & VT & $1 \varepsilon$ & ك5 & تشجع الجامعة \\
\hline & & & & $\% 11 . \wedge 1$ & $\%$ r $.0 r$ & $\% \varepsilon r . . \varepsilon$ & $\% 19.90$ & $\%$ \%.TV & $\%$ & أعضاء هيئة \\
\hline & & & & 71 & 90 & 1149 & זי & 17 & ك5 & تساعدة \\
\hline $1 \cdot v .1 T$ & 11 & $T .72$ & $1 . \times 1$ & $\%$ \% .^o & $\% r \leq .9 r$ & $\% r 4 . \leqslant \wedge$ & $\% 17.0 \leqslant$ & $\% \varepsilon . Y$. & $\%$ & أعضاء هيئة \\
\hline 20004 & 4 & r & 1 & r & 19 & 17. & vo & r) & ك5 & الإداريون القادة \\
\hline (2) & & 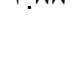 & 1. & $\% 9 . \leqslant 0$ & דr.r. & $\% \leqslant 1.99$ & $\% 19.79$ & $\% 0.01$ & $\%$ & طبالجاتعة \\
\hline 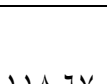 & 17 & r & 1 - & or & Ar & $1 \leqslant 9$ & VT & r. & 5 & بدرب الإداريون \\
\hline $11 \mathrm{~T} . \mathrm{T}$ & 11 & T.人! & $1 . \cdot v$ & $\% 1 r .91$ & $\%$ Y I.VA & $\%$ \%. 11 & $\% 19.90$ & $\%$ \% ro & $\%$ & أعضاء هيئة \\
\hline & & & & $\varepsilon r$ & v. & 149 & $1 . r$ & ru & كs & الجامعة \\
\hline NT. 19 & $r$ & $r .0$ & 1.15 & $\% 11.4 q$ & $\% \backslash \wedge . r \vee$ & 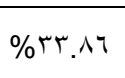 & $\% r v . r$ & $\% 9 . \leqslant 0$ & $\%$ & ألتدريس بهاء هيئة \\
\hline & & & & זr & $\wedge 7$ & ITr & VV & rr & ك & بالقارةك \\
\hline 109.01 & 9 & T.9Y & 1.91 & $\% \wedge .77$ & \%rr.ov & $\% \leqslant r .0 r$ & $\% r \cdot . r)$ & $\%\urcorner . \cdot \varepsilon$ & $\%$ & في الإداريونة \\
\hline & & & & rv & q & 100 & vo & r) & ك5 & الجامعةٌ في \\
\hline $1 \leqslant 0 . r 9$ & $\pi$ & T.AV & $1 . \cdot r$ & $\% 9.71$ & $\% r \leq . \leq 1$ & $\% \leq \cdot.\rceil \wedge$ & $\% 19.79$ & $\% 0.01$ & $\%$ & الاستفادة من أنبار \\
\hline & & & & rᄉ & $v$. & r & $1 \ldots$ & r) & ك & الإداريوم الَّادة \\
\hline Tro."T & $z$ & $T . \cdot z$ & $\cdot .4 \lambda$ & \%v.ro & $\%$ \%.rV & $\% \leqslant r .0 r$ & \%rт.ro & $\% 0.01$ & $\%$ & التدريس من هنئة \\
\hline & & & & r & $T \varepsilon$ & ITV & 99 & $r$. & ك & الجامعة \\
\hline 110.11 & 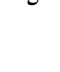 & 1.1 & $\ddots .7 \lambda$ & $\% \wedge .1 \leq$ & $\% 17 . \wedge$ & $\% \leqslant r . \wedge r$ & $\%$ \% .91 & $\%$ o. ro & $\%$ & لتطوير نظاما \\
\hline & 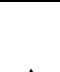 & & & rV & $0 \xi$ & & ro & «1 & 5 & يحرص القادة \\
\hline 119.09 & 1 & $T . T 4$ & 1.9 & $\% v .+q$ & $\%) \leq .1 V$ & $\%$ \%o. IV & 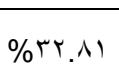 & $\% 1 \cdot . \vee 7$ & $\%$ & على تطابيق \\
\hline
\end{tabular}


يتضح من الجدول السابق أن عبارات محور المستوى التظيمي قد جاءت بلرجات

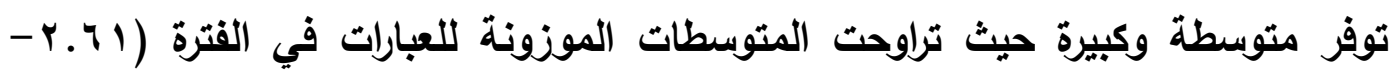
جr.r). ويترتيب العبارات تنازليا بحسب المتوسط الموزون يلاحظ أنها جاءت بالترتيب

يحرص القادة الإداريون على تطابق قراراتهم وأفعالهم مع قيم الجامعة وأعرافها،

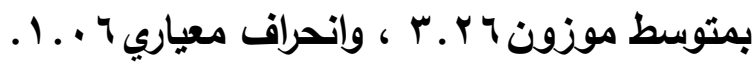
تستخدم الجامعة وسائل الاتصال المتبادل ( لوحات الإعلانات الالكترونية،

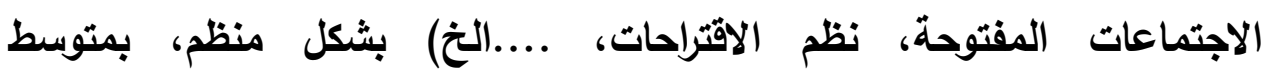

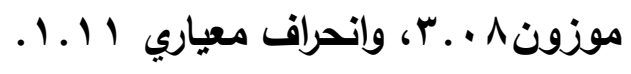

• تلدعو الجامعة أعضاء هيئة التّريس بها للإسهام في وضع رؤيتها، بمتوسط

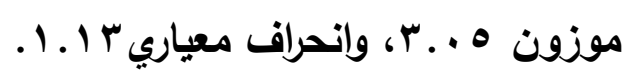

• يدعم القادة الإداريون أعضاء هيئة التدريس من أجل تنفيذ روئية الجامعة

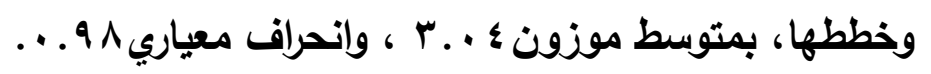

• تتبنى الجامعة نظاما لتطوير روئها من خلال المستويات الإدارية المختلفة

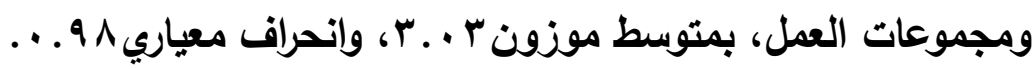

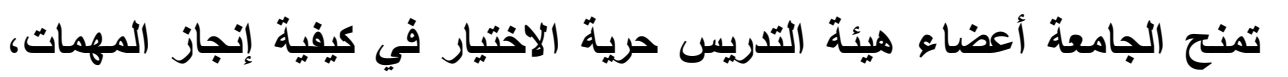

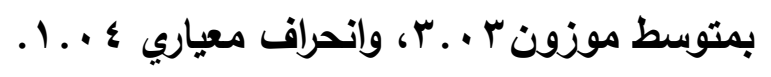
• ت تتيح الجامعة البرامج التدريبية لجميع أعضاء هيئة التدريس باستمرار، بمتوسط كوناه موزون ا +.ب، وانحراف معياري • 1. 1. تثجع الجامعة أعضاء هيئة التدريس على التفكير من منظور عالمي، بمتوسط

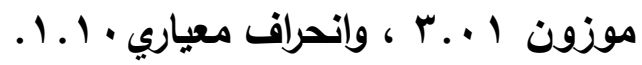
•يبحث القادة الإداريون في الجامعة باستمرار عن فرص التعلم، بمتوسط

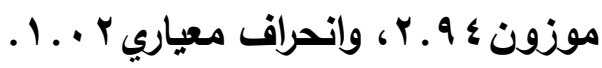

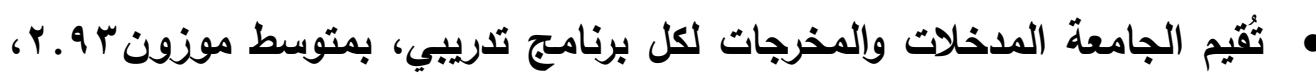
وانحراف معياري 1 ..1. • تعمل الجامعة مع المجتمع المحلي لتلبية الحاجات المتبادئة، بمتوسط

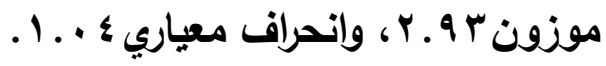


• يشارك القادة الإداريون في الجامعة أعضاء هيئة التدريس في المعلومات الحديثة عن الاتجاهات التظظيمية، بمتوسط موزون ب 9.ب، وانحراف معياري 1 ..1.

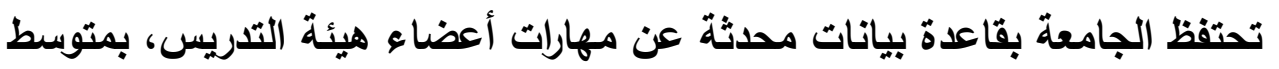

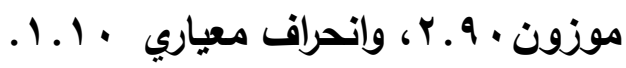
يدعم القادة الإداريون بالجامعة طلبات أعضاء هيئة التريس المتعلقة بفرص

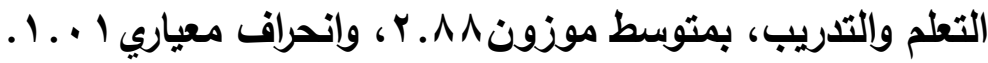
تضع الجامعة في اعتبارها الاستفادة من وجهات نظر المستفيدين من خدماتها في

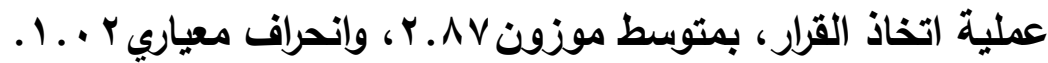
تدعم الجامعة أعضاء هيئة التدريس ذوي المبادرات البناءة محسوية المخاطر،

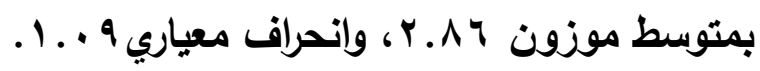
• تُمكن الجامعة أعضاء هيئة التدريس من الحصول على المعلومات المطلوية في

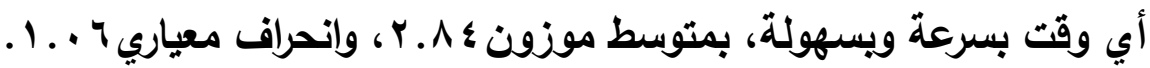
• تُقوض الجامعة أعضاء هيئة التدريس للقيام بالرقابة على الموارد المطلوية

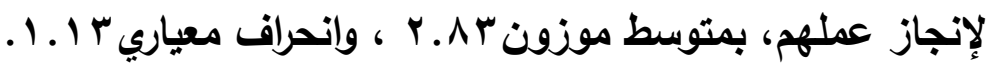
تبتكر الجامعة النظم لقياس الفجوة بين الأداء الحالي والأداء المتوقع، بمتوسط

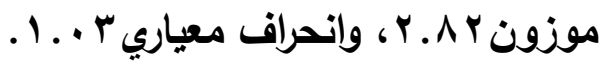

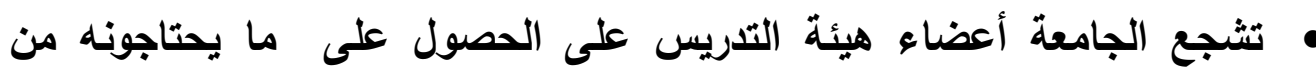

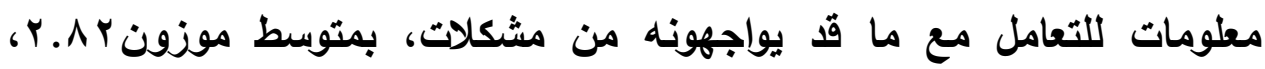
وانحراف معياري ...1. أ. يدرب القادة الإداريون أعضاء هيئة التريس طبقا لاحتياجاتهم، بمتوسط

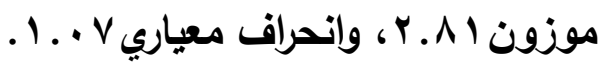
تساند الجامعة أعضاء هيئة التدريس ذوي حب المغامرة في العمل، بمتوسط

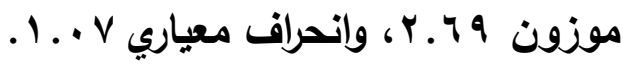
تساعد الجامعة أعضاء هيئة التدريس على الموازنة بين متطلبات العمل هونل

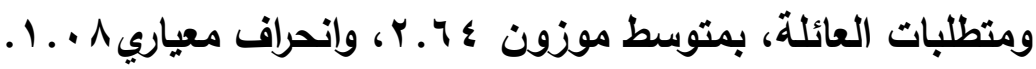
تهتم الجامعة بمعرفة أثر قراراتها في الروح المعنوية لأعضاء هيئة التدريس، بمتوسط موزون 11. 1 ، وإنحراف معياري 11.1. 
التصور المقترح لتحويل جامعة الأزهر إلى منظمة متعلمة

مقدمه:

في ضوء الإطار النظري للاراسة، وفي ضوء نتائج الدراسة الميدانية، وكذا في

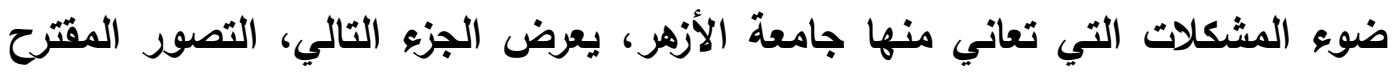

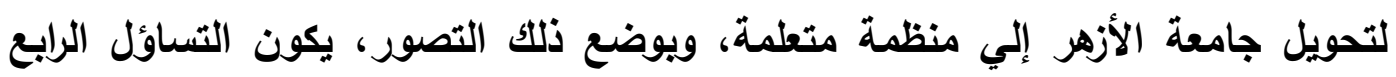
والأخير من تساؤلات الاراسة قد تمت الإجابة عليه كسابقيه من تساؤلات.

هذا وقد أسفر التحليل المنهجي والإحصائي لاستبانة أبعاد المنظمة المتعلمة، التي تم تطويرها بواسطة Marsick \& Watkins, 1993 والتي تم استخدامها وتطبيقها من قبل الباحث على عينة من أعضاء هيئة التدريس بجامعة الأزهر، عن توافر أبعاد

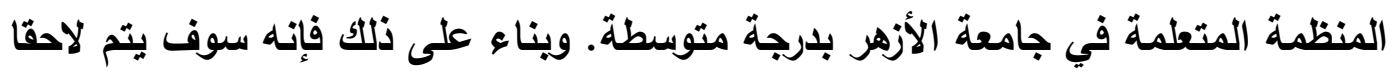

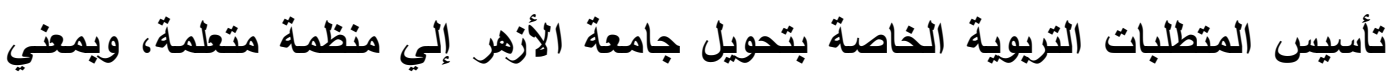

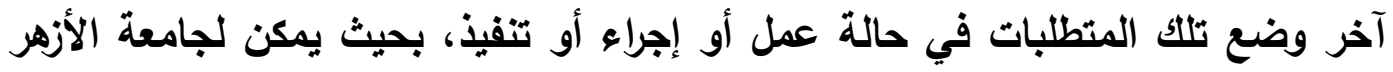
بناء على تلك المتطلبات أن تكون قادرة على التحول إلي منظمة متعلمة. 


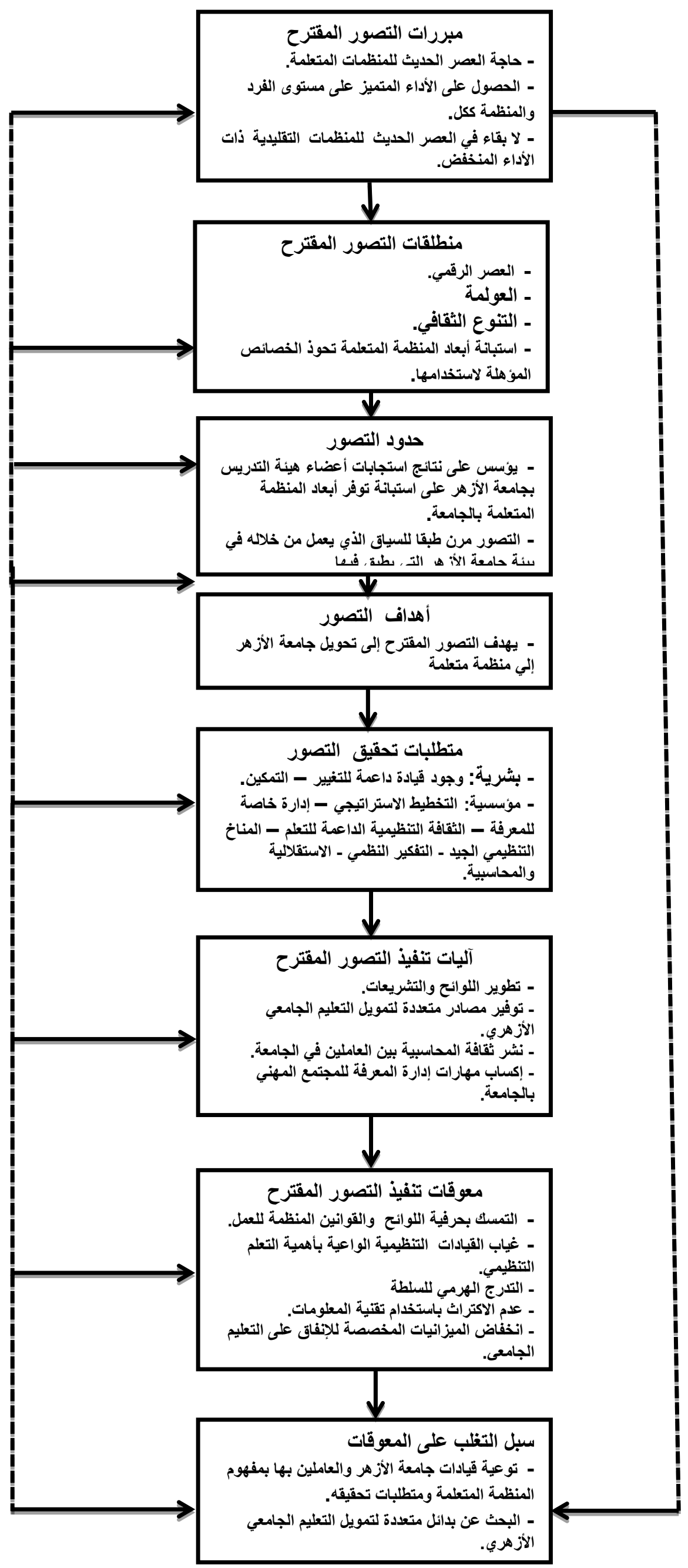

17

شكل رقم ( 1 ) يوضح مكونات التصور المقترح لتحويل جامعة الأزهر إلى منظمة متعلمة 
مبررات التصور المقترح:

للتصور المقترح مجموعة من المبررات لعل من أهمها: التعامل مع التغيرات السريعة

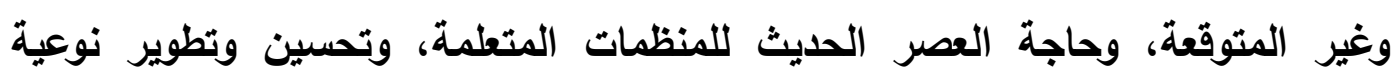

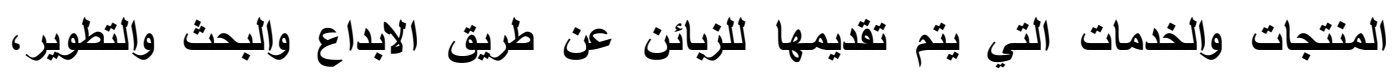

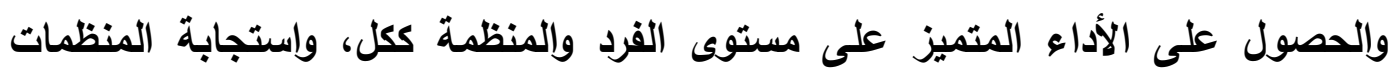

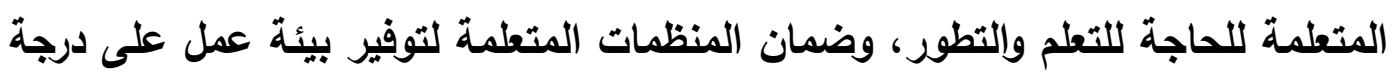

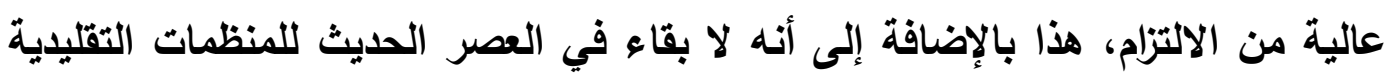

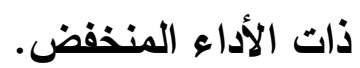

منطلقات التصور المقترح:

يعتمد التصور المقترح على جملة من المنطلقات الأساسية يتعلق بعضا منها

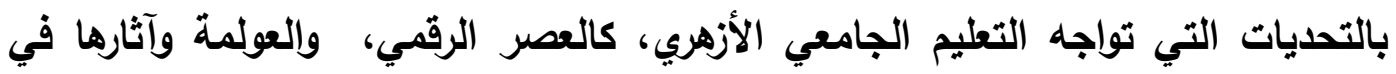

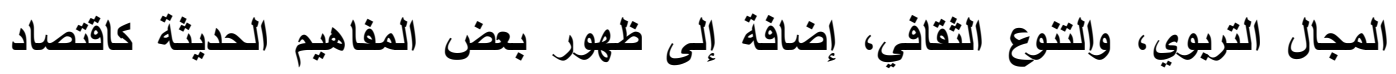

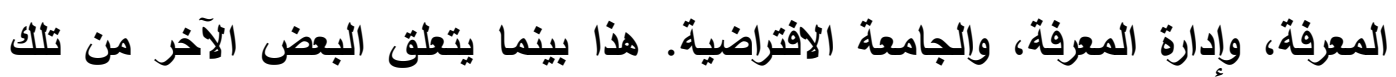

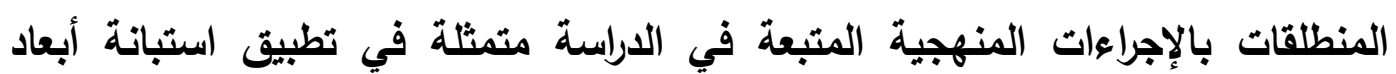

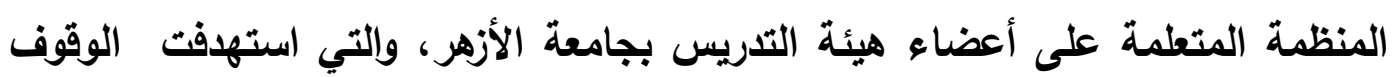
على درجة توفر تلك الأبعاد بالجامعة من وجهة نظرهم.

حدود التصور المقترح:

يؤسس التصور المقترح على نتائج استجابات أعضاء هيئة التريس بجامعة

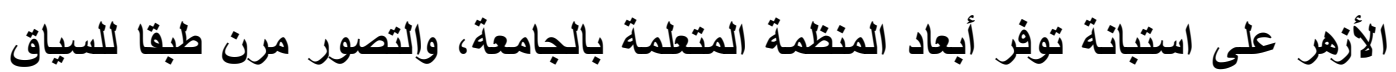
الأي يعمل من خلاله في بيئة جامعة الأزهر التي يطبق فيها. أهداف التصور المقترح:

يهاف التصور المقترح إلى تحويل جامعة الأزهر إلي منظمة متعلمة؛ بما يمكنها

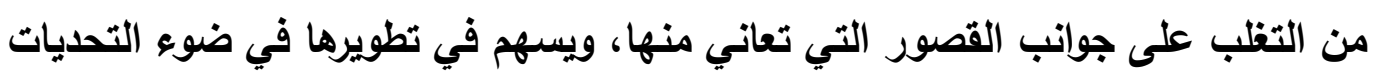
التي تواجهها. 
متطلبات تحقيق التصور المقترح:

يتطلب تحقيق التصور المقترح مجموعة من المعايير التي يمكن إدراجها في:

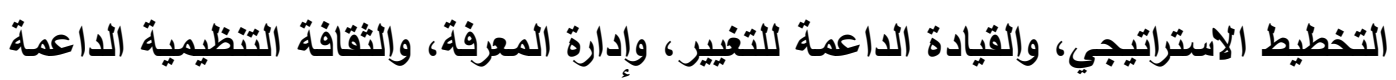

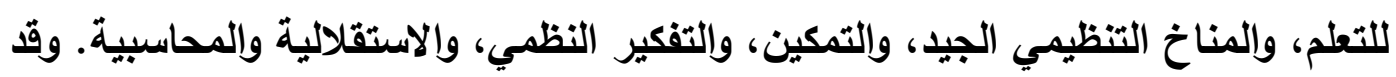

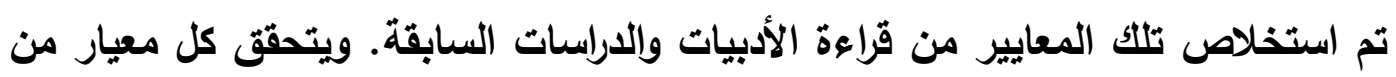
تلك المعايير من خلال مجموعة من المؤشرات السلوكية. وفيما يلي بيان ذلك. 1 - التخطيط الاستراتيجي: ويتحقق ذلك المعيار من خلال المؤشرات السلوكية التالية: - أن يكون للجامعة روئية ورسالة معتمدة ومعلنة. - مشاركة جميع العاملين في إعداد روئية الجامعة ورسالتها. - - أن تعبر روئة الجامعة ورسالتها عن دورها التعليمي والبحثي والمجتمعي. - أن يكون للجامعة غايات وأهداف استراتيجية واضحة. - - أن يكون للجامعة خطة استراتيجية واضحة معتمده ومتكاملة العناصر وقابلة للتفيذ. - - أن تستفيد الجامعة من النماذج العلمية الرائدة عند وضع خطتها الاستراتيجية. - - أن تثارك الجامعة المعنيين بوضع الخطة الاستراتيجية. - أن تحدد الجامعة الفرص والتهديدات الداخلية والخارجية. - - أن تقوم الجامعة بمتابعة تطبيق الخطة الاستراتيجية. r - القيادة الداعمة للتغيير : ويتحقق ذلك المعيار من خلال المؤثرات السلوكية التالية: - قيام القيادة بوضع خطط خاصة بالتغيير والعمل على تحقيقها. - تجديد القيادة في مسئوليات العاملين حسب احتياجات العمل. - بحث القيادة بشكل مستمر عن فرص التعلم المناسبة للعاملين. - ادراك القيادة مفهوم منظمة التعلم ومتطلبات تطبيقه في الجامعة. - حرص القيادة على إعداد صف ثاني من القيادات، لايه اقتناع بفكرة منظمة التعلم. - - تميز القيادة بالمرونة في تطبيق اللوائح والقوانين المعمول بها في الجامعة. 


$$
\text { - - تحديد القيادة بالتنسيق مع العاملين برامج التدريب اللازمة لهم. }
$$

- مناقثة القيادة مع العاملين المشكلات التي يمكن أن تعوق تحقيق أهداف الجامعة. - - تثجيع العاملين بالجامعة على العمل الفريقي وجعله أساسا لعملية التعلم. - - تثجيع العاملين بالجامعة على تقديم إبداعات متواصلة تمكن الجامعة من التكيف المتواصل مع متطلبات البيئة المتجددة. - أن تسيطر القيادة الجامعية على الأحداث وتسير معها ولا تتصرف نتيجة لها. - منح القيادة العاملين فترات راحة من أجل البدء في مراجعات تعليلية للعمليات الخاصة بالجامعة.

\section{- - توضيح القيادة الجامعية روئيتها للعاملين بالجامعة .} - - توفير القيادة برامج للتدوير من أجل تقديم أفراد جدد داخل الجامعة. - - نشر ثقافة التعلم من خلال الأخطاء، دون تطبيق أية عقويات، للمساعدة على حدوث عملية التعلم. - أن تمتلك القيادة المعرفة الجيدة بالأهداف الاقتصادية الخاصة بالمنظمة. - - تقبل القيادة النق القائم على أسس منطقية.

ب- إدارة المعرفة: ويتحقق ذلك المعيار من خلال المؤشرات السلوكية التالية: - أن تمتلك الجامعة نظم ويني هيكلية تضمن تصنيف المعرفة المهمة وخزنها وإتاحتها لمن يحتاجها ويقدر على استخذامها. - أن تظور الجامعة داخليا وخارجيا وياستمرار استراتيجيات وأساليب المشاركة في المعلومات.

- - تأسيس إدارة خاصة للمعرفة، يتولى مهامها (مدير إدارة المعرفة)، من أجل تسهيل عملية الاتصال بين العاملين في جميع المستويات التنظيمية. - أن يتوافر بالجامعة النظم الإكترونية متعددة الأعراض في جميع التسهيلات الخاصة

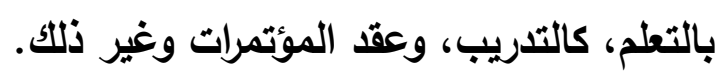
- توفير الجامعة لمشروعات تختبر فيها الأساليب الجديدة التي أدخلتها على السلع والخدمات الخاصة بها. 
- - تأكيا الجامعة المستمر على الدور الحيوي لإنتاج المعرفة والاستفادة منها في تطوير السلع والخدمات الجامعية بشكل إبداعي. - مقارنة أداء الجامعة بأداء الجامعات ذات الأداء المتميز. - تثكيل فرق العمل في الجامعة من الأقسام والإدارات المختلفة من أجل تبادل الخبرات والمعارف. - - تحديد الاحتياجات التدريبية للعاملين بصورة دورية، واتخاذ الإجراءات الملائمة لتنفيذ البرامج الملبية لاحتياجات التدريب. - وعي العاملين في الجامعة بأهمية التثارك المعرفي والتعلم المستمر مع الآخرين. - اعلام قيادة الجامعة العاملين بنتائج تقييم الأداء، ومناقثهم فيها عند الضرورة، واستخدام النتائج للمحاسبة وتحسين الأداء. - - جذب الجامعة صناع المعرفة واستقطابهم والاحتفاظ بهم وتحفيزهم، والعمل على المأل توفير البيئة المناسبة المشجعة لهم على أداء مهامهم على الوجه الأكمل. - وضع روئة واضحة لكيفية إدارة الأصول المعرفية ورأس المال الفكري في مجالات

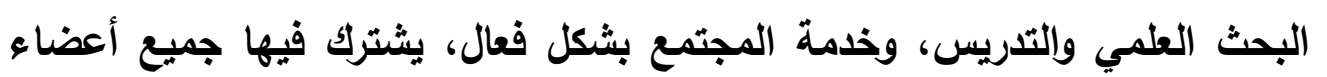
هيئة التدريس، والأفراد العاملين بالجامعة. - -

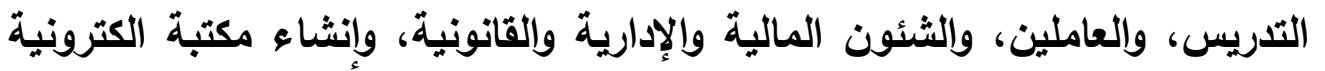
بكل كلية تتيع الاتصال بقواعد البيانات العالمية. - إنثاء بنية تلدعم إدارة المعرفة، بحيث تثمل الموارد المالية والتكنولوجية والبشرية. - التزام الإدارة العليا بتدعيم عمليات إدارة المعرفة في كافة وحدات المؤسسة وتثجيع العاملين على تطبيق وممارسة إدارة المعرفة التظيمية. - - تحسين البيئة التعليمية الجامعية، من خلال تطوير شبكات الاتصالات والمعلومات بالجامعة ورفع كفاءتها وتطوير مواقع الكليات على شبكة الاتترنت وكذا تطوير البريد الالكتروني لأعضاء هيئة التدريس.

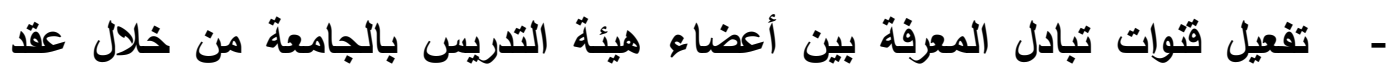
المؤتمرات العلمية وإلندوات، وحلقات البحث العلمية، والاهتمام بالبحوث البئية البينة 
القائمة على الفرق البحثية، وتيسير إجراءات الاشتراك في الجمعيات العلمية العالمية، وكذلك تسهيل إجراءات النشر العلمي بالدوريات العلمية.

- الإدارة الاستراتيجية للأصول المعرفية بالجامعة وكلياتها، حيث يتطلب تحقيق جودة التعليم تحديد المعرفة التظيمية الكامنة للمؤسسة والتي نتمثل في القيم والمعايير والاتجاهات التي توجه سلوك الأفراد العاملين في الجامعة، كما يتطلب ذلك تحديد القيم الاستراتيجية الموجهة لخطط الجامعة وتوجهاتها المستقبلية، ويتم ذلك من

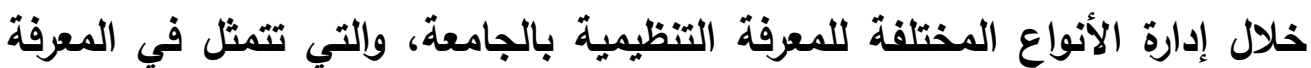
الظاهرة والكامنة، والمعرفة الداخلية والخارجية، ومدى إمكانية تحويلها. - - التحول نحو الهياكل الثبكية بدلا من الهياكل البيروقراطية، مع إتاحة المشاركة بالمطلومات وتثجيع التعاون مما يتطلب نظم مطلومات داعمة لذلك. - إدارة سلسلة القيم Value Chain Management بالجامعة، حيث إن مؤسسات التعليم الجامعي لا توجد منعزلة عن بعضها البعض، ولكنها توجد على شكل سلاسل قيم، بحيث تكون لكل إدارة داخل المؤسسة قيمتها من المعرفة. ع- الثقافة التظظيمية الداعمة للتعلم: ويتحقى ذلك المعيار من خلال المؤثرات

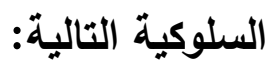

- - ترسيخ ثقافة التعلم التظيمي بين العاملين في جامعة الأزهر . - - نقل ثقافة منظمة التعلم إلي العاملين بالجامعة عن طريق الثعارات، والطقوس، والاحتفالات، والقيم والأعراف، والمكافآت التنظيمية. - - تقيم الجامعة أنموذجا أخلاقيا يحتذى به الطلاب . - تبني الجامعة منظومة من القيم توجه العمل بها. - عرص القادة والعاملون بالجامعة على اتساق أفعالهم مع قيم وأعراف الجامعة. - أن تتسم تعاملات الجامعة كمنظمة مع منظمات المجتمع الأخرى بالصدق والثفافية. - أن تكون الثقافة السائدة في المنظمة ملائمة لتوليد المعرفة ونقلها. - - نثر ثقافة التفكر والتأمل بين العاملين في الجامعة. ه- المناخ التظظيمي: ويتحقى ذلك المعيار من خلال المؤشرات السلوكية التالية: - - توفير الجامعة مناخا يحقى تطورا في القرة البنائية، والثقافية، والقيادية للتعلم. 
- - توفير الجامعة بيئة للتفاعل الاجتماعي تحدد كيفية استخدام المعرفة في مواقف وظروف معينة. - - تفعيل الجامعة الأنثطة التي توثق العلاقات الإنسانية بين العاملين. - اتاحة الفرصة الكاملة للعاملين للتشاور والتعبير عن الآراء. - مرص الجامعة على معرفة أثر قراراتها على الروح المعنوية للعاملين. - توفير الجامعة لبيئة تعليمية داعمة تعطي للعاملين الحرية في التصرف والتعلم من أخطائهم.

צ- التمكين: ويتحقق ذلك المعيار من خلال المؤشرات السلوكية التالية: - بذل الجامعة قصارى جهدها من أجل تطوير وتدعيم الأفراد العاملين بها ليكونوا قادرين على التعلم والانجاز. - - أن تكون الصلاحيات بالجامعة لا مركزية ويتم تحويلها إلي الآخرين. - ممارسة قادة الجامعة دور المدربين والموجهين والمسهلين لعملية تعلم الموظفين. - - تبادل الجامعة المعلومات مع المستهلكين بشكل جيد للحصول على آرائهم بخصوص التعلم وتحسين السلع والخدمات. - إثراك الجامعة في القرارات الخاصة بالعملية التعليمية الجهات الخارجية كالموردين والجمعيات العلمية والمهنية والمجتمع المحلي. - - تفويض الجامعة الصلاحيات للعاملين بما يتناسب ومسؤولياتهم وقدراتهم على التعلم. - - تطوير الجامعة مواردها البشرية بحيث تحوذ التمكن والقدرة على انجاز الوظائف وتعلم المهام. - إثراك القيادة الجامعية العاملين في حل المشكلات واتخاذ القرارات. - - تأكيد ثقة قيادات الجامعة في مرؤوسيهم وإمدادهم بمزيد من المعلومات، وحرية التصرف والاختيار. - شعور الموظفين بقرتهم على التصرف ذاتيا في التعامل مع الأزمات بدلا من انتظار الأوامر والتوجيهات من الإدارة العليا. 
- احترام أفكار فرق العمل من قبل القيادة الجامعية وأخذها بجدية. - مكافأة قيادات الجامعة العاملين ذوي السلوكيات والتصرفات الإدارية المقبولة. - - توفير قيادات الجامعة التدريب الملائم للعاملين بالجامعة لإكسابهم المعرفة والمهارة والأدوات اللازمة للتصرف الفعال بصفة مستمرة.

- V إحداث الجامعة التوافق بين المقرات التي تقدمها مع معايير التخصصات المتعارف عليها عالمياً. - - ت - تعزيز مكانة الأستاذ الجامعي وإحترامه. - - تطوير نظم عمل الجامعة الإداري بشكل مستمر. - التعديل الاوري للبرامج الأكاديمية بما يخدم حاجات سوق العمل. - حرص الجامعة على المزاوجة بين النظرية والتطبيق في العملية التعليمية التعلمية. - حرص الجامعة على أن تكون نسبة عدد الطلبة لكل عضو هيئة تدريس متسقة مع

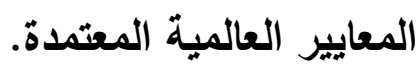
- اعتماد المناهج في الجامعة بعد دراسة حاجات سوق العمل. - مناقثة الخيارات الخاصة بالمناهج التعليمية بحرية لاختيار أفضها عند الثروع بالتطورات والتغيير فيها. - استغلال الجامعة للمرافق والإمكانات المتوافرة لايها وإستخدامها استخد/ما صحيحا. - - تقدير الجامعة للحاجات المستقبلية لسوق العمل وفق روية شاملة. - بحث الجامعة عن حلول إبداعية لردم الهوة بين مخرجاتها وحاجات سوق العمل. - الأخذ بعين الاعتبار حاجات سوق العمل عند قبول الطلبة في التخصصات المختلة. - - تقييم الجامعة للمدخلات والعمليات والمخرجات عند تنفيذ التغييرات. - استفادة الجامعة من خبرات جامعات عالمية مشهود لها بالتميز. - استعانة الجامعة بخبرات مختصين محليا وعالمياً عند التخطيط لبرامجها المختلفة. - توافر قاعدة بيانات بالجامعة حول حاجات سوق العمل من التخصصات المختلفة. 
- اعتماد الجامعة بناء القدرات والمهارات بعيدا عن القولبة النمطية. - مراعاة الجامعة لأن يكون عدد الطلبة في الصفوف والمرافق متسقا مع المعايير العالمية.

1 - الاستقلالية والمحاسبية: ويتحقق ذلك المعيار من خلال المؤثرات السلوكية التالية: - - تقييم أداء العاملين بالجامعة في ضوء معايير الأداء القومية. - الحرية الكاملة للجامعة في تصريف شئونها المالية في ضوء تثريعاتها. - وضع الجامعة لبدائل حقيقية ومتنوعة للتمويل بما يمكنها من أداء رسالتها. - - تنسيق الجامعة بين أجهزة الرقابة المالية والإدارية بما لا يؤثر على مصلحة العمل. - - تمتع الجامعة بالاستقلال الأكاديمي وأن تكون هناك حدود وضوابط لتدخل الجهات الأخرى في عملها. - - نثر إدارة الجامعة لثقافة المحاسبية بين العاملين. - - تطبيق مبدأ المساعلة والمحاسبية بثكل مستمر بما يضمن سرعة اكتثاف الأخطاء

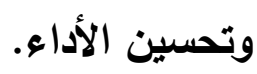

آليات تحقيق التصور المقترح:

إن الانتقال بالتصور المقترح من حيز النظرية إلي حيز التطبيق من خلال إعماله في

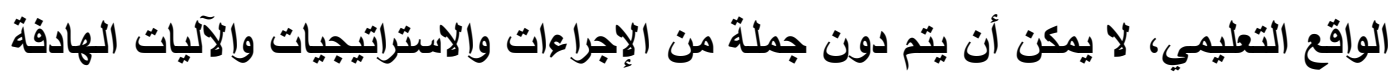

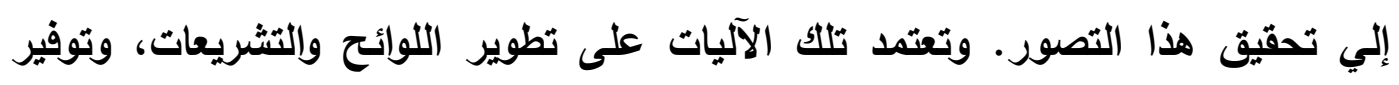

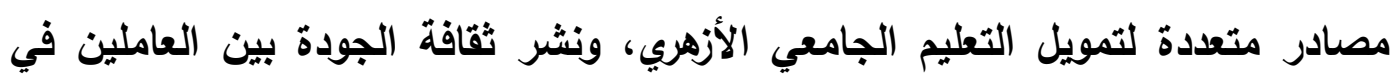

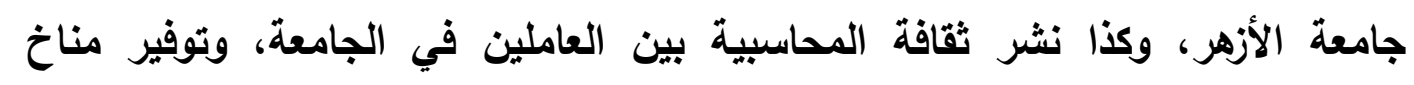
تنظيمي فاعل( ثقافة للتعلم التنظيمي)، هذا بالإضافة إلى إكساب مهارات إدارة المعرفة ل المجتمع المهني بالجامعة. 
معوقات تنفيذ التصور المقترح:

إن تحويل جامعة الأزهر من منظمة تقليدية إلي منظمة متعلمة قد يواجه بجملة

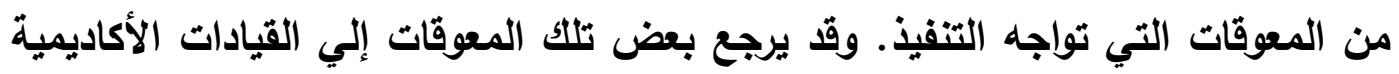

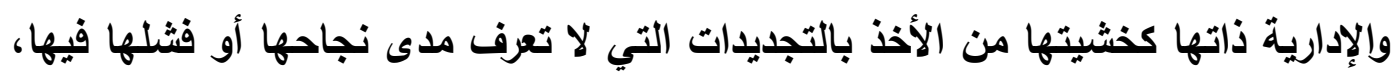

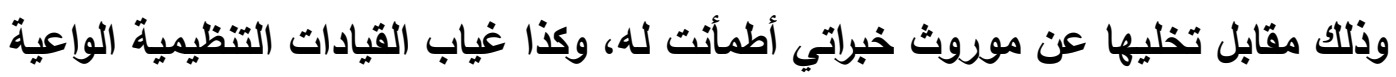

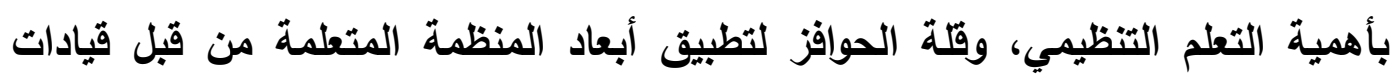
الجامعة، كما قد يرجع بعضا من تلك المعوقات إلى التمسك بحرفية اللوائح والقوانين المنظمة للعمل، والتمسك أيضا بالتدرج الهرمي للسلطة وما ينجم عنه من ضعف التهات التواصل

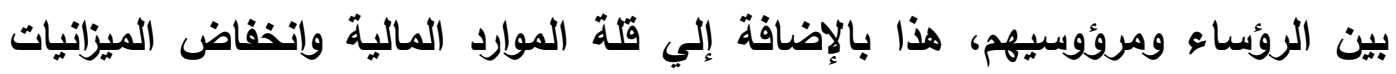

والاهتمام بالإنفاق على جوانب محددة قد لا تصل مباشرة إلي جوهر العملية التعليمية. سبل التظلب على المعوقات: - مبل حتى يمكن التظلب على معوقات تحويل جامعة الأزهر إلى منظمة متعلمة فإنه يمكن

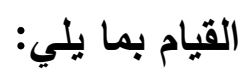

- توعية قيادات جامعة الأزهر والعاملين بها بمفهوم المنظمة المتعلمة ومنطلبات

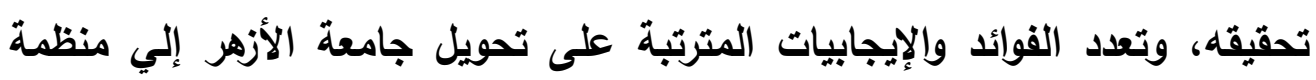

متعلمة.

- البحث عن بدائل متعددة لتمويل التعليم الجامعي الأزهري بجانب التمويل الحكومي، وذلك من خلال التمويل الأتي من داخل الجامعة، عن طريق تبني مفهوم الجامعة لئميل

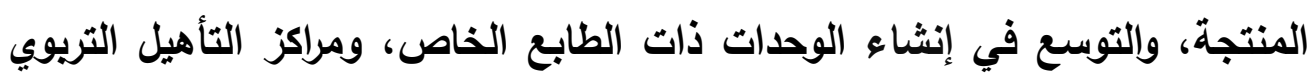
بكليات جامعة الأزهر على مستوى محافظات جمهورية مصر العربية.

تحكيم التصور المقترح: تم تحكيم التصور المقترح من قبل ( \& أ)(") أستاذا من خبراء التربية في مجال أصول التربية، والتربية الاسلامية، والادارة والتخطيط والدراسات المقارنة، وعلم النفس، والمناهج. وقد تمثلت معايير الحكم على مدى مناسبة، أو علم مناسبة التصور المقترح

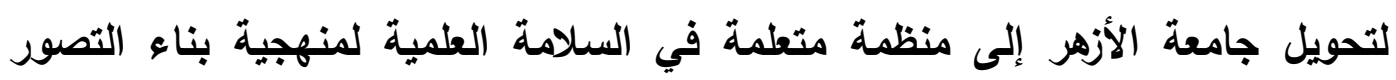

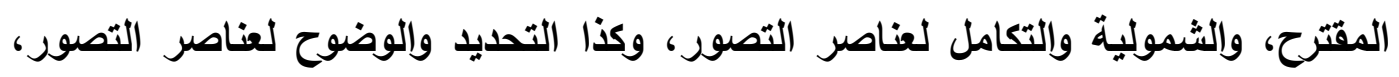

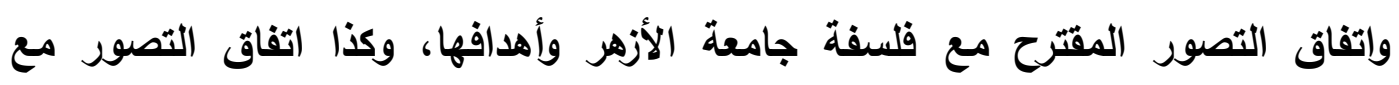


التوجهات الحديثة في إدارة مؤسسات التعليم العالي، وأخيرا اتسام التصور المقترح بالواقعية وقابلية التنفيذ. وقد اتفقت عينة الخبراء جميعها على توفر معايير الحكم السابقة

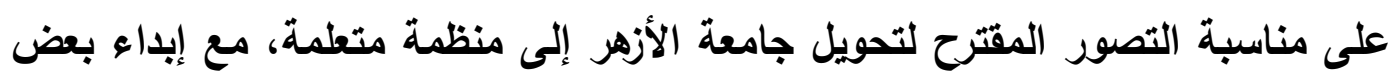
الملاحظات التي تم أخذها في الاعتبار عند صياغة التصور النهائي.

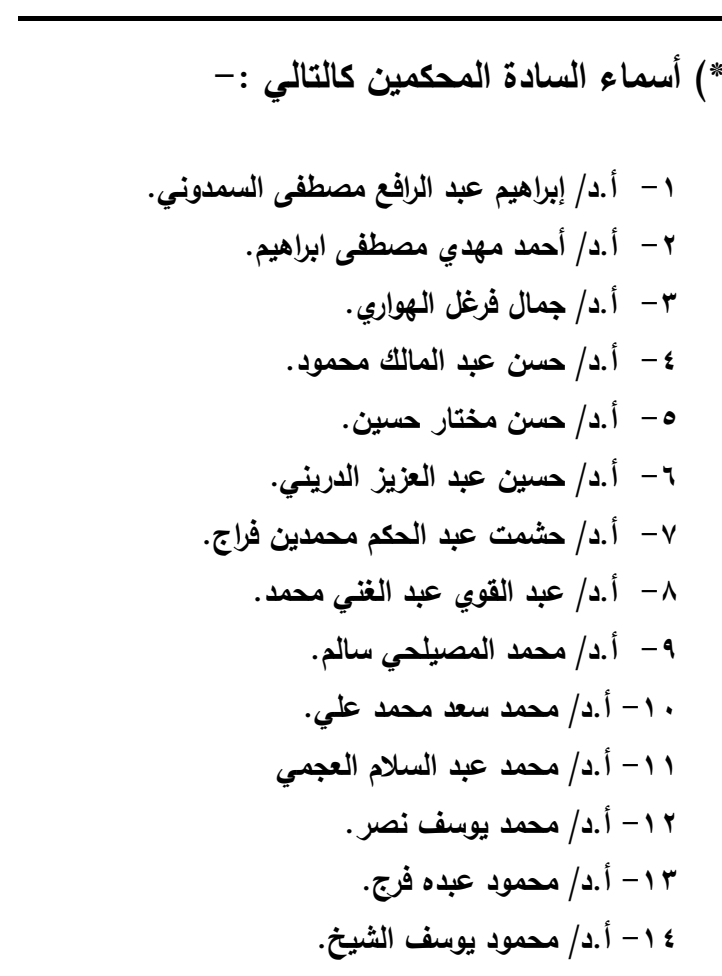

\section{المراجع:}

إبراهيم، إبراهيم أحمد السيد (r ا + ץ). دور المناخ التنظيمي في نشر ثقافة الجودة لاى أعضاء هيئة التدريس بكليات جامعة الأزهر بالدقهلية، مجلة كلية التربية بينها، العدد

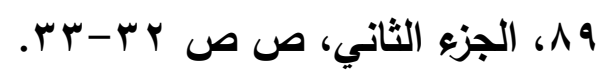

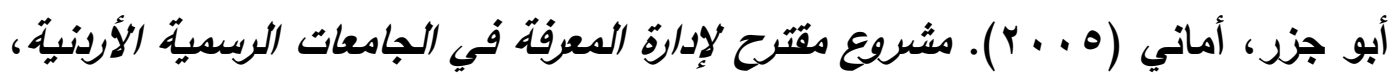
رسالة دكتوراه غير منشورة، جامعة عمان العربية للاراسات العليا، عمان، الأردن. أبو حشيش، بسام محمد، ومرتجي، زكي رمزي (11) (1). " مدى توافر أبعاد المنظمة

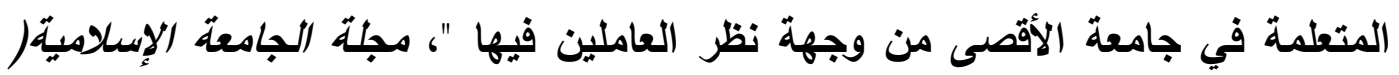

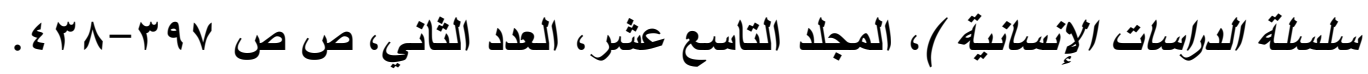




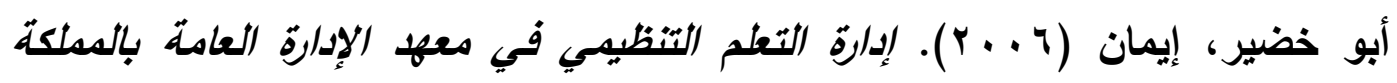

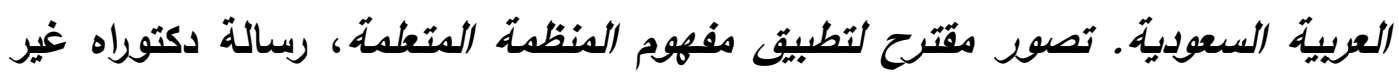
منشورة، جامعة الملك سعود.

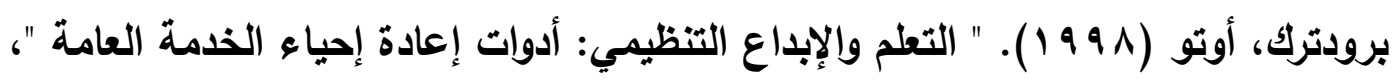

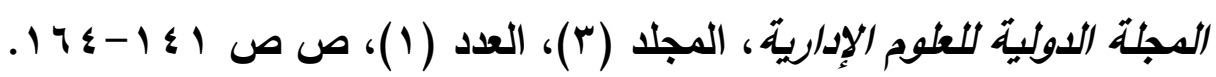
بكار، براء (ץ . . ץ). " إدارة الإبداع في المنظمات المتعلمة "، رسالة ماجستير غير منشورة، جامعة اليرموك، إريد، الأردن.

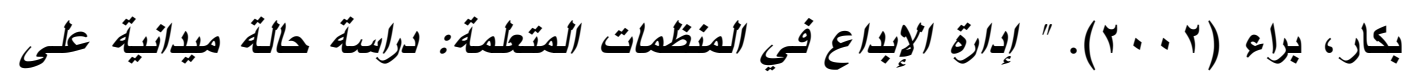

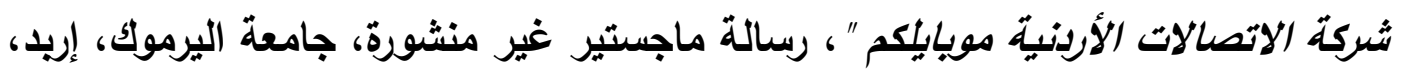
الأردن.

جاد الرب، سيد (؟ . . ץ). إدارة الموارد الفكرية والمعرفية في منظمات الأعمال العصرية، منثورات جامعة قناة السويس.

جامعة الأزهر (99 99 (1). جامعة الأزهر في سطور، العلاقات العامة. جرار، صلاح (ه . . ب). " سبل تحسين جودة الأداء لعضو هيئة التدريس في كليات

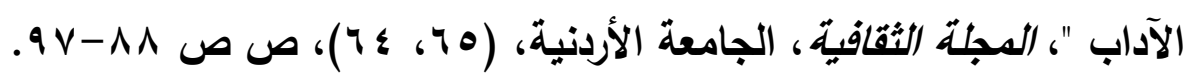
جلال، أبو بكر أحمد صديق (9 . . . r). تظوير إدارة جامعة الأزهر باستخد/م مدخل إعادة

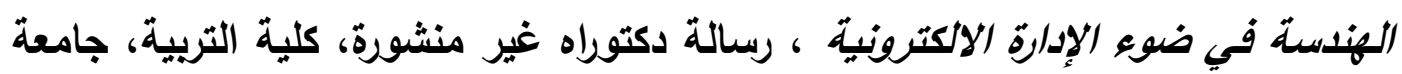
الأزهر.

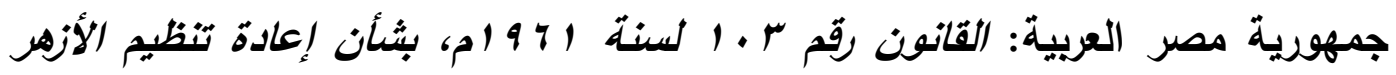

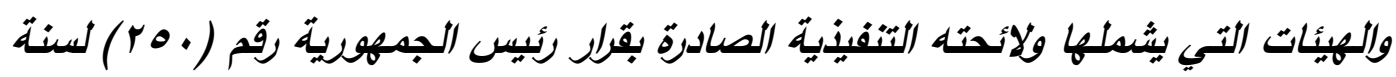
هV 9 ام، وفقاً لآخر التعديلات.

جواد، شوقي ( . . ب). إدارة الاستراتيجيات، عمان: مكتبة الحامد للنشر والتوزيع.

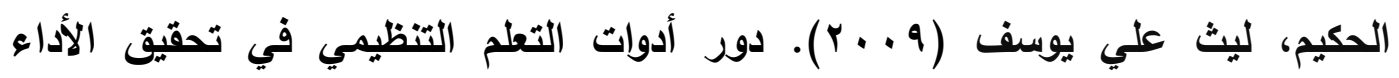

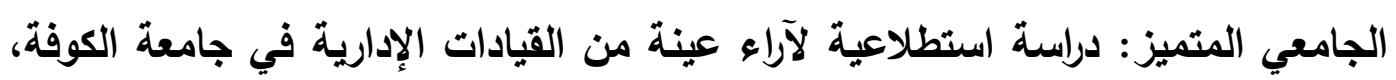

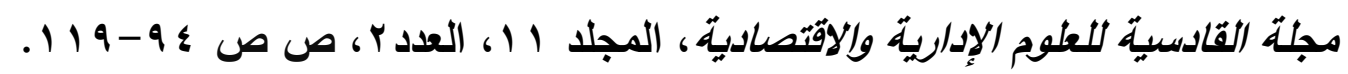
حمود، خضير (• • ( ). منظمة المعرفة، عمان: دار صفاء للنشر والتوزيع. 
حيدر، عبد اللطيف (؟ . . ץ). الأدوار الجديدة لمؤسسات التعليم في الوطن العربي في ظل

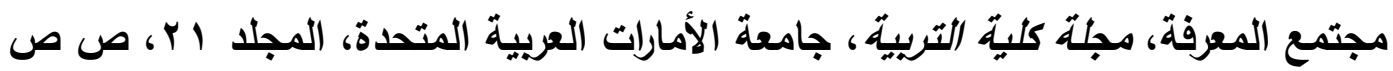
.$\leqslant \leqslant-1$

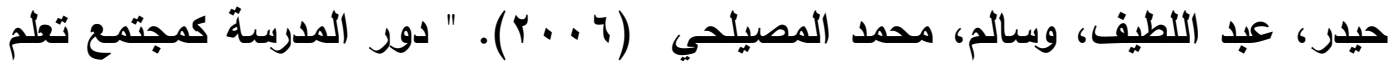

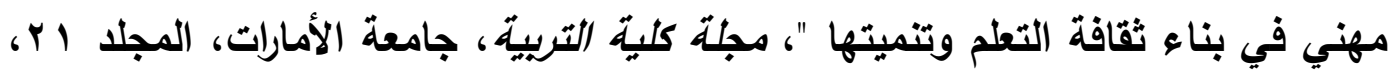

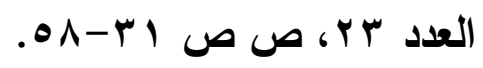

خصاونة، سامي (ه . . ץ). " جامعة المستقبل في الأردن، آراء وأفكار واقتراحات"، المجلة

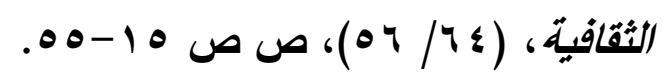

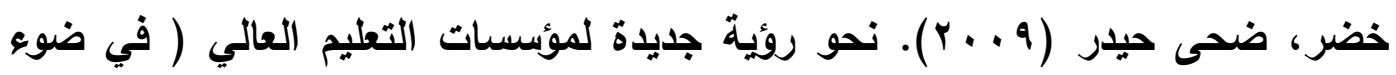

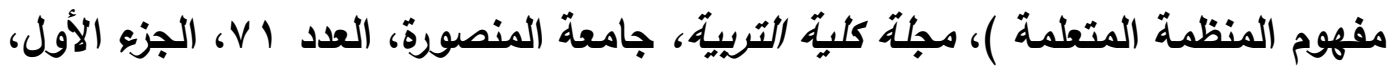

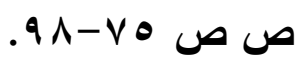

خضر، ضحى حيدر، وخصاونة، سامي عبد الله (11 (1). "تطوير أنموذج لممارسة مجالات المنظمة المتعلمة كما يراها أعضاء هيئة التدريس في الجامعة الأردنية"، مجلة التهائه

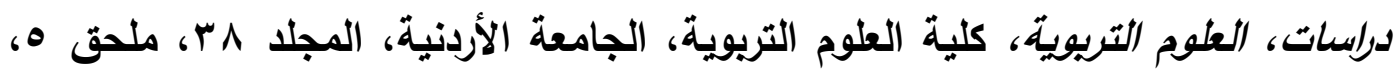

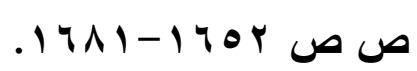

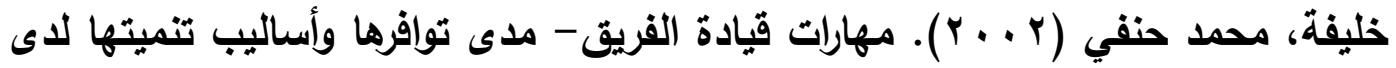

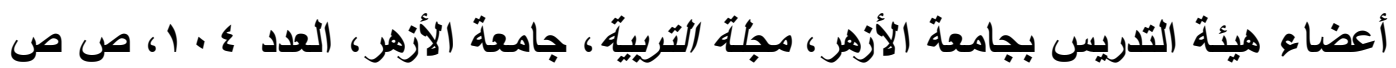
$. v \cdot-r q$

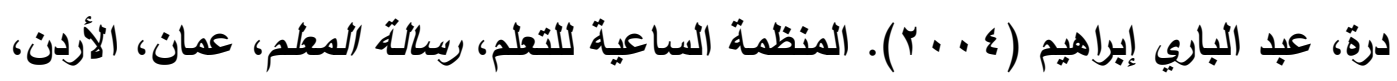

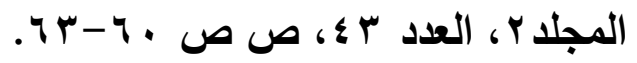

الايحاني، سلطان غالب (10 ب ب). أبعاد المنظمة المتعلمة والقيادة التحويلية والعلاقة بينهما لاى القيادات الجامعية في جامعة الكويت من وجهة نظر أعضاء هيئة التدريس،

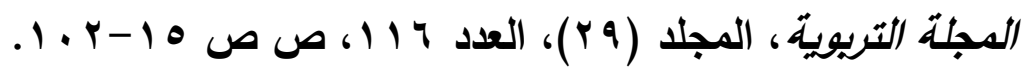

الأبيان، إسراء محمد، والثرمان، منيرة محمود (YV (Y). استراتيجية مقترحة لتحويل الجامعات الأردنية الرسمية إلي منظمات متعلمة من وجهه نظر القادة الأكاديميين

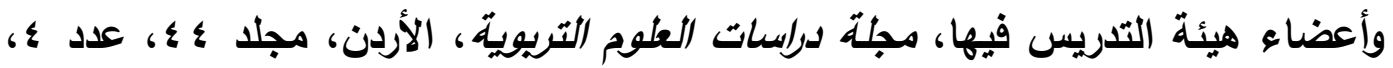

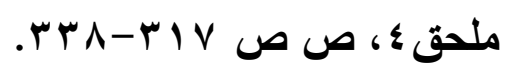




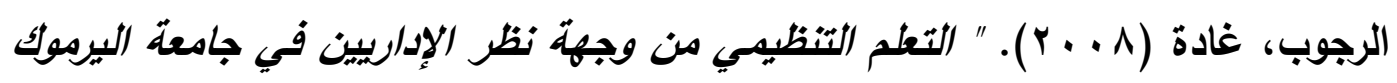
"، رسالة ماجستير غير منشورة، جامعة اليرموك، إريد، الأردن. الرشدان، يحيى (11 + r). المنظمات المتعلمة في عصر العولمة،، عمان، الأردن: دار المسيرة للنشر والتوزيع والطباعة.

زايد، عبد الناصر، ويويشيت، خالد أحمد، والمطيري، ذعار شجاع ضيف الله (9 . . ؟). المنظمة المتعلمة وتطبيقاتها في المملكة العربية السعودية ( دراسة حالة ) ). القطاعات الرئيسية في الهيئة الملكية بالجبيل، بحث مقدم إلي المؤتمر الدولي للتنمية الإدارية" نحو

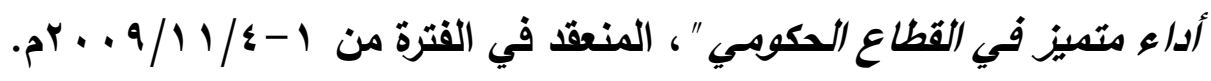
السالم، مؤيد (1 . . r). نظرية المنظمة والههيكل والتصديم، عمان: دار وائل. سلطان، سوزلان، وخضر، ضحى ( • ( ب ). المؤسسات التريوية كمنظمات متعلمة، عمان:

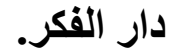

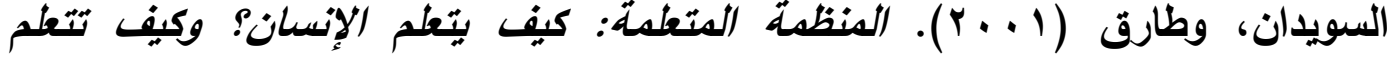
المنظمات؟ ، بيروت: دار ابن حزم للطباعة والنشر والتوزيع.

الثملة، ميسون عبدالله أحمد (ه . . ץ). مقومات التحول نحو المنظمات المتعلمة: دراسة

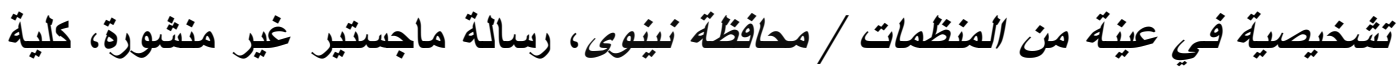
الإدارة والاقتصاد، جامعة الموصل، العلق.

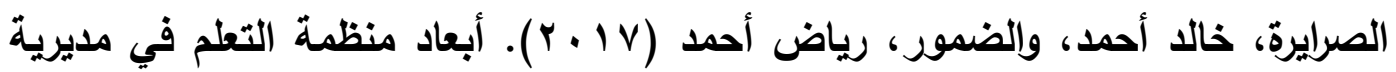
تربية وتعليم قصبة الكرك في الأردن، مجلة دلاسات العلوم التريوية، الأردن، المجلد ؛ ؛ ؛

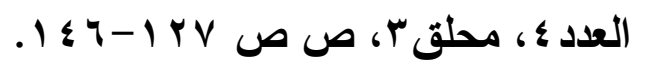

عبابنة، صالح (· ( + ). درجة ممارسة العاملين في العدارس العامة في ليبيا للتفكير

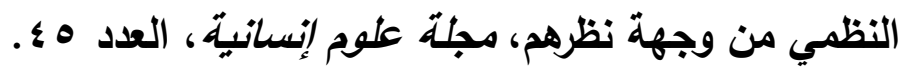

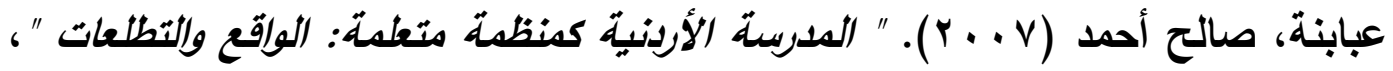

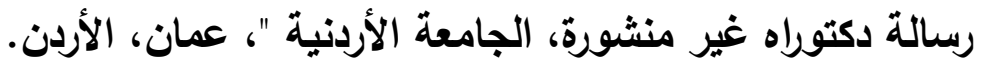
عبابنة، صالح أحمد، والطويل، هاني عبد الرحمن (9 . . ب). " درجة ممارسة العاملين في

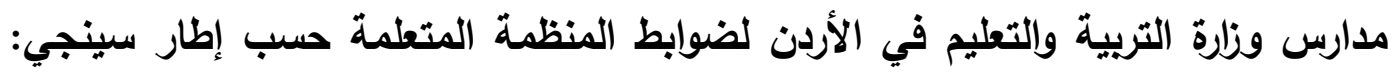

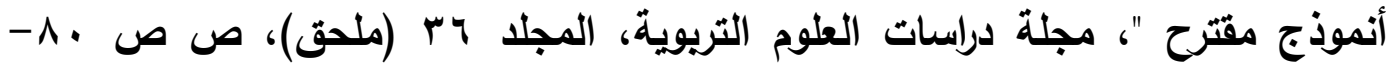


عبد الله، ولاء محمود، وأبو راضي، سحر محمد (ع ا +r). استراتيجية مقترحة لتطوير

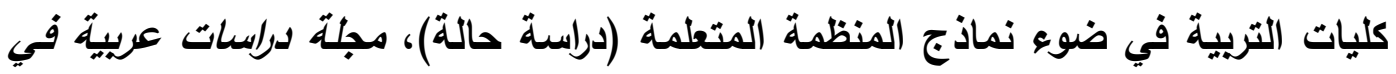

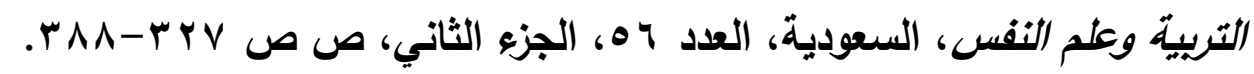
العتيبي، تركي بن كديميس، وإبراهيم، هيفاء بنت عبد العزيز سليمان (10 + ب). درجة

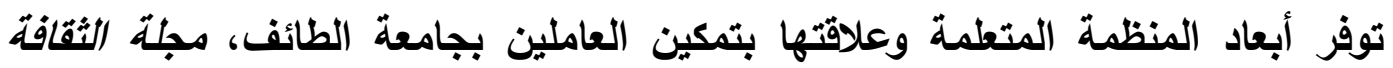

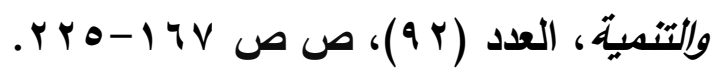

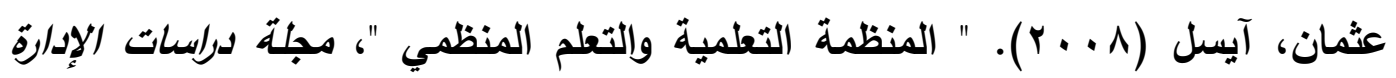
المعاصرة، المجلد ب، العدده، ص ص ب r - آب.

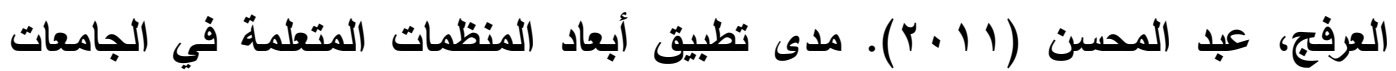

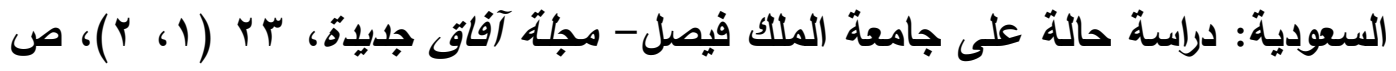
ص

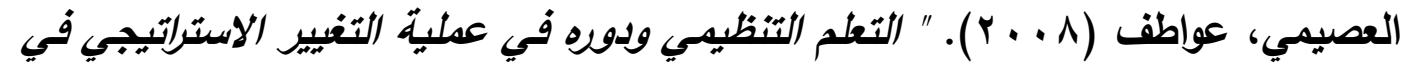
الجامعات السعولية "، رسالة ماجستير غير منشورة، جامعة أم القرى، السعودية.

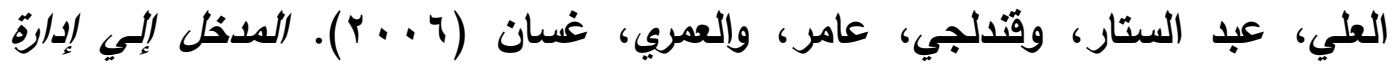
المعرفة، عمان، الأردن: دار المسيرة للنشر والتوزيع والطباعة.

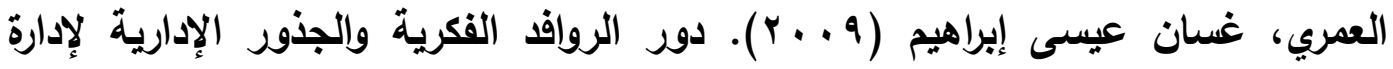

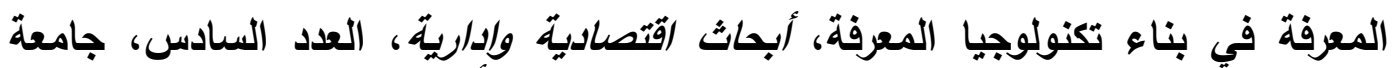

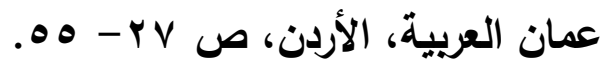

العنزي، سعود عيد الحثربي (1 1 Y). مدى امتلاك جامعة تبوك لمعايير المنظمة المتعلمة

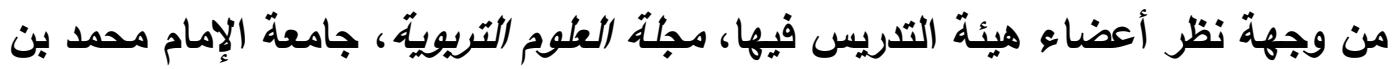

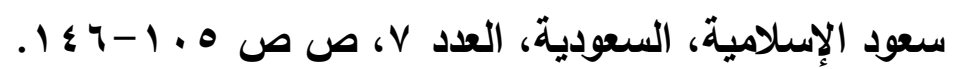
العياصرة، معن، والحارثي، خلود (10 ب (Y). " درجة ممارسة مديرات الثانوية بمدينة

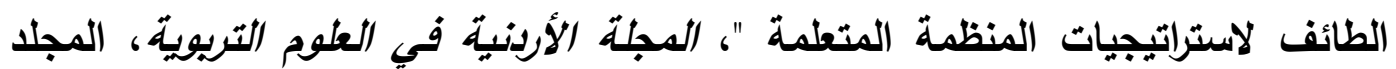

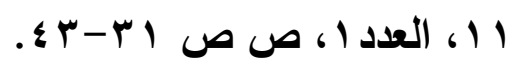
الكبيسي، عامر خضير (ه . . ץ). إدارة المعرفة وتطوير المنظمات، الإسكندرية: المكتب

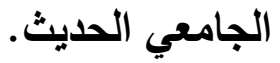




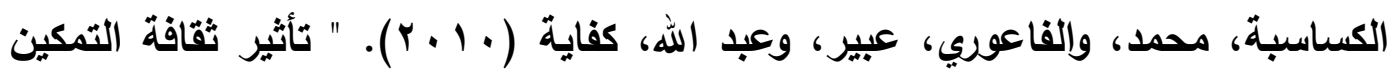

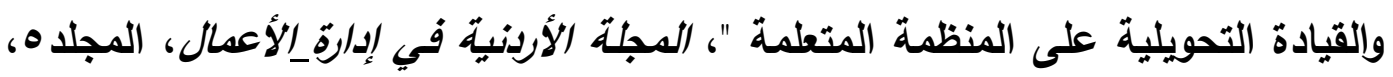

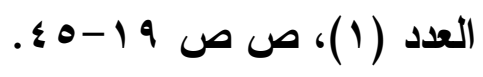

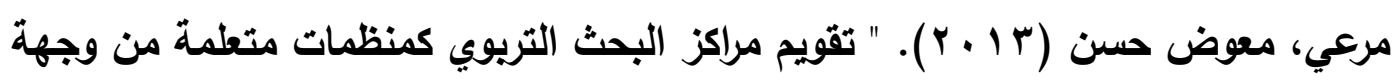

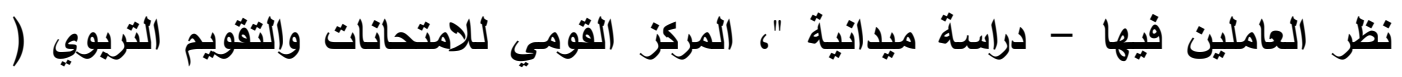

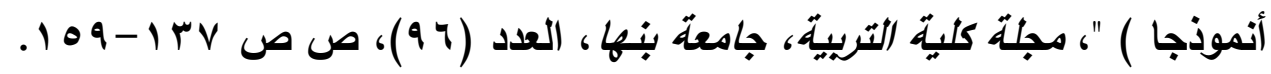
المزروع، شذى مزروع عبد الله (0 1 ب ب). درجة ممارسة أعضاء هيئة التدريس لمقومات

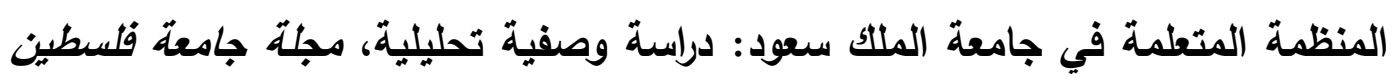

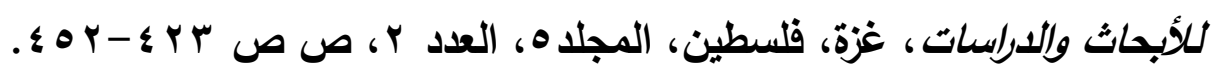

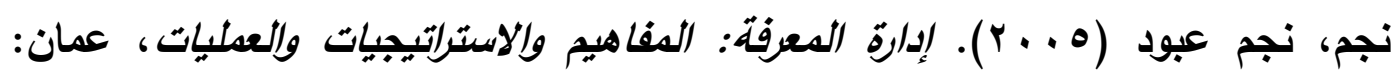
مؤسسة الولق للنشر والتوزيع. نصار، على عبد الرؤوف، وعبد العليم، رمضان محمود (Y Y (Y). متطلبات تطبيق

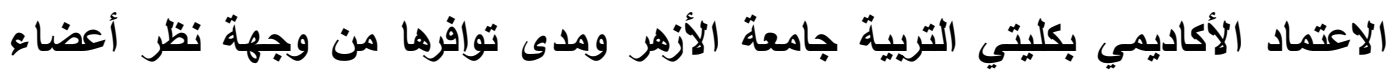

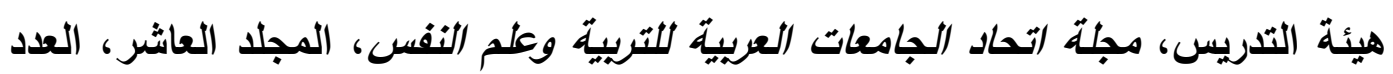

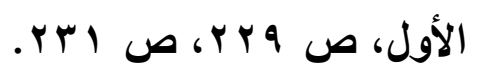
نصر، محمد يوسف مرسي (Y . . Y). تطوير الإدارة الجامعية في ظل التوسع في إنثاء الكليات الإقليمية بجامعة الأزهر، رسالة دكتوراه غير منشورة، كلية التربية، جامعة الأزهر . نور، حسين محمد ( ب . . r). اتجاهات طلاب كلية التربية جامعة الأزهر نحو التعلم الذاتي

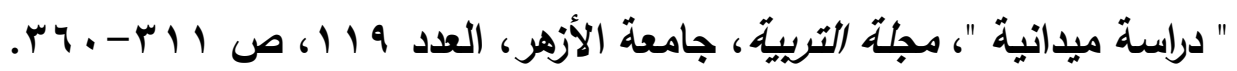

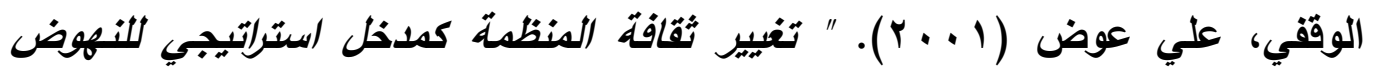

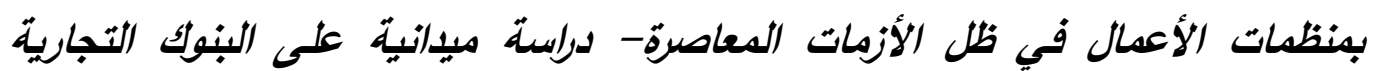
الأرنية "، رسالة ماجستير غير منثورة، جامعة جدارا، الأردن. 
Abu-Tineh, A. M. (2004). Exploring the relationship between the perceived leadership style of principals and their teachers' practice of the five disciplines of learning schools. (Doctoral Dissertation, Florida State University).

Agaoglu, E. (2006). The Reflection of the Learning Organization Concept to School of Education. Online Submission, 7(1), 132148.

Ahrenfelt, B. (2001). Förändring som tillstånd: att leda förändringsoch utvecklingsarbete i företag och organisationer.

Al - Otaibi, S. (2000). The learning organization. Development of a conceptual model and an instrument for assessment in Saudi Arabia. (DBA, University of Hull).

Alexiou, A. (2005). A tale of the field: reading power and gender in the learning organization. Studies in continuing education, 27(1), 17-31.

Armstrong, A., \& Foley, P. (2003). Foundations for a learning organization: organization learning mechanisms. The Learning Organization, 10(2), 74-82.

Auluck, R. (2002). Benchmarking: a tool for facilitating organizational learning?. Public Administration and Development: The International Journal of Management Research and Practice, 22(2), 109-122.

Barcus, S. A. (2007). The Impact of organizational learning and training on multiple job satisfaction factors. (MA Thesis, University of North Texas).

Berrio, A. A. (2007, August). Assessing the learning organization profile of ohio state university extension using the systems- 
linked organizational model. In PICMET'07-2007 Portland International Conference on Management of Engineering \& Technology (pp. 1542-1547). IEEE.

Bersènaitè, J., \& Šaparnis, G. (2007). Assessment of Features, State and Success Factors of a Learning Organisation: Aspect of Staff Opinions, Social Research 21(9), 20-27.

Birnbaum, R., \& Edelson, P. J. (1989). How colleges work: The cybernetics of academic organization and leadership. San Francisco: Jossey- Bass Publishers.

Bowen, G. L., Ware, W. B., Rose, R. A., \& Powers, J. D. (2007). Assessing the functioning of schools as learning organizations. Children \& Schools, 29(4), 199-208.

Boyle, E. (2002). A critical appraisal of the performance of Royal Dutch Shell as a learning organisation in the 1990s. The Learning Organization, 9(1), 6-18.

Bradford, P. F. (2000). Illinois community college presidents' perceptions of leadership for creating or maintaining learning colleges. DAI ERIC ED 479223.

Brown, L. M., \& Posner, B. Z. (2001). Exploring the relationship between learning and leadership. Leadership \& Organization Development Journal, 22(6), 274-280.

Cambron-McCabe, N., Lucas, T., Smith, B., \& Dutton, J. (2012). Schools that learn: A fifth discipline fieldbook for educators, parents, and everyone who cares about education. USA: Broadway Business. 
Can, N. (2011). Developing activities of learning organizations in primary schools. African Journal of Business Management, 5(15), 6256-6260.

Carroll, J. S. (1998). Organizational learning activities in high-hazard industries: the logics underlying self-analysis. Journal of Management studies, 35(6), 699-717.

Castañeda, D., \& Rios, M. F. (2007). From individual learning to organizational learning. In ECKM2007-Proceedings of the 8th European Conference on Knowledge Management: ECKM (p. 192). Academic Conferences Limited.

Chiang, A. H. (2005, June). The university as a learning organization: A case study of teamwork and team learning in a private university in Taiwan. In Proceedings of HERDSA Annual Conference (pp. 101-109).

Chunharas, S. (2006). An interactive integrative approach to translating knowledge and building a" learning organization" in health services management. Bulletin of the World Health Organization, 84, 652-657.

Clark, B. R. (1986). The higher education system: Academic organization in cross-national perspective. USA: Univ of California Press.

Clark, B. R. (Ed.). (1987). The academic profession: National, disciplinary, and institutional settings. USA: Univ of California Press.

Collison, C., \& Parcell, G. (2007). Learning to fly: practical knowledge management from leading and learning organizations. UK: John Wiley \& Sons. 
Davie, H. T., \& Nutley, S. M. (2000). Developing learning organisations in the new NHS. Bmj, 320(7240), 998-1001.

Dineen, B. R., \& Noe, R. A. (2003). The Impact of team fluidity and its implications for human resource management research and practice. In Research in Personnel and Human Resources Management (pp. 1-37). Emerald Group Publishing Limited.

Drader, A. (2004). Malaspina university colleges as learning organization. (Doctoral Dissertation, University of Royal Roads, Dissertation Abstracts International, AAT MQ 86606).

Draft, R. (2000). Management. USA: Cengage Learning.

Duke, C. (2002). The morning after the millennium: building the longhaul learning university. International Journal of Lifelong Education, 21(1), 24-36.

Endlich, N. A. (2001). An investigation of the nexus between strategic planning and organizational learning. (Doctoral dissertation, Virginia Tech).

Fahey, R. (1998). The Fifth Discipline: The Art \& Practice of The Learning Organization. Currency. New York.

Freed, J. E. (2001). Why become a learning organization?. About Campus, 5(6), 16-21.

Friedman, H. H., Friedman, L. W., \& Pollack, S. (2005). Transforming a university from a teaching organization to a learning organization. Review of Business, 26(3), 31-36.

Garwin, D. A. (1993). Building a learning organization. Harvard business review, 71(4), 73-91. 
Gephart, M. A., Marsick, V. J., Van Buren, M. E., Spiro, M. S., \& Senge, P. (1996). Learning organizations come alive. Training \& Development, 50(12), 34-46.

Granberg, O., \& Ohlsson, J. (2014). Från lärandets loopar till lärande organisationer. Studentlitteratur AB.

Griego, O. V., Geroy, G. D., \& Wright, P. C. (2000). Predictors of learning organizations: a human resource development practitioner's perspective. The Learning Organization, 7(1), 512.

Hill, C. \& Jones, G. (2001). Strategic management theory, $5^{\text {th }} e d$. USA: Houghton Mifflin Co.

Hyatt, J. (1998). A Rough Guide to Change. London: Charities.

Juceviciene, P. (2009). The alternative trajectories towards the learning organization. Social Sciences (1392-0758), 64(2).

Karash, R. (1995). Why a learning organization? Navran Associates Newsletter.

Karash, R. (2002). Dialog on learning organizations. Available at: http// www.learning.com/html

Kezar, A. (2005). What campuses need to know about organizational learning and the learning organization. New Directions for Higher Education, 2005(131), 7-22.

Lee, T. P. (2004). Using Systems Thinking to Improve Organizational Learning in the Public Sector: Perspective of Public Officials. Thunghai University: Taiwan.

Leithwood, K. \& Louis, K. (1998). Organizational learning in schools: An introduction, in: K. Leithwood and K. Louis (eds). 
Organizational learning in schools (Lisse, Swets and Zeitlinger), Netherlands.

Lin, H. (2004). A study of learning organization and faculty development in higher education. (Doctoral dissertation, University of Idaho).

Macdonald, S. (1995). Learning to change: An information perspective on learning in the organization. Organization Science, 6(5), 557-568.

Macdonald, S. (1995). Learning to change: An information perspective on learning in the organization. Organization Science, 6(5), 557-568.

Marquardt, M. J. (2011). Building the learning organization: Mastering the five elements for corporate learning. Hachette UK.

Marquardt, M.J. (2002). Building the learning organization: Measuring the five elements for corporate learning, $\left(2^{\text {nd }} e d.\right)$. USA : Davies- Black, Inc. publishing.

Marsick, V. J., \& Watkins, K. E. (1999). Facilitating learning organizations: Making learning count. Gower Publishing, Ltd..

Marsick, V. J., \& Watkins, K. E. (1999). Facilitating learning organizations: Making learning count. UK: Gower Publishing, Ltd..

Moilanen, R. (2001). Diagnostic tools for learning organizations. The learning organization, 8(1), 6-20.

Moilanen, R. (2005). Diagnosing and measuring learning organizations. The Learning Organization, 12(1), 71-89. 
Morgan, G. (1986). Images of organization thousand oaks. UK: SAGE publications.

Mulford, B. (2000). Organizational learning and educational change. In Hargreaves , A liberman, A, Fullan, M \& Hopkins, D. (ed) (2000). International Hardbook of Educational Change, vol. 5 (1), London: Kluwer International Hand books of Education.

Muse, W. V. J. (2000). A study of faculty's perception of worker alienation and degree of favorability toward learning organization theory. DAI. NO AAT 9939631.

Nonaka, I., \& Takeuchi, H. (1995). The knowledge-creating company: How Japanese companies create the dynamics of innovation. Oxford university press.

O'Conner, J., \& McDermott, I. (1997). The art of systems thinking: Essential skills for creativity and problem solving. San Francisco: Thorsons.

O'Connor, N., \& Kotze, B. (2008). 'Learning Organizations': a clinician's primer. Australasian Psychiatry, 16(3), 173-178.

Ortenblad, A. (2007) Senge's many faces: problem or opportunity?, The Learning Organization, 14(2).108-122

Pang, K. N. (2003). Transforming school into learning organizations. China: The Hong Kong Institute of Educational Research and the Chinese University Press.

Pedler, M., Burgoyne, J., \& Boydell, T. (1991). The Learning Company: A Strategy for Sustainable Development. UK McGraw-Hill. 
Reece, P. D. (2004). Universities as learning organizations: how can Australian universities become learning organizations? (Doctoral dissertation, Murdoch University).

Robertson, B. J. (2015). Holacracy: The new management system for a rapidly changing world. USA: Henry Holt and Company.

Schön, D., \& Argyris, C. (1996). Organizational learning II: Theory, method and practice. Massachusetts: Addison-Wesley Publishing Company.

Senge, P. M. (1991). The fifth discipline, the art and practice of the learning organization. Performance+ Instruction, 30(5), 37-37.

Senge, P. M. (1992). The fifth discipline: The art and practice of the learning organization. Milsons Point. New South Wales Australia, Random house Australia.

Senge, P., \& Cambron-McCabe, N. L. T., Smith, B., Dutton, J., \& Kleiner, A.(2000). Schools that learn: A fifth discipline fieldbook for educators, parents, and everyone who cares about education. New York: Doubleday.

Simonaitien, B., Leonavičienè, R., \& Žvirdauskas, D. (2004). Manifestation of Leader's Communicative and Educational Abilities as a Premise for Learning Organisation Development. Social Sciences (1392-0758), 46(4).

Skuncikiene, S., Balvociute, R., \& Balciunas, S. (2009). Exploring characteristics of a learning organization as learning environment. Socialiniai tyrimai/Social Research, 1(15), 64-75.

Smith, B. H. (2003). The university as a learning organization: Developing a conceptual model (Doctoral dissertation, Montana 
State University-Bozeman, College of Education, Health \& Human Development).

Smith, J. (1998). An ongoing learning dialogue: an experiential model in progress. Empowerment in Organizations, 6(4), 119-123.

Sporn, B. (1999). Adaptive University Structures: An Analysis of Adaptation to Socioeconomic Environments of US and European Universities. Higher Education Policy Series 54. Taylor and Francis, Inc.,

Srikanthan, G., \& Dalrymple, J. F. (2007). A conceptual overview of a holistic model for quality in higher education. International Journal of Educational Management, 21(3), 173-193.

Sugarman, B. (1997). Learning, working, managing, sharing: The new paradigm of the learning organization. The Journal of Pedagogy, Pluralism \& Practice. 5, 1-15.

Swieringa, J., Wierdsma, A., \& Swieringa, J. (1992). Becoming a learning organization: Beyond the learning curve. Wokingham: Addison-Wesley.

Thomas, K., \& Allen, S. (2006). The learning organisation: a metaanalysis of themes in literature. The learning organization, 13(2), 123-139.

Thornton, B., Peltier, G., \& Perreault, G. (2004). Systems thinking: A skill to improve student achievement. The Clearing House: A Journal of Educational Strategies, Issues and Ideas, 77(5), 222230.

Tosey, P., Visser, M., \& Saunders, M. N. (2012). The origins and conceptualizations of 'triple-loop'learning: A critical review. Management Learning, 43(3), 291-307. 
Watkins, K. E., \& Marsick, V. J. (1993). Sculpting the learning organization: Lessons in the art and science of systemic change. Jossey-Bass Inc., 350 Sansome Street, San Francisco, CA 94104-1310.

Watkins, K. E., \& Marsick, V. J. (1996). In action. Creating the Learning Organization. Alexandria VA: American Society for Training and Development.

Weick, K.E. (2000). Educational organizations as loosely- coupled systems. In Dill, D. (ed). (2000). The nature of academic organization, New York: Lemma Publishers, PP. 125-145.

Wu, S. H. (2006). Improvement of school performance: Implementing total quality management and learning organization in selected technological universities, technological colleges, and colleges for professional training in Taiwan (pp. 1-206). Spalding University.

Wu, W. Y., Chiang, C. Y., \& Jiang, J. S. (2002). Interrelationships between TMT management styles and organizational innovation. Industrial Management \& Data Systems, 102(3), 171-183. 